The copyright of this thesis vests in the author. No quotation from it or information derived from it is to be published without full acknowledgement of the source. The thesis is to be used for private study or noncommercial research purposes only.

Published by the University of Cape Town (UCT) in terms of the non-exclusive license granted to UCT by the author. 


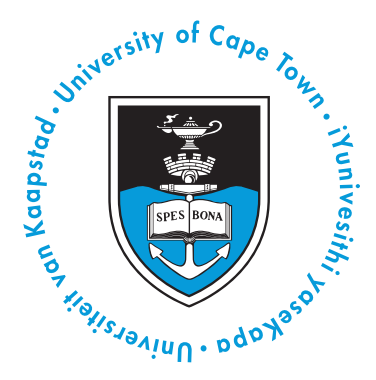

University of Cape Town

\title{
Civil society leadership in the struggle for AIDS treatment in South Africa and Uganda
}

\author{
Eduard Grebe \\ Supervisor: Prof Nicoli Nattrass \\ Thesis presented for the degree of \\ Doctor of Philosophy
}

December 2012 
Hierdie proefskrif word opgedra aan my ouma,

Gertruida Woutrina van Niekerk (née Morkel)

Copyright $(C 2012$ Eduard Grebe. 


\begin{abstract}
This thesis is an attempt to theorise and operationalise empirically the notion of 'civil society leadership' in Sub-Saharan Africa. 'AIDS leadership,' which is associated with the intergovernmental institutions charged with coordinating the global response to HIV/AIDS, is both under-theorised and highly context-specific. In this study I therefore opt for an inclusive framework that draws on a range of approaches, including the literature on 'leadership', institutions, social movements and the 'network' perspective on civil society mobilisation.

This framework is employed in rich and detailed empirical descriptions ('thick description') of civil society mobilisation around AIDS, including contentious AIDS activism, in the key case studies of South Africa and Uganda. South Africa and Uganda are widely considered key examples of poor and good leadership (from national political leaders) respectively, while the Treatment Action Campaign (TAC) and The AIDS Support Organisation (TASO) are both seen as highly effective civil society movements. These descriptions emphasise 'transnational networks of influence' in which civil society leaders participated (and at times actively constructed) in order to mobilise both symbolic and material resources aimed at exerting influence at the transnational, national and local levels. They endeavoured to influence both AIDS policy and the course of the epidemic directly. I conclude that these networks played a key role in the effectiveness of both TAC and TASO.

These qualitative case studies are complemented by econometric analyses. At the continental level, I attempt to measure the impact of civil society mobilisation on the performance of national governments through a cross-country regression analysis applied to 42 Sub-Saharan African states. This analysis fails to show a strong relationship between the presence of AIDS NGOs and HAART and PMTCT coverage (controlling for a range of factors) - potentially supporting my hypothesis that civil society mobilisation is only effective in certain circumstances. At the local level, a second set of regression models using household survey data investigates whether TAC's mobilisation in Cape Town impacted appreciably on HIV prevention efforts. They show a significant relationship between contact with TAC and not endorsing false conspiracy beliefs about AIDS as well as condom use, indicating that TAC's impact is not restricted to the national policy level.
\end{abstract}




\section{Acknowledgements}

I would like to thank and acknowledge the contributions of the following people:

- My spouse, Janneke van Rooyen, without whose support and encouragement this research would not have been possible.

- My mother, Marianna Kritzinger (née van Niekerk), who believed in me even when I did not.

- Jonathan Shapiro, for allowing me to use several of his cartoons.

- Dr Minka Woermann, whose contributions to a joint paper were crucial to the formation of my understanding of 'leadership' (see Appendix A).

- Dr Adrian Leftwich, for insightful comments on various draft papers that I used in writing this thesis.

- Dr Larry Adupa, who assisted tremendously with arranging access to key informants in Uganda.

- All those who generously agreed to be interviewed for this research, often despite punishing schedules (see Appendix G).

- Most importantly, my supervisor and mentor, Prof Nicoli Nattrass, whose contributions over five years have been innumerable. Without her investment in me, none of this research would have been done. Without her intellectual guidance I could not even pretend to be a serious social scientist. 


\section{Contents}

1 Introduction 1

1.1 Leadership for a global AIDS response . . . . . . . . . . . 3

1.1.1 From stigmatised 'gay disease' to global public health priority 3

1.1.2 Towards an architecture for a globally coordinated AIDS response . . . . . . . . . . . . . . 7

1.1.3 The problem of 'AIDS leadership' . . . . . . . . . 13

1.2 Approaching 'civil society leadership' on AIDS . . . . . . . . 17

1.2.1 What is required of theory? . . . . . . . . . . . 18

1.2.2 The literature on AIDS activism . . . . . . . . . 20

1.3 Research design and methodology . . . . . . . . . . . . . 24

1.4 Chapter outline ... . . . . . . . . . . . . . . . . . 24

2 Givil society and national leadership on AIDS: Do NGOs make a difference? 29

2.1 Introduction . . . . . . . . . . . . . . . . . . . . . . 29

2.2 Hypotheses . . . . . . . . . . . . . . . . . . 34

2.3 Methods and measures . . . . . . . . . . . . . . . . . 35

2.3.1 Dependent variables and countries included . . . . . . . 35

2.3.2 Measures of civil society mobilisation on AIDS . . . . . 36

2.3.3 Other potential predictors and controls . . . . . . . . 39

2.4 Results and discussion . . . . . . . . . . . . . . . . . . . . 42

2.5 Conclusions . . . . . . . . . . . . . . . . . . . 43

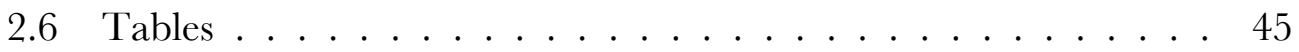




\section{South Africa: Givil society leadership as contesting government}

policy 49

3.1 Introduction and background . . . . . . . . . . . . . . . 49

3.2 Theorising civil society mobilisation on AIDS . . . . . . . . . 52

3.2.1 Social movement theory . . . . . . . . . . . . . 53

3.2 .2 'New' social movements . . . . . . . . . . . . 58

3.2.3 The network perspective in the social sciences . . . . . . 60

3.2.4 'Transnational social movements' . . . . . . . . . . . . 63

3.2.5 Transnational advocacy networks . . . . . . . . . . . 64

3.2.6 Transnational networks of influence . . . . . . . . . 67

3.2.7 Global civil society? . . . . . . . . . . . . . . . . . . 68

3.3 Origins of the Treatment Action Campaign . . . . . . . . . . . 69

3.4 From the struggle against apartheid to activism under democracy . 72

3.5 Mobilising through networks . . . . . . . . . . . 76

3.5.1 Personal networks: a resource for movement building . . . 76

3.5.2 Mobilising civil society alliances and international solidarity networks . . . . . . . . . . . . . . . . . 82

3.5.3 Influencing the state . . . . . . . . . . . . . 93

3.5.4 Illustrating networks of influence . . . . . . . . . . . . 95

3.6 Towards consensus on AIDS treatment access . . . . . . . . . 96

4 Givil society leadership and HIV prevention in South Africa 101

4.1 Introduction . . . . . . . . . . . . . . . . . . . 101

4.2 Background: The challenge to AIDS science and TAC's resistance 104

4.2.1 Promotion of AIDS denialism and conspiracy beliefs by political leaders . . . . . . . . . . . . . . . . 104

4.2.2 Contesting denialism and mobilising through 'treatment literacy' . . . . . . . . . . . . . 107

4.3 Methods . . . . . . . . . . . . . . . . . . . . . 109

4.3.1 Measures ................... 111

4.4 Results and discussion . . . . . . . . . . . . . . . . . 114

4.4.1 Multivariate models for AIDS conspiracy beliefs . . . . . 115

4.4.2 Multivariate models for condom use at last sex . . . . . . 118 
4.5 Conclusions . . . . . . . . . . . . . . . . 121

4.6 Tables . . . . . . . . . . . . . . . . . . . . . . . . 122

5 Uganda: Givil society leadership 'in partnership with the state' 133

5.1 Introduction: state leadership and the making of an 'African success story' . . . . . . . . . . . . . . . . . . . . . 134

5.2 The origins of The AIDS Support Organisation . . . . . . . . 140

5.3 The context of civil society leadership: 'partnership' and Uganda's multisectoral approach . . . . . . . . . . . . . . . . . . 144

5.4 Puritanism, authoritarianism and 'partnership institutions' beholden to the executive . . . . . . . . . . . . . . . . . . . 149

5.5 Holding the purse strings: the impact of donors . . . . . . . . 156

5.6 Movement evolution: from volunteer network to professional service delivery organisation . . . . . . . . . . . . . . . . 159

5.7 Concluding thoughts . . . . . . . . . . . . . . . . 163

6 Conclusion: The global AIDS movement in an era of resource $\begin{array}{ll}\text { constraints and shifting priorities } & 166\end{array}$

6.1 The decline of the global AIDS treatment movement . . . . . 167

6.2 What is needed? . . . . . . . . . . . . . . . . . . . . . . 169

A The leadership literature: structure, agency, 'systemic leadership' and institutions

A.1 'Agential' and 'relational' perspectives on leadership . . . . . . . . 172

A.2 Extending the relational leadership perspective by means of institutional analysis . . . . . . . . . . . . . . . . . . 173

A.3 A relational model of transformative leadership . . . . . . . . 182

B An epidemiological model for HIV incidence, prevalence and mortality trends in Uganda (1974-2004) 186

B.1 Methods and data . . . . . . . . . . . . . . . . . . . . . . . . . 187

B.2 Results . . . . . . . . . . . . . . . . . . . . . . . . . . . . 190

$\begin{array}{ll}\text { G List of interviews } & 195\end{array}$ 
D aids2031 Givil Society Online Survey Questionnaire

Bibliography 


\section{List of Figures}

1.1 Individual leadership: Zackie Achmat of the Treatment Action Campaign takes on the pharmaceutical giants . . . . . . . 2

1.2 UN Secretary-General Kofi Annan opens discussions on a new partnership on AIDS in Africa in 1999 with UNAIDS Executive Director Peter Piot looking on . . . . . . . . . . . 4

1.3 International AIDS assistance $(2002-2011) \ldots \ldots \ldots$

1.4 Jonathan Mann of the WHO's Global Programme on AIDS addresses the UN General Assembly in 1987 . . . . . . . . . . . 8

1.5 WHO Director-General Halfdan Mahler, under whom Jonathan Mann directed the Global Programme on AIDS . . . . . . . . . 9

1.6 Peter Piot with civil society leaders Eric Sawyer and Noerine Kaleeba on World AIDS Day in 1995 . . . . . . . . . . . 12

2.1 HAART coverage vs. number of NGOs (UN directory) . . . . . . 37

2.2 PMTCT coverage vs. number of NGOs (UN directory) . . . . . . 38

3.1 AIDS denialism at the highest level . . . . . . . . . . . 50

3.2 A cabinet revolt leads to policy change . . . . . . . . . . . 51

3.3 The ‘boomerang pattern' of civil society influence in less open polities 67

3.4 Government inaction on AIDS . . . . . . . . . . . . . 70

3.5 The South African government out of step with the world . . . . . 86

3.6 President Mbeki: a lone voice for unreason . . . . . . . . . . 87

3.7 The scientific community calls the South African government to

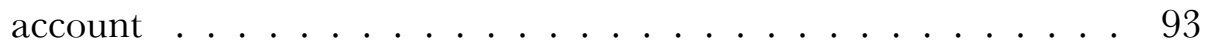

3.8 Network of influence around the Treatment Action Campaign . . 97 
3.9 Network diagram showing 'betweenness centrality' to highlight brokerage roles . . . . . . . . . . . . . . . . 98

3.10 Betweenness centrality as a measure of 'brokerage' . . . . . . . . 99

4.1 Tshabalala-Msimang promoted conspiracy theories . . . . . . 105

5.1 Ruhakana Rugunda (in a later role representing Uganda at the UN) 135

5.2 Epidemiological model for Uganda showing new adult HIV infections and adult HIV prevalence rate (1974-2004) with major political developments . . . . . . . . . . . . . . . . 137

5.3 Noerine Kaleeba in 2008 . . . . . . . . . . . . . . . . . . . . 143

5.4 Partnership mechanism of the Uganda AIDS Commission . . . . 153

5.5 The US remains the most influential donor in Uganda through PEPFAR ..................... 157

5.6 Sign for the TASO clinic in Tororo, Uganda . . . . . . . . . 160

B.1 EPP 2011 best fit prevalence curves (urban and rural) . . . . . . . 189

B.2 Epidemiological model for Uganda showing new HIV infections and HIV prevalence rate for adults (15-49), 1974-2004 . . . . . . 190

B.3 Detail of epidemiological model: prevalence rate, incidence rate and AIDS cases (peak years indicated with dotted lines) . . . . . 193

B.4 Detail of epidemiological model: new infections, HIV+ population and AIDS deaths (peak years indicated with dotted lines) . . . 194 


\section{List of Tables}

2.1 Parsimonious models for HAART and PMTCT coverage in SubSaharan African countries . . . . . . . . . . . . . 45

2.2 Modelling HAART coverage in SSA using Civil Society Survey indicators . . . . . . . . . . . . . . 46

2.3 Expanded models for HAART and PMTGT coverage in SubSaharan African countries . . . . . . . . . . . . . 47

4.1 Demographic breakdown of the CAPS 2009 sample . . . . . . . . 122

4.2 Weighted conspiracy models . . . . . . . . . . . . . 123

4.3 Gender-interacted conspiracy model (Africans) . . . . . . . . . . 125

4.4 Weighted condom models . . . . . . . . . . . . . . . 128

4.5 Gender-interacted condom model (Africans) . . . . . . . . . . . 130

B.1 Epidemiological model for Uganda (1974-2004) . . . . . . . . . . 192 


\section{Chapter 1}

\section{Introduction}

The human immunodeficiency virus (HIV) and the disease it causes (AIDS) represent a major challenge facing humanity. Nearly thirty years since the first AIDS cases were identified, about 30 million people have died of the disease (UNAIDS, $2011 \mathrm{c}: 3)$ and 34 million people were thought to be living with HIV in 2010 (UNAIDS, 201 lb:6). While new infections have been declining, 2.7 million new infections and 1.8 million deaths occurred in 2010, 1.2 million of those in Sub-Saharan Africa (ibid.:7,10). Progress has been made, especially in providing treatment, but the challenge remains.

The story of society's response to this unprecedented epidemic is still emerging and is only beginning to be analysed. It is a tale of denial, tardy responses and institutional failures, but also one of triumphs in research, drug development, global activism, international cooperation and occasionally in political leadership.

It is a tale, also, of innovation in global institutions and global health governance, in which the World Health Organisation (WHO) and the United Nations (UN) were shaken out of bureaucratic intransigence and ossified 'business as usual' approaches to global health challenges. This shakeup was the work of unconventional public health figures like Jonathan Mann (the first head of the WHO's Global Programme on AIDS) and Peter Piot (the first executive director of the Joint United Nations Programme on HIV/AIDS or UNAIDS), but above all of a global AIDS activist movement, perhaps the most impressive example of health activism the world has seen. Where successes have been achieved (and there have 
Figure 1.1: Individual leadership: Zackie Achmat of the Treatment Action Campaign takes on the pharmaceutical giants

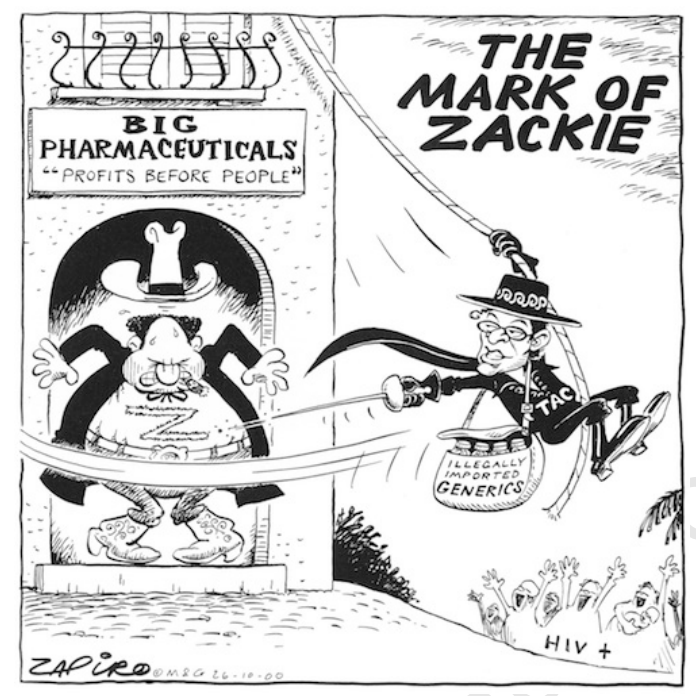

Source: www. zapiro.com. (C2000-2012 Zapiro. Printed with permission from Zapiro.com.

been spectacular successes as well as dismal failures), these have resulted, at least in part, from leadership. Visionary leadership has occurred at the national political level (such as by leaders in Uganda, Brazil and Thailand), at the global intergovernmental level (such as by Mann and Piot) but also within the private sector and civil society - both within countries and globally. The most visible success in the response to AIDS has been the provision of antiretroviral treatment to millions of poor people - more than five million people in low and middle-income countries (UNAIDS, 2010:7). Given the huge obstacles (massive costs, logistical challenges, expensive patented drugs, etc.), this could never have been achieved had it not been for the emergence of a global coalition that mobilised support for treatment access as a fundamental right and a moral imperative. This coalition - which I refer to as the 'global AIDS treatment movement' - was constructed through vigorous global treatment activism from social movements and civil society organisations (CSOs) across the globe, 'medical activism' from a global community of politically and ethically committed researchers and clinicians, and ‘bureaucratic activism' from officials in governments and intergovernmental organisations. 
In this thesis I will attempt to tell the story of how AIDS, a disease whose viral cause is transmitted largely through sex (and in certain regions mainly through needles used for injecting drugs) was transformed from a stigmatised disease few politicians would mention to a global public health priority. I will do this by focusing on the efforts of civil society leaders (and their interactions with national and international leaders and bureaucrats) in two highly significant cases: Uganda, the 'poster boy' for effective political leadership (as one of the first African countries to show declines in new infections) and South Africa, whose response was rightly seen as informed by criminal denial and inaction, but where a policy reversal under activist pressure saw the establishment of the world's largest antiretroviral treatment programme.

\subsection{Leadership for a global AIDS response}

\subsubsection{From stigmatised 'gay disease' to global public health priority}

The global AIDS activist movement deserves substantial credit for the unprecedented international public health response since the 1990s. In the 1980s, activism was concentrated in North America and Europe (especially the United States), where the epidemic first came to light as it wreaked havoc among gay men. Activism - led by a generation politicised in the 1960s and 70s Stonewall-era - was aimed at the neglect and denial of political leaders and at securing investment in research and gaining access to experimental drugs (see Epstein, 1996). But after the spectacular success of triple-therapy - known as highly active antiretroviral therapy (HAART) - essentially transformed AIDS into a manageable chronic disease in industrialised countries, the focus of activism shifted to expanding the availability of antiretroviral drugs in developing countries where the majority of HIV infections occurred (Smith and Siplon, 2006).

Expanding treatment access to the millions of patients in middle and lowincome countries (especially Southern Africa) would require, however, both a substantial reduction in the prices of antiretroviral drugs - in 1997 a year's treatment cost about US\$16,000 per patient (Schneider and Garrett, 2009:7) - and signific- 


\section{Figure 1.2: UN Secretary-General Kofi Annan opens discussions on a new partnership on AIDS in Africa in 1999 with UNAIDS Executive Director Peter Piot looking on}

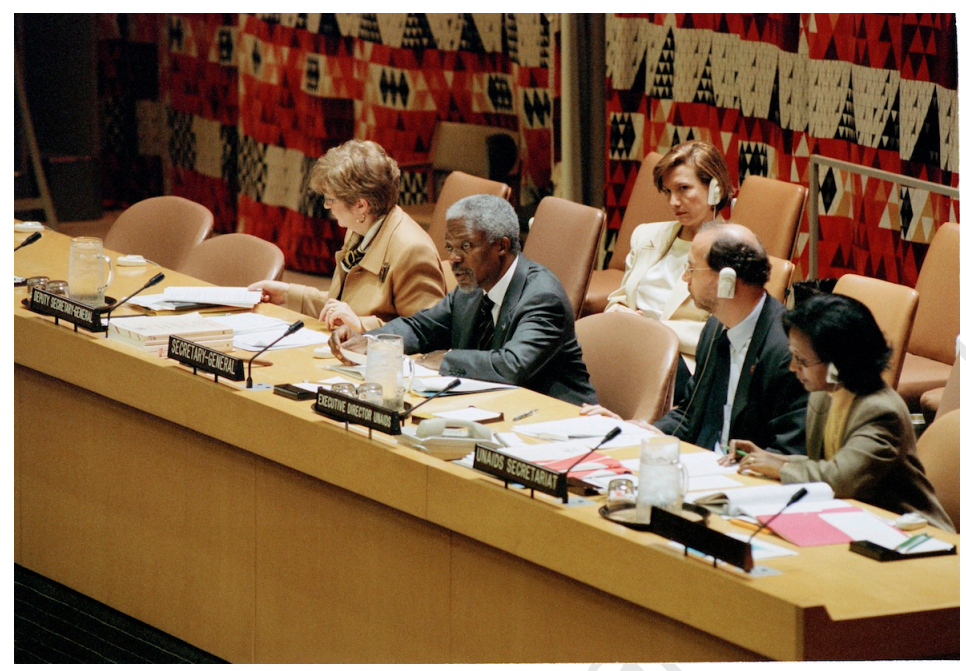

Source: UN Photo/Eskinder Debebe. CUnited Nations 1999.

http://www. unmultimedia.org/s/photo/detail/158/0158044.html

ant resource transfers from industrialised countries. On both counts the global AIDS treatment movement has been spectacularly successful: by 2010 poor countries could purchase first-line drugs ${ }^{1}$ at US $\$ 143$ per patient per year (Médecins

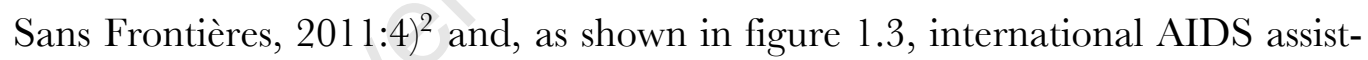
ance disbursements rose from US\$1.2 billion in 2002 to US $\$ 7.7$ billion in 2008 (Kates et al., 2012:5). International assistance for AIDS has remained around that

\footnotetext{
${ }^{1}$ 'First-line' refers to the cocktail of three drugs that patients are typically prescribed when initiating antiretroviral therapy. When the virus becomes resistant to one or more of these drugs (usually after some years), the patient is switched to a 'second line' regimen and eventually to 'third-line' or 'salvage' regimens, if available. Public HAART programmes in developing countries generally do not offer treatment options beyond second-line regimens.

${ }^{2}$ The US $\$ 143$ per patient per year (ppy) is the lowest price from a generic manufacturer for a tenofovir-lamivudine-efavirenz co-pack. The same regimen in a one-pill-per-day fixed-dose combination is US $\$ 173$ ppy and from the originator company is offered at US\$613 ppy to low-income countries (Médecins Sans Frontières, 2011:4). Tenofovir-based regimens are better tolerated than the stavudine-based regimens initially rolled out in most countries and the WHO has recommended shifting from the latter to the former since 2006. A stavudine-based fixed-dose combination (lamivudine-stavudine-nevirapine) can be purchased for as little as US\$55 ppy (Médecins Sans Frontières, 2011:82).
} 
level, with a brief reduction in 2010 - probably largely owing to the global financial crisis - but have stopped rising.

Figure 1.3: International AIDS assistance (2002-2011)

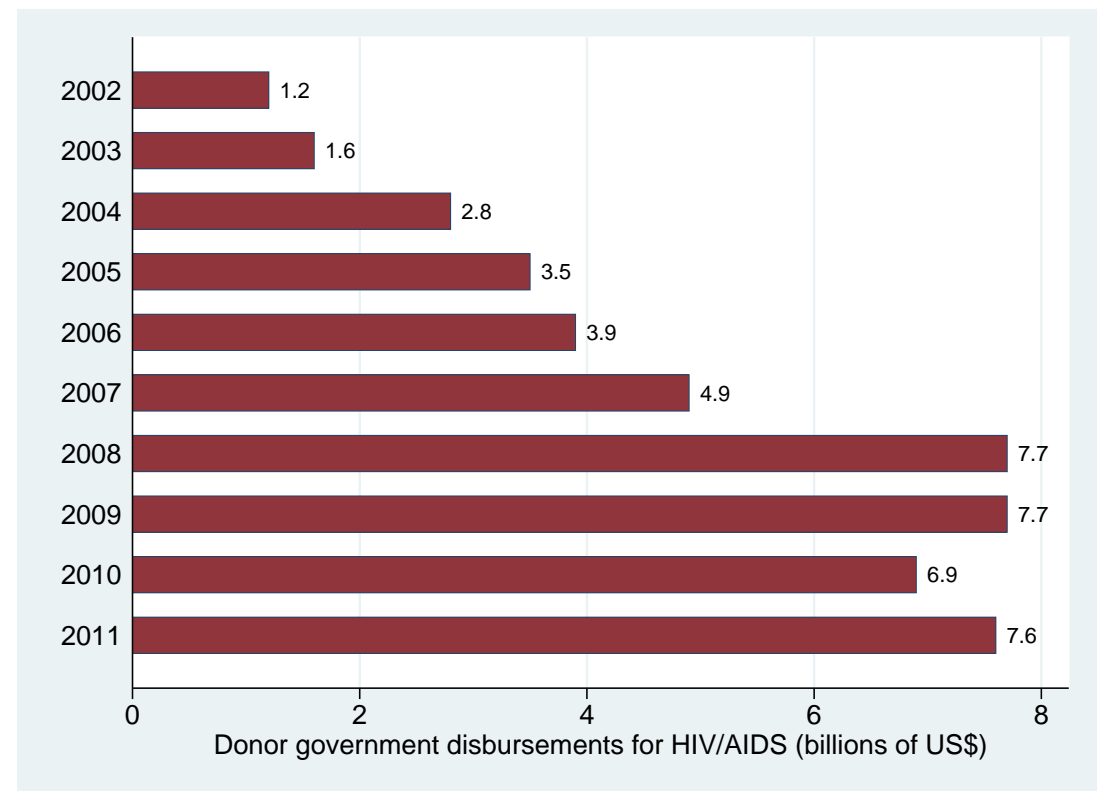

Source: The Kaiser Family Foundation (Kates et al., 2012:5).

Two critical factors in the rapid increases in international assistance for AIDS programmes was the creation of the Global Fund to Fight AIDS, Tuberculosis and Malaria (GFATM or the Global Fund) in 2002 as a dedicated multilateral vehicle for channelling funding from donor governments (and some private donors) to HIV prevention and AIDS treatment efforts in developing countries and the United States President's Emergency Plan for AIDS Relief (PEPFAR), which was established in 2003. The majority of the assistance is channelled through the Global Fund and PEPFAR, as the largest multilateral and bilateral funding vehicles respectively. Visionary individual leadership and coalition-building played an important role in the creation of both, with the Global Fund primarily an initiative of then-UN Secretary-General Kofi Annan, and PEPFAR of then-US President George W. Bush. In both cases coalitions had to be constructed to support the initiatives, with the Global Fund representing a coalition of donor countries and 
PEPFAR requiring congressional earmarking of its budget.

The Bush Administration managed to secure US $\$ 15$ billion allocated over the first five years of the programme (with additional allocations since), in a process that was notable for the unusual allegiance of AIDS activists, development/debt relief activists (such as the Irish rock star Bono) and and evangelical Christians (an important support base for then-President Bush). The mobilisation of support from the American 'religious right' was indeed surprising, with even the controversial senator Jesse Helms (who had consistently opposed funding for AIDS in the past) supporting the bill. ${ }^{3}$ However, the support of this constituency came at a price: much of the money was to be channelled to religious groups, and while most of the funds would be spent on AIDS treatment, $\$ 1$ billion was earmarked for HIV prevention programmes that promoted sexual abstinence. Other religiously-inspired conditions imposed by PEPFAR on recipients included requirements not to target commercial sex workers or to provide reproductive health services that may include termination of pregnancy. (These conditions have substantially changed under the Obama administration.) Nevertheless, PEPFAR has become the largest source of funding for AIDS efforts in developing countries (and is extremely influential in the 'focus countries' where most of its funding is allocated. The Kaiser Family Foundation reports that $77 \%$ of all international AIDS assistance is now bilateral rather than multilateral (Kates et al., 2012:3), with PEPFAR dominating bilateral financing - the United States was responsible for $59.2 \%$ of all donor government disbursements for AIDS in 2011 (Kates et al., 2012:6). Both PEPFAR and the Global Fund have received substantial criticism, but it is undeniable that much of the progress in the global AIDS struggle has been funded through these two vehicles.

The rapid progress in treatment provision resulted from a broad coalition that emerged in the late 1990s around the idea that treatment access represented a moral imperative. It united the unlikeliest of partners: a global activist network comprising new movements across the developing world (among the most prominent being the Treatment Action Campaign), veteran activists in the United States,

\footnotetext{
${ }^{3}$ Senator Helms had even said in 1995 that AIDS funding should be reduced because homosexuals contracted the disease through their "deliberate, disgusting, revolting conduct" (Epstein and Halperin, 2007:185).
} 
international bureaucrats and even conservative American politicians. Individual leadership played a key role in the emergence of the global AIDS treatment movement: activists and civil society leaders like TAC's Zackie Achmat, TASO's Noerine Kaleeba and the New York-based Treatment Action Group's Mark Harrington and Gregg Gonsalves made moral appeals that resonated in the global media and with certain political leaders. Jonathan Mann and Peter Piot brought vigour to efforts at coordinating the international response and brought activists and representatives of affected communities to the table at the highest levels, helping to lend scientific and political legitimacy to the claims of activists. Kofi Annan and George W. Bush managed to garner support for global AIDS funding, and later former US President Bill Clinton used his foundation to negotiate access to generic antiretroviral medicines. Without individual leadership, the coalition could not have been built.

In the next section I will briefly discuss the emergence of a global architecture for addressing AIDS, including coordination at the intergovernmental level through the World Health Organisation's Global Programme on AIDS from 1986 and the new Joint United Nations Programme on HIV/AIDS established in 1996.

\subsubsection{Towards an architecture for a globally coordinated AIDS response}

Early international efforts at responding to AIDS in Sub-Saharan Africa were driven mainly by infectious diseases researchers. During the early 1980s, many believed the disease to be confined to homosexuals and the risks to the general population confined to the safety of the blood supply. The World Health Organisation under its director-general Halfdan Mahler mainly saw concerns about HIV /AIDS in Africa as a diversion from the WHO's 'Health for All' programmes in developing countries (Lisk, 2010:13). However, through projects such as Projet SIDA in the then-Zaïre, an international collaboration on which Jonathan Mann represented the Centers for Disease Control in Atlanta and Peter Piot the Institute of Tropical Medicine in Antwerp, the extent of AIDS in Africa was documented (see Piot, 2012:133-147) and eventually it become clear that HIV was being transmitted heterosexually and that a coordinated global response would be necessary. Dr 
Figure 1.4: Jonathan Mann of the WHO's Global Programme on AIDS addresses the UN General Assembly in 1987

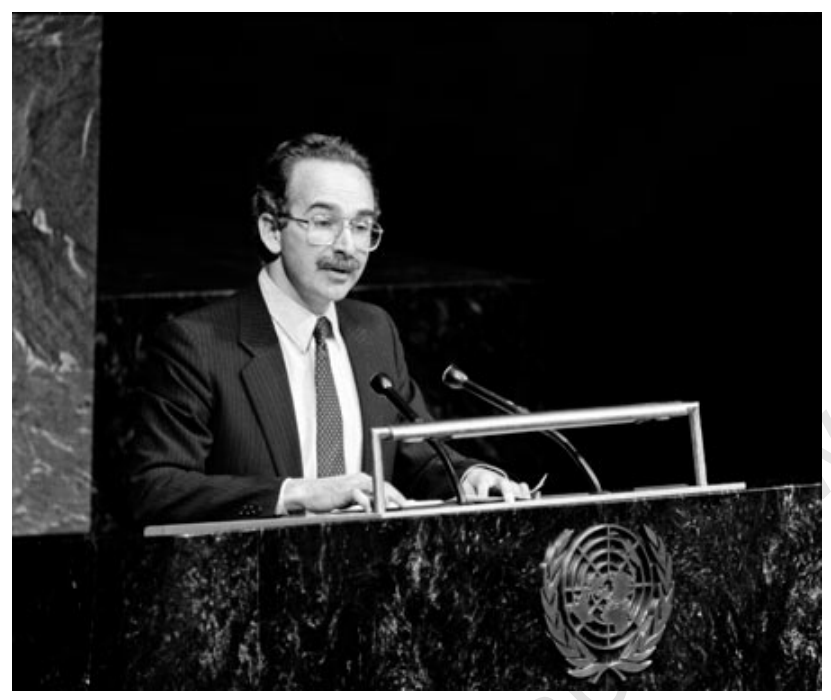

Source: UN Photo/Saw Lwin. OUnited Nations 1987.

Fakry Assad of the WHO's Division of Communicable Diseases was given overall responsibility for the agency's HIV/AIDS activities (Lisk, 2010:13). He organised an important first meeting on AIDS in Africa, held in Bangui, capital of the Central African Republic in October 1985 (Piot, 2012:149). The Control Program on AIDS was set up within the Division of Communicable Diseases in 1986 and Jonathan Mann recruited from his directorship of Projet SIDA to become its director. The Control Programme on AIDS was renamed the Special Program on AIDS in February 1987 and then the Global Programme on AIDS (GPA) in January 1988 (Knight, 2008:15).

The GPA grew rapidly under Mann's leadership, who had won the confidence of Director-General Mahler (Lisk, 2010:16), who himself became a strong advocate for action on HIV/AIDS. Mann placed strong emphasis on human rights and combating stigma and discrimination and insisted on the necessity of social justice and human dignity for the promotion of public health (Ligon-Borden, 2003:318). This is a legacy that survives as a central tenet of the approach espoused by UN agencies and most global actors. Although written later, Mann's approach during 


\section{Figure 1.5: WHO Director-General Halfdan Mahler, under whom Jonathan Mann directed the Global Programme on AIDS}

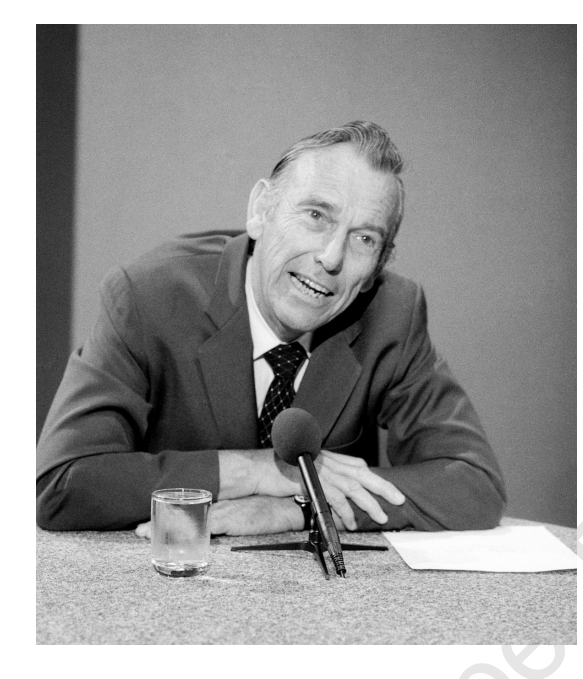

Source: UN Photo/Pernaca Sudhakaran. CUnited Nations 1987.

his tenure at the GPA is captured well in the following passage:

The new public health recognises that the positive impact of traditional public health work will be inherently limited and inadequate without a commitment to changing societal conditions which constrain health and create vulnerability to preventable disease, disability and premature death. This is the precise point where the human rights framework becomes critical.

We suggest that a society in which human rights are promoted and protected, and in which human dignity is respected is a healthy society; that is, a society in which people can best achieve physical, mental and social well-being. (Mann, 1995:230-231). ${ }^{4}$

The GPA was funded mainly through direct contributions from wealthy countries, and therefore bypassed the usual WHO budgetary process. It focused on

\footnotetext{
${ }^{4}$ See also Mann (1997) and Mann (1998).
} 
providing planning and technical assistance to countries, especially poorer countries with emerging epidemics, and in many ways Mann came to be seen as the leader of the global AIDS movement. The GPA further worked directly with countries, sending consultants from Geneva to assist in planning interventions, thereby bypassing (and raising the ire of) the WHO's powerful regional directors (Piot, 2012:159), in addition to its high profile and extra-budgetary resources leading to friction and jealousy (Lisk, 2010:20). As long as Mann could count on Mahler's support, he survived the infighting, but after the election of Hiroshi Nakajima (a former regional director for the Western Pacific) as Director-General in 1988, his position became increasingly difficult. Nakajima sought to scale down the GPA and limit Mann's authority, for example by placing the GPA under the supervision of a General Management Committee with representation of the UN agencies that had sponsored the GPA's creation-UNICEF, UNDP, UNFPA, UNESCO and the World Bank (Lisk, 2010:20-21). This ultimately resulted in Mann's resignation in March 1990 and his replacement by Michael Merson, the former head of the WHO's Control of Diarrhoea Programme. Piot (2012:181) describes the news of Mann's resignation as a "blast of icy air," since "Jonathan was our moral leader; for some he had acquired the status almost of a saviour." Although Mann's leadership of the GPA was by no means flawless - the structural and institutional weaknesses of the GPA arguably strengthened the hand of his critics and probably contributed to its eventual demise - real progress had been made and a human rights approach to the fight against AIDS had been established. After leaving the WHO Mann returned to academia. He was appointed the first Francois-Xavier Bagnoud Professor of Health and Human Rights at Harvard University in 1993, and remained a prominent voice in the fight against AIDS. He died tragically in the 1998 crash of Swissair Flight $111 .^{5}$

Perceptions of the GPA's dysfunction, lack of inter-agency cooperation and other factors led the GPA's General Management Committee to commission an external review, which got underway in 1991. The External Review Committee's eventual report (WHO, 1992) included a range of recommendations, including new mechanisms to ensure coordination of the global response within and outside the UN system and that a working group be established to take forward its

\footnotetext{
${ }^{5}$ For more on Mann and his legacy, see Krim (1998); Marks (2001); Ligon-Borden (2003).
} 
proposals. A twelve-member task force was established with representation from donor countries, low-income countries, UN agencies and civil society, which by 1993 had developed a proposal for a new "joint and co-sponsored" programme, a proposal that was officially put forward by Canada at that year's World Health Assembly. This type of programme was strongly favoured by donor countries (Knight, 2008:23), and despite a huge amount of wrangling (and strong opposition from within the WHO and certain other UN agencies), the structure of the new programme and its governance by a Programme Coordinating Board (PCB) was finally agreed and endorsed by the Economic and Social Council (ECOSOG) in 1994. The ECOSOC resolution called for the establishment of a Committee of Cosponsoring Organisations (CCO), which started meeting in 1994 and finalised practical plans for the establishment of the new programme during 1995. It was to be called the Joint United Nations Programme on HIV/AIDS (UNAIDS) and Peter Piot, who had been recruited to the GPA by Mike Merson in 1992, was appointed in December 1994 to lead the transition process and to become the first Executive Director when UNAIDS officially opened for business on 1 January $1996 .{ }^{6}$

What became clear almost immediately was that Piot wished to continue and deepen the approach pioneered by Mann in certain key respects, including a human rights focus and involving civil society (including activists) in decision-making. As can be seen in figure 1.6, he shared a platform on World AIDS Day in 1995, before UNAIDS had even opened its doors, with New York activist and Housingworks founder Eric Sawyer and the Ugandan founder of TASO, Noerine Kaleeba. In fact, involving civil society leaders became a key feature of his term of office at UNAIDS. Representatives of the worst-affected and most marginalised communities (including sexual minorities and 'grass-roots' African groups) were brought to the table at the highest levels of the global AIDS response. He fought numerous internal battles in order to ensure adequate civil society representation and participation in UNAIDS processes and structures, including the PCB. In an interview he told me:

I had a completely different view on what [UNAIDS's] programme

\footnotetext{
${ }^{6}$ For a more detailed review of the complex set of events leading to the creation of UNAIDS, see Lisk (2010:27-42), Piot (2012:193-232) and Knight (2008:18-46).
} 


\section{Figure 1.6: Peter Piot with civil society leaders Eric Sawyer and Noerine Kaleeba on World AIDS Day in 1995}

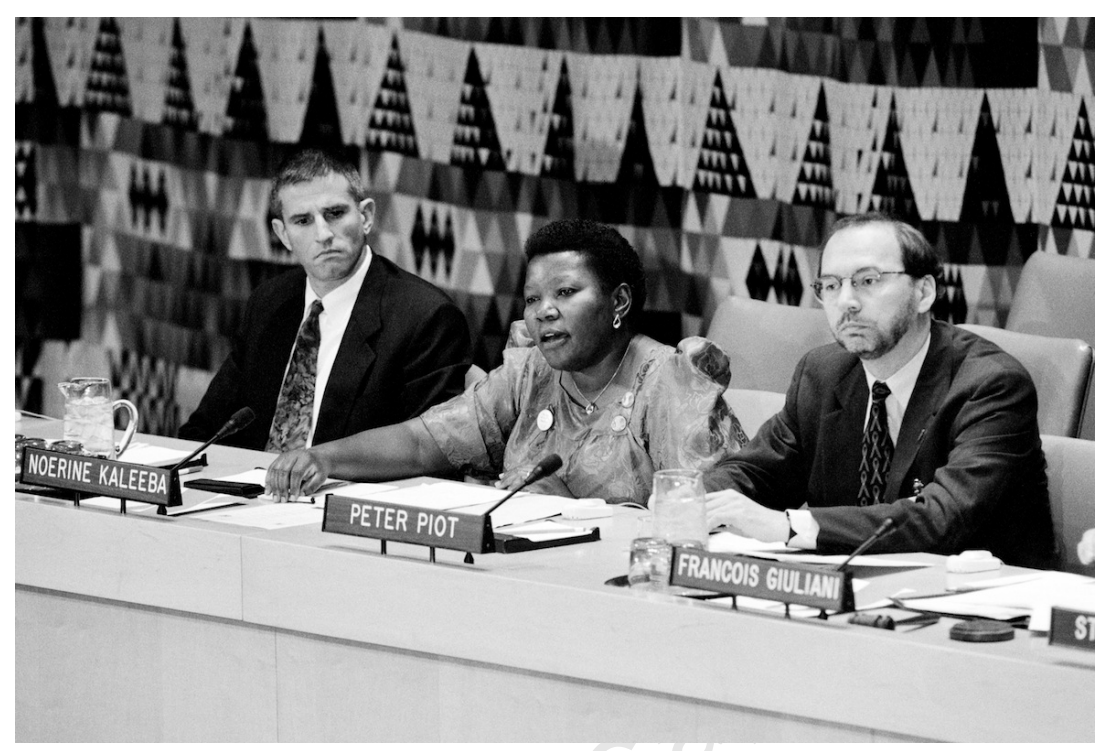

Source: UN Photo/Milton Grant. OUnited Nations 1995.

should be than most people. ...Fundamentally, it came down to the fact that I felt that this new programme should be accountable to - to use a big word - the people. The first sentence of the UN Charter reads "We the people..." Whereas the UN colleagues felt that that the programme should be accountable to the UN system. The first big fight I had was on the question, "who is my boss." The cosponsoring agencies wanted it to be the CCO [Committee of Cosponsoring Organisations], in other words the UN system. And I said this is not possible, then we're judge and jury. I want to be accountable to the member states and to people representing the fight against AIDS, people affected by AIDS. So that was a fundamental difference in opinion. ...I had to go to ECOSOC to win that fight, because the CCO disagreed with me, led by Nakajima and UNICEF.

For me it was just a natural thing that NGOs and civil society should 
be on the board [the PCB]. It was not something that came from an ideological or very theoretical, political scientific type of position. I just could not imagine that a programme dealing with AIDS would not involve those who are affected, that they would not be represented in the governance. ... That was my own background. And it was both from a perspective of justice and of effectiveness - how can you be effective in your decision-making if you're not involving those who are actually on the front lines? It's as simple as that. ${ }^{7}$

Within and around UNAIDS, calls for leadership on AIDS became increasingly frequent, including prominently from Piot himself. But what does 'leadership' actually mean? And can calling for leadership have any impact if we cannot define exactly what it means? I turn to these questions in the next section.

\subsubsection{The problem of 'AIDS leadership'}

Already while working at the GPA, Piot became convinced that leadership was a critical factor in successfully responding to a complex global challenge like AIDS:

I started to become interested in decision-making at the highest level. I could see how political AIDS is, because it's not just a matter of making sure the labs function and the condoms are available and the drugs stay cold: you need the political heavy lifting to have an impact. Budgets must be voted, and political will and leadership are vital. (My emphasis. Piot, 2012:207).

Reviewing references to 'leadership' in UNAIDS speeches and documents reveals that it has been used primarily in this sense of 'political commitment' from political leaders: i.e. a willingness to face up to and address the issue of AIDS, and to do the 'political heavy lifting' required for an effective policy response. For example, an early collection of prevention 'best practice' case studies argued that "Political action and leadership is clearly needed to set the direction for a national response" and that "in many countries a lack of political will has delayed a coherent response dealing with the epidemic" (UNAIDS, 1998b:6). A case study of

\footnotetext{
${ }^{7}$ Interview, P. Piot (20 December 2010).
} 
Senegal's response to the epidemic contrasted the willingness of Senegalese politicians to address AIDS with the inaction of politicians in other countries (UNAIDS, 1999:11), while also praising religious and community leadership.

A call for leadership on AIDS is therefore in the first place simply a call for political leaders to confront the challenge of AIDS, to place it on the national agenda and speak about it (Piot was hugely frustrated in early days of UNAIDS when most African countries exhibited a near-complete denial of the issue $\left.{ }^{8}\right)$. But the call for leadership is not restricted to governmental leadership and commitment from political leaders. It is also used in a second and wider sense - as something that is required at all levels and in all domains of society. In a 2007 interview, Piot said:

Our point is that leadership is not only something for prime ministers or for the top. It is on all levels. ...Fostering informal leadership is one of our main activities. I think it is one of the most important achievements of UNAIDS, to put AIDS on the agenda on various levels: in business, in trade unions, in women's organisations. (Vandenbruaene and Piot, 2007:438).

More formally, he has argued with former UNAIDS staffer (and Senegalese Health Minister from 2001 to 2003) Awa Marie Coll-Seck that government interventions need to be complemented by a broader societal mobilisation against AIDS (Piot and Coll-Seck, 2001). AIDS leadership in the view of UNAIDS under Piot was therefore something that always included civil society leadership. This includes AIDS activism such as the gay-led activism of the $1980 \mathrm{~s}^{9}$ and TAC's activism, as well as the less radical work of care, support and combating stigma by organisations like TASO. In a speech in 2008, Piot explicitly linked leadership on AIDS and state-civil society cooperation:

I arrived here yesterday from South Africa, where I saw very positive signs of strong new leadership on AIDS. The National AIDS Council has a clear agenda, and it is good to see government and civil society really rallying together to achieve this. (Piot, 2008).

\footnotetext{
${ }^{8}$ Interview, P. Piot (20 December 2010).

${ }^{9}$ In the same interview quoted earlier, Piot argued that "leadership in the MSM [Men who have Sex with Men] communities was the driver of the response to AIDS in the eighties" (Vandenbruaene and Piot, 2007:438).
} 
'Leadership' with respect to AIDS is therefore used in both a narrower and in a wider sense, while it is also used with modifiers like 'political' and 'community' in various contexts. These distinctions are not always clear and the term is neither explicitly defined nor is a real theory of leadership advanced. Furthermore, the term has definite normative content: the call for leadership is a call for a particular kind of leadership, not the leadership of South Africa's AIDS-denying president Thabo Mbeki, but rather of Senegal's Abdou Diouf. ${ }^{10}$ While the distinction between 'good' and 'bad' leadership may seem clear in this instance, leadership can also be much more ambiguous, as the case study of Uganda in chapter 5 will demonstrate with respect to Yoweri Museveni. The normative content of the notion of leadership has not been spelled out in a systematic fashion, and over-simplification can be dangerous.

Even in the scholarly literature, case studies have frequently used the concept of leadership in a fairly off-hand way, not explicitly defined (see, for example Putzel, 2004). Bor (2007) has made an attempt to systematically examine national leadership on AIDS, but equates leadership with political commitment to addressing HIV/AIDS. In his cross-national analysis, he uses a measure of political commitment as the main indicator of leadership, defining 'political commitment' as follows: "Political commitment' refers to the extent to which top-level government leaders (viz. heads of state and their appointees) support AIDS as a priority on the national agenda" (Bor, 2007:1586). ${ }^{11}$ However, a 'political commitment' definition of AIDS leadership is problematic for several reasons. It fails to differentiate between commitment to specific policies and to the issue more broadly, between commitment at the discursive level and at the level of implementation and between commitment to 'good' and 'bad' AIDS policy (Thabo Mbeki displayed extraordinary commitment to AIDS denialism, at great political cost).

There is therefore a need to address the lack of explicit conceptualisation and theorisation associated with the concept of 'AIDS leadership'. It would perhaps be unreasonable to chide Piot and others involved in the day-to-day struggle against AIDS for this lack of theorisation, but without adequate theory, it is hard to imagine how it can be studied empirically. We will need to conceive of AIDS lead-

\footnotetext{
${ }^{10}$ See, for example, Piot (2012:196).

${ }^{11}$ Also see chapter 2 from page 29.
} 
ership in a way that accommodates (at the very least) the distinctions mentioned above and that also allows objective measures of the quality of leadership - i.e. actual polices, their implementation and the results of those policies; what leaders $d o$ and not just what they say. ${ }^{12}$

This thesis is therefore an attempt to conceptualise and reflect upon the broader notion of leadership in the AIDS response, particularly as it pertains to 'civil society leadership' in Sub-Saharan Africa. But in looking at civil society leadership, I necessarily also have to look at efforts in the intergovernmental and governmental domains, and at transnational, national and local levels. In an attempt at dealing with the complex nature of the AIDS response, I opt for rich historical accounts punctuated by more restricted analyses employing quantitative techniques and programmatic outcomes as measures of performance, such as the proportion of people in need who are being reached by prevention of mother-to-child transmission (PMTCT) ${ }^{13}$ and antiretroviral treatment. It is not a philosophical reflection on the idea of AIDS leadership, but an empirical and grounded account that hopes to clarify through concrete discussion.

I focus on the examples of Uganda and South Africa both in order to investigate how one should think conceptually about civil society mobilisation around AIDS and investigate empirically whether civil society mobilisation makes a difference to the quality of the national and international response. Both of these countries had large-scale HIV epidemics (Uganda's earlier than South Africa's) and both have prominent civil society movements active on AIDS: Uganda's TASO and South Africa's TAC. However, the countries also differ in important respects, including level of development and reliance on foreign assistance, institutional arrangements like the openness of the political system and the response of their respective governments during the worst periods of the AIDS epidemic. These two examples are returned to repeatedly during the course of my investigations of country-level

\footnotetext{
${ }^{12}$ Measuring the quality of 'AIDS leadership' is difficult and raises a number of serious methodological issues. These will be discussed in greater detail later. Suffice it to say that my focus is on measurable results of national HIV prevention and AIDS treatment programmes (for example HAART and PMTCT coverage), while taking into account factors that influence these outcomes but fall outside the immediate control of leaders (such as the size of the epidemic, national income, international assistance, etc.). See chapter 2 for a more detailed treatment of these issues.

${ }^{13}$ Administering a short course of one or more antiretroviral drugs can substantially reduce the risk of vertical transmission of HIV from a mother to her child.
} 
national leadership, civil society opposition to state policy, state-civil society cooperation and the impact of civil society mobilisation on communities with respect to HIV prevention.

For the sake of clarity, two further things should be emphasised at this point. First, the response to AIDS operates at transnational, national and local levels, with complex interactions between activities at these levels. For example, much of the progress in rolling out treatment in poor countries has been driven at the transnational level, with universal guidelines issued by the World Health Organisation, targets set at UNAIDS, transnational activism driving drug prices down and funding for the roll-out provided through the Global Fund and PEPFAR. Actual delivery takes place in national health systems and local health facilities, sometimes monitored by local activists. Second, the response to AIDS is complex and may include a wide range of interventions, not necessarily in a coordinated fashion. Efforts to prevent HIV infection may include public awareness and behaviour change campaigns, promotion of HIV testing, distribution of prevention technologies like condoms and emerging technologies like microbicide gels, PMTCT by means of antiretroviral drugs and medical interventions like medical male circumcision. Sometimes these efforts are aimed at specific high-risk populations (like sex workers or men who have sex with men), at other times at the general population. Sometimes AIDS treatment is even considered a prevention intervention (since it reduces the risk of transmission). The emphasis on these various prevention and treatment interventions varies substantially between different contexts and at different times, depending on perceived priorities, interpretation of the scientific evidence and political and cultural sensitivities. The AIDS response is therefore complex and differentiated, making defining and measuring 'leadership' a difficult task indeed.

\subsection{Approaching 'civil society leadership' on AIDS}

I will not put forward a detailed theoretical framework here. Instead, I will briefly review some of the most important theoretical pointers provided by the existing 
literature on AIDS activism and mobilisation, and raise a number of overarching issues to be considered. A more detailed theoretical consideration of AIDS activism, which draws on the sociological literature on social movements and activist networks, is included with the first empirical case study (chapter 3).

\subsubsection{What is required of theory?}

The topic of AIDS activism cuts across disciplines, is complex, under-theorised and does not lend itself to neat theoretical explication. I will therefore consciously draw upon an eclectic mix of conceptual and theoretical frameworks. A key overarching theoretical question is the (age old) question of structure and agency, and in particular how much explanatory weight should be attached to choices made by individual agents (leaders), and how much to the contextual factors that impose incentives and constraints on agents. Any sophisticated and helpful account of civil society leadership on AIDS must grapple with this structure-agency problematic. Rather than 'solving' the problem, the framework we adopt must be able to account for both structural factors and individual agency in explaining processes and outcomes.

As I have already argued, individuals and their particular, contingent experiences seem to have had a major influence on the development of AIDS activism. The case studies will demonstrate that relationships between concrete individuals, the emotions that drive activism and solidarity, and psychological factors (at both the group and individual levels) cannot be escaped. These issues are best addressed in detailed historical narratives such as those later in this thesis, but it is important to emphasise early on that our theoretical choices must be able to account for individual agency. Sociological approaches such as the sociology of social movements (upon which I draw extensively) often employ structural explanations to the exclusion of individual idiosyncrasies and moral purpose that sometimes transcend context and structure. On the other hand, structural factors should not be ignored in favour of a 'big man theory of history' that boils down to pure agency. This approach is particularly prevalent in the literature on leadership from the management and applied ethics fields (see appendix A). The synthesis approach that I will propose in chapter 3 emphasises 'networks' precisely because this concept op- 
erates at the nexus of structure and agency, allowing us to think about leaders both in terms of their 'structural' position in the network and about the propagation of influence and impact through the network.

A second issue that I believe to be of some significance is the ability of theory to inform a politically and ethically engaged discussion. On the one hand this involves accounting for the moral concerns of agents ('ethical leadership'), on the other it is not possible to reflect on AIDS activism while not (at least implicitly) adopting ethical and political positions oneself. Through this entire project runs a concern with social justice, equality and human rights and it would be disingenuous to pretend to complete scholarly detachment (and in any event such detachment would probably not be desirable, even if achievable).

The sociology of political contention is of a largely descriptive and explanatory character, so I also draw to some extent on the political philosophy of civil society, which exhibits a greater normative focus. Some scholars from this tradition have shown some empirical interest in real social movements, while at the same time making politico-philosophical interpretations. For example Smith (1998:2-3) argue that new social movements "[politicise] new areas of the social" and I have employed a similar perspective in interpreting TAC as an example of the kind of political contestation central to what Laclau and Mouffe term 'radical democracy' (Grebe, 2009a).

It seems to me that a hybrid approach, which exhibits both a political engagement and an empirical focus centred around a 'network perspective' is most appropriate for framing the empirical investigation of AIDS activism and civil society leadership. While sociological models are very useful as an explanatory framework (particularly in a comparative context), a more political-philosophical approach is also required, in part because any study of AIDS activism necessarily has to adopt a position on whether AIDS activism should be encouraged (and what kind of activism is likely to be beneficial). An apolitical and a-ethical analysis may at first seem more defensible, but would be severely impoverished, particularly in the context of HIV/AIDS, which is a deeply political and ethical question. ${ }^{14}$

\footnotetext{
${ }^{14}$ This question echoes in some ways the theoria/praxis debates in critical philosophy. I would here align myself with thinkers like Horkheimer who argued that neither empirical social research nor social theory can be conducted in isolation from ethical and political understanding.
} 


\subsubsection{The literature on AIDS activism}

Given the fact that AIDS first (visibly) emerged among gay men in the United States, and shortly thereafter in other parts of the world, it is not surprising that political mobilisation around AIDS in the 1980s drew on the gay liberation movement - which has since expanded to a rights movement of Lesbian, Gay, Bisexual, Transgender and Intersex (LGBTI) communities and other sexual minorities (Paxton, 2012:145). I discuss the ways in which later global and third-world activism linked up with and drew on the experiences of Northern AIDS activism rooted in the gay rights movement in chapter 3. The literature on early AIDS activism is therefore intertwined with the literature on LGBTI activism, sexual rights, queer studies and similar areas with an identity politics focus. This is also the case with later studies of AIDS and LGBTI rights movements in Latin America (de la Dehesa, 2010) and Asia (Weiss, 2006), and even sex workers in Southeast Asia (Pisani, 2009), where the focus remains on mobilising around minority identities and social exclusion.

In the view of Paxton (2012:145), in Sub-Saharan Africa, "identity politics has relied upon a person's HIV status itself to be the marker of identity, rather than on another socio-personal identity which has a high degree of co-incidence." While this is undoubtedly true (the Treatment Action Campaign's 'HIV-Positive' T-shirts are perhaps, on one interpretation, a visible emblem of identity-based mobilisation), it is important to point out that the mobilisation strategies of African movements sometimes go significantly beyond identity politics - and in fact TAC's leadership explicitly rejects identity politics. ${ }^{15}$ For more on this issue see chapter 3 . The identity politics theorisation of AIDS activism draws, at least implicitly, on the 'new social movements' perspective that will be discussed later, together with certain notions of symbolic politics. While I have in the past applied this perspective to South African AIDS activism (drawing on Judith Butler's notion of the 'rearticulation of political signifiers'), I also emphasised the importance of avoiding the essentialising impulse central to identity politics (Grebe, 2009a). Identity politics is therefore not a sufficient frame for thinking about political mobilisation on AIDS in Africa.

\footnotetext{
${ }^{15}$ Interview, Z. Achmat (30 April 2008).
} 
Other theorisations of Northern AIDS activism include Deborah Gould's focus on the role of emotion in her sympathetic accounts of the history of the ACT UP movement in the United States (Gould, 2002; 2009) and Steven Epstein's epistemic framing in his detailed (and excellent) account of the politics of knowledge of the early AIDS epidemic and activist attempts to influence the research and treatment agenda (Epstein, 1996). Gould (2009:3) calls her book an "enquiry into the affective stimuli and blockages to political activism" and mentions emotions such as "rage, anger, indignation, hope, pride and solidarity." These emotions are probably universal drivers of political mobilisation - especially around a deadly and neglected disease - and are certainly echoed in the accounts of many TAC activists (see chapter 3). This is a dimension that seems highly relevant to the mobilisation of activists, especially their personal motivations when they are taking risks, and in particular to the more confrontational forms of activism (direct action, civil disobedience, etc.). Emotion and affect will therefore feature in my accounts, but does not become a primary frame for theorising civil society leadership, in part because significant parts of the mobilisation described were not of the highly confrontational sort (especially in the chapter on Uganda).

Epstein draws significantly on the sociology of science and knowledge, particularly as it pertains to the construction of 'credibility'. Both Youde (2007a) and Didier Fassin (Fassin and Schneider, 2003; Fassin, 2007) later applied similar frames to the South African AIDS denialist controversy. The notions of 'epistemic communities' and 'counter-epistemic communities' (Youde, 2007a:43-48) are potentially very useful in explaining the emergence and political longevity of anti-scientific accounts of AIDS and an account that is sensitive to the black South African experience of colonialism, apartheid and racist abuse - "the festering wounds of the past" (Fassin, 2007:122) — may go some way towards explaining the vehemence of Mbeki and his supporters' AIDS denialism. However, neither of these studies were explicit accounts of AIDS activism and therefore, while useful in reflecting on this particular dimension, do not provide a framework for theorising civil society leadership on AIDS more broadly. In some ways, despite Youde and Fassin's focus on South Africa, Epstein's fusion of science studies and social movement research in order to explore the "role of movements in the construction of credible knowledge" (Epstein, 1996:19-22) is more applicable to the politics of 
knowledge that TAC engaged in. Certainly TAC drew substantially on the experiences of American AIDS activists (and replicated their focus on learning the science of HIV) and on its links with scientists to bolster the scientific credibility of its claims (see chapters 3 and 4). I do reflect to some extent on the politics of knowledge in chapter 4 , but the focus is on the effectiveness of TAC's contestation of the Mbeki administration's epistemic frame. More generally, I consider the science-vs.-denialism clash in South Africa primarily as an explanation for why rather than how activists mobilised, and it is therefore not a primary theoretical frame.

Probably the most important study of global AIDS activism published to date, Raymond Smith and Patricia Siplon's Drugs into Bodies draws on multiple theoretical frames, including McAdam's political process model of social movement mobilisation and Keck and Sikkink's 'transnational advocacy networks' (Smith and Siplon, 2006:73-80). They analyse both domestic AIDS activism in the United States (the first wave of activism) and the global AIDS treatment movement that emerged later (the second wave), showing how the latter drew on the former, but constructed a global coalition around a vision of universal access to AIDS treatment. The success of this broadening of the scope of treatment activism, and its inclusion of a globally distributed and disparate set of actors, points to the greater applicability of Keck and Sikkink's framework, which attributes the success of human rights activism networks precisely to the linking of separate issues under an umbrella of universal claims, than McAdam's model, which attributed the decline of the civil rights movement to a "loss of focus" (Smith and Siplon, 2006:159160). They also employ Keck and Sikkink's work to think about 'issue framing' in activist claims, including the construction of "a compelling story of heroes and villains" (Smith and Siplon, 2006:160). I take my cue from them in making use of both the social movement literature (see section 3.2.1) and 'transnational advocacy networks' (see section 3.2.5) for theorising AIDS activism. I further adopt and make central to my analysis their focus on the construction of transnational networks of activists (and attempt to develop this network perspective further) as well as attempting to employ a conception of 'coalition politics' (Smith and Siplon, 2006:161) in thinking about both domestic and transnational activism. In a sense I merely adapt and apply their framework to the study of transnational AIDS treatment activism from the perspective of Southern movements (and per- 
haps what could be thought of as a third wave of activism - concurrent to the second - characterised by domestic activism in the developing world and SouthSouth transnational networks in addition to North-South collaboration).

I will not review in detail here the literature on the two movements used in the case studies in this thesis (that fits more properly in the relevant chapters). However, a number of recurring themes do occur in the literature that may be useful in theorising AIDS activism more generally. It should be noted that the literature on TASO is very limited, and generally does not consider the organisation primarily as a social movement. There is therefore very limited theoretical insight to be gleaned from this literature. However, a number of authors have reflected on TAC as a social movement, primarily within the context of post-apartheid politics in South Africa. The first recurring theme is an emphasis on the continuity between TAC and the earlier anti-apartheid struggle (Friedman and Mottiar, 2006; Mbali, 2006; Robins, 2004) and the second relates to TAC's 'framing' of its claims in terms of a 'human rights discourse' (Johnson, 2006; Mbali, 2006). These points, while undoubtedly accurate, do not really provide much of a theoretical framework, and are perhaps too rooted in the specific historicity of South African politics to be of much wider applicability. This is true also of Mbali's more recent work in which she has, however, started to apply ideas like resource mobilisation and networks (Mbali, 2010).

Perhaps the boldest attempts to engage theoretically with the phenomenon of treatment activism in South Africa have come from Steven Robins (2004; 2006; 2008), who employs what might be termed a discursive-identity perspective that emphasises both the deployment of "global discourses of science, medicine, liberal rights and social justice together with grassroots mobilisation" and "new forms of biological and therapeutic citizenship, gendered identities and political subjectivities" (Robins, 2008:101). It is worth noting that political subjectivity has been considered with respect to North American AIDS activism, for example by Brown (1997), who argues that AIDS activism in Vancouver constituted a kind of 'radical citizenship,' implying a new way of thinking the relationship between individuals and the state. These perspectives have some value for making sense of AIDS activism, but, as with accounts focusing on symbolic politics, have often exhibited limited interest in the empirical reality of social movements and run the risk of 
glamorising activist movements and ignoring concrete contexts.

\subsection{Research design and methodology}

The fact that 'AIDS leadership' is under-theorised and highly context-sensitive means that any theoretical framework imposed on the questions raised above is unlikely to be fully satisfactory and we cannot hope for it to do much more than frame a historical analysis. I therefore opt for a rich and detailed empirical account or 'thick description' (Geertz, 1973) that nevertheless supplements historical and qualitative methodologies with econometric analyses. Some chapters utilise primarily the former and others primarily the latter. The primary methods used in each chapter are briefly described in the chapter outline provided below.

In line with the recommendation of George and Bennett (2004:6), I attempt to employ the case study method and quantitative methods in such a way that they complement one another - i.e. I hope to compensate for the limitations of each by using the other. Therefore, while case studies are better suited to "closely examin[ing] the hypothesised role of causal mechanisms in individual cases" and for "addressing causal complexity" (George and Bennett, 2004:19), quantitative methods may well be better suited to exploring potential relationships between particular well-defined factors. For example, in chapters 3 and 5, the complex politics of civil society mobilisation on AIDS and its relationship with governmental AIDS responses are carefully examined using a case study approach. On the other hand, evaluating TAC's potential impact on specific parameters relevant to HIV prevention in Cape Town (for which survey data exists) is more suited to a quantitative approach and is consequently studied using statistical models in chapter 4 .

\subsection{Chapter outline}

\section{Ghapter 2: Givil society and national leadership on AIDS: Do NGOs make a difference?}

This chapter focuses on the empirical question of whether civil society mobilisation impacts on the quality of national HIV responses. It reviews the literature 
on national AIDS leadership, particularly cross-country quantitative analyses like those of Bor (2007) and Nattrass (2006; 2008b) that seek to explain differential outcomes (e.g. varying levels of HAART coverage) when controlling for nonleadership drivers (such as national income and disease burden) in terms of political factors.

However, like Sullivan Robinson (2011), the models reported here are restricted to Sub-Saharan Africa, owing to limitations in the data on civil society available. This results in a very small N (42-46 countries). In order to cope with this limitation, the models are highly parsimonious. Two sources of data on NGOs active on HIV/AIDS are used: (1) A directory of African NGOs compiled by the United Nations in 2003 and also used by Sullivan Robinson (2011) and (2) a global on-line survey of HIV/AIDS civil society organisations conducted under the auspices of UNAIDS as part of the aids2031 project. ${ }^{16}$ A series of cross-country regression analyses is used to analyse the potential relationship between an active civil society (especially in the AIDS sector) and HAART coverage and MTGTP coverage.

\section{Ghapter 3: South Africa: Givil society leadership as contest- ing government policy}

This chapter provides a detailed historical case study of the Treatment Action Campaign (TAG) in South Africa. A theoretical framework for thinking about civil society mobilisation on AIDS is also developed, after a review of the social movement and related literature, that draws on ideas from a range of disciplines and traditions, and which conceptualises civil society mobilisation as the mobilisation of 'networks of influence'.

TAC came to prominence (in fact, became the world's most prominent AIDS activist organisation) in the context of state-supported AIDS denialism and government resistance to evidence-based responses such as antiretroviral treatment. The chapter describes TAC's forceful campaign against denialism and for access to treatment, a campaign that is widely (though not necessarily accurately) cred-

\footnotetext{
${ }^{16}$ Prof. Nicoli Nattrass and I participated in the aids2031 project's 'Leadership Working Group' and ASRU conducted contract research for aids2031. I helped design, implement and analyse the data from the aids2031 Civil Society On-Line Survey under under contract from the Leadership Working Group.
} 
ited with the dramatic policy turnaround that occurred in 2003/4. The case study draws on extensive interviews with former and present TAC leaders and members to provide a detailed historical narrative of the emergence and impact of TAC, describing how TAC's founders drew on their experiences and networks from the anti-apartheid struggle to build the movement. It also describes how the movement's influence was built using new local and transnational support networks and how it succeeded in leveraging 'networks of influence' (which also included scientists, bureaucrats and politicians) to contribute to the formation of a moral consensus on treatment access and the construction of an inclusive civil society coalition that pursued policy change.

\section{Ghapter 4: Givil society leadership and HIV prevention in South Africa}

This chapter revisits the 'civil society leadership' of TAC, this time employing quantitative analysis to investigate whether TAC's mobilisation in Cape Town (where the organisation originated and is strongest) impacted appreciably on HIV prevention efforts.

Drawing on and extending joint research with Nicoli Nattrass (Grebe and Nattrass, 2012), the chapter uses multivariate logistic regression (in a sample of young adults in Cape Town, collected as the fifth wave of the Cape Area Panel Study) to explore the potential impact of contact with TAC (together with other socioeconomic, cultural, psychological and political determinants) on conspiracy beliefs about the origins of AIDS. Further, it investigates the impact of both AIDS conspiracy beliefs and contact with TAC on condom use. It finds that indeed, never having heard of TAC substantially and significantly increased the odds of believing AIDS conspiracy beliefs for Africans and, controlling for demographic, attitudinal and relationship variables, AIDS conspiracy beliefs drove unsafe sex among African women and AIDS denialism and never having heard of TAC were significant determinants of unsafe sex among African men. The chapter provides some evidence that TAC's opposition to anti-science and AIDS denialist rhetoric coming from the Mbeki administration had a real and measurable impact on the beliefs and behaviour of young adults in the city where the movement is strongest. 


\section{Chapter 5: Uganda: Givil society leadership 'in partnership with the state'}

The second detailed historical case study focuses on The AIDS Support Organisation (TASO) in Uganda. TASO emerged much earlier than TAC, at the height of the Ugandan AIDS epidemic. In contrast with TAC, the Ugandan state was relatively supportive, but TASO also adopted a largely non-political stance focusing on delivering services to people living with and dying from AIDS, rather than on contesting policy.

The chapter also draws on extensive interviews with former and current TASO leaders, employees and 'clients' as well as others in the Ugandan AIDS sector to draw a rich narrative of the emergence and activities of the organisation. It tells the story of a surprisingly professional and effective organisation in a very poor country with a high burden of disease, but also illustrates how historically-specific structural and institutional factors constrain 'political opportunities', with the organisation showing some timidity in challenging government policy even where the tendencies have been undeniably problematic. TASO currently provides the bulk of antiretroviral therapy in Uganda, relying on foreign donors like PEPFAR to fund their services and on the Ugandan government for access to state health care facilities, further limiting its political freedom of action. TASO nevertheless shares some characteristics with TAC in that it draws extensively on local and international support networks.

\section{Chapter 6: Conclusion: The global AIDS movement in an era of resource constraints and shifting priorities}

This chapter briefly reviews some of the main insights from the thesis and discusses future challenges for the global AIDS movement.

\section{Appendix A: The leadership literature: structure, agency, 'systemic leadership' and institutions}

This appendix briefly reviews the 'agential' and 'systemic' perspectives in the leadership literature. The prevalent perspective in the leadership literature is the 
former, in which the emphasis is on 'character' and the individual traits of effective and ethical leaders. However, it then draws on both the emerging relational model of leadership and the literature on institutions in order to propose a 'relational model of transformative leadership.' This model of leadership is better suited to thinking about 'AIDS leadership' than traditional perspectives, since it emphasises both structure (the relationships, networks and institutional contexts within which leaders are embedded) and agency (the choices of individual leaders). This conception of individual leadership informs the discussion in the empirical case studies of chapters 3,4 and 5 .

\section{Appendix B: An epidemiological model for HIV incidence, prevalence and mortality trends in Uganda (1974-2004)}

This appendix describes an epidemiological model for the HIV and AIDS epidemics in Uganda from 1974 to 2004. It employs UNAIDS's Epidemiological Projection Package (UNAIDS, 201 1a), a tool for country-level estimation and short-term projection of HIV / AIDS epidemics by fitting a standard epidemiological model on observed HIV surveillance data. The primary source of surveillance data is HIV seroprevalence among antenatal clinic attendees in Uganda, both at urban and rural sites. The urban and rural epidemics are modelled separately. The model is calibrated using a population-based seroprevalence survey conducted in 2004. It does not incorporate the impact of antiretroviral therapy (which started becoming widely available in the mid-2000s), but does allow for credible estimation of HIV epidemiological trends for the reported period. Adult HIV prevalence is estimated to have peaked in 1988 (at 20.03\%) and adult HIV incidence in 1984 (at $4.03 \%$ ), while Uganda's prevalence declines of the early 1990s appear to have resulted largely from deaths outstripping new infections from 1991 (continuing to do so until 2004). These estimates help contextualise the discussion of political and civil society leadership in Uganda in chapter 5 by calling into question the praise heaped on the Museveni government on the basis of the supposed success of prevention campaigns conducted after 1986 when the National Resistance Movement came to power. 


\section{Ghapter 2}

\section{Givil society and national leadership on AIDS: Do NGOs make a difference?}

\subsection{Introduction}

This chapter investigates national leadership on AIDS by modelling programmatic outcomes and how this may be affected by civil society mobilisation. It draws on the existing (limited) literature on cross-country comparisons of 'AIDS leadership' using quantitative methods and attempts to improve upon existing approaches that do not include measures of civil society activity. Developing such measures of civil society mobilisation presents a significant challenge owing to very limited availability of data.

An argument that runs through most of this thesis is that the political pressure civil society places on national political leaders (and governments on the whole) results in a greater commitment to, and better performance in, the execution of measures to mitigate the impact of HIV/AIDS. Specifically, I investigate by means of cross-national regression analysis how the presence of larger numbers of non-governmental organisations may impact on HAART coverage (i.e. the proportion of people in need of antiretroviral treatment who receive it) and better PMTCT coverage (the proportion of mothers requiring antiretrovirals to prevent 
transmission of HIV to their babies who receive it) in Sub-Saharan African countries. HAART coverage is a good indicator of the quality of the treatment response and data is available for most African countries. PMTCT coverage is more limited as an indicator of prevention efforts, but the quality of the available data is relatively good, as opposed to indicators such as condom distribution and behaviour change campaigns that are much less easily available and hard to compare between countries (or male medical circumcision, which is too new and not widely implemented across the continent).

A number of attempts have been made to measure and model national 'AIDS leadership' through cross-country quantitative analyses, using a variety of measures and approaches. The most important attempts are those of Nattrass (2006); Bor (2007); Lieberman (2007); Desmond et al. (2008); Nattrass (2008b;c); Schwardmann (2008); Haacker (2009).

Nattrass (2006) makes use of cross-country Ordinary Least Squares regression analysis to explore which factors 'explain' HAART coverage. Her analysis highlights that especially regional and economic factors are important, and that, controlling for per capita income, HIV prevalence and other factors, Sub-Saharan African countries fare better than predicted (Nattrass, 2006:335). She also found that being an established democracy improved HAART coverage, controlling for other relevant factors, but it was not clear whether this resulted from democracies making better use of available resources or from international donors' preference for democratic countries. She included in her final model Log of GNP per capita (PPP), share of per capita income spent on health, being in the Latin American and Caribbean region, being in the Sub-Saharan African region, differential between urban and rural HIV prevalence, being an established democracy and log of adult HIV prevalence, of which all except HIV prevalence turned out to be significant and positive (Nattrass, 2006:331).

Nattrass (2008b) deepens her investigation of government leadership on AIDS by specifically investigating whether country reputations for 'good' and 'bad' leadership are warranted. Employing similar regression models, but adding measures of international assistance on AIDS, she finds that both being a PEPFAR focus country and having received Global Fund grants during the first round were statistically significantly associated with better HAART coverage (in 2006), as was 
log of adult HIV prevalence and the proportion of HIV-positive persons living in urban areas. In models not controlling for region, being an established democracy was associated with better HAART coverage and 'language fractionalisation' with poorer HAART coverage, but when region is controlled for, these effects fall away and being in Latin America and the Caribbean or in West Africa significantly benefits HAART coverage. She does not, however, attempt to model 'AIDS leadership' directly, instead reporting the regression residual of the models (i.e. the difference between the HAART coverage predicted by the model and real HAART coverage) and suggesting that this residual may represent a leadership deficit or benefit, given that predicted HAART coverage is what could be expected given " objective' constraints/opportunities facing governments" (Nattrass, 2008b:404). While this is an innovative approach, and does seem to confirm that some countries with reputations for good leadership performs better than expected (e.g. Uganda and Thailand) and with poor reputations poorer than expected (South Africa), this is also a highly unorthodox approach. It is in fact not possible to determine what proportion of the regression residual for each case represents 'random error' $(\epsilon)$ or unobserved factors, and it is further quite possible that unobserved factors other than 'leadership' may be driving the bulk of the residual.

Bor (2007), in contrast with Nattrass, tries to model 'AIDS leadership' directly by means of a 'political support' score constructed as part of the 2003 AIDS Program Effort Index in 54 developing countries. He defines 'political commitment' as follows: "'Political commitment' refers to the extent to which top-level government leaders (viz. heads of state and their appointees) support AIDS as a priority on the national agenda" (Bor, 2007:1586). Bor elects to model 'political commitment' in part because, unlike epidemiological outcomes, it is not influenced by contextual factors outside the control of governments, like institutional capacity, (Bor, 2007:1586) and can therefore be seen as a 'purer' measure of political leadership comparable over a larger number of cases. His findings include that political commitment does not seem to be greater in democracies than in autocracies or motivated by competitive elections (Bor, 2007:1598) but that a free and independent media does seem to predict for political commitment on AIDS (Bor, 2007:1597), that leaders are less responsive to AIDS where income inequality is high and that AIDS is likely to be a political priority in countries with high HIV prevalence (Bor, 
2007:1585).

I am, however, unconvinced of the value of modelling 'political commitment' on AIDS rather than programmatic outcomes. Apart from problems with using the API political support score acknowledged by Bor (2007:1588), such as that it is based on the subjective evaluations of a small number of key informants (and is therefore vulnerable to bias), there are other reasons to reject this as a measure of 'AIDS leadership':

1. It has not been updated since 2003 (which is not long after many developing countries started to ramp up, with the support of international donors, antiretroviral therapy provision - and which may very well have reinvigorated AIDS efforts across the board, including prevention efforts. AIDS treatment may have given political leaders the opportunity to sell their achievements to electorates and the public, which it is harder to do when no or little treatment is being provided, resulting in greater 'political commitment' as reflected in the willingness of leaders to speak about HIV/AIDS. I therefore expect results for 2003 to differ significantly from results obtained from more recent data.

2. Serious questions are raised about the reliability of the data by the fact that South Africa scored close to the regional average for East and Southern Africa on this measure (79 compared to 80) and substantially higher than the regional average for Latin Americana and the Caribbean (69) and Asia (66). South Africa is a single case, but given its prominence as an example of abysmal leadership on AIDS (and borne out in outcomes like HAART coverage in Nattrass' work), this seems to undermine the credibility of the index substantially.

3. Even when countries show strong 'political commitment' on AIDS, but are unable to translate that commitment into positive outcomes (such as HAART coverage, condom distribution or reductions in incidence or prevalence), this still suggests poor 'AIDS leadership' (as long as one controls for the contextual factors that impact on those outcomes, such as resource availability, capacity and size of the epidemic). 
Lieberman (2007) is mainly interested in the effect of ethnic division on countries' AIDS policy responses, hypothesising that ethnic fractionalisation renders elites less willing to mobilise around risk from a stigmatised condition (fearing that their ethnic group would suffer reputational harm). He models a range of dependent variables in cross-national regression analyses, including government and donor expenditure on AIDS, mentions of AIDS in budget speeches, HAART coverage and an AIDS Policy Index. He finds strong evidence for his central hypothesis, including that ethnic fractionalisation is associated in multivariate models with lower HAART coverage and poorer AIDS Policy Index scores (Lieberman, 2007:1423).

The only earlier study I am aware of that has attempted to model the potential effect of civil society mobilisation on HIV/AIDS outcomes is one by Sullivan Robinson (2011). She hypothesises that the prevention and treatment activities of local Non-Governmental Organisations should mitigate the effects of the HIV epidemic and uses cross-national regression analysis (for African countries) both to identify factors that predict the number of NGOs active in HIV/AIDS work and to investigate the relationship between the number of local HIV NGOs and HIV/AIDS outcomes, namely change in HIV prevalence between 2001 and 2009 and HAART coverage in 2009. She finds that number of HIV NGOs per 10 million population is not statistically significantly related to change in HIV prevalence, but that whether the country had an International Planned Parenthood Federation affiliate founded by 1986, HAART coverage and whether the epidemic peaked prior to 1999 are associated with reductions in HIV prevalence and whether the country is a PEPFAR focus country associated with increased prevalence ${ }^{1}$ (Sullivan Robinson, 2011:27). She also found that the number of HIV NGOs per 10 million population and being a PEPFAR focus country were significantly associated with better HAART coverage, while cultural fractionalisation and being a former British colony were associated with poorer HAART coverage (Sullivan Robinson, 2011:27).

\footnotetext{
${ }^{1}$ This is not surprising, given that PEPFAR has funded large-scale antiretroviral treatment programmes and effective treatment should prevent AIDS deaths, thus resulting in increased HIV prevalence.
} 


\subsection{Hypotheses}

The primary hypothesis I test in this chapter is that NGOs active on AIDS result in better HIV prevention and AIDS treatment responses, because they (1) put pressure on national governments to improve the response to AIDS and (2) provide donor agencies with reliable partners for implementing treatment and prevention programmes. I would therefore expect a positive association between the number of NGOs active on AIDS in a country and (1) HAART coverage (as an objective measure of the treatment response) and (2) PMTGT coverage (as an objective measure of the prevention response). In order to test this hypothesis one must control at least for a number of factors that could be expected to constrain the ability of governments to implement programmes, including disease burden (in countries with large epidemics it would be more difficult to achieve high HAART and PMTCT coverage), level of development (both in terms of institutional capacity and resource availability) and external resources for AIDS (countries receiving large quantities of external aid for AIDS programmes could be expected to do better).

However, an equally credible hypothesis - and one that runs completely counter to the first - is that civil society responds to the need for effective responses to AIDS, including a large epidemic and weak government responses. If this hypothesis holds one would expect a negative association between treatment and prevention performance and the number of NGOs active on AIDS. This leaves us with a murky picture that the data may or may not be able to clarify. If the data suggests such a negative association, a different set of models may be required predicting the number of NGOs (rather than predicting HAART and PMTCT coverage) in order to investigate this potential relationship.

A third possibility is that only some NGOs and only in some contexts make a difference to the quality of AIDS responses by governments. For example, it may be that social movements or activist organisations are more likely to have an impact by placing pressure on governments than NGOs that simply provide services or who are aid/charity-oriented rather than activism/advocacy-oriented. It is further possible (in fact likely) that institutional arrangements significantly determine the degree to which NGOs can be effective, for example state repression may severely 
hamper the ability of civil society to impact on governments' responses.

\subsection{Methods and measures}

\subsubsection{Dependent variables and countries included}

The models presented in this chapter use Ordinary Least Squares regression analysis of country-level data for Sub-Saharan African countries to predict HAART coverage and PMTCT coverage. In both cases data for the dependent variables are sourced from the WHO. Coverage rates are logged since an increase of one percentage point is much more significant at lower coverage rates than at high coverage rates.

As indicated earlier, HAART coverage is considered an indicator of the quality of the treatment effort and PMTCT coverage of the prevention effort and the models should be read jointly. However, PMTCT coverage may in some countries be a better indicator of the quality of the overall AIDS response than HAART coverage, since the resource and infrastructural requirements are much lower (and consequently these services were rolled out earlier in developing countries), meaning that (1) poor performance is more likely to reflect a failure of 'AIDS leadership' and (2) it should be less sensitive to the availability of foreign assistance (which in some African countries like Uganda fund the bulk of AIDS efforts).

In line with my critique of the AIDS Program Effort Index used by Bor (2007), I prefer programmatic outcomes (HAART and PMTCT coverage) as an indicator of country-level leadership rather than a political or policy indicator.

AIDS spending, which is used by Lieberman (2007), may very well be a useful measure of AIDS leadership, but like 'political support' countries may be unable to translate fiscal commitment into positive outcomes. Since I am primarily interested in whether civil society mobilisation results in better quality government responses, HAART and PMTCT coverage (when one controls for for appropriate contextual factors) is likely to be a better indicator.

One major weakness of the models reported in this chapter is the small $N$ (42 countries) resulting from the restriction to Sub-Saharan African countries. This is largely the result of data availability - one of the two measures of civil society 
organisations included in the models are only available for African countries (see next subsection). However, I also agree with Sullivan Robinson (2011) that restricting the analysis to Sub-Saharan Africa removes a number of interpretational problems given the highly characteristic nature of the African epidemic, although, for the same reason, I diverge from her in not including countries to the north of the Sahara. Partly in order to cope with this limitation, the initial models are highly parsimonious and are only modestly expanded later.

\subsubsection{Measures of civil society mobilisation on AIDS}

The key factor investigated for its potential effect on HAART coverage and PMTGT coverage is the existence of civil society organisations actively mobilising around the AIDS response.

Two sources of data on NGOs active on HIV/AIDS are used: (1) A directory of African NGOs compiled by the United Nations in 2003 (United Nations, 2003) and also used by Sullivan Robinson (2011) and (2) a global on-line survey of HIV / AIDS civil society organisations conducted under the auspices of UNAIDS as part of the aids2031 project. $^{2}$

The UN directory of African NGOs was compiled by sending questionnaires to African NGOs through UN networks in African countries. Following Sullivan Robinson (2011:14), I define civil society organisations active on HIV/AIDS as those that reported HIV or AIDS as an 'action area'. Organisations whose primary purpose is not HIV/AIDS are therefore included in the analysis. It is important to mention that the database is unlikely to be exhaustive, and the use of UN networks may introduce bias (for example excluding organisations that have not received funding from large international donors or worked on UN-sponsored projects), although the responses would hopefully be similarly biased across countries. Since more populous countries could be expected to have larger numbers of NGOs than less populous ones, the number of NGOs in the directory active on HIV/AIDS was added up for each country and then divided by the population of each country

\footnotetext{
${ }^{2}$ Prof. Nicoli Nattrass and I participated in the aids2031 project's 'Leadership Working Group' and ASRU conducted contract research for aids2031. I helped design, implement and analyse the data from the aids2031 Civil Society On-Line Survey under under contract from the Leadership Working Group.
} 


\section{Figure 2.1: HAART coverage vs. number of NGOs (UN directory)}

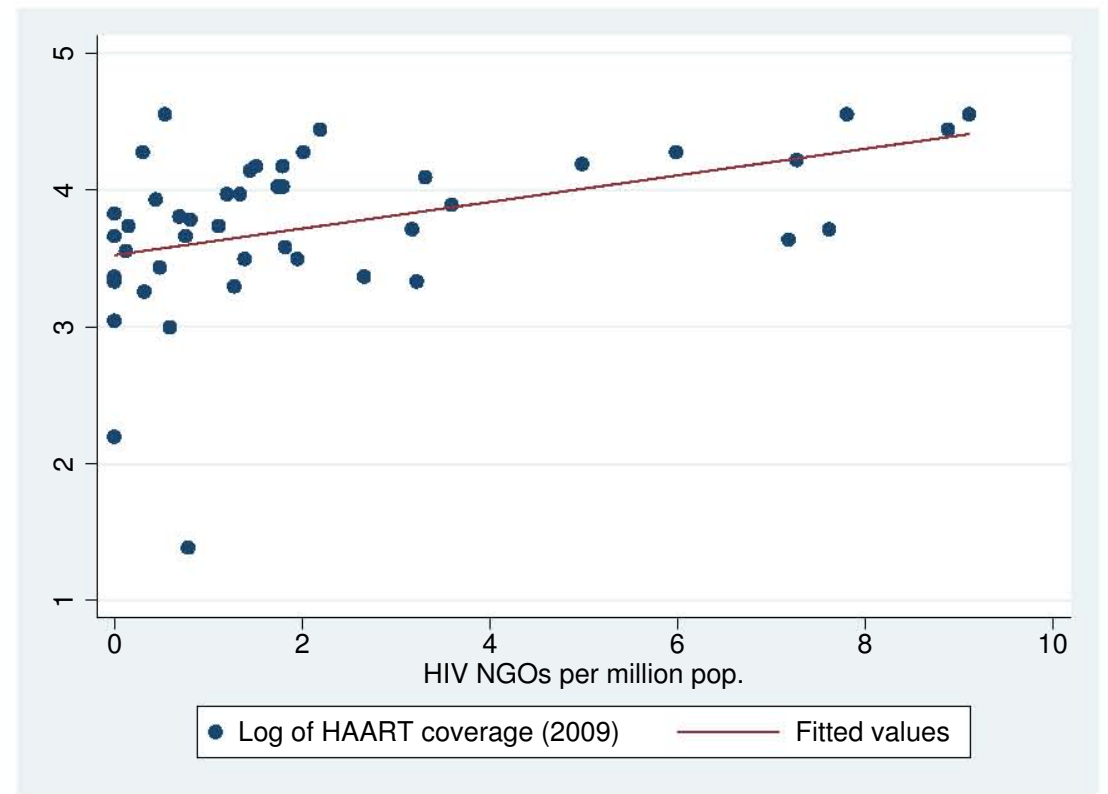

Source: Own calculations.

(according to World Bank data in 2006) in tens of millions. This variable is reported as HIV NGOs per million pop. in the models and included in models 1, 3, 7 and 9. Bivariate analysis of HAART coverage and PMTGT coverage vs. the number of HIV NGOs in the UN directory strongly suggest that there exists a relationship (see Figures 2.1 and 2.2 for the clustering of Sub-Saharan African countries around a fitted bivariate regression line).

The aids2031 Online Civil Society Survey (hereafter CSSS) was conducted by contacting NGOs on the UNAIDS and United Nations Non-Governmental Liaison Service (UN-NGLS) databases of HIV/AIDS NGOs via email and requesting that an online questionnaire be filled out by a knowledgeable representative of the organisation. Both transnational and local NGOs were included in the survey (although international NGOs would be counted under the country in which their headquarters are located for the purposes of this analysis). Like with the UN directory it is important to emphasise the limitations of this survey, especially the fact that it is not based on a representative sample (and may suffer from bias). While the researchers attempted to recruit as many as possible respondents (each represent- 


\section{Figure 2.2: PMTGT coverage vs. number of NGOs (UN directory)}

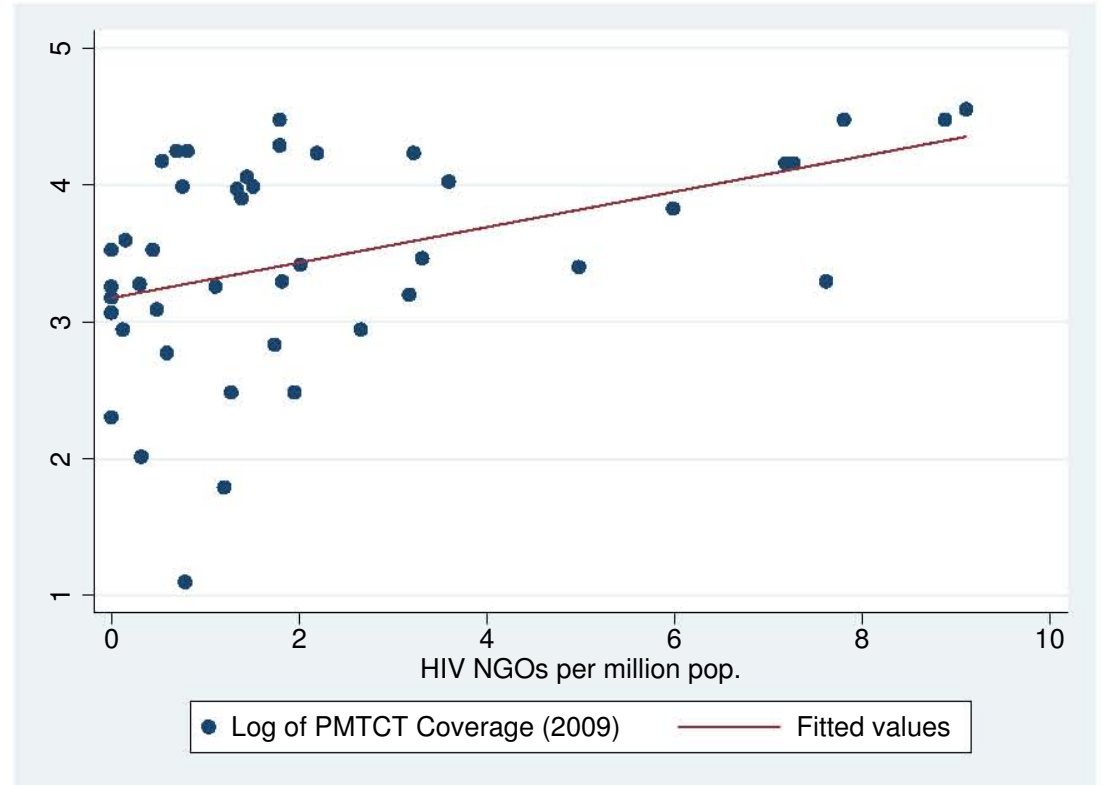

Source: Own calculations.

ing a $\mathrm{CSO}$ ) from as many different countries as possible, the survey was collected online (which may bias the results against CSOs without internet access, such as those from rural Africa) and was only available in English (which may bias results against, especially Latin American, Francophone African and Eastern European $\mathrm{CSOs})$.

The primary variable constructed using CSS data is simply the number of responses from NGOs headquartered in a country, divided by the population in 2006 (from the World Bank) in tens of millions and reported as CSS responses per million pop. in the models and included in models 2, 4, 8 and 10. In addition, because of a concern that this variable may not be the best way to capture the level of civil society activity on HIV/AIDS in a country, two further variables were constructed based on the CSS data and investigated (in models 5 and 6). These are:

- Number of 'true CSO' responses from a country. In this case organisations that are not considered likely to mobilise a civil society constituency (such 
as quasi-government organisations) are excluded. The variable is simply the number of CSOs who responded to the survey from the designated categories, on the assumption that this number would be a rough indicator of how much activity exists in civil society on AIDS. It is reported as CSS 'True GSO' responses per million pop.

- Number of reported CSO employees in responding organisations (the total for each country) divided by population. This was attempted as a better indicator of the level of resources and activity from civil society in each country. It is reported as CSS NGO employees per million pop.

\subsubsection{Other potential predictors and controls}

As argued above, HAART and PMTCT coverage are only a meaningful indicators of national AIDS leadership if we control for the contextual factors that could be expected to influence it, including the size of the epidemic (since it would be more difficult to reach a high proportion of those in need of treatment where HIV prevalence is high) and level of development and resource availability. However, I attempted to keep models as parsimonious as possible, first running models with very few controls and then somewhat expanded models that include controls the literature suggests should influence 'AIDS leadership' and performance. The following controls were included in all models:

- Log of adult HIV prevalence in 2008. As mentioned previously, this is an important control since it is much more difficult to achieve high HAART and PMTCT coverage in large epidemics (reflected in higher HIV prevalence rates). The prevalence rate is logged since an increase of one percentage point is much more significant at lower prevalence than at high prevalence. Source: World Health Organisation.

- Log of GNI per capita at purchasing power parity (2008) as an indicator of level of development and resources available. This is an important control since countries with higher national incomes would find it easier to provide HAART and PMTCT. Per capita income is logged since an increase 
of US\$1 PPP average income at lower incomes is more significant than at higher incomes. Source: World Bank.

- PEPFAR focus country. This is a dummy variable capturing whether the country is a focus country of the US President's Emergency Plan for AIDS Relief and is included as an indicator of the level of external resources for HIV and AIDS interventions. PEPFAR is the largest donor for HIV/AIDS in Sub-Saharan African countries, and while there is a correlation between large epidemics and being a PEPFAR focus country (the inclusion of an HIV prevalence control isolates this effect to some degree), other factors also influenced selection. It is reasonable to assume that PEPFAR focus countries would have more resources available to combat HIV/AIDS than non-PEPFAR countries. Source: PEPFAR (2009).

These further controls were included in the expanded models (7-10), based on the literature that suggests political stability and democracy are associated with better outcomes and ethnic or linguistic divisions with poorer outcomes:

- Free or partly free (FH 2008). This is a dummy variable indicating whether the country was classified as at least 'partly free' by Freedom House in 2008 and is included as an indicator of civil rights and democracy (in the broader non-institutional sense), since it may be expected that (1) democracies would place greater incentives on political leaders to respond effectively to AIDS - although Bor (2007) found this not to be the case for his API measure of political commitment, Nattrass (2006) did find that democracies achieve better HAART coverage - and (2) greater levels of political freedom would provide civil society organisations with greater freedom to pressurise governments.

- Stable state (Norris 2006). This is a dummy variable derived from data from Norris's cross-national dataset, indicating political stability and the absence of war (Norris, 2009). It is included since countries facing conflict and instability may be expected to fare less well in implementing HIV/AIDS prevention and treatment interventions. 
- Press Freedom $>50$ (FH 2006). This is a dummy variable indicating that the country scored 50 or higher Freedom House's 2006 press freedom index. It may be expected that in countries with a freer press leaders would face greater pressure to perform in HIV/AIDS interventions, and in fact Bor (2007) found an association between press freedom and political commitment to AIDS.

- Ethnic fractionalisation (Alesina 2002). This is an ethnic fractionalisation index (0-1) derived from Alesina (2002) and sourced from Norris (2009) and is included in order to account for the potential effect of ethnic divisions on the willingness of political leaders to vigorously pursue HIV/AIDS policies as postulated by Lieberman (2007).

One further control that I considered including, because Bor (2007) found income inequality to be associated with weakened commitment to AIDS, is the Gini coefficient. However, including it in the models brings the $N$ down to 29 because data is not available for all Sub-Saharan African countries. In these models all variables lose significance and they are therefore not reported.

An appropriate time-ordering of variables is difficult in these models. The civil society on-line survey was only conducted in 2010, and the latest available HAART coverage data dates from 2009. I will therefore have to assume (not unproblematically) that the responses provided in 2010 reflect accurately the situation long enough in the past that civil society organisations could have influenced government policies and implementation that ultimately would have partly determined HAART coverage. In the case of the UN directory data (collected in 2003) the time-ordering is appropriate. In the case of economic variables, such as income per capita, the latest available data was used so as to describe current conditions in each country. Political variables (such as 'political rights' and 'freedom of the press' scores) were taken from a few years before the HAART coverage variable in order to ensure proper time-ordering.

I did not include or remove variables from the analysis simply on the basis of significance - unlike, say, Bor (2007), who uses reverse stepwise regression - and make use of simple linear regressions (Ordinary Least Squares) with independent variables and controls that my theoretical model and the literature suggests 
should influence HAART coverage, while trying to keep models as parsimonious as possible. Variables that are not statistically significant are not removed from the model, since they are still necessary in order to parse out potential effects that could be inappropriately picked up in other variables, resulting in false significance or incorrect sizes of coefficients.

\subsection{Results and discussion}

Models 1-4 (Table 2.1) are highly parsimonious models for HAART coverage (1 and 2) and PMTCT coverage (3 and 4).

The UN directory variable (HIV NGOs per million population) is significantly associated with improved HAART coverage and PMTCT coverage in models 1 and $3(b=0.059 ; p=0.016$ and $b=01.00 ; p=0.005)$, but the CSS responses indicator is significantly associated with worse performance on HAART coverage (model 2, $b=-0.023 ; p=0.028$ ) but shows no effect on PMTCT coverage.

HIV prevalence and per capita income are significantly associated with better HAART coverage in model 2, and per capita income with better PMTCT coverage in model 4, but are not significant when used with the UN directory variable in models 1 and 3, suggesting that the latter variable may be picking up income and prevalence effects to some extent.

Being a PEPFAR focus country is associated (highly significantly) with improved PMTGT coverage $(b=0.803 ; p=0.001$ in model 3 and $b=0.649 ; p=$ 0.005 in model 4), but surprisingly, not HAART coverage.

Models 1 and 2 explain about $35 \%$ and $31 \%$ of the variance in $\log$ of HAART coverage, while models 3 and 4 explain about $46 \%$ and $38 \%$ of the variance in log of PMTCT coverage.

Models 5 and 6 (Table 2.2) repeat models 1 and 2, but use alternative variables constructed from the Civil Society Survey.

The C.SS 'True CSO' variable, like the raw C.SS responses variable is significantly associated with poorer HAART coverage (model 5), while the CSS NGO employees variable is not significant (model 6). The predictive power of the models are not substantially affected (adjusted R-squared of 0.31 and 0.30 vs. 0.31 in model 2). 
Models 7-10 (Table 2.3) expand models 1-4 by introducing further control variables.

None of the additional control variables are significant in any of the models, except for political freedom, which is - surprisingly - marginally significantly associated with worse HAART coverage in model $7(b=-0.259 ; p=0.097)$. Being a PEPFAR focus country also becomes a significant predictor of improved HAART coverage in model 7 when the additional controls are added $(b=0.323 ; p=$ $0.083)$.

However, the significance and sign of the predictor variables I am mainly interested in are not altered. HIV NGOs per million population (from UN directory data) remain significantly associated with improved HAART coverage ( $b=0.065 ; p=0.029$ in model 7 and $b=0.091 ; p=0.012$ in model 9), while number of CSS responses per million population remains a significant predictor of worse HAART coverage $(b=-0.017 ; p=0.077)$ in model 8 and insignificant in model 10.

The explanatory power of the models are not greatly improved by the addition of the further control variables.

\subsection{Conclusions}

While the results in models 1 and 7 seem to confirm Sullivan Robinson's results and those in models 2 and 9 to provide additional evidence for the positive impact of HIV/AIDS NGOs on policy performance, the fact that the contrary result is found with a different indicator in models 2 and 8 casts doubt on the veracity of the result. Models 1, 27 and 9 seem to support the first hypothesis - that NGOs active on AIDS result in better HIV treatment and prevention responses. However, models 2 and 8 may support the second and incompatible hypothesis that civil society responds to poorer government responses. The models do provide strong evidence of the impact of donor funding on both HAART and PMTCT coverage, but particularly the latter, as indicated by the large size and significance of the coefficients for PEPFAR Focus country.

These models and the available data therefore do not allow us to come to strong conclusions with respect to the effect that the number of civil society organisations 
active on HIV/AIDS in a country may have on the quality of that country's prevention and treatment response. However, the limitations of the data and contradictory results suggest that further work is needed. In addition, it seems plausible that both effective and ineffective civil society mobilisation are included in the relatively undifferentiated measures dictated by the available data, and that some civil society organisations may well be effective even if we cannot discern the factors determining effectiveness using this analysis. The case studies presented in the following chapters suggest that this is indeed the case, and may help to tease out some of the relevant factors. It is to be hoped that future quantitative work may provide the evidence across countries that would be required in order to confidently generalise conclusions from case study research. 


\subsection{Tables}

Table 2.1: Parsimonious models for HAART and PMTCT coverage in Sub-Saharan African countries

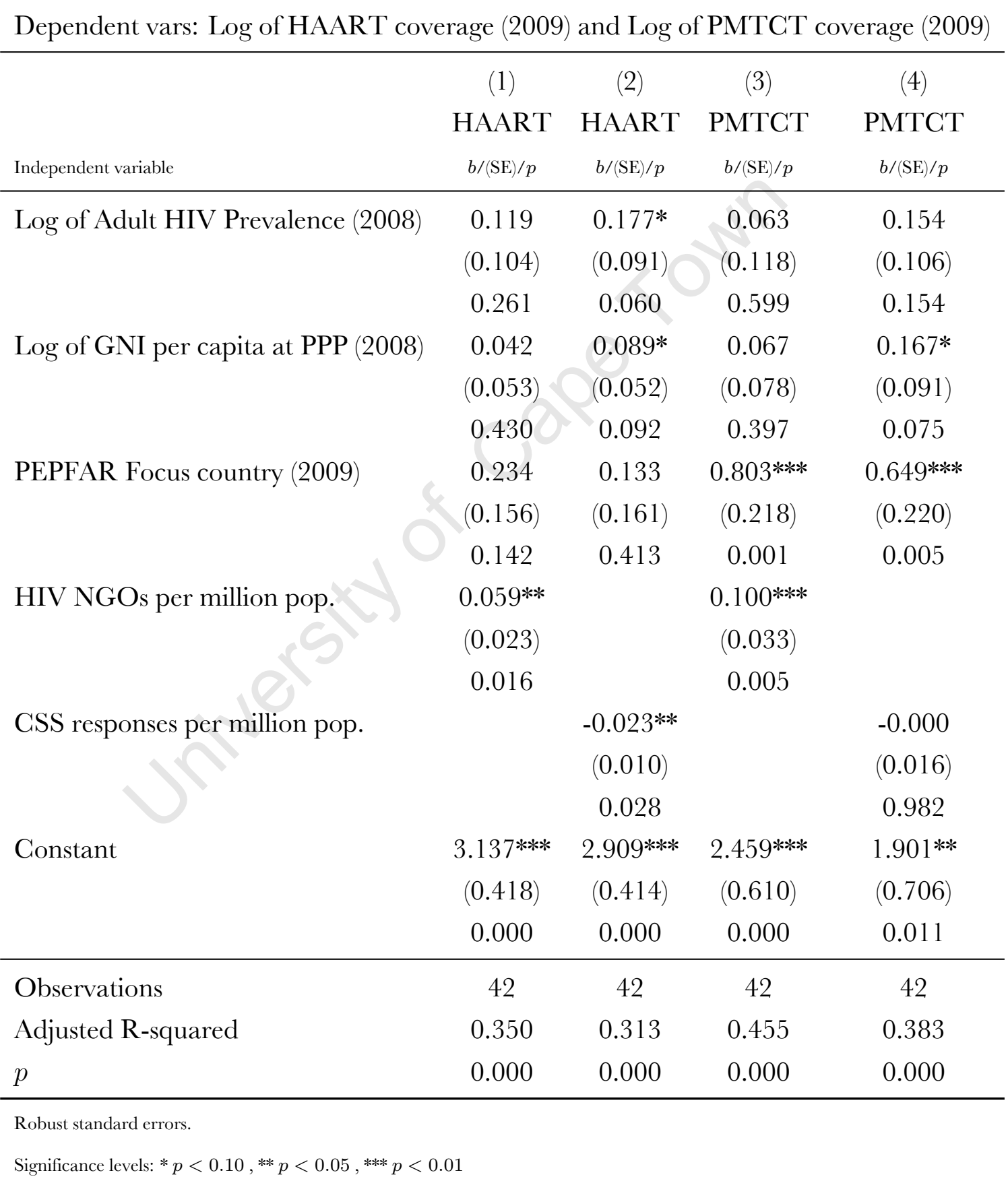


Table 2.2: Modelling HAART coverage in SSA using Givil Society Survey indicators

\begin{tabular}{|c|c|c|c|}
\hline \multicolumn{4}{|c|}{ Dependent var: Log of HAART coverage (2009) } \\
\hline & $(1)$ & $(5)$ & $(6)$ \\
\hline Independent variable & $b /(\mathrm{SE}) / p$ & $b /(\mathrm{SE}) / p$ & $b /(\mathrm{SE}) / p$ \\
\hline \multirow[t]{3}{*}{ Log of Adult HIV Prevalence (2008) } & 0.119 & $0.177^{*}$ & $0.173^{*}$ \\
\hline & $(0.104)$ & $(0.091)$ & $(0.091)$ \\
\hline & 0.261 & 0.060 & 0.066 \\
\hline \multirow[t]{3}{*}{ Log of GNI per capita at PPP (2008) } & 0.042 & $0.089 *$ & $0.101 *$ \\
\hline & $(0.053)$ & $(0.052)$ & $(0.054)$ \\
\hline & 0.430 & 0.092 & 0.067 \\
\hline \multirow[t]{3}{*}{ PEPFAR Focus country (2009) } & 0.234 & 0.133 & 0.145 \\
\hline & $(0.156)$ & $(0.161)$ & $(0.162)$ \\
\hline & 0.142 & 0.413 & 0.376 \\
\hline \multirow[t]{3}{*}{ HIV NGOs per million pop. } & $0.059 * *$ & & \\
\hline & $(0.023)$ & & \\
\hline & 0.016 & & \\
\hline \multirow{3}{*}{ CSS 'True CSO' responses per million pop. } & & $-0.023 * *$ & \\
\hline & & $(0.010)$ & \\
\hline & & 0.029 & \\
\hline \multirow{3}{*}{ CSS NGO employees per million pop. } & & & -0.000 \\
\hline & & & $(0.001)$ \\
\hline & & & 0.914 \\
\hline \multirow[t]{3}{*}{ Constant } & $3.137 * * *$ & $2.909 * * *$ & $2.806^{* * *}$ \\
\hline & $(0.418)$ & $(0.414)$ & $(0.418)$ \\
\hline & 0.000 & 0.000 & 0.000 \\
\hline Observations & 42 & 42 & 42 \\
\hline Adjusted R-squared & 0.350 & 0.313 & 0.300 \\
\hline$p$ & 0.000 & 0.000 & 0.018 \\
\hline
\end{tabular}

Robust standard errors.

Significance levels: $* p<0.10, * * p<0.05, * * * p<0.01$ 


\section{Table 2.3: Expanded models for HAART and PMTCT coverage in Sub-Saharan African countries}

\begin{tabular}{|c|c|c|c|c|}
\hline \multicolumn{5}{|c|}{ Dependent vars: Log of HAART coverage (2009) and Log of PMTCT coverage (2009) } \\
\hline \multirow[b]{3}{*}{ Independent variable } & $(7)$ & (8) & (9) & $(10)$ \\
\hline & HAART & HAART & PMTCT & PMTGT \\
\hline & $b /(\mathrm{SE}) / p$ & $b /(\mathrm{SE}) / p$ & $b /(\mathrm{SE}) / p$ & $b /(\mathrm{SE}) / p$ \\
\hline \multirow[t]{3}{*}{ Log of Adult HIV Prevalence (2008) } & 0.136 & $0.202^{* *}$ & 0.076 & 0.165 \\
\hline & $(0.095)$ & $(0.087)$ & $(0.118)$ & $(0.108)$ \\
\hline & 0.159 & 0.026 & 0.522 & 0.134 \\
\hline \multirow[t]{3}{*}{ Log of GNI per capita at PPP (2008) } & 0.019 & 0.047 & 0.077 & 0.125 \\
\hline & $(0.062)$ & $(0.076)$ & $(0.096)$ & $(0.105)$ \\
\hline & 0.762 & 0.545 & 0.429 & 0.242 \\
\hline \multirow[t]{3}{*}{ PEPFAR Focus country (2009) } & $0.323^{*}$ & 0.172 & $0.796^{* * *}$ & $0.606 * *$ \\
\hline & $(0.181)$ & $(0.177)$ & $(0.248)$ & $(0.232)$ \\
\hline & 0.083 & 0.340 & 0.003 & 0.014 \\
\hline \multirow[t]{3}{*}{ Free or partly free (FH 2008) } & $-0.259 *$ & -0.255 & 0.299 & 0.288 \\
\hline & $(0.152)$ & $(0.154)$ & $(0.265)$ & $(0.288)$ \\
\hline & 0.097 & 0.106 & 0.268 & 0.324 \\
\hline \multirow{3}{*}{ Stable state (Norris 2006) } & -0.292 & -0.070 & -0.135 & 0.120 \\
\hline & $(0.230)$ & $(0.269)$ & $(0.326)$ & $(0.297)$ \\
\hline & 0.213 & 0.797 & 0.681 & 0.688 \\
\hline \multirow[t]{3}{*}{ Press Freedom > $50($ FH 2006) } & -0.204 & -0.240 & 0.063 & -0.012 \\
\hline & $(0.224)$ & $(0.243)$ & $(0.285)$ & $(0.313)$ \\
\hline & 0.369 & 0.330 & 0.827 & 0.970 \\
\hline \multirow[t]{3}{*}{ Ethnic fractionalisation (Alesina 2002) } & -0.037 & -0.125 & -0.511 & -0.646 \\
\hline & $(0.269)$ & $(0.263)$ & $(0.407)$ & $(0.473)$ \\
\hline & 0.891 & 0.638 & 0.218 & 0.181 \\
\hline \multirow[t]{3}{*}{ HIV NGOs per million pop. } & $0.065 * *$ & & $0.091 * *$ & \\
\hline & $(0.029)$ & & $(0.034)$ & \\
\hline & 0.029 & & 0.012 & \\
\hline
\end{tabular}




\begin{tabular}{lcccc} 
& $(7)$ & $(8)$ & $(9)$ & $(10)$ \\
\hline GSS responses per million pop. & & $-0.017^{*}$ & & -0.003 \\
& & $(0.009)$ & & $(0.017)$ \\
Constant & & 0.077 & & 0.878 \\
& $3.621^{* * *}$ & $3.615^{* * *}$ & $2.503^{* *}$ & $2.441^{* *}$ \\
& $(0.643)$ & $(0.735)$ & $(0.962)$ & $(1.018)$ \\
\hline Observations & 0.000 & 0.000 & 0.014 & 0.022 \\
Adjusted R-squared & 42 & 42 & 42 & 42 \\
$p$ & 0.396 & 0.355 & 0.492 & 0.447 \\
\hline
\end{tabular}

Robust standard errors.

Significance levels: $* p<0.10, * * p<0.05, * * * p<0.01$ 


\section{Chapter 3}

\section{South Africa: Givil society leadership as contesting government policy ${ }^{1}$}

\subsection{Introduction and background}

Judging by the prominence it later attained, it is hard to believe that the Treatment Action Campaign (TAC) was founded by a small group of friends in 1998. It is now widely considered the most important AIDS activist organisation in the world and certainly the most successful of South Africa's post-apartheid social movements (Friedman and Mottiar, 2006). This chapter provides an account of TAC's origins and its efforts to build a coalition around the moral imperative of AIDS treatment access. In order to build a coalition capable of challenging the power of multinational pharmaceutical companies and the intransigence of the South African government, TAC's founders drew on their experiences and networks from the anti-apartheid struggle and built an extensive transnational support network. The main contribution of the paper is to trace these old and new networks and show their part in TAC's influence on AIDS policy in South Africa.

During the first five years of its existence TAC came to embody the demand

\footnotetext{
${ }^{1}$ The fieldwork for this chapter was generously funded by the aids2031 initiative. A shorter version (without the theoretical model) appeared in the journal fournal of Southern African Studies (Grebe, 2011).
} 


\section{Figure 3.1: AIDS denialism at the highest level}

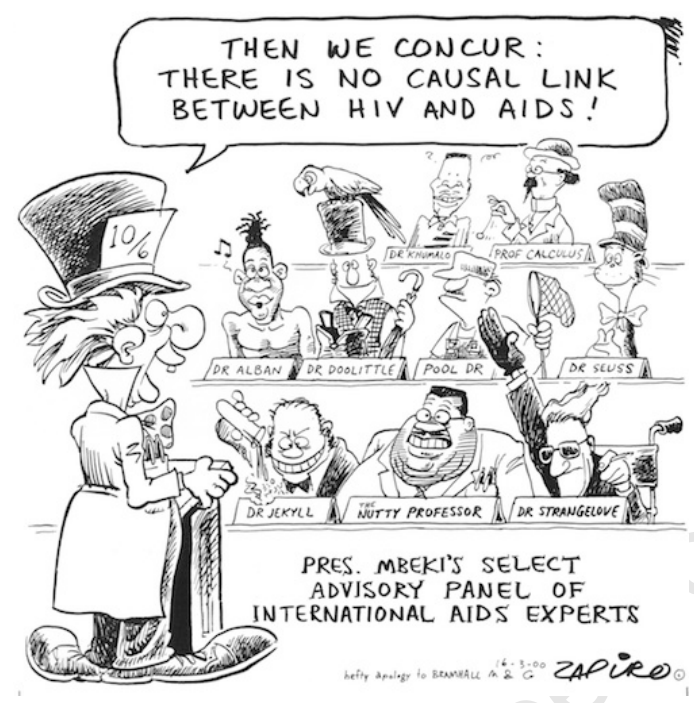

Source: www. zapiro.com. (C2000-2012 Zapiro. Printed with permission from Zapiro.com.

for access to antiretroviral drugs by poor South Africans. That AIDS policy was highly politicised and hotly contested is perhaps not surprising, given thenPresident Thabo Mbeki's public questioning of conventional AIDS science and his government's resistance to using antiretrovirals for either prevention or treatment. The scale of the human tragedy raised the temperature of public debate to a level not reached by 'everyday' political issues and the moral imperative of an issue that is literally one of life and death emboldened social actors who may not otherwise have taken a stand.

Mbeki started publicly questioning the viral aetiology of AIDS, as well as the safety and efficacy of proven antiretroviral treatment shortly after assuming the Presidency in 1999. He had been in contact with a number of notorious AIDS dissidents and later established a Presidential AIDS Advisory Panel, inviting roughly equal numbers of conventional scientists and dissidents, even though the latter are seen as an insignificant fringe movement in AIDS science. The Minister of Health, Manto Tshabalala-Msimang, became his staunch ally in battles with activists and the medical and scientific establishments and promoted nutritional and other alternatives to scientifically tested medicines. Against the advice of South 
Figure 3.2: A cabinet revolt leads to policy change

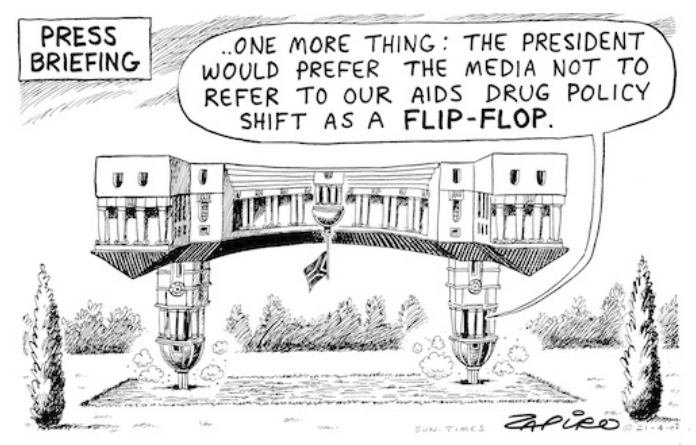

Source: www. zapiro. com. (C2002-2012 Zapiro. Printed with permission from Zapiro.com.

African and international clinicians and public health experts, the Mbeki government refused to implement a PMTCT programme until compelled to do so by the country's highest court in a case brought by TAC. South Africa came to be seen as the prime example of 'bad' political leadership on AIDS during a period that policy was driven by 'AIDS denialism'?

The cabinet finally decided to implement a national antiretroviral treatment programme in 2003 after a protracted struggle by activists. While this policy change cannot be attributed solely to TAC's campaign, it is nevertheless widely credited with helping to shape the public debate and generating substantial pressure on the state, without which the change may very well have come much later. It did so despite being a small and young movement facing strongly vested interests and powerful adversaries, notably the state and multinational pharmaceutical companies.

While mainly offering a historical narrative of the emergence and influence of TAC, this chapter also draws on a range of theoretical approaches in order to explain its apparent success. The main theoretical anchor points are the ideas of 'transnational networks of influence' and of 'coalitions' in support of AIDS treatment access. Both ideas are useful in illuminating the processes by which South African AIDS activists gained influence, managed to frame the question of AIDS

\footnotetext{
${ }^{2}$ For detailed accounts of AIDS denialism and its consequences in South Africa, see Nattrass (2007) and Geffen (2010).
} 
treatment politically and morally, and helped to generate the pressure that forced a change in policy. This includes the mobilisation of influence, both through narrow activist networks and broader networks in which a diverse set of actors participated, among them local and international activists, AIDS scientists and clinicians, individuals within allied civil society organisations, members of the South African political elite as well as individuals within state institutions.

In the next (rather long and dry) section I will review the literature on the sociology of social movements and on 'activist networks' in order to propose a theoretical framework for thinking about TAC's mobilisation and impact. After that I return to the remarkable story of one of the world's most prominent activist movements.

\subsection{Theorising civil society mobilisation on AIDS}

I have alluded to the lack of theorisation and general conceptual fuzziness associated with the notion of 'AIDS leadership'. The relationship between activism and the broad societal response to HIV/AIDS ('civil society leadership' on AIDS) is deeply contextual and its analysis requires rich empirical ('thick') description. But any such empirical project is necessarily shaped - consciously or unconsciously - by a set of prior theoretical assumptions. Since even the the most practically-oriented and historically anchored empirical studies are 'theory-laden,' it is useful to identify the most appropriate theoretical tools with which to approach the topic.

The most prominent of the sociological theories is social movement theory, a predominantly American approach (or, more accurately, set of related approaches). The best-known variants are the 'political process' model of which McAdam is the leading exponent and the European tradition articulated under the rubric of 'new social movements' by scholars like Touraine (1981), Castells (1998), Johnston et al. (1994), Offe (1985) and Kriesi (Kriesi et al., 1995; Kriesi, 1996).

Both of these variants are discussed in some detail below, followed by an evaluation of their usefulness for the study of AIDS activism. Two further approaches 
that have been quite prominent in the literature of the last decade are the study of transnational advocacy networks - still primarily a descriptive approach, but one which attempts to overcome some of the theoretical weaknesses of the more traditional sociological approaches - and a view emphasising global civil society.

\subsubsection{Social movement theory}

It is debatable whether AIDS activism can be considered a social movement in the classical conception, but it is certainly a form of contentious political activity that falls within the range of phenomena normally studied in social movement theory. Ballard et al. (2006:3) define social movements as "politically and/or socially directed collectives, often involving multiple organisations and networks, focused on changing one or more elements of the social, political and economic system within which they are located." In this they follow Tilly (1985, quoted in Ballard et al., 2006:2), who emphasises "demands or challenges to power-holders in the name of a social category that lacks an established political position" and Jelin (1986, quoted in Ballard et al., 2006:3), who considers both a high degree of popular participation and the participants "establishing themselves as collective subjects, that is, as a group or social category" essential characteristics of social movements.

Social movement theory is closely associated with traditional political sociology. It focuses on the structural preconditions and means for collective action and emphasises three broad sets of factors in the analysis of social movements. These are (1) the structure of political opportunities and constraints confronting the movement; (2) the forms of organisation (both formal and informal) available to participants; and (3) the collective processes of interpretation, attribution, and social construction that mediate between opportunity and action, known as 'framing processes' (McAdam et al., 1996:2). While this tradition is rooted in the study of revolutionary movements and popular insurgencies, its proponents claim that it is applicable also to the so-called 'new social movements' (i.e. those that demand rights or equality without aiming at the overthrow of the state) and even 'new-new social movements' (the transnational movements pressing for fairer globalisation etc.). For example, Ballard et al. (2006:3) argue that analyses of political opportunities, mobilising structures and framing processes include a wide range of the- 
oretical perspectives and work together to "bridge" approaches to old and new social movements. However, critics argue, in my view correctly, that it retains a state-centric view of politics (Taylor, 2004:4).

A basic assumption of social movement theory is that a given challenger faces political opportunities and constraints, and that changes in these opportunities and constraints on the one hand determine whether a movement emerges and, on the other, shape the ebb and flow of movement activity over time (McAdam et al., 2001:41). McAdam et al. (1996:3) point out that earlier (largely American) scholars attempted to explain the emergence of movements according to changes in institutional structure or informal power relations, with later (largely European) scholars bringing a comparative perspective to bear, i.e. to investigate how differences in the political characteristics of the nation-states within which they operate impact upon the structure, extent and success of social movements (see Kriesi 1989, Kitschelt 1996, Koopmans 1992 and Duyvendak 1992, cited in McAdam et al., 1996:3). McAdam (1996:27) identifies four dimensions of political opportunity that constitute a relative consensus among authors in the field: "[1] the relative openness or closure of the institutionalised political system; [2] the stability or instability of that broad set of elite alignments that typically under-gird a polity; [3] the presence or absence of elite allies; and [4] the state's capacity and propensity for repression." The emphasis throughout is on national political context and the way this context is presumed to shape social movements. This reflects the state-centric bias of this approach, although it must be said in the defence of social movement theorists that some have acknowledged this problem and attempted to broaden their conception of opportunity structures. For example, Tarrow (1996:54) defines political opportunity structure as "consistent - but not necessarily formal, permanent or national - signals to social or political actors which either encourage or discourage them to ... form social movements" (my emphasis). He concedes that transnational social movements present a challenge and that "national regularities in state structure must be seen as no more than the initial grid within which movements emerge and operate" (Tarrow, 1996:53).

The forms of organisation available to and employed by movements are considered key to explaining their impact. These are often termed 'mobilising structures'- defined as "those collective vehicles ... through which people mobilise and 
engage in collective action" (McAdam et al., 1996:3). A closely related term is that of 'repertoires of contention' which refers more explicitly to the types of activities (marches, sit-ins, etc.) employed by activist movements (cf. McAdam et al., 2001:43). McAdam et al. (1996:3-4) trace these ideas to two distinct theoretical perspectives, namely. that of resource mobilisation theory (which shifted the focus from grievance-based conceptions of social movements to mobilising processes and their organisational manifestations); and that of the political process model which emphasised grassroots settings (such as the workplace or neighbourhood) and local institutions (e.g. black churches in the civil rights movement). Perhaps the clearest conceptualisation is provided by Tarrow (1998:123) who distinguishes between three aspects of movement organisation: (1) formal hierarchical organisation (the dominant aspect in the literature), which refers to the formal organisation that attempts to give expression to a movement (sometimes referred to as Social Movement Organisations or SMOs); (2) the organisation of collective action at the point of contact with opponents (branches or even cells, informal social networks, clubs, etc.), which may be controlled by formal organisations, coalitions of organisations or no one in particular; and (3) connective structures that link leaders to followers, different parts of movements, organisations supporting a movement, etc. The analysis of networks presented in this chapter - which argues that they are critical to explaining both the organisational forms and forms of action of AIDS activism and the impact of activism - takes its cue from this conception of mobilising structures, but also goes beyond it. This is discussed in greater detail later.

The third factor emphasised by social movement theory - 'framing processes' - is described as "fram[ing] specific grievances within general collective action frames which dignify claims, connect them to others, and help to produce a collective identity among claimants" (McAdam et al., 2001:41). In this view, shared meanings and definitions are critical in mediating between opportunity, action and organisation; this requires at least feeling both aggrieved and optimistic that collective action can improve the situation (McAdam et al., 1996:5). Framing processes are the processes by which these shared meanings are established. This aspect served as a corrective to the resource mobilisation perspectives which accorded very little significance to ideas and subjective motivations. While David Snow et al. (1986 cited in McAdam et al., 1996:5) first employed the term, both 
McAdam et al. (1996:5) and Ballard et al. (2006:6) point to the important role of new social movement scholars such as Alain Touraine in focusing attention on the importance of subjective elements such as identity and meaning. (This is perhaps not surprising, given that many of these new social movements - e.g. those agitating for sexual liberation - were characterised by distinctive cultural aspects, and many of their demands were underpinned by strong identity claims.) The concept of framing processes is used, then, to describe both the conscious efforts of movement leaders and participants to construct shared understandings and the underlying cultural resources which they employ. Says Tarrow:

It is participants' recognition of their common interests that translates the potential for a movement into action. By mobilising consensus, movement entrepreneurs play an important role in stimulating such consensus. But leaders can only create a social movement when they tap more deep-rooted feelings of solidarity or identity. (Tarrow, 1998:6)

The above quote illustrates many of the problems with social movement theory. First, reducing the motivations of participants to 'interests' reveals an economistic bias that fails to accord with social movements - particularly in its transnational form - that succeed in building alliances between interest groups and individuals and organisations not motivated directly by their own interests. It fails to take seriously the moral claims of movements. As both Taylor (2004:6) and Keck and Sikkink (1998:1) have pointed out, these actors' motivations can not be reduced to their narrow interests as sociological and economic models tend to do. Says Keck and Sikkink (1998:8-9): "they are organised to promote causes, principled ideas, and norms, and they often involve individuals advocating policy changes that cannot be easily linked to a rationalist understanding of their "interests."'

Second, there seems to be an overemphasis on consensus and identity. This runs counter to both the empirical reality of movements that are often formed through ad hoc, temporary and fluid networks of diverse groups and individuals, and the theoretical current underlying the network conception of movement formation and action that I prefer. Social movement theorists may respond that only those movements able to construct collective identities and build consensus 
should be considered 'true' social movements. For example, Ballard et al. (2006:3) question whether all contemporary social struggles in South Africa should be considered social movements, since some may not be popularly located or do not sufficiently establish a collective identity. But this emphasis on collective identity rather limits the applicability of the theory, particularly when it comes to transnational networks (which play a crucial role in AIDS activism), since these are often based on alignments of purpose rather than the establishment of collective identities. Often organisations, groups and individuals link up and act in a coordinated fashion merely strategically. This is not to deny that in some movements collective identities are fundamental. Clearly, shared identity formation was a key part of the gay movement as it emerged in the US from the 1960s and was still critical in the mobilisation of early AIDS activism. It may even be the case that the activist movement would not have emerged (or would have been less strong) had it not been rooted in a well-established gay movement and could that movement not have mobilised identity-related sentiment. But a network approach would reject a conception of movements as monolithic entities brought about only by evacuating difference and diversity. Rather, it points to the many ways in which seemingly insurmountable differences and divergent interests are overcome by means of temporary and strategic alliances mobilised through networks that are capable of accommodating diversity precisely because they do not necessarily imply closely-knit integration between all participants. Rather, the pattern is one of complex webs of more and less integrated sub-networks (which may include very dense conglomerations indeed, including ones framed by identity) with greater and lesser degrees of proximity and identification.

Nonetheless, social movement theory does provide analytical tools that are useful in conceptualising the processes at work in activist movements - as long as we do not reduce the movements to these processes. Perhaps my argument is less one against social movement theory as one against simplistic and reductionist interpretations and applications thereof. And many of its insights are undeniably accurate. So, while I will argue that the political process model is not sufficient for our purposes, it would be absurd to suggest that there is no place for categories such as 'political opportunities' in our analysis. Obviously, the TAC's highly successful strategy of using constitutional litigation to compel the South African 
government to alter its AIDS policy, is to exploit the political opportunity afforded it by the institutional arrangement of a separation of powers established by constitutional democracy in South Africa (namely the power of the Judicial branch of the state vis-à-vis that of the Executive). Without the fundamental transformation of the state in the early 1990s such a strategy could never have been successful, and in this sense the state-centric political process model is perfectly applicable. But the emergence and success of AIDS activism cannot be explained simply in these terms.

\subsection{2 'New' social movements}

As already mentioned, the new social movements tradition acted as a corrective to the cruder forms of social movement theory - particularly resource mobilisation theory - by emphasising the centrality of cultural and identity aspects in collective action. According to Buechler (1995:442), new social movement theory, among other things, "problematize[s] the often fragile process of constructing collective identities and identifying group interests, instead of assuming that conflict groups and their interests are structurally determined" as well as recognising "a variety of submerged, latent, temporary networks that often under-gird collective action, rather than assuming that centralized organizational forms are prerequisites for successful mobilization." Manuel Castells, for example, criticises resource mobilisation theory for "incorporating [the social movement] into the political process aimed fundamentally at the state" (Castells, 1983). Both an anti-institutional orientation and group identity are seen as products of the group process and emergent from the movement's internal dialogue (Hannigan, 1985:449).

While these theorists reject simplistic notions of 'structural determinants' of movements, there is nevertheless an overriding focus on a societal totality that acts as a context for collective action (Buechler, 1995:459). For example, Alain Touraine (1981:6-7), probably the most prominent theorist of new social movements, attributes the introduction of cultural aspects into social struggles to certain fundamental changes occurring in post-industrial ('programmed') society, including the loci of domination expanding beyond the economic sphere. Both Touraine and Castells have been criticised for succumbing to structural determinism and for 
employing an evolutionary theory of social transition that is essentially speculative and lacks evidence (Hannigan, 1985:448). Even if the state-centric bias of classical social movement theory is addressed, therefore, a certain domestic bias is retained.

Buechler (1995) questions the fundamental category of 'new social movement' and argues that it obscures continuities and exaggerates differences between past and present movements, though he acknowledges that there has been a shift in emphasis and orientation in many contemporary social movements. I am inclined to agree, and consider the new social movement perspective a theoretical advance over the cruder forms of social movement theory as well as a recognition within the sociological tradition of non-structural and dynamic aspects of movement formation and collective action.

In their most recent writings, some of the key exponents of social movement theory have attempted to formulate a more dynamic model. McAdam et al. (2001:43-50) do this by reconceptualising opportunity structure as the "attribution of threat and opportunity"; mobilising structures as the "social appropriation" of organisation and membership; strategic framing as "social construction" and repertoires of action as "innovative collective action."

Nevertheless, I am not convinced that either the European new social movement perspective or the recent attempts to reformulate classical social movement theory address the fundamental theoretical weaknesses. My objections to the model are three-fold. First, it does not take sufficient cognisance of the dynamic forms of organisation - primarily the formation of transnational networks - that are increasingly in evidence. Of course, these forms are not entirely new - they have precursors as far back as the global campaign against slavery starting in the eighteenth century (see Hochschild, 2006), but have been significantly enhanced by the information and communication technologies that became prevalent in the latter part of the twentieth century. Furthermore, it is not that these forms did not exist before, but rather that they have now become the paradigmatic forms of organisation. Increasingly they are essential for success. Second, this model exhibits a state-centric and national bias and does not adequately account for the transnational dimension. Third, its morally detached perspective fails to account for the subjective motivation of actors beyond their 'interests' and itself pretends to a normative neutrality that is neither achievable nor necessarily desirable. 
It is therefore worth investigating a number of other perspectives for theoretical tools appropriate to the study of AIDS activism.

\subsubsection{The network perspective in the social sciences}

Social network analysis has become an increasingly popular technique in the social and behavioural sciences. It focuses on the webs of interrelationships between individuals. Individuals ('actors') are considered primarily as nodes in the network, rather than as the repository of individual agency. A basic premise of network thinking is that outcomes are shaped more by the 'network effects' that result cumulatively from the relationships between nodes than by the characteristics of the nodes themselves. Applied to social networks, this view holds that an individual's significance in a social configuration results from the ties (strong or weak, many or few, etc.) between that individual and others in the network.

Social network analysis is closely related to the rise of 'systems thinking' and 'complex systems' in the sciences, particularly in biology, climate science, computer science and engineering. For example, Cilliers (1998:12-13) distinguishes between two approaches to modelling complex systems: the traditional analytical approach ('rule-based' models) and connectionist models (e.g. neural networks). The former assume that a system can be adequately described by specifying rules analytically, whereas the latter acknowledges that a system may be too complex to describe in such fashion and can be approached better through models that replicate some of the features of complex systems (such as self-organisation). In this way connectionist models may be able to account for certain 'emergent properties' of complex systems that analytical models are not. Formal social network analysis makes use of statistical and mathematical techniques to describe the relational structure of networks and emphasises "explicit, mathematical statements of structural properties, with agreed upon formal definitions" (Wasserman and Faust, 1994:17) in order to develop formal and testable models.

While the application of this type of detailed structural analysis to AIDS activism may well prove to be a productive exercise, I will attempt to do so in this thesis (except to a very limited extent later in this chapter). Nevertheless, many of the concepts (employed more as suggestive theoretical constructs than as formally 
defined 'structural properties') are useful for developing an understanding of how activist networks form, organise themselves and produce social effects. In particular, as I will argue later in this section, a network perspective allows us to explain how activist movements are sometimes able to wield influence far beyond what would be expected from their position in the configuration of political power (if the latter is understood in conventional terms).

I argued earlier that any study of AIDS activism must take account of the role of individuals, and my analysis does retain individual agency as an important factor. Since a network perspective de-emphasises the characteristics of individuals in favour of network effects, it does not seem capable of helping us to accommodate the individual aspect. But despite the tension between network theory and individual agency, the former nevertheless suggest the possibility of an understanding of the role of key individuals that derives from their 'position in the network.' For example, certain individuals - owing to their particular sets of relationships with others - are uniquely able to bring together diverse groupings and to mobilise strategic individuals and groups. Perhaps a classic example is Granovetter's description of "the strength of weak ties." In Granovetter's view, having a large number of 'weak' connections to other individuals, i.e. to a generally more diverse set of acquaintances, is more important in social mobilisation than the strength of those connections. While 'strong' ties - such as close friendship and kinship may be highly effective in mobilising those individuals to whom one is so tied, these have two disadvantages: (1) one is likely to have fewer such ties and (2) they are less likely to enable mobilisation beyond a certain social grouping (such as a neighbourhood or ethnic community). The counter-intuitive conclusion is that the weak ties between individuals in different groups are more important than the strong ties within groups. There is strong empirical evidence supporting this analysis (see Granovetter, 1973; 1983). While this perspective is usually applied at the group level to explain why certain issues gain wider traction than others, it is applicable also at the level of key individuals. Empirical studies of AIDS activism seem to confirm that a relatively small number of individuals can bring to bear the intergroup linkages that are key to wide mobilisation, even if most movement participants rely on strong ties to mobilise friends and family (see chapter 3). Both 'bridging ties' and 'bonding ties' are therefore key to understanding network mobilisation. 
Cilliers (1998) points out in his philosophical study of complex systems that while a complex systems perspective undermines traditional 'structural' models, this does not preclude relatively stable patterns of interaction - and therefore relatively stable structure - from emerging in a complex system. This suggests that in certain circumstances traditional non-network-oriented approaches may be adequate, as long as one does not ignore network effects where they do occur. There are therefore two reasons why a network perspective does not preclude an emphasis on the role of individuals: (1) the influence of individuals can itself be understood in network terms, and (2) when a network exhibits relatively stable patterns of interaction, the role of particular nodes may not differ all that much from what a traditional agential analysis would suggest. In other words, as I argued earlier, structure and institutions constrain, but also enable purposive individual actions.

But a network perspective can also help us describe certain mobilising strategies that have become possible owing to technological innovation, and that have proven successful in recent struggles. Heckscher (2006) argues, for example, that there are fundamental organisational reasons to adopt a network approach to mobilisation. First, the traditional social movement model of mass action based on cohesive solidarity such as class solidarity have in recent times been unable to sustain a militant base that can energise organisation. ${ }^{3}$ And those struggles built on the identitybased 'new social movement' model have remained local and isolated (Heckscher, 2006:329). In contrast, he argues, networks - formations that are fluid, open and generally voluntary, without the stable structures and hierarchies of traditional organisations - can be very effective in dealing with complex problems of organisation, and be effective agents of social change (Heckscher, 2006:330).

It is by no means new to apply the idea of social networks to social movements and mobilisation, but the idea has generally been employed in the context of recruitment - i.e. how the social linkages between individuals and communities help or hinder recruitment of new members into movements (e.g. Tilly, 1978; Snow et al., 1980; McAdam, 1982; cited in Olesen, 2006:10). Later in this chapter I will develop a notion of 'transnational networks of influence' that draws on social movement theory but applies it specifically to the mobilisation of transnational net-

\footnotetext{
${ }^{3}$ His analysis is applied particularly to American organised labour, though he makes general points that are equally applicable to other movements.
} 
works and that goes beyond active movement participants to explain the impact and influence of activism.

\subsection{4 'Transnational social movements'}

Intellectuals broadly aligned with the left have often been rather pessimistic about the impact of globalisation, believing that it reduces the opportunities for the social regulation of the economy. In a globally integrated economy, capital is increasingly 'footloose' and able to exercise 'exit options.' The so-called anti-globalisation movement, too, is premised on this view, often aiming protest action at the institutions perceived as undermining communities by furthering the unfettered flow of capital, goods and services. But increasingly there is an alternative view, namely that the growth of communication and movement across national boundaries (facilitated in part by new communication technologies and lower cost air travel) also expands the opportunities for global movements for equity and justice. Theorists as diverse as Manuel Castells, Ernesto Laclau and Antonio Negri have adopted this more optimistic view (see Castells, 1998; Laclau and Mouffe, 1985; Laclau, 1990; Hardt and Negri, 2000; 2004). The activist movements that have been most successful at exploiting the opportunities created by economic and political globalisation are those that themselves have a transnational character - or which are able to 'jump scale' and draw on supportive international networks and resources. International AIDS activism is probably one of the best examples of this.

Earlier I criticised social movement theory for its domestic bias. A number of approaches have emerged that attempt to overcome this bias and account for the emergence of 'transnational social movements.' These include what della Porta and Tarrow (2005a:232-233) term 'transnational relations' from within the international relations tradition, such as Keohane and Nye (1972) as well as 'global civil society' and 'transnational citizenship' approaches such as Edwards and Hulme (1996), Wapner (1995) and Soysal (1994). In addition, some of the leading exponents of social movement theory have also turned their attention to the transnational domain, but argue that the essential insights of social movement theory remains applicable. Tarrow and McAdam (2005:122) argue, for example, that "although much is new and challenging about transnational contention, some familiar 
processes from the social movement repertoire, like mobilisation, are so essential to contentious politics that it is hard to understand these new phenomena as if they were wholly new." Others have attempted to apply the basic categories of social movement theory (political opportunities, mobilising structures, framing processes) to the transnational domain but also introduce concepts such as 'issue networks' (see, for example, Smith et al., 1997).

Most promising of the developments in traditional social movement theory is the notion of 'complex internationalism' elaborated by della Porta and Tarrow (2005a;b). Complex internationalism is a development of Keohane and Nye's concept of 'complex interdependence' and argument that "increasing international interdependence produces sustained interactions ...leading to the creation of interstate and transgovernmental practises and institutions below and outside of the state level of international relations" (cited in della Porta and Tarrow, 2005a:234). They include nonstate actors in their schema and define 'complex internationalism' as:

...the expansion of international institutions, international regimes, and the transfer of resources of local and national actors to the international stage, producing threats, opportunities and resources for international NGOs, transnational social movements and, indirectly, grassroots social movements. (della Porta and Tarrow, 2005a:235)

Unlike some in the social movement perspective, della Porta and Tarrow view globalisation and transnationalism as introducing aspects that are new and that require analytical reflection. They offer 'complex internationalism' as a synthetic perspective that is neither exclusive nor all-encompassing (della Porta and Tarrow, 2005a:240). In this sense it is a useful perspective, but it does not yet draw on the network perspective which I see as holding most promise for anchoring empirical reflection on AIDS activism.

\subsubsection{Transnational advocacy networks}

An approach that draws on the network perspective, and that is also able to take account of the transnational dimension of AIDS activism, is the study of 'transnational advocacy networks,' perhaps most closely associated with Keck and Sikkink's 
seminal study Activists beyond borders (Keck and Sikkink, 1998) and also employed by Smith and Siplon (2006). Their analysis is attractive since, unlike many others, it goes beyond International NGOs (INGOs) and views also the networks which domestically-focused movements leverage (and in which not all movement members necessarily actively participate) as central. It may be productive to distinguish, as Tarrow (2001:2) does, between three forms of transnational action: (1) Transnational Social Movements; (2) International Nongovernmental Organisations; and (3) Transnational Activist Networks. The third of these categories is most applicable to transnational AIDS activism. A second approach focusing on the transnational domain, the study of 'global civil society,' is briefly discussed later in this section.

According to Keck and Sikkink (1998:1), transnational advocacy networks "multiply channels of access" to the international system by creating new links among actors in civil societies, states, and international organisations. In this way, civil society actors are able to exercise greater influence over policy. They define networks as "forms of organisation characterised by voluntary, reciprocal, and horizontal patterns of communication and exchange" (Keck and Sikkink, 1998:8).

Their main argument is that the impact of activism at the domestic level is to a significant extent a function of these transnational networks. Evans (2000) argues that transnational networks enable what he terms 'counter-hegemonic globalisation.' Concrete examples of success often cited include the human rights movement, the women's movement, the environmental movement and the impact of anti-sweatshop campaigns. Importantly, they conceive of networks as deliberately constructed organisational structures: "claims around issues amenable to international action do not produce transnational networks. Activists ... do" (Keck and Sikkink, 1998:14). It is a distinct advantage of their analysis that individual agency is not ignored and that networks are not reduced to the automatic result of structural factors. Furthermore, their emphasis on active participation in transnational network formation and information flows accords with the empirical findings that certain individuals and relatively small networks of key activists play a critical role in mobilising AIDS activist movements.

Four tactics are typical of these networks: (1) information politics (quick generation of credible politically useful information and moving it to where it will have the 
greatest impact); (2) symbolic politics (employing actions and stories that make sense of a situation to an audience that is often far away); (3) leverage politics (calling upon powerful actors to affect a situation that less powerful network participants are unable to influence); and (4) accountability politics (holding powerful actors to their previously stated positions or policies) (Keck and Sikkink, 1998:16-25).

This conception of transnational advocacy networks is powerful, and appropriately refers to the links between actors within various spheres of the international system. However, in its application Keck and Sikkink often revert to a more simplistic conception of the operation of networks: namely that they increase the leverage of domestic civil society actors over national governments via the so-called 'boomerang pattern' (see figure 3.3):

When channels between the state and its domestic actors are blocked, the boomerang pattern of influence characteristic of transnational networks may occur: domestic NGOs bypass their state and directly search out international allies to try to bring pressure on their states from outside. (Keck and Sikkink, 1998:12)

Clearly, this pattern does have some applicability to AIDS activism. In De Waal's view, for example, this is responsible for much of the success of AIDS activism in Africa, where domestic activists have been able to exploit transnational networks comprising international NGOs, international (interstate) organisations - including those forming part of the UN system such as UNAIDS and the $\mathrm{WHO}$ - and donor governments as a means of leverage over their own governments, even where those governments have not been susceptible to traditional pressure exerted within the domestic political system.

African governments are ... located in new webs of accountability, reaching downwards to new domestic players $\left(\mathrm{CSOs}^{4}\right.$ and citizens in international agencies), sideways to other African governments, the African Union and subregional organisations, and upwards to a changed and permeable set of foreign institutions. African citizen activists are diversifying their channels of influence so as not to rely ex-

\footnotetext{
${ }^{4}$ Civil Society Organisations
} 


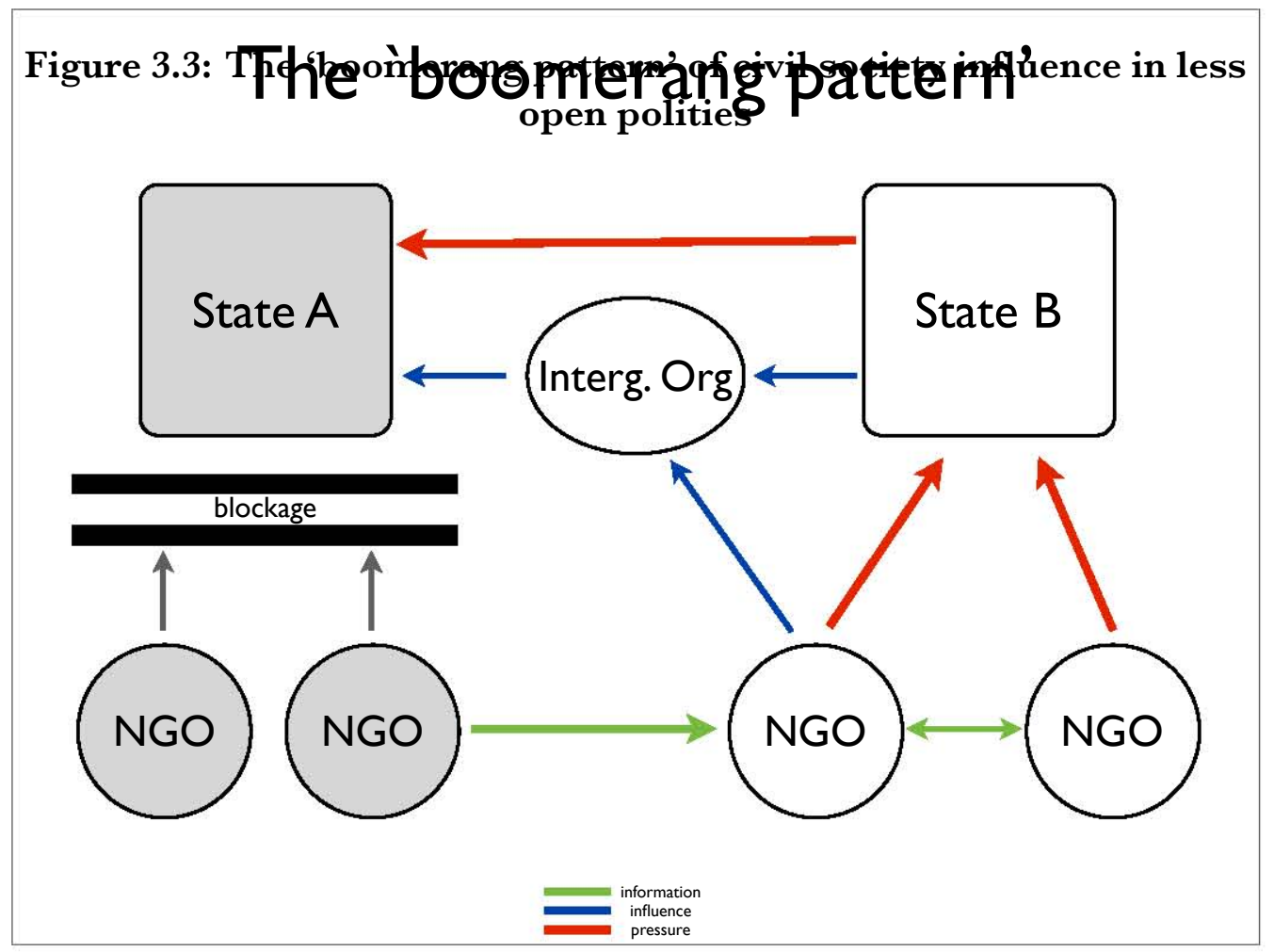

Source: Adapted from Keck and Sikkink (1998).

clusively on domestic institutions and processes that are fragile and easily manipulated. (De Waal, 2006:58-59)

\subsubsection{Transnational networks of influence}

However, transnational networks are more complex than the triangular conception of influence that the boomerang pattern suggests. While the boomerang pattern is undeniably discernible, it is but one manifestation of what could more appropriately be termed 'transnational networks of influence.' The boomerang conception neglects factors other than pressure applied by other states. In my view the network model should be expanded to include not only networks of activists and NGOs, but also other actors, so that we are describing webs of influence that may include (in the case of AIDS activism) scientific communities, international bureaucrats, diplomats, but even extending to individuals and institutions within the target state. Often pressure is brought to bear via such complex webs of influence, rather than through direct movement-to-state or state-to-state pressure. 
While Keck and Sikkink (1998:117) do consider the 'vulnerability' of the target state to pressure a key factor in network effectiveness, the empirical research drawing on the framework developed in this chapter demonstrate that allies, or at least sympathetic individuals within the target state, are often decisive (see chapter 3). The proposed conception of networks of influence is also more compatible with the general network perspective and with the theoretical innovations it allows.

Furthermore, as will become clear in the case studies, relationships (often quite close personal ones) between key players in activist movements - both within countries and across borders - have played a very significant role in the formation of transnational networks of influence (see Smith and Siplon, 2006). While McAdam and Rucht (1993, cited in Keck and Sikkink, 1998:9) acknowledge that "some issue areas reproduce transnationally the webs of personal relationships that are crucial in the formation of domestic networks," I will argue that these 'webs of personal relationships,' are in fact key to both the emergence and the influence of networks. In other words, the dense networks of friendship, love and political comradeship among gay men that contributed to the rapid emergence of AIDS activism in the United States are discernible to an extent even in international activist networks.

\subsubsection{Global civil society?}

A term increasingly common in both popular and theoretical discussions of the international dynamics of contestatory politics - particularly where this involves activists and NGOs - is that of 'global civil society.' However, there is by no means consensus on how this should be approached theoretically. Tarrow (2001:2) cautions against making too direct a jump

...from globalization or some other such process to transnational social movements and thence to a global civil society. [Theorists who do so] fail to adequately distinguish social movements, nongovernmental organizations (NGOs), and transnational networks and do not adequately specify their relations with each other or with states and international institutions.

He further cautions that states remain dominant in most areas of policy, that globalisation has been around for at least a century, and that social movements, 
transnational networks and NGOs are not the only agents operating transnationally - pointing out that states and state-led institutions often fund and control nonstate transnational actors like NGOs (Tarrow, 2001:2-3).

It is important to look critically at the dynamics of the alignments and disalignments that occur within global activist networks and networks of influence. Tvedt goes so far as to liken the adulatory accounts of NGOs as the world's conscience to the 'glorious narratives' of nineteenth century European historians and argues, in the same vein as Tarrow, that international relief and development NGOs should not be analysed as global civil society but in fact form part of a new, broader social system embedded in the international state system (Tvedt, 2004:135-136). An uncritical assumption that international NGOs form part of a global civil society that acts as counterweight to the power of other (less democratic) transnational actors - including states, international organisations and multinational corporations - would be naive.

It seems to me that global civil society, if we are to use the term at all, is best conceived of as the contested and fragmentary terrain of transnational contentious political and social action. It is not clear that the notion of global civil society significantly adds to the theoretical toolbox we can apply to transnational AIDS activism, and it certainly carries the danger of implying a unified counterweight to less benevolent transnational actors. But the notion is useful insofar as it acknowledges the critical international dimension to civil society struggles and the increasing importance of the transnational domain for activists.

\subsection{Origins of the Treatment Action Campaign}

On 10 December 1998 (International Human Rights Day), Zackie Achmat and a handful of friends and comrades from the anti-apartheid struggle in Cape Town in the 1980s founded the Treatment Action Campaign. The group stood on the steps of St George's Cathedral in Cape Town, handing out pamphlets to passersby that called for greater access to antiretroviral treatment. Many of these people told the group that they had never known AIDS could be treated: 'Passers-by were surprised. Not many of them knew that you could treat AIDS. They didn't realise that AIDS medications were freely available in Western Countries' (TAC, 2001:2). 


\section{Figure 3.4: Government inaction on AIDS}

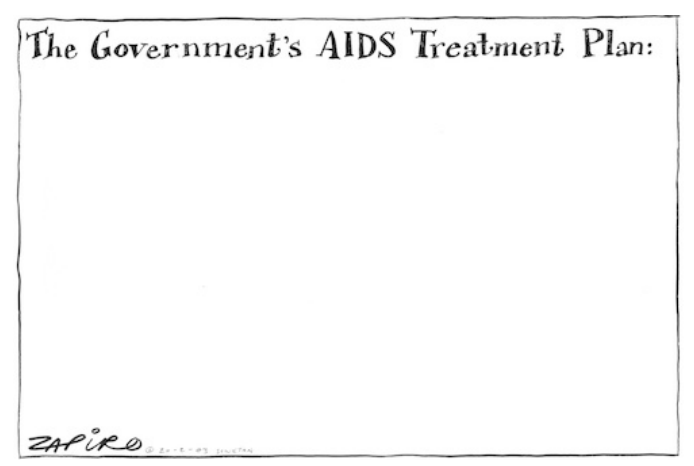

Source: www. zapiro. com. C)2003-2012 Zapiro. Printed with permission from Zapiro.com.

Shortly before, at anti-apartheid and gay rights activist Simon Nkoli's memorial service in November 1998, Achmat had called for the creation of a campaign for access to antiretroviral treatment. In his speech he acknowledged that 'government cannot do everything', but appealed to the government to work with the new campaign to bring down the cost of treatment so that it could be made available more widely. ${ }^{5}$ This statement reflects his expectation that the campaign would face strong opposition from the pharmaceutical industry, whose pricing policies (enabled by patent protection) presented the most salient obstacle to the wider availability of antiretroviral drugs. ${ }^{6}$ As it turned out, a larger obstacle became government intransigence.

It is significant that the initial announcement was made at the funeral of Nkoli, whose death the organisation later described as a 'defining moment' (TAG, 2001:2). Nkoli died of AIDS, unable to access appropriate treatment. He was considered especially courageous for having come out as gay to his ANC comrades at the time that he stood trial for his anti-apartheid activities. (In November 1986, a number activists from the Vaal triangle, Nkoli among them, and senior United Democratic Front leaders, were charged with treason in the so-called Delmas treason trial (Seekings, 2000:145).)

\footnotetext{
${ }^{5}$ Part of the speech can be seen in the video documentary 'TAC: The first five years...' (Lewis, 2003).

${ }^{6} \mathrm{Z}$. Achmat, personal communication with the author.
} 
Though they were not close, Achmat knew and worked with Nkoli, who became leader of the Gay and Lesbian Organisation of the Witwatersrand (GLO), in early 1990s gay rights activism. ${ }^{7}$ Nkoli's death shook his friends and colleagues and brought home to many the stark reality of the high cost and difficulty of obtaining correctly administered treatment. Achmat cites Nkoli's experience of 'having intermittent treatment and having tried Virodene ${ }^{8}$ and so on and [having] kidney failure and died as a consequence of not having proper medical treatment, not having medical treatment through a public healthcare programme' and the contrast with that of Edwin Cameron (who recovered rapidly from AIDS after going on ART in 1996) as crucial in his forming an understanding of what antiretroviral therapy could do. ${ }^{9}$

TAC's relatively inauspicious beginnings already reflect some of the most important characteristics of the movement: the critical role played by deeply committed activists schooled in the political lexicon of the anti-apartheid struggle, its drawing on experience gained during earlier political activities (including Trotskyist revolutionary activity and gay rights activism), the reliance on personal relationships and strong ties of affection and trust, the centrality of moral appeals and strongly symbolic gestures, and the framing of its claims in terms of human rights discourse (see Johnson, 2006).

But I will argue that there is a further crucial source of TAC's impact: its construction and leveraging of (transnational) networks of influence. These involve the effective mobilisation of international solidarity and influence through the building of activist and support networks, but also draw on the informal but robust networks (both inherited from individuals and meticulously built over time), which connect the movement to individuals from diverse fields such as science, international organisations, foreign governments, state institutions and political parties, including the African National Congress. These connections allowed it to influence, gather information from and mobilise support from many individuals who would not or

\footnotetext{
${ }^{7}$ Interview, Z. Achmat (30 April 2008).

${ }^{8}$ Virodene was a supposed anti-HIV agent 'discovered' by a South African medical technician, that was initially enthusiastically endorsed by Mbeki. Upon closer scrutiny from the medicines regulatory authority, the substance turned out to be an industrial solvent with no evidence for its safety or efficacy and the body refused permission for clinical trials. See Myburgh (2007a;b;c;d;e).

${ }^{9}$ Interview, Z. Achmat (30 April 2008).
} 
could not openly support the organisation.

\subsection{From the struggle against apartheid to act- ivism under democracy}

TAC cannot be understood without looking at the continuities between it and its historical precursors, in particular the anti-apartheid struggle (and the variety of Trotskyist agitation in which many of its founders engaged), gay activism and American AIDS activism. However, it is by no means the passive recipient of political history: while consciously drawing upon its history, it also continuously (and strategically) refashions that political legacy. This continuity has been fairly well covered in the existing literature, especially by Friedman and Mottiar (2005; 2006), Robins (2004) and Mbali (2006). In order to properly situate my account of TAC's building and leveraging of networks, I will briefly review this literature and provide further depth (especially by highlighting the founders' history of Trotskyist organising), drawing on extensive key informant interviews.

Many of TAC's early leaders were veterans of the anti-apartheid struggle. Several authors (Friedman and Mottiar, 2005; Robins, 2004), as well as TAC's leaders themselves, ${ }^{10}$ have pointed to what one could term TAC's 'struggle heritage' as central to its self-conception as well as to its engagement within the South African polity. The continuity with this history is evident in its political style and strategy and its use of symbolism and culture - what Robbins has called the 'creative reappropriation of locally embedded political symbols, songs and styles of the antiapartheid struggle' (Robins, 2004:665). TAC employs the political lexicon of the struggle: as at political rallies of liberation movements like the ANC-aligned United Democratic Front during apartheid, speakers at TAC events commonly start with the right-fisted salute and the cry 'Amandla!' (power), which the audience answers with 'Awethu!' (to the people). Members address each other as 'comrade', sing struggle songs (the words of which have been altered to refer to TAC's demands) and toyi-toyi ${ }^{11}$ at protest marches. Being situated within this tradition also provides

\footnotetext{
${ }^{10}$ Interviews, Z. Achmat (16 June 2007) and M. Heywood (17 December 2007 and 10 January 2008).

${ }^{11}$ An often-spontaneous dance, usually involving the stomping of feet accompanied by the chant-
} 
TAC with legitimacy that opposition politics in South Africa generally lacks.

Friedman and Mottiar point to the similarity between the tactics employed in the struggle against apartheid and those employed by TAC (Friedman and Mottiar, 2006:25). These include the use of the courts, international solidarity, broad alliances and (occasionally) civil disobedience. Its focus on mass mobilisation is arguably related to the involvement of key leaders in the campaigns of the United Democratic Front during the 1980s.

TAC has framed its struggle with a 'human rights discourse,' arguing that access to life-saving treatment is a fundamental human right (Mbali, 2006). That this is the primary framing of TAC's demands becomes apparent with even a cursory review of its pamphlets, posters, documents and public statements. This rightsbased discourse also represents the intersection of what I call the 'politics of moral consensus $^{12}$ and a key TAC strategy, namely the use of litigation to enforce the legal rights conferred by the new South African Constitution. By frequently stating that the rights it insists upon are guaranteed by the Constitution, it both strengthens the moral force of its appeal by locating it within the trajectory of South Africa's liberation and makes clear that its challenge is not to the legitimacy of the government or the state, but to government policies.

TAC's appeals to the traditions of the ANC-led liberation struggle and to a universal human rights discourse were crucial to the legitimation of its demands within the political context of post-apartheid South Africa. Zackie Achmat himself has acknowledged that TAC risked losing the support of its own members if it were 'seen to be threatening democratically elected leaders' (quoted in Friedman and Mottiar, 2005). This was especially important in order to withstand the direct attacks upon its legitimacy and credibility, fuelled by Mbeki and his circle's apparent view of TAC as a front for international pharmaceutical companies in a CIA-supported campaign to promote the view that HIV causes AIDS. In an infamous caucus meeting of ANC parliamentarians in September 2000, Mbeki is reported to have said, 'The Treatment Action Campaign is leading the statements and vitriol against one. They are funded by pharmaceutical companies in the US'

ing of political slogans or singing, traditionally used during political protests in South Africa.

12 This formulation is derived from Achmat's own statement that TAC owes much of its impact to its success in constructing a moral consensus around access to treatment. Interview, Z. Achmat (16 June 2007). 
(Feinstein, 2007). This allegation has resurfaced repeatedly, and was actively promoted by AIDS denialists like Matthias Rath and Antony Brink.

But, as Friedman and Mottiar point out, it is not merely a question of maintaining legitimacy; TAC strategically exploits its struggle heritage:

TAC's location, albeit in ambiguous fashion, in the ANC tradition also gives it an important asset: it enables it to use the imagery of the ANC's anti-apartheid struggle as an important 'discursive tool' in its attempt to achieve legitimacy and moral support. It has referred, for example, to its civil disobedience campaign as a 'Defiance Campaign', evoking a celebrated ANC campaign against apartheid laws in 1952.

(Friedman and Mottiar, 2005:522)

The location of TAC within ANC tradition is certainly ambiguous given the association of its founders with earlier 'entryist' attempts to influence the ANC and shift it towards revolutionary socialist politics. Zackie Achmat, Mark Heywood, Jack Lewis, Deena Bosch, Laddie Bosch, Sharon Ekambaram and Herman Reuter are early TAC activists who were members of the 'Marxist Workers' Tendency of the ANG' (MWT). The MWT was a Trotskyist group, closely associated with the Militant Tendency in the United Kingdom, active in exile and underground in South Africa during the 1980s.

According to Heywood, those early TAC cadres drew on their shared experience, and specifically a common 'method of analysis and work' developed in the course of their revolutionary activity. ${ }^{13}$ This included a common analysis of the state and state power, derived to a significant extent from Marxist thinking ${ }^{14}$ and a shared emphasis on the importance of mass mobilisation.

Arguably, TAC's loyalty to the ANC as the primary liberation movement, while at the same time not shying away from holding the party and the ANC government to account (including a willingness to engage in open conflict), also derives

\footnotetext{
${ }^{13}$ Interview, M. Heywood (10 January 2008). Both Heywood and Achmat pay pay tribute to Rob Petersen (who later practised as an advocate in Cape Town, but in exile in London at the time) as a political mentor to whom they owe much of their strategic thinking.

${ }^{14}$ It should be noted that most of these former MWT members no longer pursue revolutionary socialist politics, though many still draw on Marxist conceptual tools (Interview, M. Heywood, 17 December 2007).
} 
from the early cadres' experiences in the MWT. Lewis recalls the view that revolutionary activity had to be undertaken under the ANC umbrella, but that they also had an awareness of the 'problematic' ANC leadership. ${ }^{15}$ Despite its attempt to operate within the ANC, the MWT was not tolerated by the ANC. While Achmat himself was never formally expelled from the ANC, almost the entire MWT leadership (including Rob Petersen, Martin Legassick and Paula Ensor) were. Many former members routinely refer to the attitude of the ANC's exiled leadership to left-wing dissent as 'Stalinist'.

Interestingly, TAC was not the first health-focused initiative by former MWT members. The Bellville Community Health Project (part of the Progressive Primary Healthcare Network), run by Achmat, Lewis and Deena Bosch in the early 1990s, provided experience with and knowledge of health policy questions and, more importantly, experience with health-focused community mobilisation. ${ }^{16}$ Even the focus on drug prices and the use of generic competition to bring them down derives to some extent from this experience. ${ }^{17}$

Mbali attempts to show how earlier traditions of both gay rights activism and anti-apartheid activism shaped TAC (Mbali, 2006). This is an important corrective to the usual tendency of concentrating only on the struggle heritage, and taken together with the heritage of global AIDS activism in the American AIDS activist movement, which built on the gay rights struggles of the 1970s, calls into question the radical separation of identity-based 'new social movements' and the 'new new social movements' of which contemporary AIDS activism is arguably an important example. In any event, TAC's struggle is clearly not rooted in identity politics, and a nuanced historical perspective must acknowledge both continuities and discontinuities with identity-based struggles.

Mbali argues that 'the emergence of anti-apartheid, gay rights activism situated in universal rights-based discourse provided the basis for such gay rights activists to form broad-based, human rights-focused alliances, such as TAC, in the postapartheid era' (Mbali, 2006:134). Certainly it is true that some of the strategies that TAC employed with great success - such as constitutional litigation - can be

\footnotetext{
${ }^{15}$ Interview, J. Lewis (24 November 2007).

${ }^{16}$ Interviews, Z. Achmat (16 June 2007); J. Lewis (24 November 2007); D. Bosch (26 November 2007).

${ }^{17}$ Interview, Z. Achmat (30 April 2008).
} 
traced to key activists like Achmat's role in prior gay rights activism. Achmat led the National Coalition for Gay and Lesbian Equality (NCGLE) at the time that it launched two landmark cases in the early post-apartheid period, successfully challenging - on the grounds of non-discrimination provisions in the in the new South African Constitution - the continued criminalisation of 'sodomy' and the unequal treatment of foreign same-sex partners of South Africans (compared to heterosexual spouses). ${ }^{18}$

The anti-apartheid struggle, left-wing organising, gay rights activism and the new struggle for access to AIDS treatment were linked in the minds of the early TAC activists, and they relied both on the skills they had acquired and the relationships that had been established during the earlier struggles in embarking on the new.

\subsection{Mobilising through networks}

\subsubsection{Personal networks: a resource for movement build- ing}

The interlinked networks of activists that early TAC leaders had built up prior to TAC's founding became an important resource in the building of TAC, particularly with respect to (1) a shared political outlook, (2) a network of people that could be drawn on to mobilise resources for the new campaign and (3) relationships of trust which could underpin leadership in the fledgling movement. Heywood explains it as follows:

I think the [MWT] experience was important, and I think part of the experience was that a group of us had already established a way of working together and a certain level of trust. And I think there was a kind of unconscious method that had been developed, a political method, a way of thinking about the government, about the state, about social organisations, about social mobilisation and so on. You

\footnotetext{
${ }^{18}$ National Coalition for Gay and Lesbian Equality and Another v Minister of Justice and Others 1998 (12) BCLR 1517 (CG) (S. Afr.); National Coalition for Gay and Lesbian Equality and Others v Minister of Home Affairs and Others 2000 (1) BCLR 39 (CG) (S. Afr.).
} 
know the [Marxist Workers'] Tendency people provided the initial cadre that was needed to get TAC up and running. Let me just say that it was never a deliberate plan; it wasn't as if we reconstructed the Tendency grouping for TAC. It was just the group of people whom Zackie, in particular, drew on when we started up TAC. That group of people and their connections, people like myself, Sharon [Ekambaram] came in early, Laddie Bosch, Deena Bosch, and other people... ${ }^{19}$

Achmat argues that the 'institutional memory of activism' is a resource that the organisation actively tapped: 'You require a body of educated activists ... a body with a knowledge that is institutionally transmitted. ${ }^{, 20}$ While he underplays the importance of individuals in making this knowledge available to the organisation ('not through any individual, but through our collective knowledge $\left.{ }^{21}\right)$, he nevertheless acknowledges the importance of certain key individuals:

...I think that we have a very powerful team of leaders and there is complexity in that team as it's operated over the years. You will have someone like me, who is probably a very domineering and dominating personality, who makes, who has a long experience, at the time of the start of TAC about twenty-five years experience in politics ... and you'd have Mark Heywood with also about twenty years of experience, and you'd have Theo Steele [senior trade union leader and early TAC activist] with thirty years of experience in politics, you'd have someone like Hermann Reuter with twenty years in politics, you'd have someone like Sipho Mthathi with about five years in student activism ... and then a serious history in TAG. So you'd have any number of people from Nonkosi Khumalo [now TAC Chairperson], later Vuyiseka Dubula [now TAG General Secretary], Nathan Geffen [now TAG Treasurer] who did not have any political experience, but brought enormous scientific experience and technical capacity to

\footnotetext{
${ }^{19}$ Interview, M. Heywood (10 January 2008).

${ }^{20}$ Interview, Z. Achmat (16 June 2007).

${ }^{21}$ Interview, Z. Achmat (16 June 2007).
} 
TAC. ${ }^{22}$

In addition to the skills and experience they bring, individuals can make available to the movement their established networks. The social networks of individuals are both a means by which the movement is initially launched (until it is established enough and has gained enough momentum to start drawing people in) and a strategic resource available to the movement. Both the history of TAC's origins and the reflections of the activists themselves, point to trust as a critical element of the networks used to build up a movement. The high level of trust often derives from the blurring of personal and professional relationships. It is impossible to spend time with the TAC leadership without forming the impression that there exists genuine friendship between most of the individuals involved, and a number of key leaders are even present or former romantic partners.

Certainly the relationships of trust built up during MWT activities (particularly between Achmat and Heywood) were a key resource in building the new movement. While both underplay this dimension, it is clear from what they do say that there is an unusual rapport between the two and a meeting of minds that resulted in their becoming the strategic and tactical 'masterminds' of TAC. Sharon Ekambaram, an early TAC activist and MWT member who is also married to Heywood, describes their relationship thus:

Mark and Zackie have an incredible connection, and it just cannot be explained. I think it's one of the strengths of TAC in that while they have disagreements, they can discuss almost everything, you know, it's just... I don't know if it's the same now, but for a while they couldn't go without a day, talking three or four times, but work-related...23

For most of the first decade of TAC's existence, the leadership of the organisation (including senior staff members and elected officials) exhibited an exceptional degree of deference to Achmat and Heywood on matters of political strategy. ${ }^{24}$

${ }^{22}$ Interview, Z. Achmat (16 May 2008).

${ }^{23}$ Interview, S. Ekambaram (11 January 2008).

24 The author directly observed this, and it is confirmed by several interviews (J. Berger, 16 December 2007; D. Bosch, 26 November 2007; V. Dubula, 18 April 2008; S. Ekambaram, 11 January 2008; N. Geffen, 19 April 2008). 
Significant strategic decisions such as the initiation of legal action or civil disobedience often resulted from ideas raised by either Achmat or Heywood with consensus rapidly emerging in the National Executive Committee (NEG) - the highest policymaking body of TAC between National Conferences, later renamed the National Council - and the Secretariat (elected officials who make day-to-day decisions). TAC leaders acknowledge the existence of an informal 'core group' of leaders around Achmat and Heywood that during the early years effectively made the important decisions. Later, this group generated most of the strategic thinking that informed important decisions of the formal structures. Nathan Geffen recounts how important decisions were usually made informally, often over the phone, by a small number of individuals who formed the core of the movement. ${ }^{25}$ (It should be noted that the character of leadership has shifted substantially in recent years with the transition to a new generation of leaders and Achmat's withdrawal from TAC's day-to-day work.)

Both the trust that underpinned decision-making, and the fact that this did not necessarily imply unanimity is illustrated by the example of the decision in 2000 to import generic fluconazole from Thailand in defiance of Pfizer's patent. Planning for this action (named the Christopher Moraka Defiance Campaign in honour of a TAC activist who died of AIDS-related cryptococcal meningitis, unable to afford the life-saving treatment (see Cameron and Geffen, 2005)) proceeded largely without Heywood's involvement. Upon learning of it he was not convinced of its wisdom, fearing that neither TAC's membership nor the general public would understand it. ${ }^{26}$ He acknowledges that Achmat had to 'push that through', but cites it as one of a number of occasions where Achmat's decisive leadership proved vital to TAC's success. ${ }^{27}$

However, as the organisation grew, structures became more formal, members organised in branches became more influential, new leaders rose through the ranks and a significant staff complement managed an increasing number of formal programmes with large budgets. Opposition from the rank and file or in the NEC has overturned significant proposals put forward by Achmat and Heywood. For

\footnotetext{
${ }^{25}$ Interview, N. Geffen (19 April 2008).

${ }^{26}$ Interview, N. Geffen (19 April 2008).

${ }^{27}$ Interview, M. Heywood (17 December 2007).
} 
example, a proposal to accommodate a key ally, the Congress of South African Trade Unions (COSATU), during the 2003 civil disobedience campaign (by renaming the campaign a 'mass protest campaign') was rejected by members and NEC delegates during deliberations. ${ }^{28}$

Despite the fact that the TAC leadership drew heavily on pre-existing networks, it became increasingly diversified, and what Achmat refers to as second and thirdgeneration leaders increasingly became part of the web of trust-based relationships which drove TAC's strategic decision-making. Heywood acknowledges that the building of this second layer of leadership was a deliberate strategy of the earlier leaders, because 'we realised that TAC needed a local and black leadership, particularly HIV-positive persons'. ${ }^{29}$ It was remarkably successful at pulling individuals like Mandla Majola, Vuyiseka Dubula and many others into both formal and informal decision-making processes. Majola is an early TAC member recruited to its first branch in Gugulethu and who then helped organise its earliest branches in the African townships of Cape Town. Majola later became National Organiser and a very prominent leader before returning to local activities as a 'district organiser'. Dubula is a young TAC leader who only joined the organisation in 2002 and later joined the Western Cape provincial staff. She was elected General Secretary - the most senior executive position in the organisation - at its 2008 National Conference and is now considered one of the most prominent AIDS activists in the world. That early leaders were serious about building a new generation of TAC leaders is illustrated by the fact that both Achmat and Heywood relinquished their senior positions (as Chairperson and National Treasurer respectively) and did not make themselves available for re-election at the 2008 Conference. Achmat stood unopposed for the position of Deputy General Secretary. Nonkosi Khumalo, a former TAC staff member who had later moved to the Heywood-led AIDS Law Project (now renamed Section27) was elected Chairperson.

This is not to suggest that the growth of TAC and the bureaucratisation of the organisation did not produce tensions and difficulties. The tension between the requirements of an NGO bureaucracy administering formal programmes and accountable to donors on the one hand and a democratic membership-based political

\footnotetext{
${ }^{28}$ Interviews, Z. Achmat (16 May 2008); N. Geffen (19 April 2008).

${ }^{29}$ Interview, M. Heywood (10 January 2008).
} 
organisation proved very difficult to manage at times. There have been tensions at the regional level between paid staff members and elected leaders serving on bodies like the Provincial Executive Committees (now Provincial Councils). ${ }^{30}$ Tensions also arose over salary differentials between national and regional staff or perceived unnecessary interference in the work of regional staff members by national managers. $^{31}$

While tensions within both the senior leadership and the national management team arose periodically, these have in the main been managed successfully. ${ }^{32}$ During 2007 a serious disagreement arose between the organisation's first elected General Secretary (Sipho Mthathi) and members of her management team on the one hand, and other elected members of the Secretariat, including Achmat, on the other. This led to a breakdown of trust that resulted in Mthathi and several other senior staff members leaving the organisation. In response to the crisis, an Organisational Review Commission was established, which recommended significant restructuring of the governance and management structures of the organisation, including a stronger oversight role for the National Council and Secretariat, aimed at preventing similar incidents (Achmat, 2008:15). The organisation's National Conference adopted these proposals in March 2008. Achmat has repeatedly blamed weak management systems for these problems, ${ }^{33}$ and in his last report as Chairperson to the organisation's 2008 National Congress stated:

Historically, TAC leadership and management survived through trust and cohesion that was built through struggle and friendship. The dramatic growth of TAC and the new and complex political tasks, as well as the day-to-day permanent crisis of implementation of HIV prevention and treatment required a different approach.

...A skilled political leadership in TAC has managed many of these issues over more than nine years. ... To support skilled political leadership and a motivated membership, TAC requires a professional man-

\footnotetext{
${ }^{30}$ Interviews, V. Dubula (18 April 2008); M. Majola (21 April 2008); P. Ramothwala (11 January 2008).

${ }^{31}$ Interviews, V. Dubula (18 April 2008); P. Ramothwala (11 January 2008).

${ }^{32}$ Interview, N. Geffen (18 April 2008).

33 Personal communication with the author.
} 
agement and reliable systems that can function in the absence of individuals in leadership or staff. (Achmat, 2008:15-16)

The difficulties are arguably a result of a hybrid leadership model in which cohesion is maintained both through informal trust-based relationships and formal authority. Despite the difficulties, TAC has managed to make a relatively successful transition from small and highly flexible activist grouping held together by trust and a strong commitment to common goals, to a formal and bureaucratised organisation that nevertheless retains many characteristics of the former. The hybrid model has therefore served it well, but difficulties are likely to persist as it tries to incorporate the strengths of both 'activist movement' and 'corporate NGO' leadership models. Many other AIDS activist organisations, including ACT UP' in the United States, failed to make similar transitions and as a result failed to sustain themselves (see Epstein, 1996; Smith and Siplon, 2006). Others, like Gay Men's Health Crisis, remain strong, but do not have the political and radical character of true activist organisations.

\subsubsection{Mobilising civil society alliances and international solidarity networks}

It is clear that personal networks and relationships constituted a key resource in building the movement. This included the establishment of alliances with other civil society organisations. Heywood's position as director of the AIDS Law Project (ALP) - at that stage a project within the respected Centre for Applied Legal Studies (CALS) at the University of the Witwatersrand, but which has since become independent and has been renamed Section27 - provided access to resources that the fledgling TAC would not have been able to mobilise on its own. The association with Wits and CALS also helped legitimise it, especially in the eyes of donors and scientists. Heywood had in fact been hired to the ALP by Achmat, who became its director in the early 1990s, before leaving to become director of the $\mathrm{Na}-$ tional Coalition for Gay and Lesbian Equality (NCGLE). Important relationships were formed during this time, including through participation in consultative struc-

\footnotetext{
${ }^{34}$ The name ACT UP is sometimes explained as an acronym for AIDS Coalition To Unleash Power, but is universally known simply as ACT UP.
} 
tures established by the Department of Health after the new government came to power in 1994, such as an NGO funding committee and other regular meetings between then-director of HIV/AIDS Quarraisha Abdool Karim and civil society representatives. ${ }^{35}$ Later, after Abdool Karim had left government service and returned to academic research at a prominent HIV/AIDS research centre at the University of KwaZulu-Natal, the relationship with her would remain important. She provided crucial expert testimony in TAC's litigation to compel the government to provide PMTCT. Some time after Achmat left the ALP, Heywood became its director and continued to develop its role as a major advocate for progressive legal reform and HIV/AIDS policy.

When TAC was founded, the intention was not to 'go it alone', but rather to build a broad front of progressive organisations pushing for access to AIDS treatment. It was envisaged that TAC would be a campaign operating within the National Association of People Living with HIV/AIDS (NAPWA) and supported by a range of organisations. Achmat attributes TAC's later split from NAPWA to entrenched interests that resisted its radicalisation and transformation into a massbased movement. White middle-class gay men dominated NAPWA at the time, and the organisation's work reflected this bias. ${ }^{36}$ Achmat and Heywood, supported by NAPWA members like Mercy Makhalamele and Prudence Mabele, attempted to gain political control of NAPWA. According to Achmat they met with fierce resistance from NAPWA leaders, including its director Peter Busse and the chair of its board, Mary Crewe. ${ }^{37}$

Despite the failure to transform NAPWA, the campaign continued to make use of resources provided by existing civil society organisations and to build up a network of supporters. TAC operated largely from the NCGLE offices at first, ${ }^{38}$ and later made use of the resources of the AIDS Consortium, a consortium of HIV/AIDS organisations in Johannesburg. ${ }^{39}$ The founders took care to build relationships with the leaders of civil society organisations, in particular the labour movement, and courted religious leaders. This approach was clearly rooted

\footnotetext{
${ }^{35}$ Interview, Q. Abdool Karim (9 June 2008).

${ }^{36}$ Interview, Q. Abdool Karim (9 June 2008).

${ }^{37}$ Interview, Z. Achmat (30 April 2008).

38 Interview, Z. Achmat (30 April 2008).

${ }^{39}$ Interview, S. Ekambaram (11 January 2008).
} 
in earlier political experience and echoed the activities of the NGGLE under Achmat's leadership. Says Achmat:

...that was also part of my training in the Marxist Workers' Tendency, of understanding that you need to construct the broadest coalition possible to deal with a particular issue. ... [W] understood from Marxism and the 'united front' tactics of Marxism that you constructed the broadest possible alliance under the leadership of the working class, and that's where I learnt my politics from. But also from the UDF, and the days before the UDF, the same approach... ${ }^{40}$

Some of the new organisation's most reliable allies were drawn from Anglican and Catholic church leaders, the ANG-aligned Congress of South African Trade Unions (COSATU) - the largest trade union federation in South Africa - and a number of NGOs like the Children's Rights Centre. TAG has since been at great pains to cultivate and sustain its alliances. In fact, until recently its constitution provided for representation on its National Executive Committee for various 'sectors', like labour, the faith-based sector, women's sector and people living with HIV/AIDS (PWAs) (TAG, 2008).

It is unlikely that the activists would have been able to establish alliances with the labour movement had it not been for the Struggle background of many of the early TAC activists (who would otherwise have lacked credibility with trade union leaders). Heywood acknowledges this: 'Zackie in particular, and myself to a lesser extent, were known before TAC, so quite a lot of the people that we encountered in the early days through TAG didn't see us as Johnny-come-latelies who had suddenly arrived on the scene. They knew us from our involvement before, and trusted us from our basic credentials... ${ }^{41}$ Building these alliances was a deliberately executed strategy:

...from the very beginning we made a point of involving these organisations in TAC so that they could assess for themselves the bona fides of TAC because they had been involved in trying to put the thing together.

\footnotetext{
${ }^{40}$ Interview, Z. Achmat (30 April 2008).

${ }^{41}$ Interview, M. Heywood (17 December 2007).
} 


\begin{abstract}
And you have to invest in these relationships. Very deliberately I keep contact with Vavi [General Secretary of COSATU], with Madisha [President of COSATU at the time] and so on. Even when we don't need them or they don't need us, we talk to them, keep them in the picture so that there's a kind of thread that runs through the years. ${ }^{42}$
\end{abstract}

This strategy of building alliances with other civil society organisations and making use of international solidarity networks was already evident in one of TAC's earliest major campaigns, namely against the pharmaceutical industry's efforts to undermine a piece of legislation designed to enable the government to force down the cost of medicines. The Medicines and Related Substances Amendment Act, passed in 1997, aimed at allowing the government to reduce the cost of patented medicines by allowing for 'parallel importation' (import of the originator company's product by other parties than its designated distributor) and, depending on interpretation, compulsory licensing of pharmaceutical patents. Almost immediately the Pharmaceutical Manufacturers' Association of South Africa (PMA) started opposing the Act, filing notice of motion in 1998 challenging the constitutionality of the Act, as well as its compliance with the Trade-Related Intellectual Property Rights (TRIPS) agreement that forms part of the World Trade Organisationadministered international trade regime, and of which South Africa is a signatory. Only in 2001 did the case come to Court, but after less than a month and a very vigorous campaign by TAC and its allies (both South African and international), the parties settled out of court in what is widely seen as a clear defeat for the pharmaceutical companies (Gleary and Ross, 2002). TAG actively solicited the support of its trade union and other civil society allies and also solicited support from international allies in the form of 'global days of action', etc., in order to bring pressure to bear on the multinational pharmaceutical companies in their home countries and on their supporters in the U.S. government. Commentators have variously ascribed the retreat by the PMA to activist pressure (Friedman and Mottiar, 2005) and to the public relations disaster the case turned into for the companies (Van Niekerk, 2005).

\footnotetext{
${ }^{42}$ Interview, M. Heywood (17 December 2007).
} 
Figure 3.5: The South African government out of step with the world

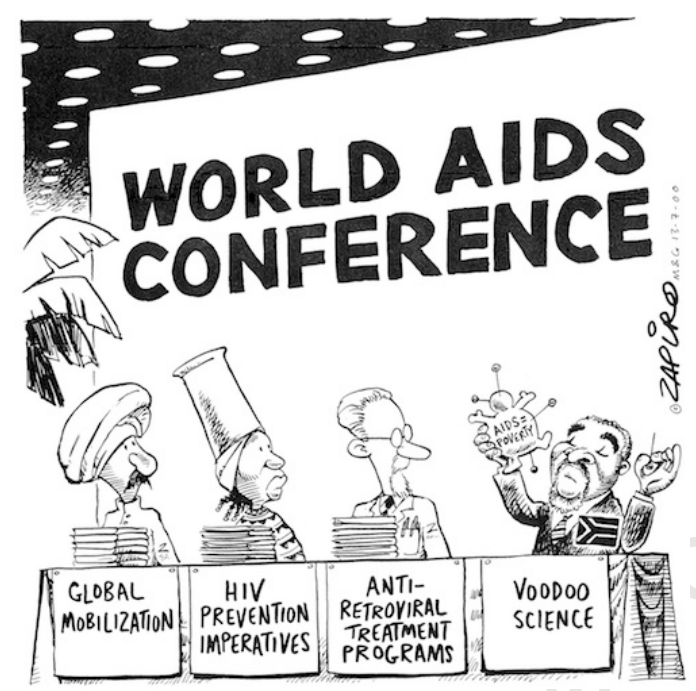

Source: www. zapiro.com. C2000-2012 Zapiro. Printed with permission from Zapiro.com.

A key moment in the establishment of TAC's international solidarity network was the XIII International AIDS Conference, held in July 2000 in Durban. The conference is widely remembered as a turning point in the global AIDS response, with the moral imperative of wider availability of antiretroviral drugs taking centre stage at the conference. ${ }^{43}$ A number of factors contributed to this: the impact of speeches by former South African president Nelson Mandela, teenage activist Nkosi Johnson and HIV-positive judge Edwin Cameron, the fact that the conference was held for the first time in a developing country, but also the visibility of activists and the appeal they made for treatment access. ${ }^{44}$ In his speech, Cameron drew a sharp contrast between his own situation as a wealthy African who is able to purchase life-saving treatment and the millions of AIDS patients in Africa condemned to death by the fact that they cannot do so, saying:

Amidst the poverty of Africa, I stand before you because I am able to purchase health and vigour. I am here because I can pay for life itself. To me this seems a shocking and monstrous iniquity of very

\footnotetext{
${ }^{43}$ Interviews, G. Gonsalves (20 December 2007); S. Abdool Karim (9 June 2008); H. Coovadia (10 June 2008).

${ }^{44}$ Interview, S. Abdool Karim (9 June 2008).
} 
Figure 3.6: President Mbeki: a lone voice for unreason

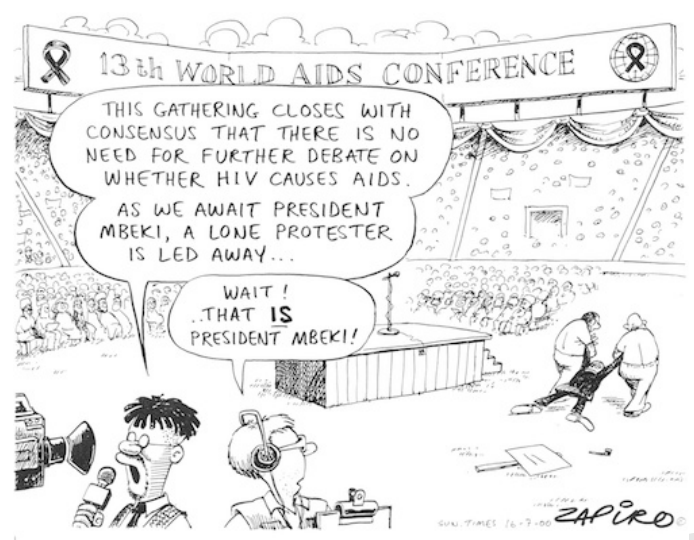

Source: www. zapiro.com. (C2000-2012 Zapiro. Printed with permission from Zapiro.com.

considerable proportions - that, simply because of relative affluence, I should be living when others have died; that I should remain fit and healthy when illness and death beset millions of others. (Cameron, 2000)

Activists and increasing numbers of doctors and scientists echoed this strong moral appeal at the conference. TAG organised a 'Global March for HIV/AIDS Treatment', which was attended by several thousand protesters and actively supported by a wide range of local and international organisations. The march was the point where TAC started garnering wide international attention and was the most significant public action yet for the young movement.

TAC drew heavily on its civil society network, particularly its extensive links with South African trade unions, NGOs and CSOs, to mobilise support for the march and its demands. ${ }^{45}$ The marchers prominently carried banners of many organisations not directly involved in the field of AIDS. ${ }^{46}$ While the principal focus of mobilisation was local, ${ }^{47}$ the activists also drew on (relatively new) links with international activists to mobilise support for the march. It was endorsed by at least 258 organisations from across the world: activist organisa-

\footnotetext{
${ }^{45}$ Interview, M. Heywood (10 January 2008).

${ }^{46}$ See http://www.tac.org.za/photos/durb1.jpg, retrieved on 7 July 2008.

47 Interview, M. Heywood (10 January 2008).
} 
tions, NGOs, academic groupings and trade unions from countries like the US, Canada, the UK and Europe, Bolivia, Argentina, Chile, Brazil, Malaysia, Thailand, Bangladesh, Mexico, Senegal, Kenya, Zimbabwe and Namibia, as well as many from South Africa (Health GAP Coalition, 2000). American activist organisations - principally Health GAP, ACT UP Philadelphia, Treatment Action Group (TAG) and Gay Men's Health Crisis (GMHC) - actively mobilised for the Global March in the weeks leading up to the conference, issuing appeals for support, press releases and setting up a website with campaign materials in English, French and Spanish. ${ }^{48}$ This international mobilisation substantially enhanced the legitimacy of the activists' demands in the eyes of the watching world media.

According to prominent international AIDS activist Gregg Gonsalves, working for the New York-based Treatment Action Group (TAG) at the time, the Durban conference was a galvanising moment for the international treatment access movement, with many US-based groups (like the AIDS Healthcare Foundation) diversifying their programmes based on 'political solidarity' with TAC and patients in the developing world. ${ }^{49}$ For American activists, the Global March explicitly linked back to the political marches at earlier conferences, like the Sixth International AIDS Conference held in San Francisco in June 1990 that was the site of substantial activist mobilisation (see, for example Orkin, 1990). American activists 'reconnected to their own anger' from earlier struggles, an anger that had been dissipating as treatment became widely available in the US. But Gonsalves attributes the greatest impact to the 'vibrancy' and 'political culture' of TAC, which ignited the international activist movement. ${ }^{50}$

From this point onward, TAC and its leaders played an increasingly central role in the international network of activists at the heart of the global treatment access movement, as the African epidemic became a key focus for American and European activists. As Smith and Siplon have argued:

The protest march was notable not only in demonstrating the ability of the South African AIDS activist Treatment Action Campaign (TAC)

\footnotetext{
48 The website is no longer active, but is archived on the Internet Archive at http://web.archive.org/web/20000815095002/http://durban2000march.org/, retrieved on 7 July 2008.

${ }^{49}$ Interview, G. Gonsalves (20 December 2007).

${ }^{50}$ Interview, G. Gonsalves (20 December 2007).
} 
to mobilise thousands of grassroots activists from deeply impoverished communities ... [but also to] work within the global treatment activist movement that had furnished organisations and individuals that had supported TAC in this project. (Smith and Siplon, 2006:81-82)

TAC's most significant achievement in organising the action was perhaps its ability to connect the widely divergent social spheres of South African communities most affected by HIV/AIDS (its grassroots activists consist largely of poor and unemployed Africans, primarily women), the South African workers' movement, transnational social justice movements, aid-oriented Western NGOs such as Medecins Sans Frontieres (MSF) and American AIDS activists rooted in the militant activism and service response mobilised in urban gay communities in the United States during the 1980s.

To be sure, TAC leaders like Achmat had recognised early on that a South African campaign for access to antiretroviral treatment could not succeed without a global campaign. This was partly necessary in order to exercise pressure on the South African state (through the so-called 'boomerang effect'), but more importantly, in order to address impediments like the intellectual property provisions of the international trade regime that operate at the global level. Achmat credits Eric Goemaere of MSF with helping him see this. ${ }^{51}$ Goemaere came to South Africa in 1999 and later set up the first public sector antiretroviral treatment programme in Khayelitsha outside Cape Town in partnership with TAC. At Goemaere's instigation, Achmat attended an MSF conference on access to medicines in Amsterdam in late 1999 at which he met activists already active on intellectual property rights issues, notably Jamie Love and Thiru Balasubramaniam of the Consumer Project on Technology (CPT, now Knowledge Ecology International) as well as American AIDS activists Asia Russell and Paul Davis from ACT UP Philadelphia. ${ }^{52}$ After the conference, Achmat and other TAC activists maintained contact with these international activists - principally by email, including through the IP-Health mailing list moderated by Love. ${ }^{53}$

\footnotetext{
${ }^{51}$ Interview, Z. Achmat (16 May 2008).

${ }^{52}$ ACT UP Philadelphia is one of the few ACT UP chapters still active.

${ }^{53}$ Interview, Z. Achmat (16 May 2008). The IP-Health list has a public archive available at http://lists.essential.org/pipermail/ip-health/. A review of the archive confirms that Achmat was one of its more active members during this period.
} 
TAC later made use of these contacts in mobilising international support during the PMA case described earlier (Smith and Siplon, 2006:98). Activists, for example, targeted the Gore presidential campaign in an attempt to end the US Government's measures against South Africa and in support of the pharmaceutical industry (which included placing South Africa on a so-called intellectual property 'watch list'). Love and CPT also assisted during a complaint laid by TAC with the South African Competition Commission for 'excessive pricing' practises by Glaxo SmithKline (GSK), which led to a settlement in which GSK agreed to voluntarily licence its products to generic manufacturers. ${ }^{54}$ The transnational activist network to which TAC leaders belonged was decisive in changing the intellectual property framework that was hampering access to antiretroviral drugs. Particularly the TRIPS (Trade Related Intellectual Property Rights) agreement, which required World Trade Organisation members to implement patent provisions, including on pharmaceuticals, was an impediment to the availability of generic ARVs. Generic drugs were seen as essential for greater access given the extremely high prices charged by originator companies at the time (see Berger, 2002; 't Hoen, 2002). An important milestone was the Doha Declaration (adopted during the WTO Ministerial Meeting in Doha in November 2001), which recognised the right of developing countries experiencing public health emergencies to override intellectual property rights on pharmaceutical products. ${ }^{55}$ While the Brazilian government took the lead in pushing for the adoption of the declaration, and MSF's international campaign was important in creating a climate in which developed countries could not oppose it, Achmat argues that the Doha declaration could not have occurred without the PMA case and the attention TAC and its allies' campaign focused on the relationship between intellectual property rights and access to AIDS treatment. ${ }^{56}$

While the building of an international solidarity network was therefore driven

\footnotetext{
${ }^{54}$ Interview, J. Berger (16 December 2007).

55 Specific measures available include compulsory licences and parallel importation. The full text of the declaration is available at http://docsonline.wto.org/imrd/directdoc.asp?DDFDocuments/t/WT/Min01/DEC2.doc, retrieved on 14 January 2008; An explanation of the declaration is available at http://www.wto.org/english/tratop_e/ dda_e/dohaexplained_e.htm, retrieved on 14 January 2008.

${ }^{56}$ Interview, Z. Achmat (16 May 2008).
} 
by strategic considerations, personal connections were important even here. Early in 2000, Achmat visited the United States and was put in touch with Gregg Gonsalves and Mark Harrington of the Treatment Action Group (TAG) in New York by Loring McAlpin, a mutual friend who had met Gonsalves and Harrington through ACT UP New York. ${ }^{57}$ Joint TAC/TAG 'treatment literacy' workshops were held early in 2000 in Johannesburg and Cape Town and included American and South African activists as well as medical professionals like Dr Herman Reuter.

According to Gonsalves, it is possible to distinguish between between two 'generations' of American activists with whom TAC established links around the time of the Durban conference. The 'first generation' - activists who had been active in ACT UP and the American AIDS activism of the 1980s (including people like Gonsalves and Harrington) - were at the time less active in international struggles. A ‘second generation' of activists, which included people like Asia Russell and Paul Davis of ACT UP Philadelphia and Alan Berkman of Health GAP, had a greater interest in global treatment access and a better understanding of the intellectual property and trade policy issues. ${ }^{58}$ While TAC leaders had met the 'second generation' activists first, they ended up forming closer relationships with 'first generation' activists, mediated to a significant extent by Gonsalves. Gonsalves has remained the most important link between TAC leaders and American activists. More recently, he played a central role in forging relationships between TAC activists and Asian, African and Eastern European activists, for example organising the International Treatment Preparedness Summit in 2003, out of which the international activist alliances International Treatment Preparedness Coalition and Pan African Treatment Access Movement developed. He later moved to South Africa and helped organise the AIDS and Rights Alliance for Southern Africa.

The closer relationship with 'first generation' American activists may in part be explained by the strong personal bond that developed between, in particular, Achmat and Gonsalves. It is probably also related to greater personal identification resulting from shared experiences, including gay activism and first-hand experience of the HIV epidemic (like Achmat, Gonsalves and Harrington are HIV-

\footnotetext{
${ }^{57}$ Interview, G. Gonsalves (20 December 2007).

${ }^{58}$ Interview, G. Gonsalves (20 December 2007); also see Smith and Siplon (2006).
} 
positive) $\cdot{ }^{59}$

A further network that was significantly strengthened during and after the Durban AIDS Conference is the activist-scientist networks that helped TAC activists establish their credibility in scientific debates and contributed to the politicisation of scientists. A key moment was when South African president Thabo Mbeki shocked delegates at the Conference by citing poverty (as opposed to HIV) as a leading cause of death and stating 'we cannot blame everything on a single virus' (T. Mbeki (2000), cited in Nattrass, 2007:68), which prompted many scientists to align themselves with the activist movement. ${ }^{60}$ For some scientists like Prof Hoosen Coovadia, the denialist attack on science and evidence-based health policy did more to politicise their thinking than the moral claims around treatment access. ${ }^{61}$ Hundreds of leading AIDS scientists signed the Durban Declaration - addressed to President Mbeki and also published in Nature ${ }^{62}$ - affirming the scientific consensus on the viral aetiology of AIDS. Gonsalves points also to Cameron and Mandela's speeches at the conference as key moments in the 'radicalisation' of the scientific AIDS community. ${ }^{63}$ But sustained political engagement by the scientific community from 2000 onwards is attributable to a significant extent to their participation in the emerging 'transnational network of influence' involving key South African and American activists (as well as, especially later, from elsewhere in Africa, Asia and Europe).

These activist-scientist networks (particularly with respect to North American scientists) drew on strong linkages established earlier between activists like Gonsalves and Harrington and the scientific community during the late 1980s and early 1990s, when new drug development, testing and registration, participation in clinical trials, etc. were cent- ral to activist efforts to promote greater access to treatment (more so than pricing and intellectual property). Epstein (1996) and Smith and Siplon (2006) provide excellent overviews of this period of American treatment activism. Gonsalves, for example, was a member of ACT UP New

\footnotetext{
${ }^{59}$ Achmat himself mentions being personally affected by HIV as a factor in the rapport between 'first generation' American AIDS activists and TAC activists.

${ }^{60}$ Interview, S. Abdool Karim (9 June 2008).

${ }^{61}$ Interview, H. Coovadia (10 June 2008).

${ }^{62}$ Nature 406 (6 July 2000), pp. 15-16.

${ }^{63}$ Interview, G. Gonsalves (20 December 2007).
} 


\section{Figure 3.7: The scientific community calls the South African government to account}

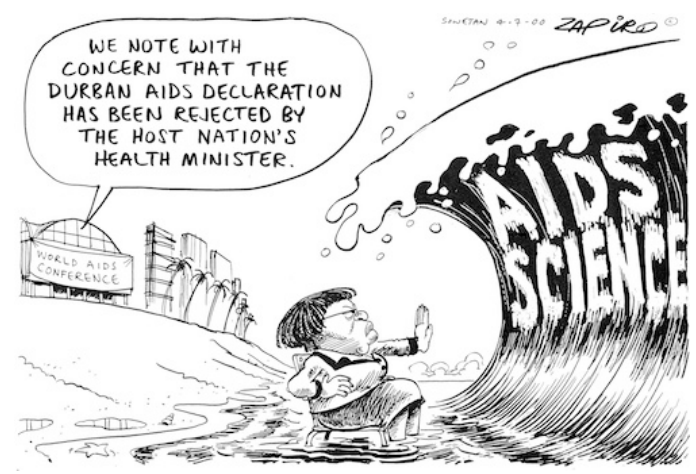

Source: www. zapiro.com. C2000-2012 Zapiro. Printed with permission from Zapiro.com.

York's Treatment and Data Committee from 1990 and Harrington from even earlier. The committee worked to open up scientific structures, with members for example 'crashing' an AIDS Clinical Trials Group Network (ACTG) meeting in 1989, prompting it to set up a Community Constituency Group(Epstein, 1996:286).

Leveraging these international networks has become an important strategy in TAC's mobilisation since 2000, with international solidarity campaigns, including frequent calls for 'Global Days of Action', playing a significant role in its campaigns. ${ }^{64}$ For example, TAC's complaint over Glaxo SmithKline's pricing policies and its campaign to get the South African government to commit to a public sector antiretroviral treatment programme drew heavily on its international solidarity network.

\subsubsection{Influencing the state}

In order to make sense of the networks described in this paper, they should be understood in a more inclusive and dynamic sense than that of 'transnational activist networks' (Keck and Sikkink, 1998). My alternative - 'transnational networks of influence'-includes the sort of networks that Keck and Sikkink describe, but ex-

\footnotetext{
${ }^{64}$ Interview, M. Heywood (10 January 2008).
} 
pands the notion to include actors such as scientific communities, diplomats and bureaucrats active in international organisations and even extending into the institutions of the target state. When from these networks emerge a consensus on a set of moral or policy ideas and when they are deliberately employed to influence the broader society (in particular the state, as the embodiment of society's policy decision-making), it makes sense to think of them as the foundations of 'coalitions' in the sense used by Leftwich and Hogg (2007), i.e. sets of actors or groups acting in accordance with shared goals (also see Yashar, 1997:15).

The networks of influence that formed the basis of the emerging AIDS treatment coalition extended into the South African state and the ruling party. A number of ANC parliamentarians were sympathetic to TAC (or at least open to its messages), even at the height of government denialism, including Barbara Hogan, Pregs Govender, Andrew Feinstein and Essop Jassat. Mark Heywood maintained a cordial relationship with Nono Simelela (Chief Director: HIV/AIDS during the period of greatest conflict between TAC and the government) and she even attended a conference organised by the organisation. ${ }^{65}$ The President of the Medical Research Council (MRC), Malegapuru Makgoba, displayed a high degree of independence from the government, and at times aligned himself with TAC. For example, during a controversy over the MRC's 2001 report into mortality (Dorrington et al., 2001), which the government tried to suppress, he refused to withdraw the report, despite intense pressure (see Nattrass, 2007:92-93).

Clearly, the South African state did not operate as a monolithic entity that simply resisted or yielded to external pressure. Confusion and reversals in South African AIDS policy may be explained in part by shifting patterns of power and influence within state, ruling party and civil service institutions. An example of policy confusion resulting from internal disagreement was when the Treasury increased the budget for HIV/AIDS programmes substantially in the 2003/2004 budget - apparently with a view to funding a national antiretroviral treatment programme - but well before the cabinet had agreed to such a roll-out and while the President and Minister of Health maintained their staunch opposition to such a programme. Even the decision to implement the programme taken in August of that year is widely considered a cabinet revolt (Nattrass, 2007) of which neither

\footnotetext{
${ }^{65}$ Interviews, M. Heywood (18 December 2007 and 10 January 2008).
} 
the Minister nor the President was supportive. Despite the antiretroviral treatment programme, the Minister continued to express scepticism about antiretroviral drugs and support for alternative and untested 'treatments' (see Geffen, 2005; 2010).

A rapprochement occurred between activists and the government in 2006 during the Minister's prolonged illness. Under the leadership of Deputy Minister of Health Nozizwe Madlala-Routledge, with the support of Deputy President Phumzile Mlambo-Ngcuka, a new National Strategic Plan for HIV/AIDS - which included ambitious targets for the expansion of antiretroviral treatment and other policies to which the Minister was known to be hostile - was adopted in what the media often described as a 'palace coup'. Following her return, the progress was rapidly reversed and tensions flared up, culminating in the dismissal of the Deputy Minister by Mbeki.

The state mirrored within itself the complexities and tensions of the political battles surrounding the societal response to AIDS, and the emerging AIDS treatment coalition had both allies and opponents within state institutions at all levels. The extent of disagreement within the African National Congress with Mbeki and Tshabalala-Msimang's approaches became clear after Mbeki was removed from power and his successor immediately dismissed Tshabalala-Msimang from her post and replaced her with well-known TAC ally Barbara Hogan.

\subsubsection{Illustrating networks of influence}

In order to illustrate the 'network of influence' forming the basis of an AIDS treatment coalition sketched in the preceding sections, a number of a simplified network diagram is presented. Figure 3.8 shows the most important links in the network around the Treatment Action Campaign. ${ }^{66}$ It should be noted that this is not intended to be an exhaustive network analysis (for which I do not possess sufficient data), but rather to illustrate the points made in this paper. The nodes and relationships ('edges') included in the network diagram reflect the author's interpretation of the recollections of key informants that were interviewed in the course

\footnotetext{
${ }^{66}$ All visualisations and analysis conducted using Visone version 2.3.4 (Baur et al., 2002; Brandes and Wagner, 2004; Brandes and Kenis, 2006).
} 
of this research. Interviewees were asked extensively about the relationships they formed and which relationships they consider important to their work, but since informants were selected not primarily with a network survey in mind, there is a substantial risk of selection bias. The attempt to deduce the relative importance of nodes in the network structure based on this data therefore implies a certain circularity. Nevertheless, I believe the exercise to be useful, if only for illustrative purposes.

For reasons of economy, certain organisations are included as nodes in the network (represented by diamonds in the diagram) even though the real unit of analysis is individuals (represented by rounded squares in the diagram).

Figure 3.9 shows the same network, but reordered using a 'stress minimisation' algorithm and uniform link length, so as to better reveal the position of nodes in the network. The size of node representations are scaled according to their 'betweenness centrality', which is one measure of the importance of a node in 'brokering' interconnections between disparate network components. It immediately becomes clear that certain individuals, notably Zackie Achmat, Nathan Geffen and Gregg Gonsalves (represented by the nodes labelled ' $\mathrm{ZA}$ ', 'NG' and 'GG'), are unusually important in connecting the various clusters of the network. How few nodes have significant brokerage roles is further illustrated in Figure 3.10. These results match the perceptions of many of the informants interviewed.

\subsection{Towards consensus on AIDS treatment ac- cess}

I have argued that the unique personal histories, personalities and individual social networks of certain individuals are critical to understanding the achievements of TAC. In addition, I have pointed to its embeddedness in the political traditions of South African liberation politics and the important role of the 'network of influence' that the organisation was able to build and sustain in explaining its success at fostering a wide consensus that treatment access is a moral right.

These arguments are supported by the evidence from the history of AIDS activism in South Africa. It has been shown in this chapter that the founders of TAC 
Figure 3.8: Network of influence around the Treatment Action Campaign

$\underline{\varphi}$

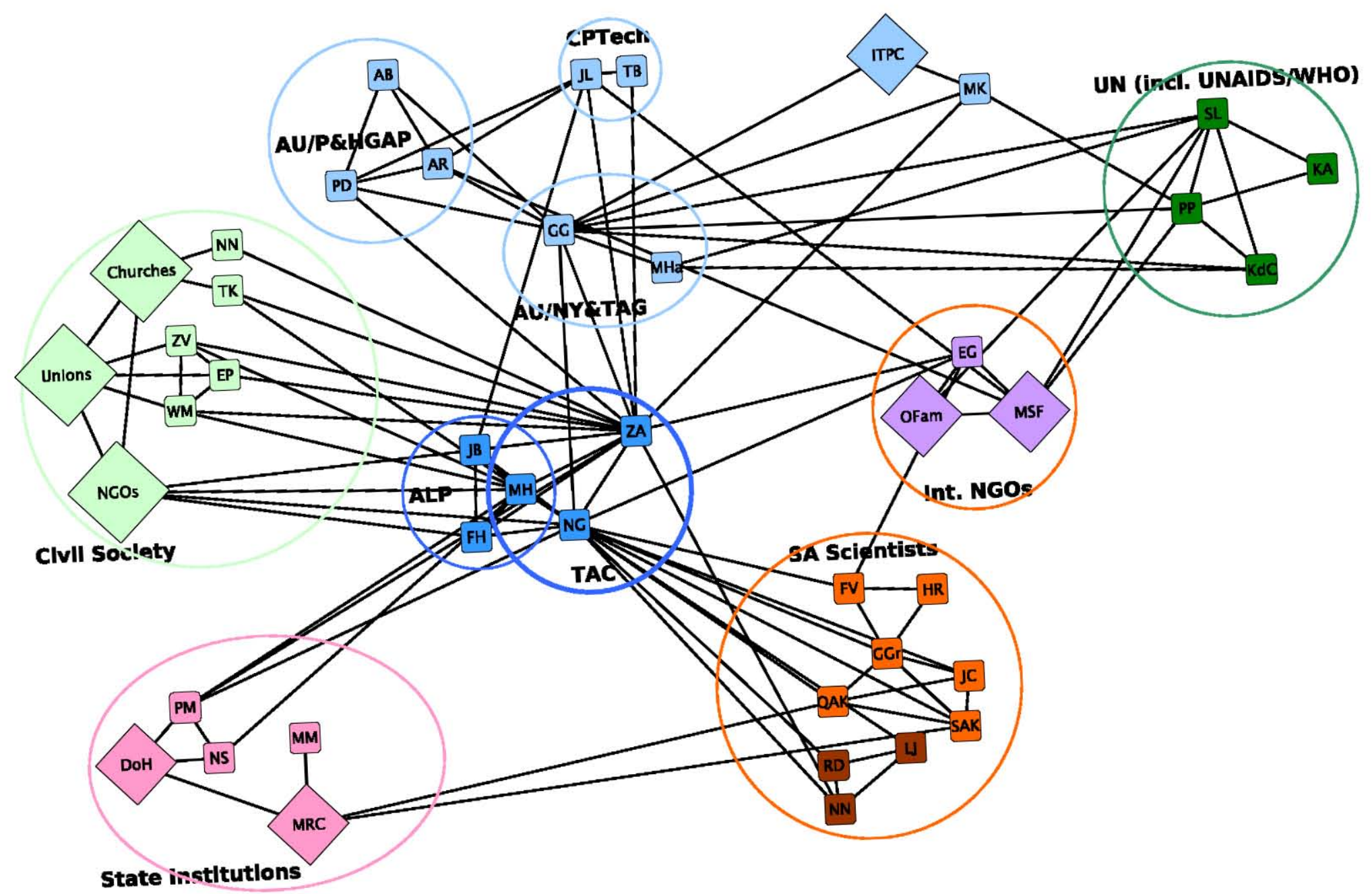


Figure 3.9: Network diagram showing 'betweenness centrality' to highlight brokerage roles

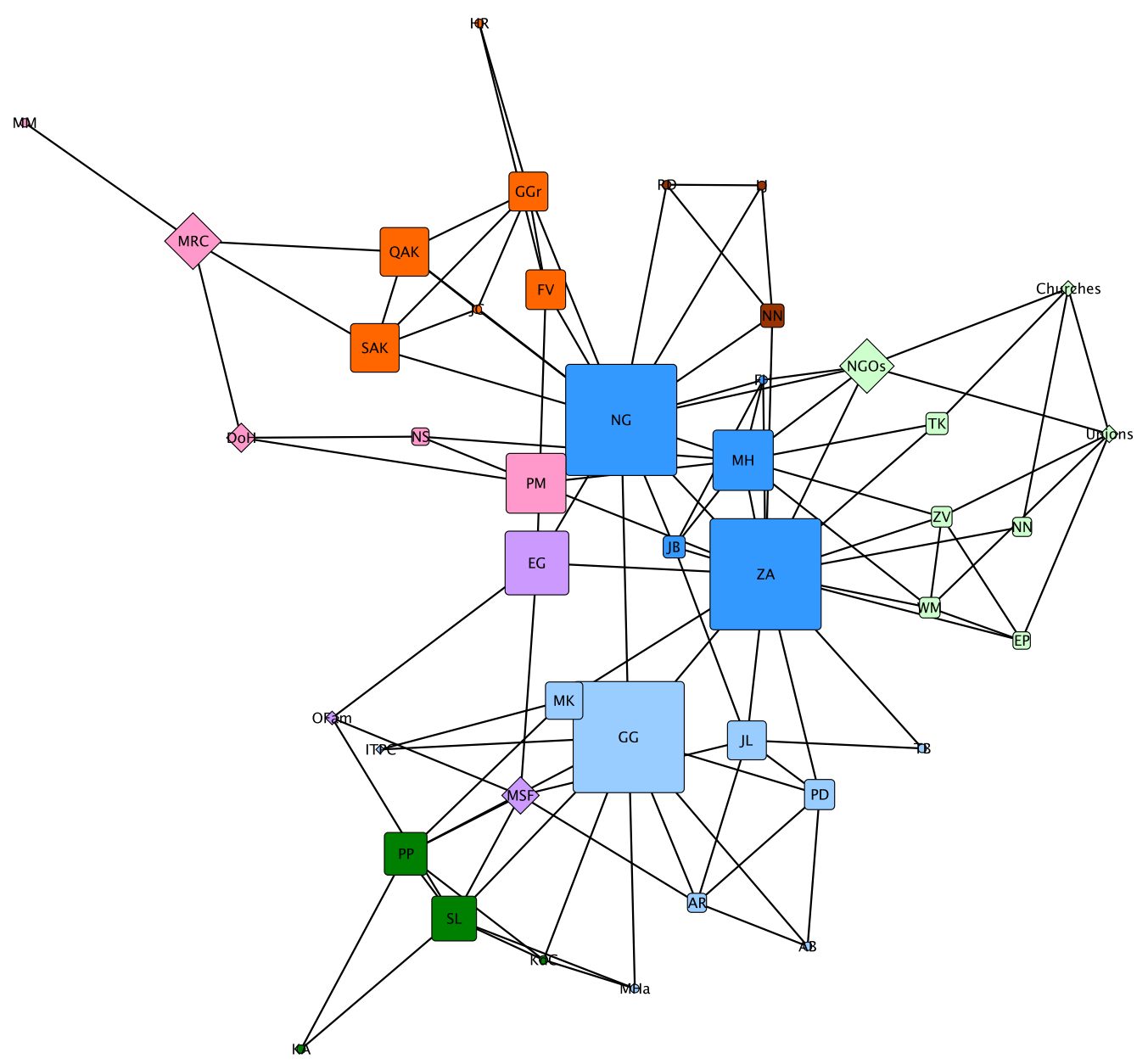




\section{Figure 3.10: Betweenness centrality as a measure of 'brokerage' Betweenness (standardized)}

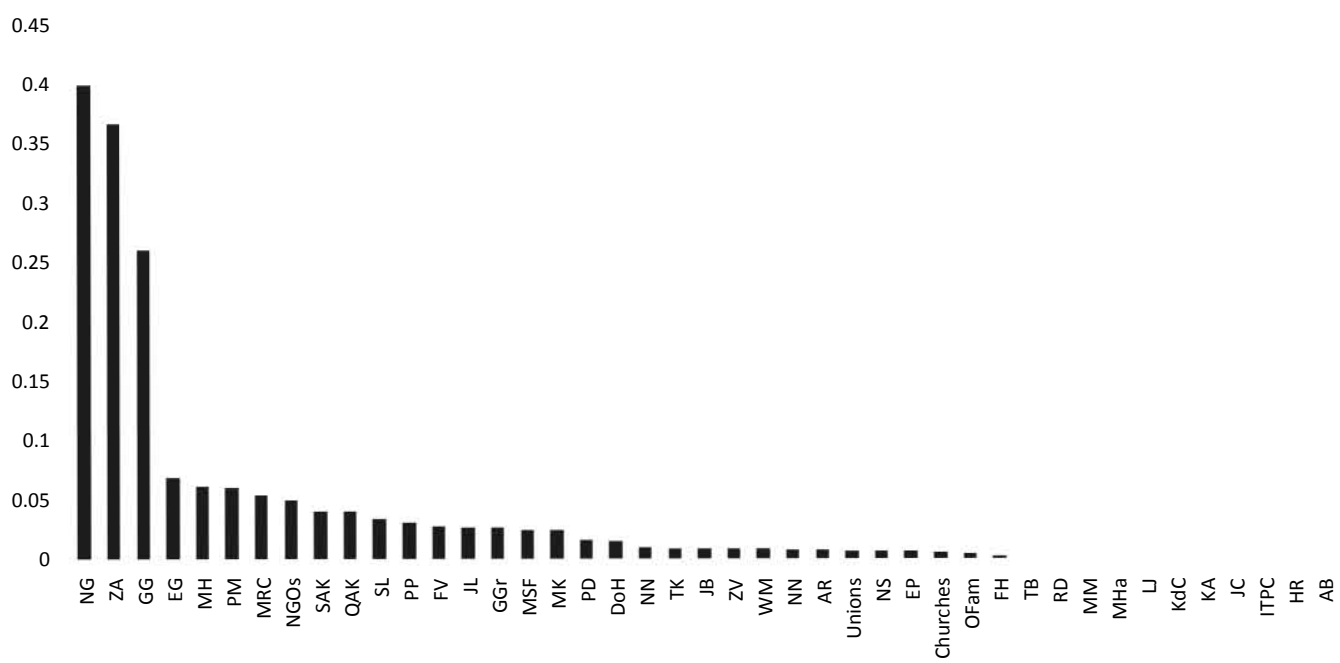

drew extensively on personal networks to mobilise resources for the movement and also built activist and solidarity networks in order to mobilise support and influence. It is also clear that the history of AIDS activism is intimately tied to a number of key personalities and that even where 'structural' patterns can be discerned (such as the utilisation of transnational networks of influence), these were often made possible by the unique connectedness and unusual capabilities of those individuals.

But in order to understand the impact of TAC, we must look beyond networks - which functions mainly to mobilise resources (including symbolic and informational resources) to the emergence of coalitions based on consensus. TAC's campaigns were informed by a desire to produce a 'moral consensus' on treatment access and in my view was instrumental in establishing an AIDS treatment coalition built on this emerging consensus.

Despite the visibility of mobilisation in the form of street protests and (on a limited number of occasions) direct action and civil disobedience, TAC's strategy was not primarily to compel a change of course through direct pressure, but rather to drive home its moral claims. Protest action is then but one component in a larger strategy aimed at building a moral consensus in society and thereby exerting both direct and indirect pressure. This is evident from its tendency to pursue its campaigns through a variety of strategies, often aimed at legitimating a central 
moral claim rather than simply exerting pressure. For example, its campaigns against 'excessive pricing' and 'patent abuse' by pharmaceutical companies were anchored by strong moral appeals.

It mobilised alliances with other civil society actors - particularly those with a high degree of popular legitimacy - and framed its moral claims within a 'rightsbased discourse' that enjoys wide legitimacy in South Africa and internationally. It is particularly powerful in the South African context where the human rights framework expressed in the post-apartheid Constitution is the outcome of a long popular struggle. (This human rights orientation arguably found its most compelling expression in the litigation by which TAC forced the South African government to make PMTCT widely available.) The fact that it could claim to speak for a broad social alliance, rather than simply on behalf of those who are HIV-positive, significantly enhanced its moral authority. Its opponents' attacks on its legitimacy and credibility - most notably the Mbeki camp painting it as controlled by pharmaceutical companies and racists - failed largely because it had successfully established its legitimacy by these means.

TAC's moral and symbolic victories in the 'the court of transnational public opinion' (Olesen, 2006), and its building of an inclusive coalition in support of treatment access, may have been decisive in the defeat of state-supported AIDS denialism and the wide introduction of antiretroviral therapy in South Africa. However, the movement is now faced with a new set of challenges: ensuring continued progress in antiretroviral treatment delivery, revitalising a weak public healthcare system and improving HIV prevention. Paradoxically, the end of denialism removes a source of public support and attention, while the new generation of leaders must continue to deal with the difficulties of bureaucratisation. While it has a rich political repertoire and much goodwill to draw upon, its continued success is by no means assured. 


\section{Chapter 4}

\section{Givil society leadership and HIV prevention in South Africa ${ }^{1}$}

\subsection{Introduction}

This chapter revisits the 'civil society leadership' of the Treatment Action Campaign described in chapter 3. Specifically, it examines whether TAC's mobilisation in Cape Town impacted appreciably on HIV/AIDS prevention efforts. Since Cape Town was the first city in which TAC built its movement, and the Khayelitsha township outside Cape Town probably remains its strongest support base (it was also the site of the TAC ally MSF's antiretroviral treatment clinic around which much of the community mobilisation and treatment education activities took place), it is appropriate to evaluate the organisation's impact in this community. The analyses and arguments in this chapter draw on a joint paper with Nicoli Nattrass (Grebe and Nattrass, 2012), although it significantly extends them and shifts the focus to the impact of TAC.

The quantitative analyses presented here explore the potential impact of TAC on both beliefs about HIV/AIDS and sexual behaviour in a sample of young adults (mostly African and coloured) collected as part of the fifth wave (2009) of the Cape Area Panel Study (CAPS). ${ }^{2}$ The sample, measures and statistical meth-

\footnotetext{
${ }^{1}$ This chapter draws substantially on a joint paper with Nicoli Nattrass previously published in the journal AIDS and Behavior (Grebe and Nattrass, 2012).

${ }^{2}$ For more information on the CAPS study, visit http://www. caps. uct.ac. za/.
} 
ods employed in this analysis are described in detail in the Methods section (section 4.3 on page 109). Before doing so, however, I will set out the background to this in the form of a brief description of TAC's activities that can reasonably be expected to have impacted on beliefs about HIV (specifically the conspiracy beliefs about the origins of AIDS that were promoted by Thabo Mbeki and his health Minister Manto Tshabalala-Msimang) and sexual behaviour (specifically the use of condoms during sexual intercourse). Why should AIDS origin conspiracy beliefs be considered an appropriate outcome to measure 'civil society leadership'? First, these conspiracy beliefs beliefs are highly relevant to HIV/AIDS prevention efforts: they imply a general scepticism towards the mainstream science on HIV/AIDS and may lead individuals to reject the HIV prevention messages based on a conventional scientific approach. AIDS conspiracy beliefs have been associated in earlier research in the United States with lack of condom use (Bogart and Thorburn Bird, 2003; Bogart and Thorburn, 2005; Ross et al., 2006; Bogart et al., 2010a), not testing for HIV (Bohnert and Latkin, 2009) and not adhering to antiretroviral treatment (Bogart et al., 2010b), while in South Africa they have been associated with never testing for HIV (Bogart et al., 2008; Tun et al., 2010). A bivariate analysis of the CAPS data confirms an association between AIDS conspiracy beliefs and never having tested for HIV (see Results - section 4.4 on page 114). Second, TAC actively contested the AIDS denialist and conspiracy theory-infused discourse on HIV/AIDS of Mbeki and his supporters. A model that predicts AIDS conspiracy beliefs and that includes contact with TAC therefore allows one to evaluate the success of TAC in combating this anti-science discourse (that had the power of high office of state behind it). Further, investigating the potential impact of TAC on condom use allows one to evaluate the success or failure of TAC's direct HIV/AIDS prevention efforts. It is therefore en evaluation of the success of TAC's 'leadership' both in the discursive 'information war' and in HIV prevention at community level.

The analyses take the form of multivariate logistic regressions, first on AIDS conspiracy beliefs and then on reported condom use at the most recent sexual encounter. In each case, a series of models are first presented that are stratified on race and gender (like in Grebe and Nattrass, 2012) and then with a number of interaction terms of race and gender on other variables (not previously reported) 
in order to elucidate the substantial race and gender differences observed in the influence of measures on the dependent variables. A number of bivariate analyses are also reported. Why the interest in race and gender? The literature suggests a link between race and AIDS conspiracy beliefs in the United States (e.g. Bogart and Thorburn Bird, 2003; Ross et al., 2006). But, even a cursory overview of the CAPS data shows that Africans in the sample are much more likely to hold AIDS conspiracy beliefs (19.7\% of African respondents scored averages of 'agree' or 'strongly agree' on an index of AIDS conspiracy beliefs while the proportion of non-Africans was only $2.6 \%$ ) and that men are much more likely to endorse conspiracy beliefs than women (25.8\% of African men vs. $14.8 \%$ of African women). Niehaus and Jonsson (2005) found that conspiracy accounts in South Africa were strongly gendered. Africans are also more likely to report using condoms than non-Africans at their most recent sexual encounter $(64.1 \%$ of Africans vs. $35.9 \%$ of non-Africans). Furthermore, TAC's mobilisation was most vigorous in African communities. So, we would expect race to be an important determinant of both conspiracy beliefs and of condom use in the multivariate models. Furthermore, race and gender are likely to substantially affect the impact of familiarity with TAC in the models.

Finally, before proceeding to setting out the background to the quantitative analyses, it is important to define what is meant by 'AIDS origin conspiracy beliefs' and 'AIDS denialism'. Then-President Thabo Mbeki and his health minister promoted both AIDS conspiracy theories and AIDS denialist claims (see section 4.2). AIDS origin conspiracy theories refer to beliefs that AIDS was deliberately man-made (often with the supposed aim of selectively killing black people), e.g. by the American government or the CIA. The specific way in which AIDS conspiracy beliefs were measured in the CAPS survey will be described later. AIDS denialism refers to claims to the effect that AIDS does not exist, or is not caused by HIV. For the purposes of this analysis, AIDS denialism can be defined as making both the claims that (1) HIV is harmless and (2) that antiretrovirals do more harm than good (both claims that Mbeki made). There is a strong link between AIDS denialism and AIDS conspiracy theories: usually AIDS denialists explain the failure of their views on HIV and AIDS to gain any traction within mainstream science as the function of a conspiracy involving the international pharmaceutical industry, 
governments and scientists. AIDS denialist beliefs and AIDS conspiracy beliefs were positively correlated in the CAPS data $(r=0.282 ; p<0.000)$.

\subsection{Background: The challenge to AIDS science and TAG's resistance}

\subsubsection{Promotion of AIDS denialism and conspiracy beliefs by political leaders}

During the late 1990s and early 2000s, then-President of South Africa, Thabo Mbeki, adopted a sceptical position with respect to conventional AIDS science - including the viral aetiology of AIDS, the scale of the HIV/AIDS epidemic and the efficacy of antiretroviral therapy (Nattrass, 2007; Geffen, 2010). The President's early pronouncements, both public and private (he later 'withdrew' from the public 'debate' about AIDS), were characterised by anti-colonial and antiWestern rhetoric, designed to appeal to African nationalist sentiments and latent anger about apartheid. The scientific view of AIDS as a viral epidemic was portrayed as rooted in racist Western stereotypes about the sexuality of Africans, antiretroviral therapy as toxic and only promoted in order to advance the interests of multinational pharmaceutical companies and the dismissal of untested traditional remedies as indicating a racist disdain for 'African solutions'. In this the President was strongly supported by his Health Minister, Manto Tshabalala-Msimang, who became the primary spokesperson for AIDS denialist arguments and arguments against antiretrovirals and in favour of alternative interventions (including nutritional supplements and African traditional medicine). She appointed, for example, the unqualified AIDS denialist Roberto Geraldo as a ministerial adviser (see Nattrass, 2007) and refused to take action against the vitamin entrepreneur Matthias Rath when he illegally treated AIDS patients with vitamin supplements and conducted unsupervised 'clinical trials' (Goldacre, 2010:131-146).

The President and supporters like Tshabalala-Msimang and the youth leader Peter Mokaba deployed arguments founded in a profound suspicion of the motives of Western experts and agencies (for example suggesting that there existed an in- 
Figure 4.1: Tshabalala-Msimang promoted conspiracy theories

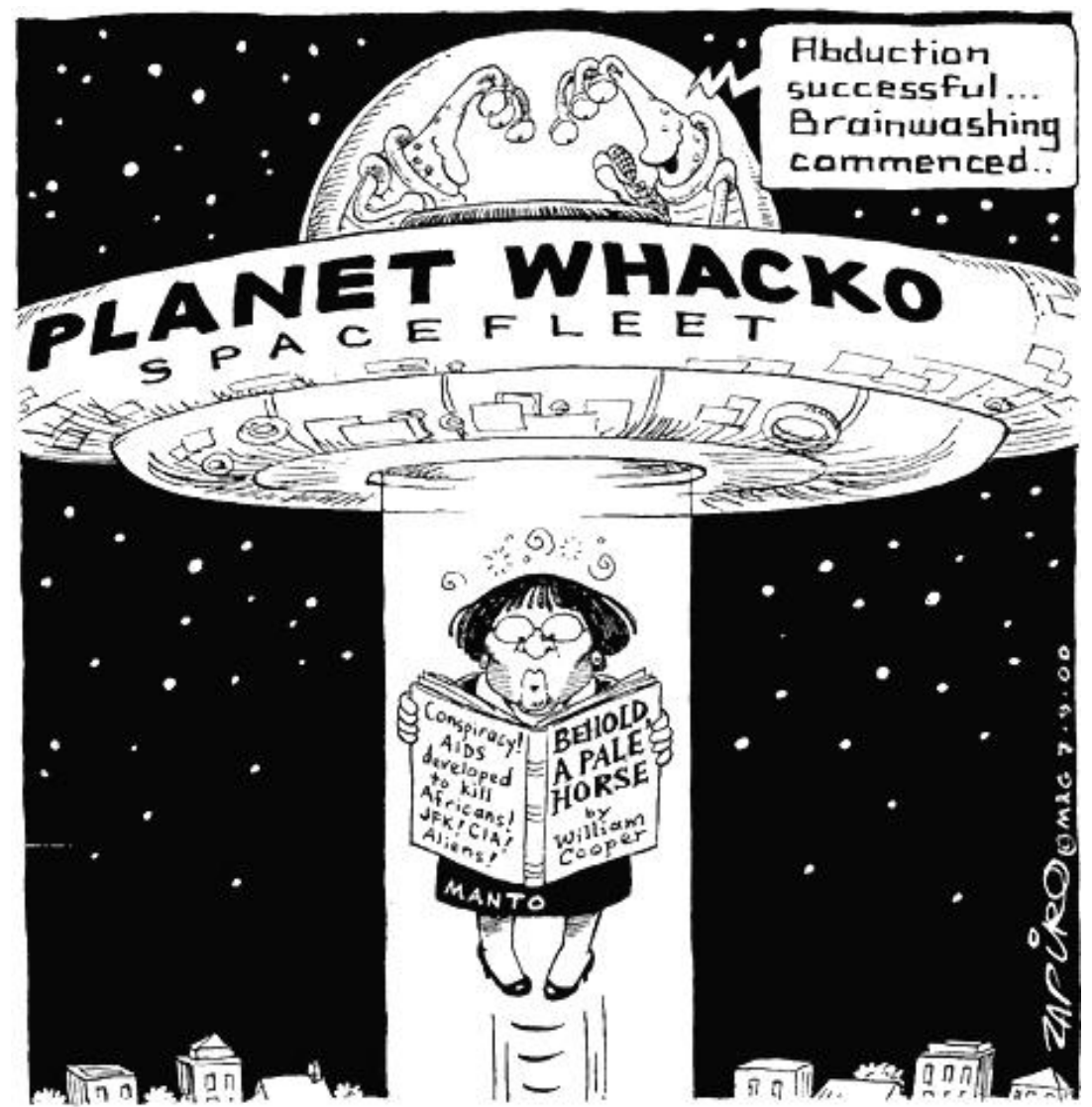

Health minister Manto Tshabalala-Msimang reportedly circulated extracts of a book written by American right-wing conspiracy theorist William Cooper (see Nattrass, 2012:23)

Source: www. zapiro.com. (C2000-2012 Zapiro. Printed with permission from Zapiro.com. 
ternational conspiracy led by the American CIA to further the interests of pharmaceutical manufacturers) and allied themselves with various groupings representing nationalist-conservative and traditionalist interests, such as African traditional healers, in contesting mainstream science. This is perhaps somewhat paradoxical given the Mbeki administration's perceived anti-populist, pro-business and probourgeois leanings. (Somewhat strangely, however, many of the central figures in Mbeki's conversion to AIDS 'dissidence' and in the promotion of alternative 'cures' or 'treatments' for AIDS were white South Africans like Anita Allen and Anthony Brink or European immigrants like Tine van der Maas and Matthias Rath. Furthermore, most of Mbeki's arguments were derived from those of American and Australian AIDS denialists like Peter Duesberg, David Resnik and Eleni Papadopulos-Eleopulos.)

Under Mbeki and Tshabalala-Msimang's leadership, the state actively resisted demands to provide antiretroviral drugs (both to prevent mother-to-child transmission of HIV and to treat AIDS) and the response to AIDS became highly politicised with the Treatment Action Campaign leading an intense campaign against state-supported denialism and in favour of science-based interventions. Despite the debate acquiring racial overtones (perhaps not surprising given the highly racialised politics of South Africa), actively exploited by Mbeki and his allies, the TAC (a largely black movement) allied itself with the largely white and middleclass-dominated scientific establishment and media in intensely contesting state denialism and the epistemological basis of it.

The science-based arguments of TAC and its allies eventually prevailed: the state reversed its policy and implemented an antiretroviral treatment programme in 2004, although the Health Minister's support for it was at best half-hearted (and neither she nor Mbeki ever recanted their denialist views) until Thabo Mbeki lost power and his successor replaced her with Barbara Hogan, who held conventional views on AIDS and who energetically pursued implementation of the antiretroviral treatment programme. Hogan's successor, Aaron Motsoaledi, is a doctor who has continued to pursue science-based AIDS policy. It must, however, be noted that models with conservative assumptions indicate that the refusal to implement antiretroviral therapy resulted in at least 330000 avoidable deaths in South Africa during the period 2000 to 2005 (Nattrass, 2008a; Chigwedere et al., 2008). The 
burden of avoidable morbidity, by extension, would be even greater.

Nevertheless, it is to be expected that AIDS denialist arguments and AIDS conspiracy theories, vigorously promoted by a number of powerful political leaders, would have found some purchase in the broader population, especially among those whose political attitudes rendered them a 'natural constituency' for Mbeki. We attempted to capture this dimension in the regression analysis in Grebe and Nattrass (2012) by including a variable indicating that a respondent expressed greater trust in Tshabalala-Msimang on HIV/AIDS than in her successor Barbara Hogan. ${ }^{3}$

\subsubsection{Gontesting denialism and mobilising through 'treat- ment literacy'}

TAC was founded in Cape Town and built its first branches in the African townships outside Cape Town, especially Khayelitsha, Nyanga, Langa and Gugulethu. The mobilisation of communities was further strengthened by the fact that the first public sector antiretroviral therapy clinic was set up in Khayelitsha by Medecins Sans Frontieres (MSF) in partnership with the Western Cape provincial government. The partnership between TAC and MSF, described in chapter 3, meant that the organisations could cooperate in attempts to mobilise the residents of Khayelitsha to access the health services offered and to build a cadre of activists to advocate for expansion of treatment access. The organisations shared office space and volunteers, with most counsellors working in MSF's treatment project being recruited from among TAC activists. TAC also used MSF's clinic as a recruiting ground for its Khayelitsha branches and the organisations collaborated on 'treatment literacy' workshops, which reached a very substantial number of people over the years. A good description of this model is provided in Jonny Steinberg's book Sizwe's Test/Three-letter Plague, which provides a detailed account of the cooperation between MSF and TAC in establishing an antiretroviral clinic in the rural Lusikisiki district of the Eastern Cape and building an activist movement to help spread the word about the benefits of antiretroviral treatment (Steinberg, 2008).

\footnotetext{
${ }^{3}$ This variable was first suggested by Nicoli Nattrass in an unpublished draft paper written before we collaborated on this analysis.
} 
A major component of TAC's community mobilisation work centred around its patient and activist education efforts, usually referred to as 'treatment literacy'. This involved organising workshops in which TAC staff (the Khayelitsha office, initially the provincial headquarters and later a district office, had a full-time 'treatment literacy coordinator' from very early on), experienced volunteers and invited experts (like doctors and nurses) taught the science of HIV pathogenesis and treatment. This resulted in the remarkable phenomenon that many TAC activists with no or very little formal schooling (and who had often never held formal employment) being comfortable speaking about the details of HIV / AIDS treatment, using terms like 'CD4-count', 'viral load', 'reverse transcriptase' and the names of medications as if these were everyday concepts. The founders of TAC saw these education efforts both as a way of preparing the population for AIDS treatment - by breaking down the fear and stigma surrounding the disease and promoting understanding of what treatment can and cannot do - and as an important mobilisation tool. Jack Lewis, a TAC founder who also established and managed the Community Health Media Trust (now Community Media Trust), which produced audiovisual treatment literacy materials in close collaboration with TAC, describes the rationale behind treatment literacy in a way that illustrates the political goals:

The point is that [in the absence of a structural social revolution], you have to then content yourself with helping [each person] have an individual social revolution through the power of science. And that's what's so fantastic about AIDS, you know, we've seen it in a man who watched his wife die and was consulting traditional healers. And then he meets TAC and MSF and he can now talk, certainly better than all the nurses - $99 \%$ of the nurses and most of the doctors - about first-line and second-line treatment and side-effects and how different combinations are put together, about ARV science and HIV science, and he has the ...the liberating effect on him as an individual. It's stupendous, there aren't words to describe it, until you've seen for yourself the power of this thing. Science is a fantastic liberating force, and that is what people don't understand about TAC. ...If you could do mass scientific literacy around health in general, and let people understand how science is and what it does and how it works, that can 
cause a movement as well in many ways, because it's a fantastically powerful, liberating thing. ${ }^{4}$

These extensive efforts to promote a sophisticated and science-based understanding of HIV/AIDS resulted in a substantial cadre of TAC activists living in the African townships of Cape Town and equipped to counter misinformation spread by political leaders, 'alternative' or traditional healers and entrepreneurs. TAC members received regular education through their branches and were encouraged to engage their families, friends and neighbours on HIV/AIDS. Some were recruited to act as more formal treatment literacy practitioners and after more in-depth training received small stipends to conduct workshops in workplaces, schools, clinics and HIV patients' support groups. In addition, the organisation engaged in a combined educational and propaganda effort in the media, which had its most prominent expression in the television series Beat It! (later Siyangqoba Beat It'), produced by the Community Media Trust (CMT) and broadcast on national television. The close links between CMT and TAC meant that the organisation received a mass media platform in which not only a scientific understanding of the disease, but also TAC's political perspective on it was promoted. This was especially true for the first series of the programme, which was broadcast on the independent E-TV channel, during which the producers had the freedom to openly criticise state policy and give TAC activists very prominent exposure ${ }^{5}$ (and which coincided with the period of the worst state-supported AIDS denialism). For a detailed history of Siyangqoba Beat It!, see Hodes (2010).

TAC saw this educational function as a key element of its work, and it is therefore not unreasonable to assume that it could measurably impact on the beliefs about HIV and sexual behaviour of young adults in the city where it started its work and has built the strongest structures.

\subsection{Methods}

This chapter presents results from a cross-sectional analysis of the December 2010 internal release of data from the fifth wave (2009) of the Cape Area Panel Study

\footnotetext{
${ }^{4}$ Interview, J. Lewis (24 November 2007).

${ }^{5}$ Interview, J. Lewis (24 November 2007).
} 
(CAPS). The CAPS is a longitudinal study of young adults in metropolitan Cape Town, South Africa.

For the first wave of the study, a two-stage sample was employed. Primary sampling units (geographical Enumerator Areas as defined in the 2000 Census) were stratified on main population group (African, coloured, white). PSUs were then randomly selected within each stratum and households randomly within each PSU. Weights were calculated to correct for sample design and household nonresponse. A total of 4752 young adults and adolescents were interviewed from the selected households. The panel of selected households and young adults were then re-interviewed in several waves (2003/4, 2006 and 2009). The fifth wave (2009) collected a range of demographic, labour-market, health, sexual behaviour and attitudinal information from 2901 young adult respondents, ranging in age from 19 to 29.

The sample has become less representative over time, owing to attrition, especially among white respondents, but it is still broadly representative of urban Africans and coloureds. Table 4.1 on page 122 summarises the race and gender breakdown of the sample.

Weights were calculated and supplied with the dataset. ${ }^{6}$ These are to correct for sample design and non-response (both initial and attrition) allowing analysis that remains representative for urban Cape Town, assuming that household nonresponse within each PSU and young adult non-response/attrition was random. Weights were not calibrated for representativity on race, gender or other demographic variables. This is a somewhat problematic assumption, since non-response and attrition may be related to factors such as labour market participation and social stability (e.g. propensity to migrate).

As in Grebe and Nattrass (2012), multivariate logistic regressions were used to predict AIDS conspiracy beliefs and condom use behaviour. The first series of models (models 1-5, reported in tables 4.2 and 4.3 are regressions on a binary dependent variable with value 1 if the respondent scored more than 9 on an AIDS conspiracy belief index generated by summing values of responses to three statements about the man-made origins of AIDS (each on a 5-point Likert scale with

\footnotetext{
${ }^{6}$ Weights were calculated by Prof. Martin Wittenberg of UCT's School of Economics and DataFirst research data archive.
} 
$1=$ strongly disagree and 5=strongly agree). The three statements are 'AIDS was invented to kill black people', 'AIDS was created by scientists in America' and 'AIDS was deliberately created by humans'. Models 1-4 are stratified by race and gender, while model 5 is an unstratified model with gender interactions (run for Africans) to investigate the size and significance of gender differences.

The second series of models (models 6-10 in tables 4.4 and 4.5) are regressions on a binary dependent variable with value 1 if the respondent reported using a condom during their most recent sexual encounter. Models 6-9 are stratified by race and gender, while model 10 is an unstratified model with gender interaction terms (run for Africans), to estimate the size and significance of gender differences identified in Grebe and Nattrass (2012).

Unlike in Grebe and Nattrass (2012), all regression analyses were conducted using Stata's soy suite of commands, i.e. correcting for sample design and nonresponse using stratification, PSU and weight variables. Notably, while this necessarily affects variance estimates, the impact on which coefficients were statistically significant was minimal, pointing to a surprising degree of robustness of the analyses previously reported.

\subsubsection{Measures}

Variables were selected for inclusion in the multivariate models on two grounds: the existing empirical and ethnographic literature suggested that they would be likely determinants; or as a control necessary for the intelligibility of another variable. Stepwise regression or any other non-theoretical techniques were not used to decide on the inclusion of variables in the models, nor were insignificant variables excluded. The full review of existing literature and the detailed rationale for model building are provided in Grebe and Nattrass (2012). The focus in this chapter is on measuring the potential impact of TAC.

Seven socio-demographic indicators were included in the models both for AIDS conspiracy beliefs and for condom use behaviour. These are: race (binary variable, $1=$ respondent is African), gender (binary, $1=$ female), age in years, log of monthly household income per capita, employment status (binary, 1=employed), and educational attainment in the form of school education number of grades com- 
pleted) and tertiary education (binary, $1=$ any tertiary education).

In the models for AIDS conspiracy beliefs were also included the following:

- A measure of mental health (binary, $1=$ respondent is seriously psychologically distressed), constructed using the 6-item 'Kessler scale' (Strine et al., 2005). The scale asks how often people experience nervousness, hopelessness, restlessness, depression, worthlessness and that everything is an effort. Responses (ranging from 0 for 'never,' to 4 for 'all of the time') are summed, with scores of 13 and more typically regarded as indicating severe psychological distress (Strine et al., 2005:1134). The variable assumes a value of 1 if the respondent scored 13 or more on the Kessler scale and 0 for scores below that.

- Trust in Tshabalala-Msimang (binary, $1=$ respondent trusts Manto TshabalalaMsimang more than Barbara Hogan). Respondents were asked how much they trusted the conspiracy-promoting Health Minister (Tshabalala-Msimang) and her science-promoting replacement (Hogan) on AIDS (with response scores ranging from 1 for 'not at all' to 5 for 'very much'). The score for Hogan was then subtracted from that for Tshabalala-Msimang. A binary variable was then created, taking a value of 1 for a positive score (indicating that Tshabalala-Msimang was trusted more on AIDS than Hogan) and 0 for scores of zero or below. Unfortunately, this measure is likely to be confounded by the fact that Barbara Hogan is white, hence we include a measure of racial attitudes as a control for this, which measures the difference between the respondent's scores on a social distance scale for blacks and whites: the larger the value, the more the respondent 'likes' blacks relative to whites. This variable is also a potentially useful determinant in its own right as one would expect that those less well disposed to whites would be more predisposed to believe that AIDS may have been deliberately manufactured to harm black people.

- Never heard of TAC (binary, 1=respondent has never heard of TAC), designed to capture the influence of conspiracy-combating civil society. This variable takes a value of 1 if the respondent indicated that they had never heard of the organisation (and a value of 0 if they had). As this variable could be proxying for whether the respondent is generally well informed or not, a further 
binary control variable for being generally well-informed is included, taking a value of 1 if the respondent reported 'often' getting news from newspapers, television and radio.

- As measures of social inclusion, three binary variables were included, trust $(1=$ agrees most people can be trusted $)$, voting $(1=$ voted in the 2009 election $)$ and religious membership ( $1=$ respondent is a member of a religious organisation).

For African respondents we include two further measures:

- Traditionalism (binary, 1=agrees a man is not a man until he has been through a circumcision ritual). This indicator records whether respondents agree or disagree with the statement that 'a man is not really a man if he has not been through a traditional circumcision ceremony'.

- Belief in witchcraft (binary, 1=agrees witchcraft should always be suspected when a young person dies). This variable records whether respondents believe that witchcraft 'should always be suspected' if a young person dies. ${ }^{7}$

In the models for condom use behaviour we include the following measures in addition to the socio-demographic variables:

- Type of sexual relationship. This is captured in two binary variables indicating whether respondents reported that the most recent sexual partnership (i.e. the one for which they were also reporting condom use) was monogamous ( 1 =last sexual partnership was definitely monogamous) or concurrent ( $1=$ last sexual partnership was definitely concurrent either for the respondent or for the partner).

- Knowing someone who died of AIDS (binary, $1=$ respondent knows someone who has died of AIDS).

- Believing one can get HIV from condoms (binary, 1 =agree that you can get HIV from condoms).

- AIDS conspiracy beliefs (same as dependent variable in the first set of models).

\footnotetext{
${ }^{7}$ The insight that measures of social inclusion, traditionalism and belief in witchcraft were required in the models for AIDS conspiracy beliefs came from Nicoli Nattrass.
} 
- AIDS denialist beliefs (binary, $1=$ agrees both that HIV is harmless and that ARVs do more harm than good). This is therefore a strong measure of AIDS denialism, since the variable would only assume a value of 1 if the respondent agreed with both denialist claims.

- Never heard of TAG and the control for being well-informed (same as in models for AIDS conspiracy beliefs).

Coefficients are reported in exponentiated form (i.e. as odds ratios) and are considered statistically significant if $p<0.10$ (i.e. 90\% confidence level). In addition to odds ratios and $p$-values, standard errors are reported in the tables. Unless otherwise noted, all reported results represent the partial effect of variables in the multivariate logistic regression models, controlling for all other variables included in the relevant model.

\subsection{Results and discussion}

In this section, multivariate models for AIDS conspiracy beliefs and for condom use at last sex are presented that include 'never heard of TAC' as an explanatory variable. However, much of the US and South African data on the impact of conspiracy beliefs pertain to their correlation with lower HIV testing rates (Bohnert and Latkin, 2009; Bogart et al., 2008; Tun et al., 2010). The CAPS data is consistent with these findings. A bivariate logistic regression analysis suggests a similarly negative relationship between AIDS conspiracy beliefs and ever having tested for HIV: the odds of having ever been tested for HIV are significantly lower for respondents who endorse AIDS origin conspiracy beliefs (odds ratio $[O R]=0.620 ; p<0.000$ ). A similar bivariate logistic regression shows that those who had never heard of TAC had reduced odds of ever having testing for $\operatorname{HIV}(O R=0.691 ; p<0.000)$.

Bivariate analyses also point to the impact of having no familiarity with TAC on both AIDS conspiracy beliefs and condom use: a bivariate logistic regression showed that respondents who had never heard of TAC had greater odds of endorsing AIDS conspiracy beliefs $(O R=1.383 ; p=0.008)$ and reduced odds of reporting condom use at last $\operatorname{sex}(O R=0.425 ; p<0.000)$. This suggest both an independent effect of TAC on condom use, and an effect on condom use via its 
effect on conspiracy beliefs. However, to gain a more granular understanding of these direct and mediated effects, we need to include both TAC and conspiracy beliefs in the multivariate model for condom use.

Substantial race and gender differences were observed in the models predicting AIDS conspiracy beliefs and in the models predicting condom use in Grebe and Nattrass (2012), suggesting that the differing dynamics of belief formation about AIDS and decision-making about safe sex need careful further study and must be taken into account in AIDS prevention programmes. These are further elucidated here by means of the new models using interaction terms.

\subsubsection{Multivariate models for AIDS conspiracy beliefs}

Four models predicting AIDS conspiracy beliefs are reported in Table 4.2 on page 123: for the full sample, for Africans, and one each for African men and women. Table 4.3 on page 125 reports largely the same model for Africans (model $5)$, but instead of a gender-stratified model, gender is interacted on each of the variables that seem to operate differently in men and women. This allows us to evaluate of the impact of gender without sacrificing degrees of freedom through gender stratification, and also allows us to see the size and significance of the difference between men and women with respect to variables that differed between men and women.

Bivariate analysis showed that Africans were much more likely to endorse AIDS conspiracy beliefs (19.7\% of Africans averaged scores of 'agree or strongly agree' on the index of AIDS origin conspiracy beliefs, the figure for non-Africans was only $2.6 \%)$ and that levels of endorsement were higher amongst men $(25.8 \%$ of African men vs. $14.8 \%$ of African women). This is consistent with ethnographic research by Niehaus and Jonsson (2005) and was borne out in the multivariate models: Africans had substantially greater odds of endorsing conspiracy beliefs in model $1(O R=6.771 ; p<0.000)$, but the gender effect turned out not to be statistically insignificant in the non-stratified models. Even so, as shown in models 3 and 4, there are major differences in what factors are associated with AIDS conspiracy beliefs for African men and women. For example, men who reported that they kept up with news were substantially less likely to endorse AIDS conspiracy 
beliefs $(O R=0.487 ; p=0.037)$, whereas women who did so had almost twice the odds of those who did not $(O R=1.739 ; p=0.039)$. This gender difference was statistically significant in model 5 . Women who kept up with the news had almost 3.9 times the odds of endorsing AIDS conspiracy beliefs than had men who kept up with the news $(O R=3.826 ; p=0.004)$.

Serious psychological distress was associated with AIDS conspiracy beliefs in our sample (of the $7.6 \%$ of the sample so classified, $34.8 \%$ endorsed conspiracy beliefs). The multivariate regressions confirm the association: being seriously psychologically distressed more than doubled the odds of endorsing AIDS conspiracy beliefs in the full sample $(O R=2.262 ; p<0.000)$. The effect was consistent across all models.

Being a member of a religious organisation (the case for $41 \%$ of the total sample and $55 \%$ of the African sample) also significantly reduced the odds of endorsing conspiracy theories for Africans (in model 2, $O R=0.583 ; p=0.030$ ).

Having a tertiary education, living in a better-off household and voting in the last election all reduced the odds of endorsing AIDS conspiracy beliefs amongst Africans, but these effects were driven by strong effects for women (whereas they were statistically insignificant for African men). However, the effect of these variables turned out not to be measurably different for African women than for African men, with none of the interaction terms in model 5 being statistically significant.

None of the other demographic and socio-economic variables (school grades completed, employment status and age) were statistically significant in any model.

Controlling for the other variables in the model, Africans who score positively on the witchcraft variable $(7.3 \%$ of all Africans did) have more than 3 times greater odds of endorsing AIDS conspiracy beliefs $(O R=3.393 ; p=0.001)$. But there are marked differences between African men and women, with women who score positively on the witchcraft variable being much more likely to endorse conspiracy beliefs (men: $O R=2.443 ; p=0.090$; women: $O R=5.082 ; p<0.000$ ). Likewise, Africans who score positively on the traditionalism measure (the case for $88 \%$ of Africans) have substantially greater odds of endorsing conspiracy beliefs $(O R=3.114 ; p=0.009)$. This effect is was significant for African women but not men. However, interacting witchcraft beliefs and traditionalism on gender did not show an appreciable difference between African men and women, with neither of 
the interaction terms being statistically significant in model 5 .

Trusting Manto Tshabalala-Msimang more than her successor is a strong predictor of endorsing AIDS conspiracy beliefs, with those who do having almost three times the odds in the full sample $(O R=2.905 ; p<0.000)$, but driven by an especially strong effect for African men $(O R=7.682 ; p<0.000)$. The coefficient for African women was not statistically significant. In line with model 4, model 5 shows that African men who trust Tshabalala-Msimang more than Hogan have more than 7 times the odds of endorsing AIDS conspiracy beliefs than those who don't $(O R=7.653 ; p<0.000)$. Women who trust TshabalalaMsimang more than Hogan have significantly reduced odds of endorsing conspiracy beliefs compared to men who do - and this difference was highly significant $(O R=0.232 ; p=0.003)$.

The impact of never having heard of TAC is also strong and statistically significant in all but one of the models. About a quarter of the African sample (24.9\%) and $42.3 \%$ of the total sample had never heard of TAC. The multivariate regression models predict that never having heard of TAC almost doubles the odds of endorsing AIDS conspiracies in the full sample $(O R=1.904 ; p=0.001)$ and triples it for African women $(O R=3.326 ; p=0.002)$. However, there is no effect in African men. Indeed, model 5 does not show a statistically significant effect of never having heard of TAC for African men, but African women who have never heard of TAC have substantially higher odds than African men who do of endorsing conspiracy beliefs - and this difference is significant $(O R=3.119 ; p=0.017)$.

The large and significant effect of race, while expected, requires further elucidation as it can be hard to interpret, given that the effects of apartheid and of the continued racialisation of society and politics permeate almost all aspects of South African life. Therefore, while the political variable of trust in TshabalalaMsimang reflects the most direct attitudinal factor predisposing the individual to endorsement of AIDS conspiracy beliefs, it is likely that the race variable is picking up a further range of unobserved attitudinal factors. In addition, race clearly impacts on the way in which a number of the other variables operate.

These results show not only that political allegiance and authority matter for AIDS conspiracy beliefs (through the trust in Tshabalala-Msimang variable), but that TAC's contestation of Mbeki and Tshabalala-Msimang's authority on AIDS 
likely played a role in limiting the impact of their rhetoric on AIDS. Note that by including the variable capturing the difference in social distance scores for blacks and whites we can be reasonably sure that we are picking up a measure of political, rather than racial, preference. Note also that a potential endogeneity problem exists in that it is not clear whether the variable measures the impact of TshabalalaMsimang on respondents or a pre-existing receptiveness to her messages on AIDS.

The large and significant increase in the odds of endorsing AIDS conspiracy beliefs if respondents had never heard of TAC (especially among African women) provides strong evidence of the organisation's impact on knowledge of/beliefs about HIV/AIDS in Cape Town, and especially that it's treatment literacy campaigns have been effective in influencing the public understanding of AIDS science. The inclusion of the variable for being well informed means we can be fairly confident that this variable is picking up the effect of the organisation rather than simply greater knowledgeability in general. The fact that the TAC variable's effect is greater among women may result from the fact that TAC's first campaign (prevention of mother-to-child transmission of HIV) was of particular relevance to women. Women were therefore more likely to come across TAC (and indeed, most TAC activists are women) and to learn both about the science of HIV and develop a critical consciousness towards Mbeki and Tshabalala-Msimang. Compared to the Tshabalala-Msimang variable, we can be also more confident that these findings reflect the impact of the organisation, given that respondents would not have been able to avoid hearing about the organisation and its work, even if they were politically opposed to it (i.e. it does not have the same endogeneity problem). The results do suggest, however, that the organisation has not reached men to nearly as great an extent as it has women in African communities (its core constituency)-confirming a failure that leaders have sometimes spoken about candidly.

\subsubsection{Multivariate models for condom use at last sex}

Table 4.4 on page 128 presents four multivariate models of whether a respondent used a condom at last sex, using the full sample, Africans only and then African men and women separately. Table 4.5 on page 130 reports essentially the same 
model for Africans, but instead of a gender-stratified model, gender is interacted on a number of variables that seem to operate differently in African men and women.

A potential concern with the dependent variable used in these models is that it relates to a single sexual encounter, rather than consistency of condom usage over a period of time. However, in our view the risk is great that, in a survey like this, recall bias will render self-reported data on the latter substantially less reliable. And, since we control for relationship type with regard to that particular sexual encounter, we believe that the measure is an adequate indicator of whether the respondent is alert to issues of safe sex. Another potential concern is that the sexual encounter referred to in the answer may be from very long ago. However, we also ran this model on a sample restricted to respondents who explicitly reported having had at least one sexual partner in the 12 months before the interview. This restriction made no appreciable difference either to the size or significance of coefficients (Grebe and Nattrass, 2012).

The results indicate that Africans are significantly more likely to use condoms than other groups $(O R=4.019 ; p<0.000)$. Being female substantially reduces the odds of using a condom in both the full model (model $6, O R=0.358 ; p<$ 0.000 ) and for Africans (model 7, $O R=0.387 ; p<0.000$ ).

Being older was associated with lower odds of using a condom in the full sample $(O R=0.886 ; p<0.000)$ and for Africans, driven by African women $(O R=$ $0.925 ; p=0.020)$, but this effect was not seen for African men. However, the interaction term between gender and age in model 10 did not show a statistically significant difference between African men and African women. Higher household income increased the odds of using a condom in the full sample $(O R=1.200 ; p=$ 0.036), but not for Africans.

Relationship type also mattered, with a significantly higher odds of using a condom if the respondent reported being in a concurrent partnership among Africans $(O R=1.389 ; p=0.100)$. Model 10 again did not produce a statistically significant difference between African men and women on either of the relationship type variables.

Knowing someone who had died of AIDS increased the odds of condom use in the full sample $(O R=1.284 ; p=0.067)$, for Africans $(O R=1.427 ; p=0.012)$ and for African women $(O R=1.541 ; p=0.013)$, but was not significant for 
African men. The difference between African men and women did not show up as statistically significant when the variable was interacted on gender in model 10 .

A substantial minority of young adults in our sample endorsed AIDS denialist claims $(12.9 \%$ of the total sample and $18.4 \%$ of Africans). Both AIDS denialist and AIDS conspiracy beliefs significantly and substantially reduced the odds of safe sex in the multivariate models for the full sample (denial: $O R=0.592 ; p=$ 0.004; conspiracy: $O R=0.620 ; p=0.021$ ) and for Africans only (denial: $O R=$ $0.613 ; p=0.012$; conspiracy: $O R=0.664 ; p=0.054)$. However, the two factors operated differently in African men and women, with only denialism significantly reducing the odds of condom use in African women $(O R=0.525 ; p=0.009)$. But model 10 shows the difference between African women who endorsed denialist or conspiracy beliefs and African men who did so was not statistically significant.

Never having heard of TAC reduced the odds of using a condom substantially in the full sample $(O R=0.586 ; p=0.001)$, for Africans $(O R=0.710 ; p=$ $0.070)$ and for African men $(O R=0.559 ; p=0.051)$, but was not significant for African women. In model 10, too, African men who had never heard of TAC had substantially reduced odds of using a condom, compared to African men who had heard of TAC $(O R=0.503 ; p=0.014)$, while the gender difference was also significant, with African women who had never hard of TAC having substantially higher odds of using a condom than African men who had never heard of TAC $(O R=2.369 ; p=0.037)$.

As in the models for AIDS conspiracy beliefs, substantial race and gender differences exist in the factors that drive condom use. It is likely that the increased use of condoms by Africans is in response to the higher risk associated with higher prevalence among Africans in South Africa, and may also be related to the targeting of most prevention programmes at Africans.

Political factors were clearly drivers of unsafe sex, with AIDS conspiracy beliefs, AIDS denialism and never having heard of TAC being significant predictors of failure to use a condom in the full and African-only samples. The continuing legacy of AIDS denialism in South Africa therefore takes the form, in part, of likely new HIV infections among young adults resulting from conspiracy and denialrelated unsafe sex. Less gloomily, these results confirm that TAC's 'civil society leadership' on AIDS was important not only for challenging conspiracy theory- 
inspired AIDS policy and discourse, but also for promoting safer sex. Since TAC's impact on condom use should already be evident in the model through its impact on conspiracy beliefs, the variable's effect in the models for condom use should largely reflect an independent prevention effect.

\subsection{Conclusions}

The analyses presented in this chapter provide evidence from survey data that TAC's leadership on AIDS has had appreciable effects not only at the level of national politics, but also in local communities in the form of mitigating the impact of irresponsible political leadership, promoting trust in conventional HIV/AIDS science and promoting the use of condoms to prevent transmission. This is, to the best of my knowledge, the first quantitative evidence for the preventive impact of treatment activism in South Africa.

While one cannot easily extrapolate from a survey of mostly African and coloured young adults in Cape Town to communities across South Africa, the results nevertheless show that community mobilisation can (and has been) an effective tool in HIV prevention efforts. It also gives the lie to charges often made against AIDS treatment activists that they emphasise treatment at the expense of prevention and thereby harm prevention efforts. It suggests that TAC's treatment literacy efforts have been effective and deserve continued support, and also that their model of combining political mobilisation and HIV education efforts may be useful in other contexts, including in the other hyperendemic countries of Southern Africa. 


\subsection{Tables}

Table 4.1: Demographic breakdown of the GAPS 2009 sample

\begin{tabular}{lcccccc} 
& \multicolumn{2}{c}{ Male } & \multicolumn{2}{c}{ Female } & \multicolumn{2}{c}{ Total } \\
& $\mathcal{N}$ & $\%$ (row) & $\mathcal{N}$ & $\%($ row $)$ & $\mathcal{N}$ & $\%($ col $)$ \\
\hline African & 578 & 44.02 & 735 & 55.98 & 1,313 & 45.26 \\
Coloured & 658 & 46.21 & 766 & 53.79 & 1,424 & 49.09 \\
Indian & 5 & 45.45 & 6 & 54.22 & 11 & 0.38 \\
White & 77 & 50.33 & 76 & 49.67 & 153 & 5.27 \\
\hline Total & 1318 & 45.43 & 1583 & 54.27 & 2901 & 100.00 \\
\hline
\end{tabular}


Table 4.2: Weighted conspiracy models

\begin{tabular}{|c|c|c|c|c|}
\hline \multicolumn{5}{|c|}{ Dependent var: Conspiracy beliefs } \\
\hline & $(1)$ & $(2)$ & $(3)$ & $(4)$ \\
\hline & All & Africans & African men & African women \\
\hline Independent variable & $\mathrm{OR} /(\mathrm{SE}) / p$ & $\mathrm{OR} /(\mathrm{SE}) / p$ & $\mathrm{OR} /(\mathrm{SE}) / p$ & $\mathrm{OR} /(\mathrm{SE}) / p$ \\
\hline \multirow[t]{3}{*}{ African } & $6.771 * * *$ & & & \\
\hline & $(2.352)$ & & & \\
\hline & 0.000 & & & \\
\hline \multirow[t]{3}{*}{ Female } & 0.957 & 0.899 & & \\
\hline & $(0.219)$ & $(0.253)$ & & \\
\hline & 0.849 & 0.707 & & \\
\hline \multirow[t]{3}{*}{ Age } & 0.963 & 0.997 & 1.017 & 0.967 \\
\hline & $(0.029)$ & $(0.033)$ & $(0.055)$ & $(0.050)$ \\
\hline & 0.219 & 0.939 & 0.751 & 0.508 \\
\hline \multirow[t]{3}{*}{ School grades completed } & 0.936 & 1.045 & 1.023 & 1.027 \\
\hline & $(0.061)$ & $(0.068)$ & $(0.076)$ & $(0.124)$ \\
\hline & 0.307 & 0.497 & 0.758 & 0.824 \\
\hline \multirow[t]{3}{*}{ Any tertiary education } & 0.827 & $0.466^{* *}$ & 0.540 & $0.415^{*}$ \\
\hline & $(0.225)$ & $(0.140)$ & $(0.206)$ & $(0.212)$ \\
\hline & 0.485 & 0.011 & 0.108 & 0.086 \\
\hline \multirow{3}{*}{ Household income per capita (log) } & $0.785^{* * *}$ & $0.776^{* *}$ & 0.828 & $0.674 * * *$ \\
\hline & $(0.065)$ & $(0.079)$ & $(0.127)$ & $(0.102)$ \\
\hline & 0.004 & 0.013 & 0.220 & 0.009 \\
\hline \multirow[t]{3}{*}{ Employed } & 1.056 & 1.377 & $1.771 *$ & 1.289 \\
\hline & $(0.211)$ & $(0.270)$ & $(0.530)$ & $(0.379)$ \\
\hline & 0.785 & 0.104 & 0.058 & 0.388 \\
\hline \multirow{3}{*}{ Serious psychological distress } & $2.262^{* * *}$ & $3.017 * * *$ & $3.433 * * *$ & $2.348 * *$ \\
\hline & $(0.521)$ & $(0.830)$ & $(1.444)$ & $(0.940)$ \\
\hline & 0.000 & 0.000 & 0.004 & 0.034 \\
\hline \multirow[t]{3}{*}{ Trusts T-M more than Hogan } & $2.905^{* * *}$ & $4.044 * * *$ & $7.682 * * *$ & 1.615 \\
\hline & $(0.582)$ & $(0.969)$ & $(2.871)$ & $(0.572)$ \\
\hline & 0.000 & 0.000 & 0.000 & 0.177 \\
\hline \multirow[t]{3}{*}{ Attitude blacks minus whites } & $1.107 * * *$ & $1.143 * * *$ & $1.075^{*}$ & $1.268 * * *$ \\
\hline & $(0.036)$ & $(0.042)$ & $(0.044)$ & $(0.073)$ \\
\hline & 0.002 & 0.000 & 0.077 & 0.000 \\
\hline
\end{tabular}




\begin{tabular}{|c|c|c|c|c|}
\hline & $(1)$ & $(2)$ & (3) & $(4)$ \\
\hline \multirow[t]{3}{*}{ Agrees most people can be trusted } & 0.863 & 0.747 & 0.999 & 0.689 \\
\hline & $(0.197)$ & $(0.206)$ & $(0.383)$ & $(0.250)$ \\
\hline & 0.518 & 0.291 & 0.998 & 0.304 \\
\hline \multirow[t]{3}{*}{ Voted in the 2009 election } & 0.901 & $0.685^{*}$ & 0.682 & $0.572 *$ \\
\hline & $(0.186)$ & $(0.145)$ & $(0.203)$ & $(0.181)$ \\
\hline & 0.615 & 0.075 & 0.200 & 0.078 \\
\hline \multirow[t]{3}{*}{ Member of religious organisation } & 0.707 & $0.583 * *$ & $0.531^{*}$ & $0.486 * *$ \\
\hline & $(0.149)$ & $(0.144)$ & $(0.171)$ & $(0.164)$ \\
\hline & 0.102 & 0.030 & 0.051 & 0.033 \\
\hline \multirow[t]{3}{*}{ Never heard of TAC } & $1.904^{* * *}$ & $1.831 * *$ & 0.953 & $3.326^{* * * *}$ \\
\hline & $(0.409)$ & $(0.442)$ & $(0.311)$ & $(1.279)$ \\
\hline & 0.003 & 0.013 & 0.884 & 0.002 \\
\hline \multirow[t]{3}{*}{ News radio/tv/newspaper } & 1.145 & 0.945 & $0.487 * *$ & $1.739 * *$ \\
\hline & $(0.190)$ & $(0.158)$ & $(0.167)$ & $(0.464)$ \\
\hline & 0.413 & 0.734 & 0.037 & 0.039 \\
\hline \multirow[t]{3}{*}{ Traditionalism (initiation) } & & $3.114 * * *$ & 2.059 & $4.911 * *$ \\
\hline & & $(1.343)$ & $(1.098)$ & $(3.092)$ \\
\hline & & 0.009 & 0.177 & 0.012 \\
\hline \multirow[t]{3}{*}{ Witchcraft belief } & & $3.393 * * *$ & $2.443^{*}$ & $5.082^{* * * *}$ \\
\hline & & $(1.237)$ & $(1.280)$ & $(2.277)$ \\
\hline & & 0.001 & 0.090 & 0.000 \\
\hline Observations & 1866 & 2703 & 1438 & 2792 \\
\hline Strata $^{8}$ & 3 & 3 & 2 & 3 \\
\hline PSUs & 265 & 322 & 210 & 324 \\
\hline Population (weighted) & 217214 & 376774 & 178646 & 384832 \\
\hline Subpopulation & & 1115 & 489 & 626 \\
\hline Subpopulation (weighted) & & 92377 & 41549 & 50828 \\
\hline$F$ & 10.882 & 10.279 & 6.199 & 7.768 \\
\hline$p$ & 0.000 & 0.000 & 0.000 & 0.000 \\
\hline
\end{tabular}

\footnotetext{
${ }^{8}$ Where fewer than three strata, this results from a stratum being omitted because it contains no observations belonging to the relevant subpopulation.
} 
Table 4.3: Gender-interacted conspiracy model (Africans)

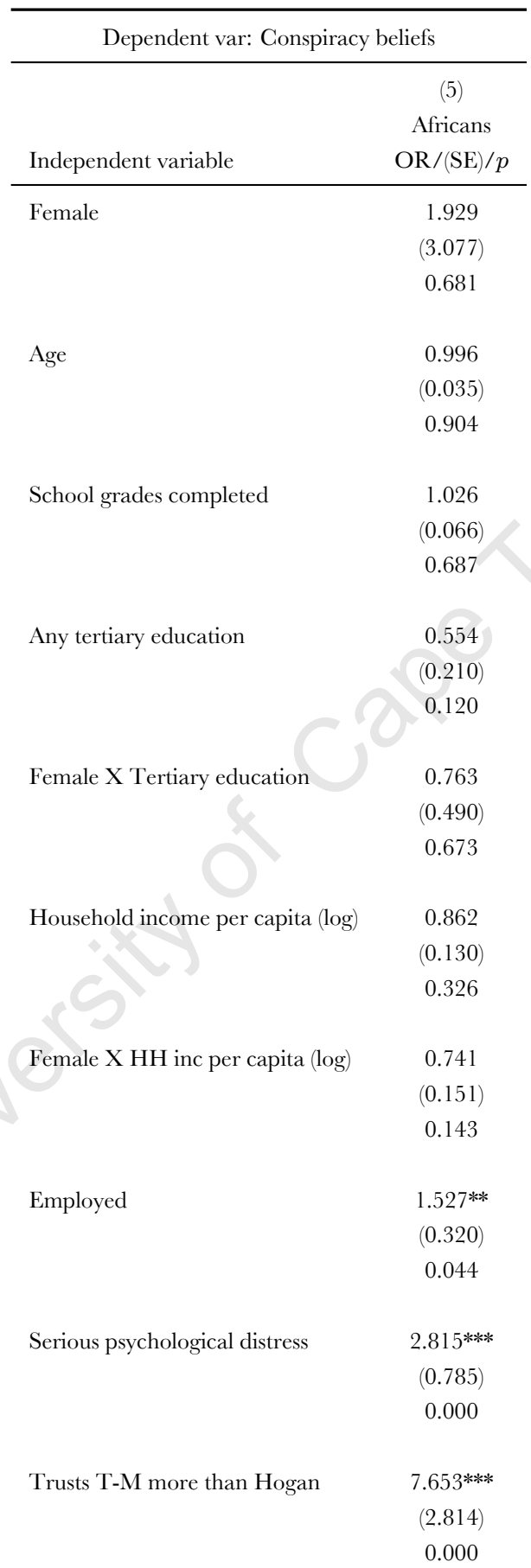


(5)

\begin{tabular}{|c|c|}
\hline \multirow[t]{3}{*}{ Female X Trusts MT $>\mathrm{H}$} & $0.232 * * *$ \\
\hline & $(0.115)$ \\
\hline & 0.003 \\
\hline \multirow[t]{3}{*}{ Attitude blacks minus whites } & $1.157 * * *$ \\
\hline & $(0.043)$ \\
\hline & 0.000 \\
\hline \multirow[t]{3}{*}{ Agrees most people can be trusted } & 0.855 \\
\hline & $(0.231)$ \\
\hline & 0.563 \\
\hline \multirow[t]{3}{*}{ Voted in the 2009 election } & 0.707 \\
\hline & $(0.210)$ \\
\hline & 0.244 \\
\hline \multirow[t]{3}{*}{ Female X Voted } & 0.752 \\
\hline & $(0.310)$ \\
\hline & 0.490 \\
\hline Member of religious organisation & $0.519^{* * *}$ \\
\hline \multirow[t]{3}{*}{ Traditionalism (initiation) } & 2.064 \\
\hline & $(1.103)$ \\
\hline & 0.176 \\
\hline \multirow{3}{*}{ Female X Traditionalism } & 2.214 \\
\hline & $(1.541)$ \\
\hline & 0.254 \\
\hline \multirow[t]{3}{*}{ Witchcraft belief } & 2.326 \\
\hline & $(1.234)$ \\
\hline & 0.113 \\
\hline \multirow[t]{3}{*}{ Female X Witchcraft belief } & 2.060 \\
\hline & $(1.409)$ \\
\hline & 0.292 \\
\hline \multirow[t]{3}{*}{ Never heard of TAC } & 1.000 \\
\hline & $(0.320)$ \\
\hline & 0.999 \\
\hline \multirow[t]{3}{*}{ Female X Never heard of TAC } & $3.119 * *$ \\
\hline & $(1.477)$ \\
\hline & 0.017 \\
\hline
\end{tabular}


(5)

\begin{tabular}{lc}
\hline News radio/tv/newspaper & $0.492^{* * *}$ \\
& $(0.168)$ \\
& 0.039 \\
& \\
Female X News & $3.826^{* * *}$ \\
& $(1.781)$ \\
& 0.004 \\
\hline Observations & 2703 \\
Strata & 3 \\
PSUs & 322 \\
Population (weighted) & 376774 \\
Subpopulation & 1115 \\
Subpopulation (weighted) & 92377 \\
$F$ & 8.439 \\
$p$ & 0.000 \\
\hline
\end{tabular}

Exponentiated coefficients

$* p<0.10, * * p<0.05,{ }^{* * *} p<0.01$ 
Table 4.4: Weighted condom models

\begin{tabular}{|c|c|c|c|c|}
\hline \multicolumn{5}{|c|}{ Dependent var: Condom used most recent sex } \\
\hline & (6) & $(7)$ & (8) & (9) \\
\hline & All & Africans & African men & African women \\
\hline Independent variable & $\mathrm{OR} /(\mathrm{SE}) / p$ & $\mathrm{OR} /(\mathrm{SE}) / p$ & $\mathrm{OR} /(\mathrm{SE}) / p$ & $\mathrm{OR} /(\mathrm{SE}) / p$ \\
\hline \multirow[t]{3}{*}{ African } & $4.019 * * *$ & & & \\
\hline & $(0.644)$ & & & \\
\hline & 0.000 & & & \\
\hline \multirow[t]{3}{*}{ Female } & $0.358^{* * * *}$ & $0.387 * * *$ & & \\
\hline & $(0.052)$ & $(0.060)$ & & \\
\hline & 0.000 & 0.000 & & \\
\hline \multirow[t]{3}{*}{ Age } & $0.886^{* * *}$ & $0.953^{*}$ & 1.003 & $0.925^{* *}$ \\
\hline & $(0.022)$ & $(0.025)$ & $(0.046)$ & $(0.031)$ \\
\hline & 0.000 & 0.075 & 0.951 & 0.020 \\
\hline \multirow[t]{3}{*}{ School grades completed } & 1.038 & 1.021 & 1.040 & 1.015 \\
\hline & $(0.045)$ & $(0.057)$ & $(0.094)$ & $(0.074)$ \\
\hline & 0.383 & 0.719 & 0.665 & 0.834 \\
\hline \multirow[t]{3}{*}{ Any tertiary education } & 1.281 & 1.129 & 1.002 & 1.277 \\
\hline & $(0.252)$ & $(0.222)$ & $(0.353)$ & $(0.327)$ \\
\hline & 0.211 & 0.536 & 0.995 & 0.342 \\
\hline \multirow[t]{3}{*}{ Household income per capita (log) } & $1.200 * *$ & 1.082 & 1.257 & 0.957 \\
\hline & $(0.104)$ & $(0.094)$ & $(0.180)$ & $(0.097)$ \\
\hline & 0.036 & 0.367 & 0.112 & 0.663 \\
\hline \multirow[t]{3}{*}{ Employed } & 1.013 & 1.041 & 0.845 & 1.240 \\
\hline & $(0.139)$ & $(0.132)$ & $(0.200)$ & $(0.212)$ \\
\hline & 0.927 & 0.751 & 0.479 & 0.210 \\
\hline \multirow[t]{3}{*}{ Concurrent partnership } & 1.143 & $1.389^{*}$ & 1.334 & 1.491 \\
\hline & $(0.228)$ & $(0.277)$ & $(0.470)$ & $(0.363)$ \\
\hline & 0.503 & 0.100 & 0.413 & 0.102 \\
\hline \multirow[t]{3}{*}{ Monogamous partnership } & 0.749 & 0.846 & 0.616 & 0.976 \\
\hline & $(0.133)$ & $(0.155)$ & $(0.231)$ & $(0.204)$ \\
\hline & 0.105 & 0.363 & 0.197 & 0.906 \\
\hline \multirow[t]{3}{*}{ Knows someone who died of AIDS } & $1.288 *$ & $1.427 * *$ & 1.112 & $1.541 * *$ \\
\hline & $(0.177)$ & $(0.202)$ & $(0.266)$ & $(0.265)$ \\
\hline & 0.067 & 0.012 & 0.656 & 0.013 \\
\hline
\end{tabular}




\begin{tabular}{|c|c|c|c|c|}
\hline & (6) & (7) & (8) & (9) \\
\hline \multirow[t]{3}{*}{ HIV from condoms } & 1.202 & 0.946 & $0.480^{*}$ & 1.115 \\
\hline & $(0.400)$ & $(0.240)$ & $(0.183)$ & $(0.370)$ \\
\hline & 0.581 & 0.827 & 0.056 & 0.744 \\
\hline \multirow[t]{3}{*}{ AIDS origin conspiracy beliefs } & $0.626 * *$ & $0.664^{*}$ & 0.690 & 0.793 \\
\hline & $(0.126)$ & $(0.140)$ & $(0.216)$ & $(0.213)$ \\
\hline & 0.021 & 0.054 & 0.238 & 0.389 \\
\hline \multirow[t]{3}{*}{ AIDS denialism } & $0.592^{* * * *}$ & $0.613^{* *}$ & 0.772 & $0.525^{* * *}$ \\
\hline & $(0.105)$ & $(0.119)$ & $(0.309)$ & $(0.129)$ \\
\hline & 0.004 & 0.012 & 0.519 & 0.009 \\
\hline \multirow[t]{3}{*}{ Never heard of TAC } & $0.586^{* * *}$ & $0.710^{*}$ & $0.559^{*}$ & 1.115 \\
\hline & $(0.091)$ & $(0.134)$ & $(0.166)$ & $(0.325)$ \\
\hline & 0.001 & 0.070 & 0.051 & 0.710 \\
\hline \multirow[t]{3}{*}{ News radio/tv/newspaper } & 1.069 & 1.076 & $1.639 *$ & 0.872 \\
\hline & $(0.158)$ & $(0.156)$ & $(0.438)$ & $(0.153)$ \\
\hline & 0.651 & 0.613 & 0.066 & 0.434 \\
\hline Observations & 1741 & 2697 & 1413 & 2811 \\
\hline Strata $^{9}$ & 3 & 3 & 2 & 3 \\
\hline PSUs & 261 & 325 & 211 & 325 \\
\hline Population (weighted) & 196632 & 376187 & 176499 & 386391 \\
\hline Subpopulation & & 1109 & 464 & 645 \\
\hline Subpopulation (weighted) & & 91790 & 39403 & 52387 \\
\hline$F$ & 16.862 & 7.080 & 2.134 & 2.512 \\
\hline$p$ & 0.000 & 0.000 & 0.014 & 0.003 \\
\hline
\end{tabular}

Exponentiated coefficients

$* p<0.10, * * p<0.05, * * * p<0.01$

${ }^{9}$ Where fewer than three strata, this results from a stratum being omitted because it contains no observations belonging to the relevant subpopulation. 
Table 4.5: Gender-interacted condom model (Africans)

\begin{tabular}{|c|c|}
\hline Dependent var: Condom used $\mathrm{m}$ & recent sex \\
\hline Independent variable & $\begin{array}{c}(10) \\
\text { Africans } \\
\mathrm{OR} /(\mathrm{SE}) / p\end{array}$ \\
\hline Female & $\begin{array}{c}1.134 \\
(1.475) \\
0.923\end{array}$ \\
\hline Age & $\begin{array}{c}0.996 \\
(0.042) \\
0.931\end{array}$ \\
\hline Female X Age & $\begin{array}{c}0.933 \\
(0.048) \\
0.180\end{array}$ \\
\hline School grades completed & $\begin{array}{l}1.025 \\
(0.057) \\
0.660\end{array}$ \\
\hline Any tertiary education & $\begin{array}{c}1.164 \\
(0.230) \\
0.441\end{array}$ \\
\hline Household income per capita $(\log )$ & $\begin{array}{c}1.064 \\
(0.093) \\
0.481\end{array}$ \\
\hline Employed & $\begin{array}{c}1.072 \\
(0.138) \\
0.592\end{array}$ \\
\hline Concurrent partnership & $\begin{array}{c}1.261 \\
(0.436) \\
0.504\end{array}$ \\
\hline Female X Concurrent part. & $\begin{array}{c}1.190 \\
(0.496) \\
0.677\end{array}$ \\
\hline Monogamous partnership & $\begin{array}{c}0.619 \\
(0.229) \\
0.195\end{array}$ \\
\hline
\end{tabular}


(10)

\begin{tabular}{|c|c|}
\hline Female X Monogamous part. & $\begin{array}{c}1.518 \\
(0.603) \\
0.295\end{array}$ \\
\hline Knows someone who died of AIDS & $\begin{array}{c}1.162 \\
(0.279) \\
0.531\end{array}$ \\
\hline Female X Knows some. died HIV & $\begin{array}{c}1.371 \\
(0.401) \\
0.282\end{array}$ \\
\hline HIV from condoms & $\begin{array}{c}0.844 \\
(0.209) \\
0.495\end{array}$ \\
\hline AIDS origin conspiracy beliefs & $\begin{array}{c}0.579 * \\
(0.179) \\
0.077\end{array}$ \\
\hline Female X Conspiracy beliefs & $\begin{array}{c}1.493 \\
(0.573) \\
0.297\end{array}$ \\
\hline AIDS denialism & $\begin{array}{c}0.753 \\
(0.288) \\
0.459\end{array}$ \\
\hline Female X AIDS denialism & $\begin{array}{c}0.706 \\
(0.320) \\
0.443\end{array}$ \\
\hline Never heard of TAC & $\begin{array}{c}0.503 * * \\
(0.140) \\
0.014\end{array}$ \\
\hline Female X Never heard of TAC & $\begin{array}{c}2.369 * * \\
(0.973) \\
0.037\end{array}$ \\
\hline News radio/tv/newspaper & $\begin{array}{c}1.075 \\
(0.164) \\
0.636\end{array}$ \\
\hline
\end{tabular}




\begin{tabular}{lc}
\hline Observations & 2697 \\
Strata & 3 \\
PSUs & 325 \\
Population (weighted) & 376187 \\
Subpopulation & 1109 \\
Subpopulation (weighted) & 91790 \\
$F$ & 4.962 \\
$p$ & 0.000 \\
\hline
\end{tabular}

Exponentiated coefficients

$* p<0.10,{ }^{* *} p<0.05,{ }^{* * *} p<0.01$ 


\section{Chapter 5}

\section{Uganda: Givil society leadership 'in partnership with the state'}

In the previous two chapters I told the story of the Treatment Action Campaign and demonstrated how transnational networks of influence helped it exert influence over AIDS policy in South Africa and also that it had a measurable impact on prevention efforts at the community level. In this chapter I tell the story of a very different - though very prominent and arguably equally important - civil society group in Uganda, The AIDS Support Organisation. I will describe the birth of TASO as a small group of volunteers, its growth and evolution into a large and professionally-run organisation administering AIDS treatment for a substantial number of patients. But I will also describe how it has been shaped by the political and institutional context within which it operates - very different to that of TAC's - and try to explain why its path has been one of 'partnership' rather than conflict with the state and why it has focused on service delivery rather than activism.

This case study will help us to see that 'civil society leadership' on AIDS can take different forms and is highly sensitive both to the choices of individual leaders and to the social and political context within which it operates. The fieldwork for this chapter largely took the form of in-depth semi-structured interviews

\footnotetext{
${ }^{1}$ The fieldwork for this chapter was generously funded by the Developmental Leadership Program. A portion of the material used here previously appeared in a DLP Research Report (Grebe, 2009b).
} 
with key informants, including early TASO volunteers and leaders (like Noerine Kaleeba, Peter Ssebanja and Dr Elly Katabira), subsequent and current TASO leaders, other civil society leaders (including prominent activists) and officials of state structures like the Uganda AIDS Commission. I further refer extensively to the literature on the Ugandan AIDS response.

\subsection{Introduction: state leadership and the mak- ing of an 'African success story'}

Uganda experienced one of the earliest large-scale HIV epidemics in Sub-Saharan Africa. In the late 1970s, North Western Tanzania and Southern Uganda probably constituted the epicentre of the African HIV epidemic (Epstein and Halperin, 2007:155-156). By the time the first AIDS cases were identified in Uganda, the existence of a mysterious wasting disorder known locally as 'Slim' was widely known in the rural South-West of the country. The virus continued to spread quickly and by the mid-1980s many communities were being ravaged by one of Africa's worst HIV/AIDS epidemics (see O'Manique, 2004; Thornton, 2008). The situation was exacerbated by the insecurity and social upheaval of a bloody civil war lasting from 1981 to 1986 that contributed to widespread fear and confusion and rendered any systematic state response nearly impossible.

By the time Yoweri Museveni's National Resistance Army took Kampala in 1986, having defeated the second Obote regime and the short-lived Okello military junta, AIDS constituted a real crisis. The Museveni government initiated HIV prevention campaigns, with the President himself frequently mentioning the risks of contracting HIV through sex, which has contributed to the Ugandan government and in particular Museveni's reputation for openness and leadership on AIDS. These campaigns included discouraging sleeping around and (to some degree) condom use, with the so-called 'zero grazing' (partner reduction) and ABC ('Abstain, Be faithful, Condomize') messages featuring prominently. The government also established an AIDS Control Programme in the Ministry of Health to steer the national AIDS response. This openness and willingness to tackle the issue of HIV and risky sex stood in sharp contrast to most African governments at the 


\section{Figure 5.1: Ruhakana Rugunda (in a later role representing Uganda at the UN)}

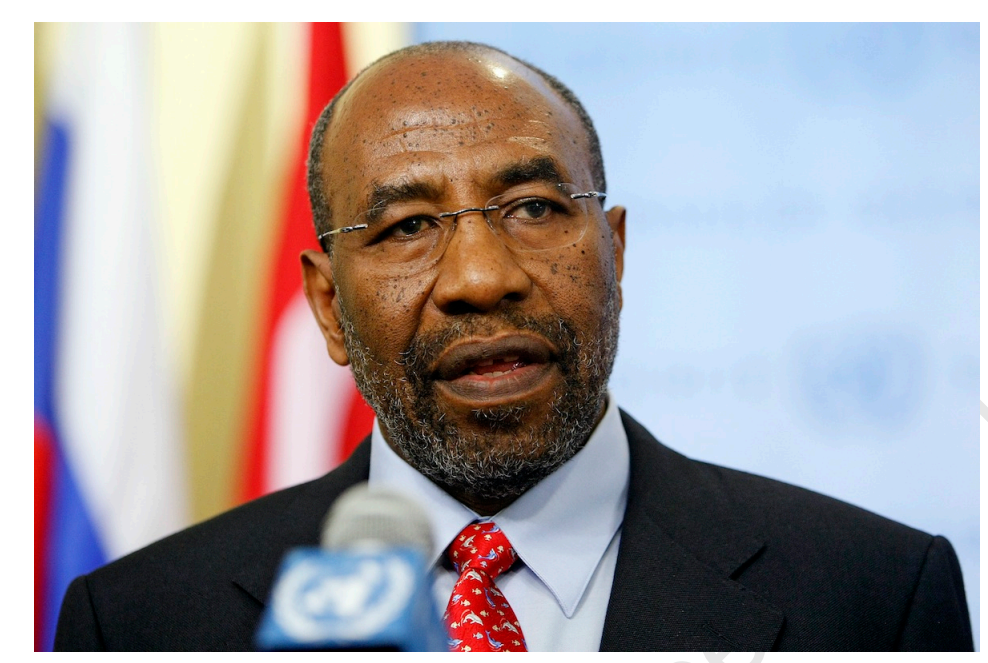

Source: UN Photo/Paulo Filgueiras. CUnited Nations 2009.

time (and even into the 1990s) ${ }^{2}$ and certainly contributed to the Ugandan government's stellar international reputation for its HIV prevention efforts. An example of the willingness of Uganda's political leaders to publicly tackle HIV/AIDS despite the reputational risks - while in many other countries leaders were denying the existence of the crisis is the Ugandan health minister, Ruhakana Rugunda's speech at the 1987 World Health Assembly, described by Peter Piot (2012:175) as a 'lone voice' calling on his peers to face the reality of AIDS on the African continent.

This reputation is so good that many consider Uganda a model for addressing AIDS in resource-poor settings (Youde, 2007b:1). But Uganda's status as a 'poster boy' for good governmental leadership on AIDS and Museveni's reputation as an exceptional African leader were probably cemented when it became apparent by the mid-1990s that HIV prevalence had started to decline, turning Uganda into the first African HIV prevention 'success story'. But is this reputation deserved? While the praise heaped on Museveni and his government probably say as much about the need of the international development, aid and public health agencies

\footnotetext{
${ }^{2}$ Interview, P. Piot (20 December 2010). See also Piot (2012).
} 
for African success stories as they do about Uganda, it is important to interrogate the basis of this reputation. In order to do so, we must look both at the evolving role of non-state actors in the Ugandan AIDS response and at the epidemiology of HIV in Uganda.

The Ugandan state's early response to the AIDS crisis took the form largely of prevention campaigns (the efficacy of which is debatable), but it possessed extremely limited capacity to provide medical services to the AIDS sick and even less to provide care and support at community level. There were few hospitals in the country, and even fewer that had the resources to provide good services. AIDS services in Uganda were pioneered by civil society working outside state structures, most prominently in the form of TASO, which was founded in 1987 by a small group of volunteers and a few passionate healthcare workers. Later in this chapter I will describe the birth of TASO, its growth to eventually become the largest provider of medical services to AIDS patients and its evolving relationship with the state. But suffice it to say that civil society stepped in where the state was largely absent.

What exactly led to the decline in HIV prevalence is uncertain, but changes in sexual behaviour - in particular reductions in the number of concurrent partners - are generally thought to have played a significant role (Stoneburner and Low-Beer, 2004; Low-Beer and Stoneburner, 2004). The Ugandan government attracted substantial credit for the apparently radical behaviour changes that would explain declining HIV prevalence (e.g. UNAIDS, 1998a; 2001). But while it is undeniably due some credit, the degree to which the prevention campaigns shaped the evolution of the epidemic should be questioned. There has been considerable debate among scholars about the relative importance of different factors (see, for example, Merson, 2006; Green et al., 2006; Gray et al., 2006; Atzori et al., 2009), while Thornton (2008:35-37) has pointed to several difficulties with Stoneburner and Low-Beer's standard epidemiological model and instead emphasises the effects of the configuration of sexual networks on HIV trends (Thornton, 2008:33). Helen Epstein and Halperin (2007:160) argues that the many small communitybased AIDS groups that were founded during the 1980s and early 1990s deserve much of the credit: "Their compassion and hard work brought the disease into the open, got people talking about the epidemic, reduced AIDS-related stigma 
and denial, and led to a profound shift in sexual norms."

\section{Figure 5.2: Epidemiological model for Uganda showing new adult HIV infections and adult HIV prevalence rate (1974-2004) with major political developments}

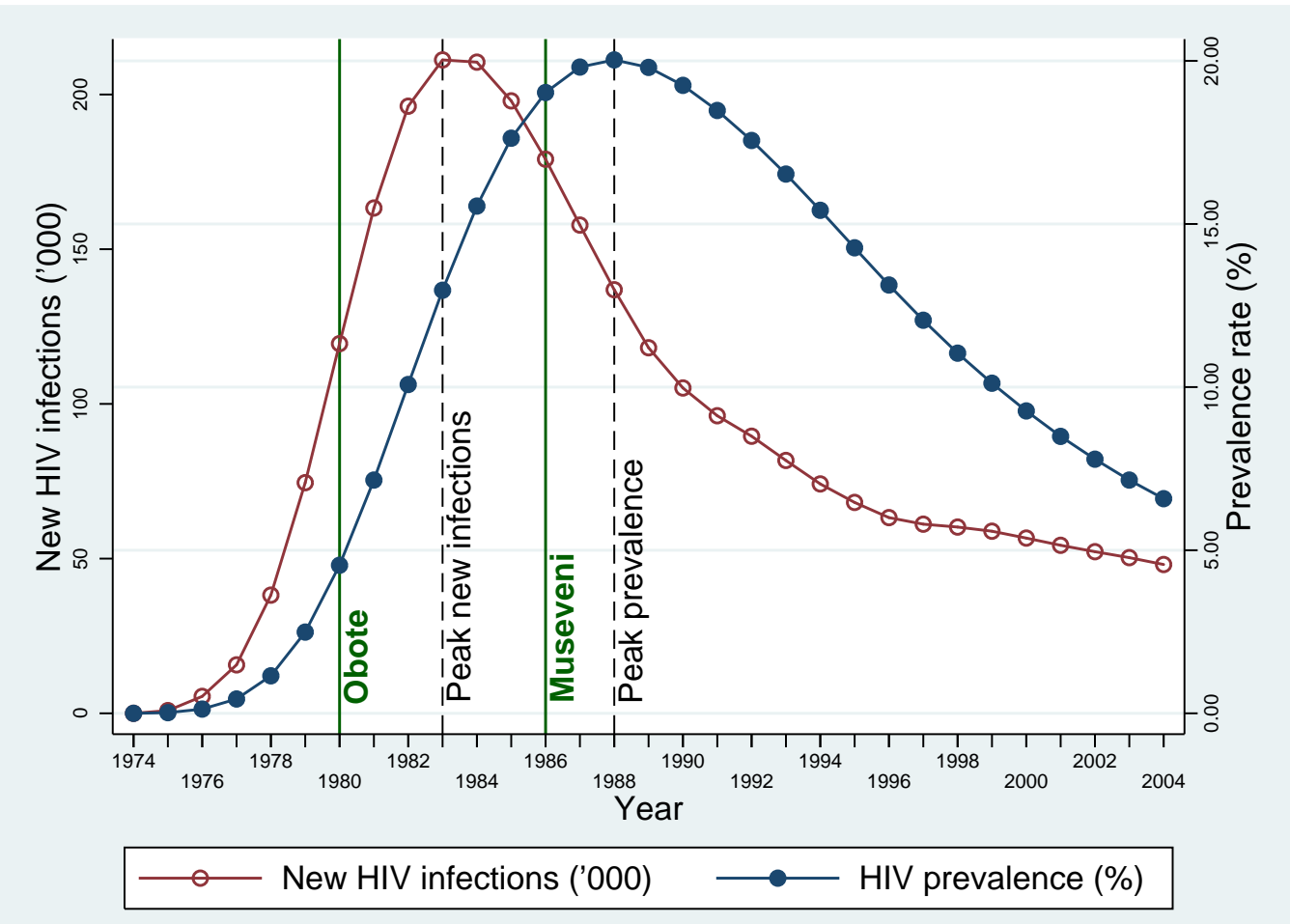

Source: Own model using Spectrum/EPP 2011 (see Appendix B).

In any event, it is fairly clear that the unexpected peak in HIV prevalence could not have resulted from the Museveni government's HIV prevention efforts (although this is not to say that those efforts had no effect). Figure 5.2 shows estimates of HIV incidence and prevalence for the period 1974-2004 according to an epidemiological model described more fully in Appendix B from page 186. The model makes use of UNAIDS's Epidemiological Projection Package (UNAIDS, 2011a) and HIV prevalence data from Ugandan antenatal clinics in order to estimate new infections, total infected population, deaths and AIDS morbidity. HIV prevalence estimates are further calibrated using national seroprevalence survey data. As can be seen in the figure, new HIV infections are estimated to have 
peaked by 1983. As shown in table B.1 in the appendix (page 192), AIDS deaths continued to rise until 1995. According to the model, the fall in HIV prevalence rates and total number of people with HIV from 1990 resulted from deaths exceeding new HIV infections. It therefore seems highly unlikely that Museveni's 'zero grazing' campaigns was the decisive factor in Uganda's prevalence declines. If large-scale behaviour change was a major factor, it seems more likely that behaviour responded to the visibility of illness and AIDS deaths, both of which had started to increase markedly by the early 1980s (see figures B.3 and B.4 on pages 193 and 194).

Despite the questionable assumptions underlying Uganda's prevention 'success story', and the fact that AIDS services are largely provided by civil society and funded by external donors, Museveni and the Ugandan government did indeed provide leadership. It did so by (1) ensuring AIDS featured prominently on the national agenda (i.e. it showed 'political commitment' in the sense used by Bor, 2007) and (2) by building partnerships with civil society and coordinating the work of various actors, first through the National Committee for the Prevention of AIDS (NCPA) and and later through the national AIDS Control Programme (ACP) and the Uganda AIDS Commission (UAG) (i.e. in the sense of Piot and Coll-Seck, 2001). Despite failings in both institutions and limits to civil society's freedom from political control (which would become a more serious problem later ${ }^{3}$ ), this at least freed civil society actors to focus on providing services where the state was unable to do so. TASO founder Noerine Kaleeba describes being brought into high-level policy discussion and says that the "terrain had been set" for civil society to respond to AIDS. ${ }^{4}$ This approach became known as Uganda's 'multi-sectoral response' and at least superficially fits with the notion of 'good national leadership on AIDS', insofar as this is conceived as political commitment and a broad societal mobilisation involving a range of stakeholders.

Furthermore, by the mid-2000s, Uganda was performing significantly better than expected (and than most of its peers, most notably the much wealthier South Africa) in the provision of antiretroviral treatment, even if this progress was largely funded by PEPFAR and implemented by civil society organisations like TASO.

\footnotetext{
${ }^{3}$ See later sections of this chapter.

${ }^{4}$ Interview, N. Kaleeba (16 October 2008).
} 
Using the novel approach described in chapter 2, Nattrass (2008b) shows that Uganda performed significantly better in HAART coverage than an econometric model incorporating its level of development, external resources, social characteristics and burden of disease would predict, something she speculates may be related to 'political leadership'.

Like TAC in South Africa, TASO has been a key element of coalitions mobilised in response to AIDS. Also like TAC, TASO initially relied heavily on the charismatic and energetic leadership of exceptional individuals, most prominently that of Noerine Kaleeba, and on strong interpersonal ties. But unlike TAC, it has treasured partnership and cooperation with the state from its inception and avoided political confrontation, focused on medical and support services to people living with HIV/AIDS rather than mobilising a constituency or pursuing broader social justice goals and more successfully (and probably more willingly) managed the process of formalisation and bureaucratisation.

Despite its prominent role in the Ugandan response to AIDS, TASO is therefore not primarily an activist organisation and can probably not be characterised as a social movement (although it does exhibit some characteristics associated with the latter). Nevertheless, it is an example of 'civil society leadership' on AIDS and, in keeping with the theoretical framework articulated in chapter 3, I will attempt to describe and analyse how contextual and structural factors have shaped the development of the organisation (and how it in turn shaped the societal AIDS response), while at the same time acknowledging factors related to individual agency (such as Kaleeba's leadership of TASO and the actions of Museveni) that have impacted on this development. I start by describing some of the early history of the organisation before turning my attention to the political and institutional context within which it has operated. I then look at the role of elite networks in the building of an AIDS response coalition in Uganda, while paying particular attention to the internal evolution of the organisation, to alliances and partnerships with other civil society actors and to the role of donors (who exert a great deal of influence). 


\subsection{The origins of The AIDS Support Organisa- tion}

Both TASO and TAG were founded by charismatic and inspirational leaders who were personally affected by HIV. In early 1987, a group of 16 men and women (the majority of whom were HIV-positive) started meeting informally to share experiences and support one another in coping with the impact of HIV/AIDS on their lives (Ssebanja, 2007:1). As the group grew, it started calling itself 'The AIDS Support Organisation' and increasingly formalised its structure and its programme of 'living positively'. Noerine Kaleeba, principal of the School of Physiotherapy at Mulago Hospital (Uganda's only teaching hospital) was the leader of the group and became its first director once it formally established itself as an organisation. ${ }^{5}$ She cites as motivation for the founding of TASO "a feeling of anger and frustration at the stigma and isolation of people with HIV and ... the fact that families were abandoning their loved ones." 6

The previous year, she had visited her husband, Christopher, in England where he had become ill and was diagnosed with AIDS. In a remarkable interview for the PBS documentary 'The Age of AIDS', she describes how she made a trip to Geneva after discovering how ill her husband was. She had read about Jonathan Mann's appointment to the WHO to direct the GPA, travelled to his office and asked to see him. She tells how she burst into tears when told she could not see Mann, upon which he discovered her and invited her into his office:

He was apparently going to a meeting, that he never went to. We sat for four hours and he talked to me. At the end of that time I was calm, I was collected. He told me that my husband was probably going to die, because at the time there was no cure. But he also said, "there is prejudice that is attached to the disease, that we have to fight, and will you help me fight it?" Jonathan Mann was a star, and the first scientist that I met with a heart of gold. (Cran, 2006).

\footnotetext{
${ }^{5}$ The group decided to name themselves 'The AIDS Support Organisation' in November 1987 (Ssebanja, 2007:9).

${ }^{6}$ Interview, N. Kaleeba (16 October 2008).
} 
This introduction to the world of intergovernmental organisations and the international response to AIDS, as well as to Mann himself, would later prove invaluable to Kaleeba as she built relationships and mobilised support for the struggle in Uganda. She also participated in the international response (she would later be recruited to work for UNAIDS under Peter Piot to develop its partnerships with civil society). She brought Christopher back to Uganda, where he died in January 1987. During the last months of his life, the Kaleebas had direct experience of the stigma surrounding AIDS, which she became determined to combat. ${ }^{7}$

Medical services for AIDS patients were extremely limited. Dr Elly Katabitra, a physician who had come across AIDS while working in England, was shocked to find large numbers of AIDS patients in Mulago Hospital when he returned to Kampala in 1986. He set up a new outpatient clinic attached to the normal infectious diseases clinic for HIV/AIDS services in late 1986, after opposing proposals for a separate inpatient ward over his concerns that segregating AIDS patients would exacerbate stigma and discrimination by marking AIDS as a "deadly and shameful disease" and that a service outside the mainstream would not be sustainable. $^{8}$ (A compassionate and highly competent physician, Dr Katabira is now the president of the International AIDS Society and a prominent international advocate for a human rights approach, progressive AIDS policy and access to AIDS treatment.) By 1987, Katabira had been put in touch with the fledgling TASO and became a key figure in their integration of social support and community-based services with medical services. At the time no life-saving treatment for HIV/AIDS was available, and the founders were responding primarily to the human tragedy caused by widespread stigma and discrimination (both within the healthcare system and the wider community), which condemned patients to lonely and undignified deaths. They wished to enable patients to "die with dignity." 9 Their focus on combating stigma was reflected in the choice to refer to the people they were serving as 'clients' rather than as 'AIDS patients' so as not to exacerbate discrimination against people with AIDS (Ssebanja, 2007:9).

This is of course in stark contrast to TAC activists, who rather than shying

\footnotetext{
${ }^{7}$ Interview, N. Kaleeba (16 October 2008).

${ }^{8}$ Interview, E. Katabira (14 October 2008).

${ }^{9}$ Interview, P. Ssebanja (15 October 2008).
} 
away from terms like 'HIV' and 'AIDS', attempted to break down stigma by promoting living openly with HIV and by wearing the iconic 'HIV-positive' tee shirts, reflecting also a degree of identity-based mobilisation. This should, however, be seen in the light of TAC's emergence (about ten years after TASO) in the context of HAART becoming available in the rich world and AIDS no longer necessarily being a death sentence, its activist roots and a more developed transnational activist movement.

The fledgling TASO reached out to communities, for example visiting neighbourhoods to identify patients, running training workshops on caring for the ill at home and combating stigma and discrimination by talking openly about AIDS, leading by example and by emphasising that the risk of non-sexual transmission of HIV was vanishingly small. A key early ally of TASO was the British charity ActionAid, who provided early logistical and administrative support ${ }^{10}$ and funded a number of early TASO initiatives, including providing the first vehicle for community visits and funding a series of AIDS sensitisation workshops organised for staff and medical personnel at Mulago and other hospitals. Even the then chairman of the AIDS Control Programme in the Ministry of Health (Dr Sam Okware) attended one of these workshops (Ssebanja, 2007:17).

TASO continued to expand: it obtained a room at Mulago hospital (the former polio clinic) to use as an office and a space to provide counselling services to clients. It wasn't long before requests for assistance from other health care workers started arriving. In May 1988 health and social workers led by Dr Sam Kalibala from Masaka hospital (in one of the hardest-hit districts) contacted TASO and with the help of a TASO team set up an HIV testing service and a day-care clinic (Ssebanja, 2007:17). This would become TASO Masaka and eventually TASO would operate 11 service centres distributed throughout the country.

Medical care for AIDS patients was woefully inadequate, and even at $\mathrm{Mu}$ lago hospital Dr Katabira battled to obtain the drugs and resources required for the most basic care. ${ }^{11}$ Initially TASO focused on providing counselling and psychosocial support, but increasingly responded to the weakness of the Ugandan healthcare system by providing medical services itself. Dr Katabira describes how

\footnotetext{
${ }^{10}$ Interview, E. Katabira (14 October 2008).

${ }^{11}$ Interview, E. Katabira (14 October 2008).
} 
Figure 5.3: Noerine Kaleeba in 2008

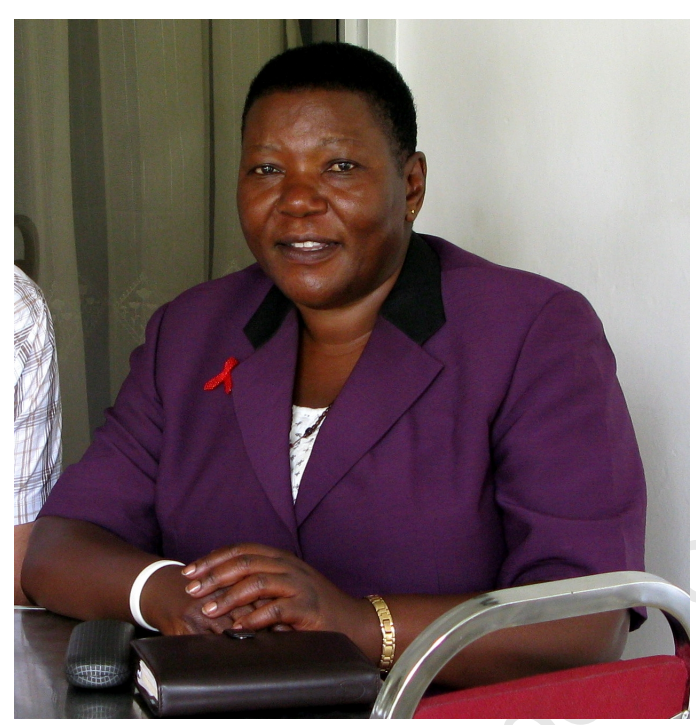

Source: Author's collection. Photo by Larry Adupa (17 October 2008).

both local and international networks were built up and information and expertise flowed in both directions. After Noerine Kaleeba and Dr Katabira went to England for training in December 1987, they suggested to their funders that it would be better to bring counselling trainers to Uganda so that these experts could see the local conditions:

We asked them specifically to bring in people for teaching us or training us, which they did. And these people who came, actually they ended up learning far more than us, because their training and ways of talking about AIDS came from a different atmosphere. They came from San Francisco, so you can imagine. Their thinking was mainly of gay people, but here they find Josephine is sick, Peter is sick, Josephine's child is sick. In fact, they had to change their material completely. And they learnt a lot, because in counselling and group discussions you learn... ${ }^{12}$

Dr Katabira also describes how he encouraged health care workers from any-

\footnotetext{
${ }^{12}$ Interview, E. Katabira (14 October 2008).
} 
where in the world to visit his AIDS clinic to encourage exchange of information and experience:

...because I knew, if what I was doing with the clinic was good, then it could also be good at Jinja hospital, at Gulu hospital and it could be good at Masaka hopital. ...People were completely changed and that's what I wanted, so they went out and said, "if you can do it, we can do it."13

TASO grew rapidly and today employs over 1000 staff and operates a large antiretroviral treatment programme (much larger than that of the Ugandan government). In contrast to TAC, which remained a smaller and more nimble activist organisation staffed largely by politically-motivated individuals, TASO has become the major provider of both medical and social support services to HIV/AIDS patients in Uganda. It is a large and professionally-run organisation with a relatively formal and inflexible management culture. This path of development was conditioned by the initial motivations of the founders (TAC was always much more oriented towards political activism and advocacy, and TASO towards service delivery), but crucially, also by the constraints imposed and opportunities provided by its specific political, institutional and social environment. Contextual differences include levels of development and state capacity (South Africa has a relatively sophisticated healthcare system and vastly greater state capacity to provide services), in political institutions and cultures, and in the roles of other influential actors such as donors. The next section will focus on these factors.

\subsection{The context of civil society leadership: 'part- nership' and Uganda's multisectoral ap- proach}

Perhaps the insight that emerges most clearly from a comparison of TAC and TASO (and their roles in helping to construct coalitions in response to AIDS in

\footnotetext{
${ }^{13}$ Interview, E. Katabira (14 October 2008).
} 
South Africa and Uganda respectively) is that the development of AIDS response coalitions is highly context-dependent. Civil society leaders and elites respond to the opportunities provided, and constraints imposed, by structural factors, including the formal legal and institutional framework of the state and the prevailing political culture (I argued in chapter 3 that TAC made extensive use of the constitutional legal framework of the post-apartheid state and drew upon the traditions and political lexicon of the anti-aparteid struggle). In other words, what social movement scholars call the 'political opportunity structure' matters. As Leftwich and Hogg (2007) argue, economic and social structure and level of development is of great consequence - in particular whether elite negotiations occur within the context of a broad societal consensus on the principles and institutions which govern it (i.e. 'robust and legitimised institutions' and 'agreed rules of the political game'). Historically determined institutions privilege certain social actors as well as define and mediate the range of interests, distribution of resources, sources of conflict, and range of coalitional opportunities (Yashar, 1997:15).

In addition to a tale of exceptional individuals who acted beyond the call of duty and left an indelible imprint on the history of AIDS in Uganda, the story of TASO is therefore also the story of Ugandan post-civil war political development, the Museveni government's response to the AIDS crisis and the actions of international donors. To a significant extent, TASO's choice to focus on service delivery (rather than activism) reflects, on the one hand, the inability of the Ugandan state machinery to provide the required services, and on the other a political system and culture that limits the freedom of civil society to speak up in opposition to the government (see Scholte, 2004:229), despite the relative independence of civil society (De Waal, 2006:108). But its effectiveness has also depended on a largely supportive state that encouraged civil society (including NGOs like TASO, faithbased organisations and foreign charities) to do what it could not, as long as this work did not threaten the consolidation of its power.

Putzel (2004:23-26) reviews the early efforts of the Ugandan government to respond to AIDS in some detail. He argues that while Uganda faced many of the same pressures as other African governments and that its adoption of a vigorous campaign was not unproblematic - for example, there was a significant backlash against (especially foreign) doctors who spoke to the international press in order 
to highlight the crisis and attract foreign assistance. However, the Museveni government did start responding to HIV shortly after coming to power: upgrading a subcommittee that had been set up by the Obote government to the National Committee for the Prevention of AIDS (NCPA) in October 1986 and making use of a World Health Organisation mission to Uganda in January 1987 to draw up a short-term intervention plan and a medium-term five year action plan. These plans formed the basis of the Aids Control Programme (the first in Africa) and a donor conference in May 1987. The President made a number of high-profile speeches in which he drew attention to AIDS, and in December 1988 he unambiguously declared AIDS a major national priority, calling for an all-out public education campaign. Putzel (2004:26) attributes the willingness of the Museveni regime to tackle AIDS head-on to four factors: (1) Museveni listened to medical experts and chose to base policy on scientific evidence rather than myths associated with HIV/AIDS, (2) the 'incentive structure' facing the government meant it had little to lose and much to gain by taking action, (3) the impact of high-level political commitment "put the epidemic beyond partisan politics" and (4) a "firm coalition behind the President's HIV/AIDS campaign."

The primary purpose of this chapter is not to investigate Museveni and the National Resistance Movement (NRM) government's motivations for taking action on AIDS, but it is important to interrogate these and other factors in order to understand the political context within which civil society leadership took place and that shaped the government's and civil society's responses as well as the interplay between them. In particular, I will return to the role of foreign donors in shaping the response. For now, however, I would like to point out a number of things. First, Putzel makes the common mistake of exaggerating the impact of the Ugandan government's early efforts, crediting it with bringing the epidemic under control on the basis of the prevalence declines observed in the mid-1990s (Putzel, 2004:19). As I argued in the introduction to this chapter, these efforts may have been effective to a degree, and are certainly deserving both of praise and of political analysis (given the relative uniqueness of the political commitment), but they could not have been the decisive factor in the course of the epidemic given that incidence declines probably started in the first half of the 1980s, before Museveni took power, and given that prevalence declines can be attributed to deaths exceeding 
new infections in the first half of the 1990s. Second, and this is not necessarily in conflict with Putzel's arguments, several Ugandan respondents attributed Museveni's vigorous leadership to the very real threat that HIV/AIDS in the military represented to the new government's power base, given that it had come to power by military means. This argument is echoed in the literature (see Ostergard and Barcello, 2005; Tumushabe, 2006; De Waal, 2006). In fact, Museveni himself has cited an incident where significant proportion of Ugandan army officers sent to Cuba for training tested positive for HIV and Cuban President Fidel Castro personally informed Museveni of the problem (Garbus \& Marseille 2003:1 1-12, cited in Ostergard and Barcello, 2005; De Waal, 2006:97). Furthermore, the new NRM government was heavily reliant on donors and needed to legitimate itself in the eyes of the international community in addition to the Ugandan public. Tumushabe (2006:8) has argued that the Ugandan 'success story' on HIV/AIDS became a critical "approval and marketing issue" for the government, and De Waal (2006:96) points out that Museveni started to trumpet his success on AIDS in the late 1990s in order to use it for political credit.

As argued earlier, TASO was founded in the context of a very weak healthcare system without the capacity to care effectively for the deluge of AIDS patients. The country had just emerged from a long period of economic mismanagement (under the Amin and second Obote regimes) and war that had decimated its infrastructure and economy. If the government were to stand a chance of successfully dealing with the impact of AIDS, it would therefore need all the partners it could get. The donor conference of May 1987 indicates that the government understood that it needed international support. But for implementation it would need local partners. When government officials became aware of TASO, they responded in a highly supportive fashion. TASO was provided with facilities at Mulago hospital (and later at hospitals throughout the country) and Noerine Kaleeba was appointed to the committee in charge of the AIDS Control Programme, apparently at the behest of President Museveni himself. Noerine Kaleeba explains:

I remember the first meeting I had with [President Museveni]. I said, "Mr President, ... I would like to do something about this disease. We have a small group set up..." I don't think he listened very much 
to what I explained about TASO, but he did say [to the head of the AIDS Control Programme], "put that woman on the committee." So when I look today at many leadership attempts by different people on the HIV front in many countries in Africa, [I realise that] I was in a country where the terrain had been set [for civil society to respond]. I think the government had already made a decision that if someone comes up and wants to do something about HIV that is correct [they should be encouraged]. So we didn't have to contend with government opposition. ${ }^{14}$

According to Thornton (2008:131), the government of Uganda began to realise in the late 1980s that AIDS was not merely a medical matter that could be dealt with through the health system alone. It started developing an approach that would yield a nationally-integrated AIDS response, bringing together all governmental organs, state-supported institutions (like schools and clinics) as well as civil society (i.e. non-governmental organisations, 'community-based organisations' and 'faith-based organisations'). This became known as Uganda's 'multisectoral approach.'

A sense of partnership therefore characterised the relationship between TASO and the Ugandan government from early on. However, over time and as TASO grew in size and influence, disagreements inevitably emerged. ${ }^{15}$ Many Ugandan AIDS activists and civil society leaders argue that TASO has failed to play a leadership role in civil society and in particular failed to support efforts to hold government to account. ${ }^{16}$

In contrast with more militant activists, interviews with senior TASO leaders indicate a general unwillingness to acknowledge conflict with government or serious failures in governmental leadership (although some are willing to recount episodes of conflict off the record). This seems to reflect a fear that open criticism would undermine TASO's partnership with the Ugandan government and consequently threaten service delivery (which is predicated on access to hospital in-

\footnotetext{
${ }^{14}$ Interview, N. Kaleeba (16 October 2008).

${ }^{15}$ Interview, A. Coutinho (14 October 2008).

${ }^{16}$ Interviews, M. Katana (24 October 2008); B. Were (30 October 2008); A. Muhinda (27 October 2008).
} 
frastructure, etc.). This belies the conventional wisdom about Uganda's 'openness' and 'partnership approach'.

While the early leadership of the Museveni regime (and of President Museveni himself) are rightly lauded, therefore, this reputation is largely based on events of the late 1980s and 1990s and must be interrogated in the light of more recent events.

\subsection{Puritanism, authoritarianism and 'partner- ship institutions' beholden to the executive}

In recent years, governmental leadership on HIV/AIDS is widely perceived to have declined in quality and vigour. A number of respondents indicate that President Museveni seems to have 'withdrawn' from the AIDS response, while others worry about shifts towards less progressive government policy on AIDS. Developments causing widespread concern include, for example, increased hostility to condom promotion, a proposed law that would criminalise deliberate HIV transmission and most recently the introduction of the Anti-Homosexuality Bill in 2009, which, while not (yet) passed, received substantial support in Ugandan society, including from prominent members of the NRM and the government. ${ }^{17}$

A puritanical and socially conservative agenda is not new in Uganda, and

\footnotetext{
${ }^{17}$ At the time of my fieldwork, the introduction of the Anti-Homosexuality Bill of 2009 and the international uproar which it occasioned had not yet occurred. The bill was introduced by Member of Parliament David Bahati in October 2009 as a private member's bill. While samesex relationships are already criminalised in Uganda (dating from British colonial rule), the bill would exacerbate repression and discrimination by introducing two new offences, 'the offence of homosexuality' carrying a penalty of life imprisonment and 'aggravated homosexuality', defined to include homosexual acts with a minor or by a person who is HIV-positive, and which would carry the death penalty. Despite strong condemnation from various quarters, including Ugandan lesbian, gay, bisexual and transgender (LGBT) activists and international human rights organisations, the bill has received substantial support from the Ugandan public and in the Ugandan media, which has framed criticism of it as 'Western interference' and as a battle over Uganda's moral self-determination (Sadgrove et al., 2012:105). While the bill has not been passed, nor has it been formally withdrawn (Amnesty International, 2012:30). The bill and the wave of homophobic sentiment expressed in the wake of its introduction seem to have tapped into a stridently socially and sexually conservative agenda in Uganda, which enjoys both public support and has powerful backers in the Museveni regime. A tragic and possibly related event has been the murder of Ugandan gay activist David Kato in January 2011 (for which a man has since been convicted, without evidence of a link to Kato's LGBT activism coming to light).
} 
elements of it can be discerned even in the early discourse on HIV/AIDS from Museveni and his government. De Waal (2006:98-105) points out that the lauded 'ABC' message of the Ugandan government has always been a rather mixed and inconsistent one, often tailored so as to please or avoid offending specific audiences. On numerous occasions the president has attacked condom promotion, especially to young people. His wife, Janet Museveni (an outspoken 'born-again' Christian), has been particularly vigorous in her condemnation of condom promotion to young people, saying to a conservative audience in the United States:

Condom use, as a preferred method of prevention or reduction or infection, is definitely not in the interest of Ugandans. Our people are still poor and the majority of them still live in remote villages in rural areas. Even if they had money to buy condoms regularly, they would find it a problem to access them. When condoms are not used consistently, they are even less effective. Therefore, it is wiser to show our people that there is a surer way to stay safe and alive; because the truth is that there is no "safe sex" outside of the situation of faithfulness to a partner.

Giving young people condoms is tantamount to giving them a license to go out and be promiscuous; it leads to certain death. (Museveni, 2004).

In the mid-2000s, the United States became (by far) the largest donor funding Uganda's AIDS efforts through the President's Emergency Plan for AIDS Relief (PEPFAR). But, as noted earlier, the programme's origins as a Bush initiative with the support of political Christianity in the United States meant that it came encumbered with policies rooted in a conservative religious agenda (such as reservation of funds for faith groups and for abstinence-based prevention programmes). As Epstein and Halperin (2007:185-201) shows, this conservative religious agenda found fertile ground in certain sections of Ugandan society, in particular a number of conservative church groups and the first lady, who led a backlash against condom promotion programmes. By 2008, this constituted a significant worry for civil society leaders, including the former director of TASO, Dr Alex Coutinho, who obliquely criticised the Museveni government (referring to an approach that 
is "anti-condoms and a little bit pro-abstinence") and arguing that Museveni had to be brought back to the forefront of HIV prevention efforts. ${ }^{18}$

It should therefore be kept in mind that the open and enabling approach of the Ugandan state, was not simply the product of 'good leadership', but to a great extent reflected structural factors like its dependence on donor funding, its lack of capacity to combat HIV/AIDS through established public health infrastructure and the new regime's need to consolidate its power.

The reticence of TASO leaders to express criticism and a general weakness on the part of civil society organisations with respect to political advocacy (described by respondents as a 'failure to hold government to account') reflects, at least in part, a political culture and institutional arrangements that discourage criticism of the government (and the President in particular). A number of respondents indicated that there are personal and professional risks to being perceived as critical - ranging from exclusion from consultative forums, being cut off from sources of funding and even personal harassment and intimidation.

Uganda's transition to multi-party democracy is relatively recent $(2005)^{19}$ and the protection of civil liberties much weaker than in South Africa, leaving civil society with substantially less space for oppositional activity. Makara et al. (2009) point out that the decision by the NRM to engineer a return to multiparty politics (while driven more by internal factional conflicts than by donor pressure) was coupled with constitutional changes designed to actually entrench the powers of the executive and the authority of the central political leadership. Makara (2010) further argues that the return to multiparty politics has not resulted in democratic consolidation, nor have elections advanced democratic freedoms. At the local level, the reintroduction of multiparty politics made little difference to the dyanmics of political contestation, and most candidates preferred to remain aligned to the NRM or stand as independents, with very few joining opposition parties (see Muriaas, 2009). The NRM therefore continues to dominate politics at both the local and

\footnotetext{
${ }^{18}$ Interview, A. Coutinho (14 October 2008).

${ }^{19}$ Uganda's political system, before the return to multi-party elections after a referendum in 2005, allowed individuals to contest seats within the fold of the National Resistance Movement, but did not allow opposition parties. The NRM presented itself not as a political party, but as a 'movement' representing all Ugandans and a vehicle for local (village-level) representative politics. This was often referred to as 'non-party democracy' or the 'movement system'.
} 
national levels. The authoritarian style of Ugandan democracy, and of Museveni's leadership, is reflected in the regime's response to challenges to Museveni's authority. For example, after Museveni's former physician Kizza Besigye ran for president in 2001, Museveni's campaign was characterised by open violence and intimidation, with Besigye fleeing into exile after the election (Izama and Wilkerson, 2011:65). After the February 2011 elections, during which Museveni again defeated Besigye, brutal state repression met peaceful 'walk to work' protests over fuel prices, in which several people died and Besigye was arrested so violently that he had to be hospitalised in Kenya (Izama and Wilkerson, 2011:64-65).

Weak civil liberties, state control of much of the press, and power concentrated in the hands of the President (coupled with widespread poverty and limited opportunities for economic advancement) therefore create a 'political opportunity structure' in which it seldom makes sense for civil society to challenge state authority. The risks of doing so are simply too great. In addition, officials are likely to be primarily concerned with their own survival, rather than their formal or moral duty - when this duty is in conflict with the interests of the political elite. It would be simplistic to term this a 'predatory coalition' in the sense of Leftwich and Hogg (2007), because often 'good leadership' (both from the bureaucracy and from civil society) has indeed occurred, but it certainly closes down space for acting against the interests of the President or the political elite (for example by strongly contesting anti-condom rhetoric and policies emanating from Museveni's inner circle).

The custodian of Uganda's 'multi-sectoral' partnership approach and the body charged with coordinating the AIDS response - the Uganda AIDS Commission (UAC) - is widely seen as being under the control of and serving the interests of the Museveni regime. The UAC exercises its coordination role through a Partnership Forum (an annual meeting of stakeholders from all sectors) and a Partnership Committee which meets regularly and takes day-to-day decisions, including on resource allocations. The Partnership Committee also acts as the Country Coordinating Mechanism for the Global Fund ${ }^{20}$ and controls a joint Civil Society

\footnotetext{
${ }^{20}$ The Global Fund disburses funds through Country Coordinating Mechanisms in which civil society and governments are supposed to be represented. The current Ugandan arrangement was the outcome of a consultative process after the Global Fund suspended Uganda's grants in 2005 after serious mismanagement of funds by the relevant agency in the Ministry of Finance, Planning and Economic Development. Global Fund grants are now dwarfed by those of PEPFAR.
} 
Figure 5.4: Partnership mechanism of the Uganda AIDS Commission

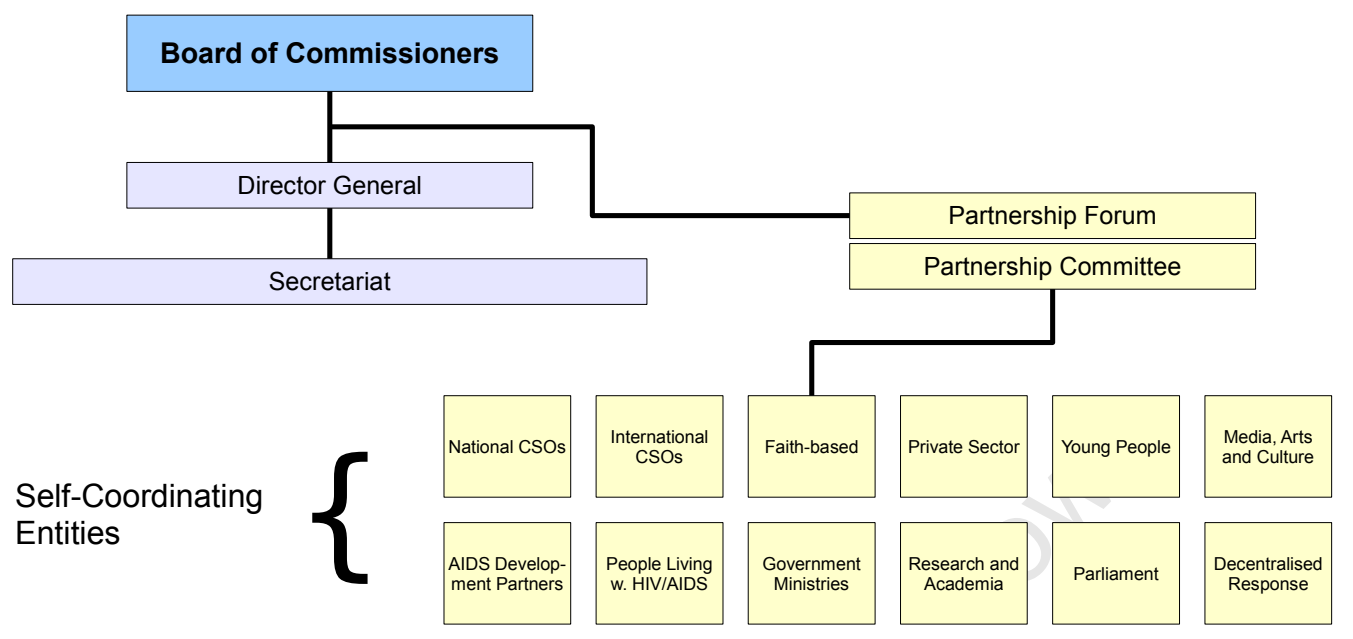

Fund (often referred to as a 'basket fund'), through which pooled donor contributions are disbursed to civil society organisations. As can be seen in Figure 5.4, sectors are organised into 'self-coordinating entities' that are supposed to develop joint policy positions and present these to the Partnership Committee on behalf of their constituencies. While there are twelve such entities, the primary function of the partnership mechanism is to coordinate the work of civil society (international, domestic and faith-based civil society organisations), donors and government. At the district level there exists a similar set of structures known as the District AIDS Coordination Committees, with representation from the political leadership of the district, government departments, local civil society organisations, the private sector and people living with HIV/AIDS.

The Director General of the UAC, Dr David Apuuli, argues that these structures are uniquely able to foster cooperation and coordination in the HIV/AIDS response because they are established by law. The Ugandan government is therefore compelled by law to meet regularly and come to joint decisions with donors, civil society and other sectors. National strategic planning on AIDS is a competency of the partnership structures. ${ }^{21}$

\footnotetext{
${ }^{21}$ Interview, D. Apuuli (21 October 2008).
} 
In reality, however, neither the UAC nor its partnership mechanism is independent of government. All commissioners are appointed by President Museveni and its Director General is perceived by independent civil society as highly protective of the President's interests. ${ }^{22}$ The UAC is not seen as effectively exercising its coordination function (neither generally nor with respect to civil society). ${ }^{23}$ Tellingly, the Director General of the UAC refused to acknowledge any conflict between civil society and the state and denied all problems with the partnership mechanism raised by other respondents. When pressed on his claim that decisions are taken by consensus and his denial that critical civil society voices were being silenced, he argued:

First of all you must understand that civil society is diverse - there are some small, there are some big - they are set up for different philosophical reasons, some are philanthropic... So you can imagine that they have different capacities, right? So that type of thing is due to happen because there are different stages of evolution and strength. Yes there are cases where we have had to sit and say "look, how do we reach a decision on this particular matter?" But we have always reached these decisions by consensus - it does not mean that the decision might have necessarily pleased everybody but the decision has been reached by majority consensus. Obviously it may not take [all] opinions and feelings [into account], but this happens in every society, you see? ${ }^{24}$

The recently established Civil Society Fund, operating under the auspices of the Partnership Committee (and supported by many of the donors) is also widely perceived as an attempt to gain control over donor funds for civil society in order to deny resources to organisations critical of the government. Despite the fact that it is still small, some of the more independent sections of civil society fear that it is effectively being turned into what could be termed a 'patronage fund' and may be

\footnotetext{
${ }^{22}$ Interviews, M. Katana (24 October 2008); B. Were (30 October 2008) and others.

${ }^{23}$ Interviews, L. Mworeko (14 October 2008); M. Katana (24 October 2008); B. Were (30 October 2008).

${ }^{24}$ Interview, D. Apuuli (21 October 2008).
} 
used to silence critical voices. ${ }^{25}$

Beatrice Were, one of the highest profile AIDS activists in Uganda and founder of the National Community of Women Living with HIV/AIDS in Uganda and former country director of ActionAid Uganda, argues that this problem is central to the failure of the Uganda AIDS Commission to play an effective coordination role:

It [the UAC partnership mechanism] is one of those mechanisms where I only feel their intensity in the room - I don't feel their impact in the community. People don't even know that it exists. To be honest, the Uganda AIDS Commission hasn't been effective in coordinating the AIDS response in the country. ...Any role where they take the lead is yet to be effective. But I think the other challenge why things are the way it is - from a civil society perspective - I think the independence of civil society is completely lost once you are there. Because the Uganda AIDS commission is ... a political institution and for civil society to be able to cause change ... [they have to] raise issues ...you have to have a degree of autonomy. I feel that through the partnership forum a lot of autonomy was lost from civil society, from activists. I also feel very strongly that there is a degree of [sic] people who are compromising their values because you have to be nice. Because now the Uganda AIDS Commission also accesses funding - the basket funding business - and they determine who receives it. So what it is is that you have to compromise certain values and be a nice person, be a nice organisation, be a nice leader in terms of not being the loud one. So that you can get the money. ${ }^{26}$

But the unwillingness of large civil society organisations like TASO to openly criticise the government, the UAC or their major donors (most significantly PEPFAR) seems to confirm that these fears are not entirely unfounded.

\footnotetext{
${ }^{25}$ Interviews, L. Mworeko (14 October 2008) and M. Katana (24 October 2008).

${ }^{26}$ Interview, B. Were (30 October 2008).
} 


\subsection{Holding the purse strings: the impact of donors}

Dr Apuuli denies that donors exert undue influence over policy processes:

I can assure you, when we decide on what shall be in the National Strategic Plan, when we do the [annual] joint review and come up with priority actions that we must do as a country for the next two years - it is not the [prerogative] of the donors to make that decision. That decision is reached by consensus and collectively, and the donors do follow what we have said they are going to do. ${ }^{27}$

But donors do have substantial influence on policies and outcomes in countries that are heavily dependent on foreign aid (Mayhew, 2002). This is particularly true in Uganda (in contrast to South Africa), where the majority of spending on AIDSrelated programmes are sourced from external sources and even state agencies like the Uganda AIDS Commission and programmes in the Ministry of Health rely for the bulk of their funding on foreign donors. More than 90\% of all AIDS spending and $93 \%$ of the UAC's budget were externally sourced in the $2001 / 2002$ fiscal year (Tumushabe, 2006:6) - and this is unlikely to have changed significantly in the interim. TASO is the major provider of medical services to HIV/AIDS patients, including the vast majority of antiretroviral therapy, and obtains all of its funding from donors.

This influence may serve (consciously or unconsciously) to broker effective AIDS response coalitions or to inhibit their formation. Their clout in Uganda has allowed the development partners to push for the inclusive partnership approach and for an enabling environment that would allow civil society to participate effectively in the AIDS response. But paradoxically, donors have also helped to inhibit the development of a vocal and independent civil society sector capable of holding the state to account.

It is important to recognise that political context and opportunity structures change over time and that this may profoundly affect the evolution of movements

\footnotetext{
${ }^{27}$ Interview, D. Apuuli (21 October 2008).
} 


\section{Figure 5.5: The US remains the most influential donor in Uganda through PEPFAR}

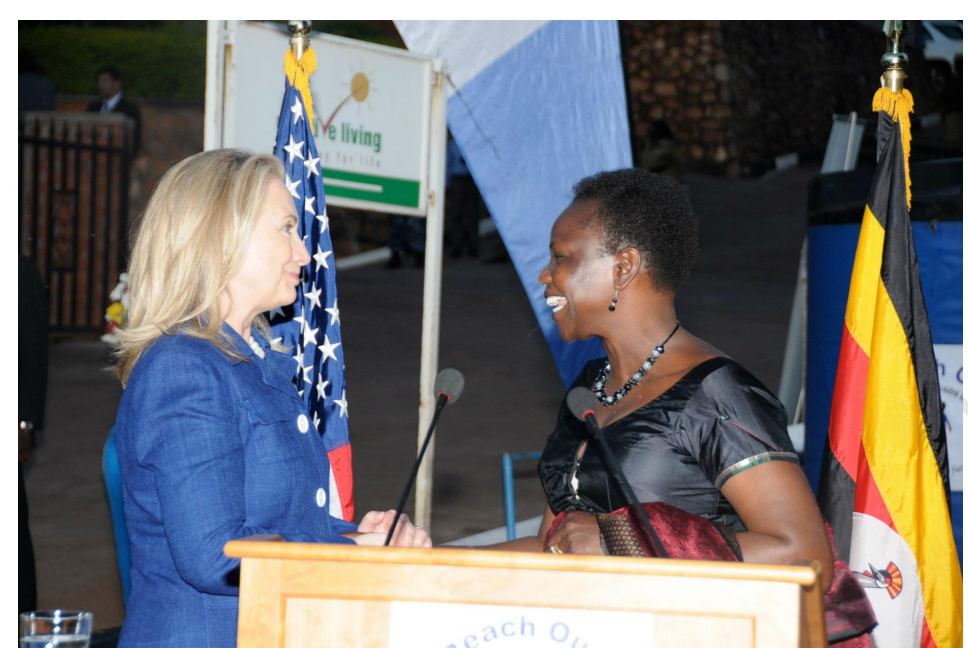

U.S. Secretary of State Hillary Rodham Clinton and current Ugandan Minister of Health Dr. Christine Ondoa at a PEPFAR-funded health clinic in Kampala (3 August 2012).

Source: US State Department. Used under Creative Commons Attribution licence. http://www.flickr.com/photos/us_mission_uganda/7723417228/

and coalitions. As the political and institutional landscape evolved in Uganda, attempts were made to close down the space for independent civil society organisations, even as the political system moved to greater openness. Institutional arrangements and historical factors profoundly shape the coalitional opportunities facing civil society actors, including opportunities to forge the state-civil society partnerships that ought to lie at the heart of AIDS response coalitions.

The influence of donors is felt in a number of ways: through direct conditionalities imposed on the receiving state and choices over which programmes and organisations to fund, but also more subtly through the competition over resources between the state and civil society as well as within civil society. The clout of donors is demonstrated by the resolution of a disagreement between TASO and the government over who was to provide the bulk of antiretroviral therapy, which was decided in TASO's favour largely because this was the preference of PEPFAR.

In situations where civil society is not well-developed or the political culture and institutions inhibit openness and broad participation in policy formulation and im- 
plementation, the potential for donors to broker inclusive coalitions is significant. The Ugandan state's lack of capacity in the late 1980s, and its resulting dependence on donors and civil society organisations to provide public services, was arguably the major factor in its adoption of an approach characterised by partnership with civil society. Unlike South Africa, where legal arrangements guarantee the freedom of civil society organisations to operate, Ugandan civil society depends on the continued tolerance of the state.

Keck and Sikkink (1998) identify a 'boomerang pattern' of influence, in which civil society organisations can obtain leverage over the state in situations where direct channels between it and the state are blocked. International allies - usually Northern NGOs, but sometimes intergovernmental organisations or bilateral or multilateral donors - can bring pressure to bear from outside, either directly or via Northern states (see Figure 3.3 on page 67). De Waal (2006:58-59) argues that this pattern is responsible for much of the success of AIDS activism in Africa, where domestic activists have been able to exploit transnational networks comprising international NGOs, intergovernmental organisations (including those of the UN system such as UNAIDS) and, crucially, donor governments as a means of leverage over their own governments - even in the most closed polities. However, the fieldwork conducted for this chapter also points to significant risks associated with powerful donors. Donors may dominate the AIDS response agenda, inhibiting open engagement and inhibiting the ability of domestic actors to build locally appropriate institutions and coalitions. Financial assistance has been used to advance a particular ideological agenda driven by the domestic politics of the donor country (and which may consequently be inappropriate), as happened with respect to condoms vs. abstinence-based prevention efforts during the years of PEPFAR as a Bush Administration initiative. Further, donors may be overly concerned with maintaining their partnership with the state, and consequently fail to support and perhaps even unintentionally undermine the development of an independent and critical civil society sector, as seems to be happening (at least to some extent) with respect to the civil society 'basket' fund administered by the UAC.

As mentioned earlier, TASO's largest funder, PEPFAR, has placed constraints on its prevention activities. ${ }^{28}$ According to activists, the alliance between the Bush

\footnotetext{
${ }^{28}$ Interview, A. Coutinho (14 October 2008).
} 
administration and conservative forces in Uganda have undermined the country's prevention efforts and threatened the reductions in HIV prevalence that occurred in the 1990s. ${ }^{29}$ PEPFAR imposed religiously-inspired conditions on recipients that undermined locally-appropriate policies (see Epstein and Halperin, 2007). Furthermore, there is some evidence that donors have discouraged vocal activism and failed to support the more radical civil society organisations. ${ }^{30}$ TASO was unable to escape the control of donors - or adopt a donation policy similar to TAC's refusal to accept funds from either the US or South African governments - because of its substantial service delivery burden. It requires both large amounts of funding from donors like PEPFAR that have sufficient resources to support large-scale antiretroviral treatment programmes and a good relationship with the state in order to meet its obligations successfully.

An important general conclusion is therefore that successful AIDS response coalitions do not imply the resolution of all conflict and contestation. In fact, suppressing conflict may harm the long-term effectiveness of coalitions by undermining the ability of civil society actors to influence policy through strong and independent positions and to engage in vigorous advocacy.

\subsection{Movement evolution: from volunteer net- work to professional service delivery organ- isation}

While the formal and semi-formal networks out of which civil society coalitions are built ('activist networks') are critical to mobilising resources in order to influence policy, dense informal networks consisting of relationships of trust are also critical in building social movements (see chapter 3). Both TAG and TASO drew heavily on pre-existing networks of friends, colleagues and acquaintances to launch the movements, but quickly pulled in like-minded individuals and created links with significant outside actors. TASO's founders did not have access to a pre-existing

\footnotetext{
${ }^{29}$ Personal communication with Gregg Gonsalves and Zackie Achmat.

${ }^{30}$ Interviews, L. Mworeko (14 October 2008); M. Katana (14 October 2008) and B. Were (30 October 2008).
} 
Figure 5.6: Sign for the TASO clinic in Tororo, Uganda

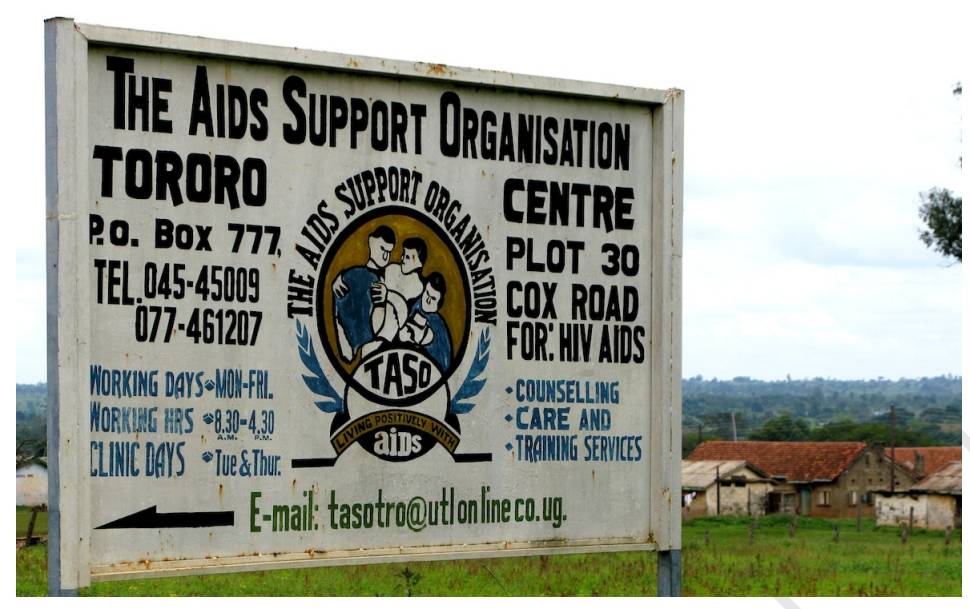

Source: Author's collection. Taken 23 October 2008.

network as geared towards collective action as that of TAC's, or at least not as politically-oriented. Nevertheless, personal friends and acquaintances-especially those formed within the context of Mulago teaching hospital in Kampala-formed the core of the early group (see Ssebanja, 2007). The importance of personal ties in these networks is confirmed by the frequent references by respondents who were involved in the founding of TASO to a 'family spirit' that governed their activities. This sense of TASO being a closely-knit family has survived largely in name, but probably contributed significantly to the early development of the organisation. Decision-making in the early history of TASO was largely informal and consensual, driven by Kaleeba and a few others. ${ }^{31}$

It is notable that the founders of both TAC and TASO were members of educated and well-connected elites. Even though Achmat was not particularly close to the post-apartheid ruling elite in South Africa and Kaleeba was not involved in political and policy issues before founding TASO, both were comfortable in elite circles and capable of engaging in policy debates in a way that most people in the poor and marginalised communities on whose behalf they were acting could never be. This enabled both organisations to mobilise support quickly from other do-

\footnotetext{
${ }^{31}$ Interviews, N. Kaleeba (16 October 2008) and P. Ssebanja (15 October 2008).
} 
mestic and international elite actors and to build support and influence networks.

I described how Kaleeba travelled to Geneva and met Jonathan Mann. She also formed links with AIDS activists and AIDS service organisations in the United Kingdom, some of which later supported TASO through training and funds. ${ }^{32}$ TASO immediately drew on the links Kaleeba established with AIDS activists in the UK and pursued support from and partnership with both the government and other local civil society organisations.

Movements (and the coalitions that they form or participate in) necessarily evolve over time. Their evolution is shaped by changes in the political context and opportunity structure, by their assessment of their own role and often by the influx of resources (with the formalisation of structures and processes that the latter requires). Some movements never progress beyond an informal (almost anarchist) phase, either because they reach their goals, circumstances render them obsolete or because their internal dynamics drive them to dissolution. Other movements, however, transform and grow. Most chapters of ACT UP - the most prominent and radical of the early AIDS activist organisations in the United States - dissolved after a few years without ever establishing formal structures (Smith and Siplon, 2006), although many prominent ACT UP members formed more permanent organisations and most long-term American AIDS activists cut their teeth in ACT UP.

Most often successful sustained social movements attract donor interest and funding, which creates pressure to formalise and institutionalise their operations. This may create tension between the charismatic and inspirational leadership required to build a social movement and the institutionalised, professional management required for sustainability and efficient service provision. Some activists express resentment over the emergence of a class of 'parasitic' AIDS professionals who are drawn to the field primarily by the promise of jobs and status, and NGOs that are set up in order to make use of the opportunities afforded by an inflow of resources:

And of course, as more money has come into the country it has become like a business. Many professionals - and I wrote this in one of

\footnotetext{
${ }^{32}$ Interview, N. Kaleeba (16 October 2008).
} 
my papers recently - have even put aside their mainstream professions and got involved in AIDS work because it's attractive, it's lucrative because of the money. And those people are not providing leadership, but they are parasites - they are like the opportunistic infections that come along with HIV infection itself. ...the people who are providing leadership are not given the right space, the professionals are kind of taking over the space which was formerly occupied by the likes of Noerine Kaleeba, by the likes of Major [Ruranga] Rubaramira, ${ }^{33}$ by the likes of Beatrice Were. But now you are getting professionals. ${ }^{34}$

Like TAC, TASO initially relied principally on relationships of trust and the strong cohesion brought about by charismatic leadership. But as the movements grew, TAC stuck more closely to its roots as an activist organisation, while TASO invested in developing professional management systems. This is reflected in employment practises, with most TASO staff recruited through formal processes on the basis of professional skills and qualifications. Noerine Kaleeba recounts how the TASO leadership made an explicit decision early in its history to build formal systems. ${ }^{35}$ Donors have also invested substantially in the development of its managerial systems, as confirmed by Elise Ayers, the chief of HIV/AIDS for USAID ${ }^{36}$ in Uganda. ${ }^{37}$

TASO has benefited from the strength of its management systems, but has also lost credibility as a social movement and the weakness of its advocacy work has been blamed on it being dominated by professional managers. ${ }^{38}$ Says prominent activist Milly Katana (who is HIV-positive and works for the International HIV/AIDS Alliance in Uganda):

I think [TASO] has lost the crowd. ...TASO is riding on the back of its history, not on its current back or its future back. Of course it's the

\footnotetext{
${ }^{33}$ Major Ruranga Rubaramira is the director of the National Guidance and Empowerment Network of People Living with HIV/AIDS. He has been living with HIV since 1989 and is a prominent PLWHA leader in Uganda and internationally. He was interviewed for this research.

${ }^{34}$ Interview, M. Katana (24 October 2008).

${ }^{35}$ Interview, N. Kaleeba (16 October 2008).

${ }^{36}$ The United States Agency for International Development (USAID) - the US bilateral aid agency - is also a significant funder of TASO.

${ }^{37}$ Interview, E. Ayers (29 October 2008).

${ }^{38}$ Interview, M. Katana (24 October 2008).
} 
biggest - outsiders trust it, value it, they give them more money and they are expanding services, which is great. But to me that doesn't mean that they are leaders. To me these are different things: you can be the biggest provider of services, but that charismatic leadership which we look for in a situation of HIV, which is a complex disease- - I don't think you can find that in TASO. ${ }^{39}$

\subsection{Concluding thoughts}

While the definitional difficulties around 'leadership' remain, effective AIDS leadership can meaningfully be described as the mobilisation of coalitions around AIDS prevention and treatment. A broad coalition that includes civil society, the state and the international community has helped Uganda to mobilise one of the more effective AIDS responses in Africa, even if the effectiveness of this response has sometimes been exaggerated. The AIDS response coalition in Uganda, which included the state, civil society, donors and the medical and research communities, has been particularly effective at expanding antiretroviral treatment access in spite of the severe resource constraints evident in the Ugandan health system.

The coalition was built, at least in part, out of networks of individuals: exceptional individuals like Noerine Kaleeba and Elly Katabira were able to build local and international networks of influence and support that were critical in transforming TASO from a small and informal group of volunteers into one of the largest and most professionally managed AIDS organisations in the world. In general, these individuals and their networks were people with education, experience and useful connections (both local and foreign), which they were able to exploit in order to mobilise a coalition for action on AIDS.

However, the evidence also shows that political context and opportunity structures, including, especially, constitutional and institutional arrangements, political culture, state actions and donor actions, shaped the choices of individuals and organisations and - crucially - presented civil society with coalitional opportunities. The coalitions that emerged are therefore best thought of as structure-agency configurations in which both systems and institutions and individuals play important

\footnotetext{
${ }^{39}$ Interview, M. Katana (24 October 2008).
} 
roles. The fact that Uganda had very weak state capacity - at a time when one of the world's worst HIV epidemics was ravaging the country - left the new Museveni government little choice but to pursue an 'open' and supportive policy with respect to civil society and the donor community. At the same time, the weakness of democratic institutions and a political culture that discouraged open criticism and dissent has limited the space for a vocal and independent civil society. The power of donors further (often inadvertently) undermined the freedom and independence of civil society. However, this very power has also at times proved an important lever for influencing the state and the partnerships between donors and civil society organisations placed a limit on state repression by making these organisations essential partners for the state (if it were to avoid losing access to resources). This 'opportunity structure' has severely restricted the ability of Ugandan civil society to adopt an activist stance, either to contest policy (e.g. on condoms, commercial sex workers or men who have sex with men) or to hold government to account or pressure it into more effective delivery (e.g. on the severe and continuing failings of the Ugandan healthcare system or to press for greater investment in healthcare from domestic fiscal resources).

As TASO grew in size and prominence and attracted resources, it faced pressure to formalise its structures and activities. It opted for a much more formal service delivery-oriented model than organisations like TAC, or even some of the smaller organisations in Uganda, and embraced a relatively rigid corporate model. This allowed it to substantially strengthen its capacity to provide services, but also undermined its credibility as an activist movement and to a certain extent it had to cede moral leadership to other civil society actors. However, the ability of the rest of Ugandan civil society to hold the government to account remains weak, owing to the limited number of individuals and organisations who choose an activist route, in part as a result of the influence formal partnership structures give the Museveni regime and conservative donors. Donors have a potential role in brokering effective coalitions, particularly where civil society is not well-developed or if the political institutions and constitutional arrangements inhibit openness and broad participation in policy formulation and implementation. In Uganda, donors have helped strengthen the hand of civil society through the 'boomerang effect' but are also perceived as having shied away from investing in a truly strong and inde- 
pendent civil society sector. ${ }^{40}$ Furthermore, while PEPFAR has funded nearly all of the progress in treatment provision, it has also, under the previous US administration, pursued policies inspired by religious ideology and informed by domestic political considerations. Owing to current political realities in the United States and the weakness of the US and world economic recoveries after the 2008 financial crisis, the Obama administration has not been able to substantially scale up this investment. While the positive role of donors is therefore undeniable, an even more effective AIDS response coalition could arguably have been achieved had donors (and the US in particular) been more attuned to locally-appropriate policy and worked harder to support the emergence of truly independent civil society in Uganda.

In the case studies of South Africa and Uganda we have seen what 'civil society leadership on AIDS' has meant in practice in two important Sub-Saharan African examples. In the next and concluding chapter I reflect on some of the challenges for the global AIDS movement going forward, especially what kind of civil society leadership will be required if we are to continue to make progress in the struggle to prevent HIV and treat AIDS.

\footnotetext{
${ }^{40}$ Interviews, L. Mworeko (14 October 2008); M. Katana (14 October 2008) and B. Were (30 October 2008).
} 


\section{Chapter 6}

\section{Conclusion: The global AIDS movement in an era of resource constraints and shifting priorities}

The notion of 'AIDS leadership' remains a problematic one. While this thesis may have contributed to the conceptual clarification that is needed, the relationship between political leadership and civil society leadership is complex and further work is required. I have, however, provided some empirical detail that helps document what civil society leadership has meant in practice.

While cross-country quantitative analysis could not conclusively show that, or under which circumstances, civil society mobilisation results in improved government responses, the evidence from the case studies suggest mobilisation indeed makes a difference. However, the domestic political conditions under which movements operate and the international context (donors, intergovernmental organisations, etc.) profoundly shape both how movements evolve and what they are able to achieve. At the same time, the transformative leadership of certain individuals, and the 'networks of influence' that they construct or participate in, can result in the formation of coalitions with extraordinary power.

In South Africa, TAC managed to effectively oppose irrational government policy and overcome the entrenched interests of pharmaceutical companies. It also managed to impact measurably on HIV prevention at the community level, 
with evidence from survey data suggesting a beneficial effect on beliefs about AIDS and sexual behaviour relevant to prevention. In Uganda, TASO participated in an effective government-donor-civil society coalition that achieved notable successes, especially in AIDS care and treatment. However, activists found their freedom to mobilise constrained.

Both of these organisations, together with other transnational activists and certain key leaders within intergovernmental and state institutions, participated in the creation of a global coalition around the moral imperative of AIDS treatment. But this coalition today finds itself weaker, perhaps even in crisis.

\subsection{The decline of the global AIDS treatment movement}

Instead of the increases in resources for AIDS programmes in developing countries that would be required to sustain progress, resources are declining (or at best remaining static). The Global Fund is in crisis, HIV/AIDS is no longer perceived in international policy fora as the major priority it once was (with attention shifting to other important questions like climate change), HIV/AIDS and public health advocates are fighting among themselves about whether disease-specific programmes are appropriate and leading activist organisations (including TAG) are in decline. If the progress that has been made is not to turn into reverses, the global public health activist movement must be revitalised and a new coalition forged around a vision of universal access to integrated and effective healthcare systems.

TAC's time of greatest influence is therefore probably (and sadly) behind it. It is in the midst of a slow and incomplete leadership transition, from its founding generation of leaders to a new generation that is competent and committed, but has less experience and inherits a movement of tired activists. It is faced with a new set of challenges: ensuring continued progress in antiretroviral treatment delivery, revitalising a crumbling public healthcare system and improving HIV prevention. The end of state-supported AIDS denialism has (paradoxically) weakened TAC by removing a source of public support and attention. Donors are turning to other projects. It is unlikely that TAC can rekindle the energy and the public support it 
had a decade ago.

TASO continues to provide antiretroviral treatment and other services to large numbers of Ugandans in need. But it is entirely beholden to donors and it cannot expand services without increased external funding. Also, as a bureaucratic and formalised service-oriented organisation, it has to some extent lost its position of moral leadership and is no longer universally perceived sufficiently independent or as an effective or legitimate voice for people living with HIV/AIDS in Uganda.

This malaise extends to the global AIDS activist movement. Many passionate activists and advocates for AIDS treatment continue to work tirelessly. But the level of attention, both from the media and from policy makers, has declined substantially. Increasingly, attention is focused on other problems, especially the continuing global economic crisis (particularly acute in Europe) and the long-term risks of climate change (which is, even with increased attention, not being addressed adequately).

With high-income countries battling recession and stagnation at home, bilateral and multilateral assistance for HIV/AIDS have not increased since 2008, in contrast to the substantial increases that would be required to increase access to antiretrovirals beyond the mere $35 \%$ of the 15 million people who require treatment currently receiving it. The Global Fund has had to cancel its eleventh round owing to funding shortfalls. There is a long way to go, and now little chance of getting to the destination.

To make matters worse, the global health architecture created to give effect to the universal access vision is not functioning optimally. Allegations of corruption and suspension or delays in disbursements are routine for Global Fund-funded projects. Even TAC just narrowly avoided the shuttering of several large projects and the retrenchment of most of its staff early in 2012, owing to severe delays in the disbursement of Global Fund funds that had been allocated to it.

Furthermore, the oppositional discourse that has emerged in the debates on global health priorities has harmed the cause of increased resources, not only for AIDS, but for health in general. While AIDS activists, global health advocates and development experts have bickered about whether we should be investing in disease-specific programmes or strengthening health systems, whether we should be focusing on malaria or diarrhoeal diseases, donors have started to look else- 
where. For a discussion of the backlash against AIDS-specific funding, see Nattrass and Gonsalves (2010). Instead of "what should we be spending on rather than AIDS?" the question should have been "how can we best use the mechanisms and programmes we have built to ensure both increased delivery of AIDS treatment and stronger health systems?"

\subsection{What is needed?}

Reversing the declines in international AIDS assistance and building a new consensus on investment in global health requires that a new vision be articulated that can unite activists and policymakers in both donor and recipient countries. A good articulation of such a vision is provided by Mark Dybul (former US Global AIDS Coordinator), Peter Piot and Julio Frenk in a recent article (Dybul et al., 2012). They argue that while much of the progress achieved in the first ten years of this century has been thanks to newly-created disease-specific institutions and mechanisms (principally the Global Fund and PEPFAR) and large philanthropic initiatives like the Bill and Melinda Gates Foundation, "the focus on specific diseases has exposed fault lines in delivering services in places where many suffer from multiple health issues at the same time or at varying points in their lives" (Dybul et al., 2012). They propose instead an integrated approach focused on the health of individuals and communities to be driven through a new international health strategy and architecture comparable to the Bretton Woods agreement of 1944 and the institutions (like the World Bank) that gave effect to it.

A new international agreement to build a rational global health architecture is a very ambitious proposal indeed. But it is a vision that global health advocates - including those focused on HIV/AIDS - could potentially unite around and that can become the foundation for a moral consensus and policy agenda to drive a new round of activism. Unless the global health movement is able to overcome what I have referred to as the 'oppositional discourse' around conflicting international health priorities (HIV/AIDS programmes vs. health system strengthening, bed nets vs. sanitation programmes) it will not be possible to focus limited advocacy resources and stand a chance of building on the progress that has already been made in rolling out antiretroviral treatment in the poorest countries. 
In pursuing this ambitious agenda, iterative and incremental advances can be achieved. While a new global health architecture is some way off (even in the bestcase scenario), improvements can be made relatively quickly in the coordination and revitalisation of the architecture that already exists.

It is also critical that building new partnerships on global health is not limited to mechanisms for transferring resources from high-income to low and middleincome countries. Significant assistance will undoubtedly remain necessary, but even the poorest countries can and must invest in the health of their populations. Not only is it unlikely - especially in the short to medium term - that sufficient resources will be mobilised from high-income countries to maintain the momentum towards universal access, but there are significant risks associated with dependency on external resources. Even now many treatment programmes are at risk because of reductions in funding to PEPFAR and the Global Fund. Countries like Uganda cannot continue to depend on donor funds for more than $90 \%$ of health expenditure. Activists, especially those who are based in low-income and African countries, must exert pressure on governments to increase health expenditure, perhaps around the goal of $15 \%$ of national budgets that African Union members pledged to allocate to health in the Abuja Declaration of 2001. African countries have largely failed to implement this commitment, resulting in a lost decade of potential improvements in health systems, greater dependency on donors and a weaker moral voice when the leaders of the G8 and other wealthy countries are criticised for failing to implement commitments on international assistance.

It is also critical that AIDS and global health activists revitalise their own movements and organisations, in order to have a base from which to work. Organisations like TAC and the many similar movements across the developing world should be supported and assisted. They are the greatest asset of the global health movement, and its best chance of success. 


\section{Appendix A}

\section{The leadership literature: structure, agency, 'systemic leadership' and institutions ${ }^{1}$}

In this appendix I briefly review the literature on 'ethical leadership' with a view to thinking more coherently about 'AIDS leadership'. First, two approaches to leadership (the 'agential' and 'relational' perspectives) are differentiated. I then turn to the relevance of the literature on institutions for thinking about leadership before presenting a short summary of the relational model of transformative leadership we have proposed elsewhere (Grebe and Woermann, 2011:23-25,38-42).

The first thing to note is a major shortcoming in the mainstream leadership and business ethics literature: here, the focus is largely on 'character' - the ethical traits of individual leaders - insofar as these traits are believed to determine whether individuals behave ethically. This fits with the traditional notion of leadership as being about agency: the decisions that individual leaders make and how these decisions impact on the organisations they lead. The recent literature, however, has started to account for systemic influences on leadership processes. Since, as I have argued, both agency and structural factors (i.e. both how structural conditions influence individual behaviour and how individual choices can transcend those

\footnotetext{
${ }^{1}$ This appendix summarises a more extensive overview (emphasising different aspects of 'leadership'), produced jointly with Minka Woermann and previously published as a DLP Research Report (Grebe and Woermann, 2011).
} 
conditions) must be taken into account, it is this evolving 'systemic perspective' that we draw upon most.

It is in order to take account of structural factors that we turn to institutionalist approaches. However, two shortcomings in this literature, particularly where it is inspired by institutionalist economics, hamper its usefulness. First, little attention is given to the influence of individual agents/leaders on institutional structures, thereby veering towards the opposite extreme as the mainstream literature on leadership. Second, many institutionalist schools of thought adopt a strict rational choice model of human behaviour, in which institutions are seen largely as mechanisms to reduce transaction costs and foster cooperation. Consequently, a reductionist view of institutions emerges that does not adequately account for the historical contingencies that impact on institutional development and evolution, or the power-plays around their content and design; but, rather sees them as the products of rational institution building (see Offe, 2006:10-12). This reductionism and ahistoricity is to be avoided.

\section{A.1 'Agential' and 'relational' perspectives on leadership}

Uhl-Bien (2006:655) refers to the two perspectives identified above as the 'entity perspective' and the 'relational perspective' respectively. The latter is only now starting to emerge in the literature and shifts the focus from individual leaders and their character traits to the structural dynamics of leadership.

In the agential perspective leadership is treated in Cartesian terms, with the 'knowing individual' seen as "the architect and controller of an internal and external order" (Uhl-Bien, 2006:655). On this view, leaders can exercise influence and control over followers, and "organisational life is viewed as the result of individual action" (Hosking et al., 1995). This perspective may take the form of 'normative' or 'descriptive' approaches (focusing on what leaders should do and do do respectively).

In contrast, the relational perspective on leadership focuses on the interdependent and dynamic relations between stakeholders, and starts with processes rather 
than persons. It treats leadership processes as emergent properties of 'the system' (see Hosking, 2007; Uhl-Bien, 2006; Collier and Esteban, 2000). This implies that leadership, rather than being the exclusive preserve of 'leaders', is "stretched over the practice of actors within organisations" (Friedman, 2004:206) and "shared by members of an organisational system" (Painter-Morland, 2008:229). This is not to argue that individuals cannot assume leadership roles, but rather that different individuals can embody leadership roles at different times, depending on circumstances (Painter-Morland, 2008).

Rather than viewing distributed leadership simply as the 'sum of the parts' or aggregated influence of role-players (Wenger, 2000:231), it can be viewed in terms of joint or 'concertive action' (Gronn, 2003:35). This notion links up well with the idea of 'coalitions' that I also make use of in thinking about the influence of AIDS activists in the broader political and social system. Gronn (2003:35) characterises distributed leadership as concertive action in terms of three features: spontaneous collaborative models of engagement, intuitive understanding resulting from close working relations and institutionalised arrangements that attempt to regularise distributed actions.

All of these factors are evident in AIDS activism (see especially chapter 3). But they also seem somewhat trite, probably characterising all workplaces and not pointing to anything distinctive in 'ethical leadership'. However, they may help us think about the effectiveness of activists without falling into the trap of focusing exclusively on 'leaders' mobilising 'followers'.

\section{A.2 Extending the relational leadership per- spective by means of institutional analysis}

I should note at this point that I employ institutional analysis not merely to extend the relational leadership model. It is also directly applicable to the study of AIDS activism in that it can help us make sense of the constraints that are imposed by context, including the institutional architecture of societies. For example, the case studies in chapters 3 and 5 point to substantial differences between the trajectories of TAC and TASO, conditioned to a significant extent by divergent political and 
institutional contexts.

The importance of institutions in shaping developmental trajectories is widely acknowledged within the social sciences. However, as Offe (2006:9) points out, the term is seldom clearly defined and often used in such a way that it would be interchangeable with 'power' or even 'the holders of power', rendering it not very useful. Some conceptual clarification is therefore in order before we can deploy the concept productively. Before delving into the conceptual thickets, however, let us start off by defining institutions very broadly as the 'rules of the game' that establish the parameters of individual action and the procedures by which collective decisions are made, disputes settled and how power is wielded. While there are of course also institutions that govern private behaviour, we are primarily interested in what occurs in the public sphere, including politics and governance, commerce, etc.

In addition to the problem of conceptual fuzziness, paradoxically, a further problem is that the notion of institutions is frequently used in a very narrow and depoliticised sense. Political scientists often use the term to refer exclusively to the formal institutions of political settlement (parliaments, the presidency, the judiciary, etc.) and neglect the informal institutions embedded in culture and tradition that may have an even firmer hold over individual behaviour - and may come into conflict with the former, see Ekeh (1975). Economists, on the other hand, often restrict the notion to the rules that regulate economic activities - i.e. institutions that enable markets to develop and trade and commerce to take place, such as enforceable contracts and private property rights (Chang, 2003). Institutions are often seen in neoclassical economics as optimal behaviour by rational economic agents interacting within frictionless markets (Greif, 2006:xiv). I would argue for a wider view that includes not only institutions directly relevant to economic transactions, but also all institutions relevant to social, political and economic development. These include both the cultural/informal institutions and the formal and legal institutions that shape and constrain individual behaviour.

In other words, I am interested in how formal and informal institutions define the 'rules' that govern both economic activity and political contestation, including elite settlements over AIDS policy, over the distribution of economic spoils and that affect who participates, how disagreements are resolved, how coalitions form 
and who 'wins'. Some of these institutions even operate at supranational level and govern interactions between states, and between national elites and international elites (e.g. in international organisations and multinational corporations).

I therefore follow Greif (2006) in considering institutions as interrelated systems of rules (legal or otherwise), beliefs, norms of behaviour and organisations. However, there is a danger of expanding the definition of institutions so widely that the concept loses analytical value. The best way to study institutional arrangements and their impact on political, social and economic outcomes is through an analytical approach to detailed historical case studies that, despite their inductive character, allows one to tease out general insights on institutions. Therefore, while institutions, the contexts within which they operate and the outcomes that they produce differ according to historical circumstances, their study can nevertheless provide generalisable insights applicable in other contexts.

The basic claim of institutional theory is that the institutional arrangements of any given polity profoundly shape the opportunities and incentives facing individuals (Skocpol, 1995; Hay and Wincott, 1998; Thelen, 1999; Pierson, 2000; Pierson and Skocpol, 2002), and most significantly those of leaders and members of elites. Institutions therefore play a big role in shaping both micro-level behaviour and systemic outcomes. Institutions are highly relevant to both the individual decisions of leaders and the elite alignments that I refer to as coalitions.

While historical institutionalist scholars are largely interested in macro-level historical changes that shape institutional and economic structures over time (see David, 2001; Pierson, 2004), the perspective is nevertheless useful to a more microlevel account of leadership and policy settlement that tries to be sensitive to the contextual factors that shape the process. Useful attempts to apply institutional analysis to include micro-level behaviour have been made by Robert Bates and associates, by extending neoclassical and strict rational choice models of individual behaviour with insights from game theory (see Bates et al., 1998). However, rational choice and economic accounts of how institutions shape behaviour have a curious apolitical view of history, in which institutions are essentially reduced to mechanisms for overcoming collective action problems (in the technical sense) and fostering cooperation between self-interested rational actors. These accounts lack a convincing view of power and seldom focus on 'bad' institutions - those that en- 
able parasitic elites to prosper or that fail to foster inclusive development.

The two predominant strands of institutional theory are New Institutional Economics (NIE), differentiated from older institutionalist economics, and Historical Institutionalism (HI). These are rooted in economics and comparative politics respectively. In the economic literature the term 'institutions' usually refers to the non-technological or social features of a society (at a given point in time) that impact on economic outcomes. Institutions influence economic outcomes because they impact on the decisions of economic agents: for example, legal recognition of contracts reduces transaction costs by addressing asymmetrical information (effectively, it restricts the freedom of agents to deceive other agents during transactions and provides a dispute resolution mechanism). In political science and sociology the emphasis is often on states and state-society relations, including such institutional arrangements as constitutions and electoral systems.

However, the approaches share important methodological similarities, including a preference for empirical historical analysis in the form of case studies and tracing social and economic changes over time. It is also worth noting that there has been a great deal of cross-fertilisation between different strands of institutionalist thinking (Hall and Taylor, 1996, cited in Thelen, 2002:92), so a rigorous separation is not possible.

New institutional economists usually define institutions as the formal and informal rules that influence behaviour by means of constraints and incentives. Ménard and Shirley (2005:1) offer this general definition:

Institutions are the written and unwritten rules, norms and constraints that humans devise to reduce uncertainty and control their environment. These include (i) written rules and agreements that govern contractual relations and corporate governance, (ii) constitutions, laws and rules that govern politics, government, finance and society more broadly, and (iii) unwritten codes of conduct, norms and behavior, and beliefs.

NIE remains rooted in mainstream economic theory in that it retains a core of rational choice theory even though it abandons some of its standard assumptions like perfect information, efficient markets and unbounded rationality. North 
(2005:21) points out that traditional neoclassical economics explores the efficiency of resource allocation synchronously under the restrictive assumptions of frictionless markets and therefore cannot explain processes of economic change (much less social or political change). NIE therefore expands the domain of economic theory, but does not substitute itself for neoclassical models. It could be argued that institutional economics is a response to criticism levelled from within other social sciences against the tendency of economists to over-simplify human behaviour as 'rational utility maximisation' and ignore social and political factors. While NIE broadens accounts of human behaviour to take into account norms, beliefs and customs and the incentives created by historically-specific institutional arrangements, institutionalist economics nevertheless remains firmly within a rational choice model. Agents are motivated by the incentives created by institutions, and the interest is primarily in institutions that support economic production and exchange. Even though NIE attempts to move beyond the limitations of neoclassical economics, institutions are still largely seen as structures that allow cooperation between selfinterested, rational utility-maximisers.

While HI scholars share many of the interests and approaches of NIE, they are less likely to restrict their focus to economic outcomes and are often more interested in social and political institutions. Historical institutionalism (perhaps reflecting its disciplinary roots in sociology and political science) is also more comfortable with interpretive accounts of history than with rational choice theories.

They have also made greater efforts to integrate into their accounts a theory of power and conflict. Jack Knight's Institutions and Social Conflict (Knight, 1992) is perhaps the most important example of this. Moe (2006), however, argues that despite the efforts to deal with power and exploitation, most institutionalist analyses still suffer from a poor theory of power. Individuals or groups may overcome collective action problems and cooperate, for example cooperation between bureaucracies and legislatures with differing interests in democratic societies. But this cooperation may nevertheless be 'exploitative' in the sense that it runs counter to the interests of 'outsiders' who do not have the power to compel the cooperating actors to take their interests into account. Argues Moe (2006:32-33):

Indeed, power is so commonly featured in [the literature relying on 
rational choice reasoning] that it is now easy to believe - as I suspect most scholars in the field do - that power is an integral part of the theory, on a par with cooperation in explaining political institutions. But it really isn't. However much power might be discussed, the fundamentals of the theory have not changed. They take their orientation from the same framework that guides all economic theory: voluntary exchange among rational individuals. They identify the key challenge as one of understanding whether rational individuals will cooperate in the face of collective action problems.

Nevertheless, these efforts by HI scholars to integrate a theory of power, together with attempts by economists like Olson (2000), are important corrective developments.

Skocpol (1995:105) identifies four processes of note in historical institutionalist policy studies: (1) the establishment and transformation of state and party organisations; (2) the effects of political institutions and procedures and social institutions on the identities, capacities and goals of social groups that become involved in politics; (3) the fit or lack thereof between the goals and capacities of politically active groups and the historically changing points of leverage created by political institutions; and (4) the ways in which previously established social policies affect subsequent policies over time. The latter process points to the centrality of changes over time in historical institutionalism.

While change in institutions over time is also a central concern for some institutionalist economists (see, for example North, 1990), the rational choice foundations of NIE makes it more likely that scholars will attempt to model one set of events and the manoeuvres of actors in one institutional setting at a time (Skocpol, 1995:106). As Pierson and Skocpol (2002:1) put it: "Historical institutionalists analyse organisational configurations where others look at particular settings in isolation; and they pay attention to critical junctures and long-term processes where others look only at slices of time or short-term manoeuvres." A further difference between institutionalists in economics and those in other disciplines is that the former frequently focus on individuals as economic agents, probably out of a desire to keep the scope of behavioural modelling manageable. This concern of HI with diachronic ana- 
lysis is captured in the notions of path dependence - the 'self-reinforcing' persistence of institutional structures or their change along distinct trajectories and of critical junctures - moments of discontinuity and major institutional upheaval (see Collier and Collier, 1991; Collier, 2007; Boas, 2007).

In broad terms, 'path dependence' refers to the idea that past decisions constrain present options. In historical institutionalism, it is usually used in the more technical sense of the dynamics of self-reinforcing or positive feedback processes by which behaviour becomes institutionalised and institutions resist change once established (Pierson and Skocpol, 2002:6), characterised by what is called in economics 'increasing returns' (Pierson, 2000:252).

This notion of path dependence usually supports a number of key claims: (1) specific patterns of timing and sequence matter in historical events; (2) starting from similar conditions, a wide range of outcomes may be possible; (3) 'large' consequences may result from contingent and relatively 'small' events; (4) particular courses of action, once undertaken, may be very hard to reverse; and (5) political and social development is often punctuated by 'critical junctures' during which the potential for change is greater and which shape the basic contours of social and political life (Pierson, 2000:251). Alternatives that may be open early in the process become increasingly unreachable and unlikely over time. This results in the self-reinforcing character of changes in institutional arrangements. In their classic study of political change in Latin America, Collier and Collier (1991) convincingly argue that large-scale political change (such as democratisation) occurs at such critical junctures, where the possibility of change is greater than under normal circumstances. These changes then become increasingly irreversible over time. Pierson and Skocpol (2002:8) argue that the macro-level interest of historical institutionalism allows it to study conjunctures - interaction effects between distinct causal sequences that become joined at particular points in time (Aminzade, 1992) — which gives it a distinct advantage over rational choice-based theories with a more micro-level focus.

Despite this, even HI often draws on economic analyses rooted in a rational choice/free exchange model in which institutions are primarily cooperative structures. Nevertheless, HI is much better than NIE and other economic models at dealing with politics and power. It is also better at dealing with institutional change, 
making it more useful for an analysis of 'leadership' and of contentious AIDS activism. In a later section, complexity and systems theory inform a relational model of 'transformative leadership'. While this connection is seldom made in the literature, historical institutionalism's focus on path dependence and critical junctures is strikingly similar to certain notions from complexity theory: the self-reinforcing character of institutions reminds one of the 'self-reproductive' character of complex systems and the relative stability that may exist in the state of a system for extended periods.

The 'analytic narratives' approach applies many of the techniques and explanatory mechanisms prevalent in NIE and historical institutionalist accounts. It is, however, closer to NIE's rational choice foundations. Analytic narratives employ rational choice theory and mathematical models (especially models from game theory) in the analysis of particular historical situations. Institutions in this view can be seen as 'self-enforcing equilibria that coordinate behaviour' and choices are regularised, stable and patterned because they are made in equilibrium (Levi, 2002:109). Particular historical circumstances are then understood with reference to the selection, longevity and transformation of equilibrium solutions that arise in particular times and places. (In classical game theory, each game has a 'solution', which represents the equilibrium state. Each 'player' attempts to optimise his/her own position - i.e. an outcome which maximises the rewards to him/her. An equilibrium emerges when each player has adopted a strategy that optimises their position, given the strategies of the other players, so that they do not face any incentive to change their strategy. The outcome realised in this situation is therefore an 'equilibrium solution' to the game.)

It then uses these models to test the applicability of general theoretical points in those specific circumstances, hoping that this allows historical case studies to contribute to generalisable social theory. It explicitly grapples with a methodological question that faces all social scientists who attempt historical analysis: how to extrapolate from historically-specific case studies to generalisable theory (Bates et al., 2000:696).

While analytic narratives have been heavily criticised by Elster (2000) as overambitious deductive history, (see also Elster, 1999) its adherents rebut this charge by arguing that merely the rational choice component of their theory (which they 
do not consider a necessary precondition of analytic narratives) is deductive and by aligning themselves with a more general attempt in the social sciences to integrate interpretive and rationalist accounts (Bates et al., 2000:69). Despite its origins in NIE, the analytic narratives approach does address larger questions of political economy such as political order, governance of the economy and polity and interstate relations (Levi, 2002:109). However, its reliance on rational choice theory limits its ability to do so. Furthermore, the application of game theory to political situations that are difficult to describe exhaustively, or in which 'players' cannot be assumed to behave as rational utility optimisers, remains very difficult. Likewise, the influence of power and ideology are difficult to incorporate in such an analysis. While the analytic narratives approach therefore improves upon some of the theoretical weaknesses of NIE, it does not provide a model that can easily be integrated into a theory of leadership.

So, can an institutional perspective inform a relational model of leadership? A strict rational choice approach, such as that employed in NIE and, less strictly, analytic narratives, essentially evacuates any space for meaningful individual agency, since individual choices are merely rational strategic responses to a situation (that is assumed to be fully describable). Individual decisions are in the final analysis simply optimising behaviour within the constraints of a given institutional arrangement ('rules of the game'). What adherents of this approach would probably see as its greatest advantage that it can offer coherent and clear explanations for behaviour - is therefore arguably also its greatest weakness. Historical institutionalist approaches that are more interpretive in character avoid this reductionism and allow greater space for individual agency to operate within the model, while nevertheless retaining an interest in macro-historical and macro-sociological processes.

A further potential problem with NIE identified above that persists in analytic narratives is the focus (inherited from neoclassical economics and from game theory respectively) on economic agents as individuals. While it is not excluded in principle, collective action is hard to model using this approach. I would follow Thelen in arguing that "institutions are important not just in how they constrain individual choice or affect individual strategies, but also in how they affect the articulation of interests, and particularly the articulation of collective interests" (original 
emphasis, Thelen, 2002:92). I argued above that HI is better at integrating power and exploitation into institutional analysis, but that even in comparative political analysis, institutional approaches still draw substantially on economic assumptions. HI's incorporation of path dependence and critical junctures further allows for a more convincing diachronic analysis than strict rational choice approaches.

The HI approach's more flexible definition of institutions, its incorporation of collective action and its model of institutional change over time is more compatible with the notion of 'coalitions' that I make use of extensively in the case studies. Yashar (1997:15) defines coalitions as follows:

...coalitions are defined as alliances among social sectors or groups. They provide the organisational framework for delineating who sides with whom, against whom, and over what. Coalitions bring together groups or institutions with heterogeneous, divergent long-term goals that they are willing to sacrifice for some intermediate, collective goals.

Coalitions, defined in this way, seem an almost perfect description of what AIDS activists pursued around access to AIDS treatment. But how did activists provide the leadership required to build coalitions for policy change? This is where a relational model of leadership, concepts related to resource mobilisation and movement building (from the social movement literature) and networks as the 'infrastructure' for coalition-building become useful.

\section{A.3 A relational model of transformative lead- ership}

In our report for the Developmental Leadership Program (Grebe and Woermann, 2011), we proposed a 'complex systemic' (i.e. relational) model of leadership that incorporates both individual agency and structural (institutional) constraints.

In such a model, individual agents both compete and cooperate in order to achieve goals (including such mundane ones as enhancing their material wellbeing). The agency of each individual allows him/her to choose from a range of possible actions, but individuals are subject to the incentive structure (both positive 
and negative) of formal and informal institutions. So on the one hand, individual choice is constrained by institutions. However, in keeping with a complex systems perspective, the patterns of individual behaviour and relationships between individuals give rise to institutions - institutions are an 'emergent property' of the system. The structure of the system is both shaped by individual choices over time and imposes itself on individuals.

To clarify: individuals make choices at the level of individual agency, but are then 'rewarded' or 'punished' by the institutions that regulate (but do not exhaustively determine) individual behaviour. Structural or systemic factors therefore promote or undermine certain choices through positive or negative 'feedback loops' in what Woermann (2010) calls 'downward causation'. Over time, these feedback loops reinforce or undermine certain patterns of behaviour, which then become institutionalised.

This may seem rather abstract. But the critical point is that institutions not only place constraints on individual behaviour, but also provide opportunities for purposive action and create the space for meaningful individual actions. For example, the institutions of democratic politics limit the power of individual political leaders but also provide a structure within which individuals can exercise meaningful individual leadership.

Another important function of feedback loops within this systemic perspective is that they represent the process through which, what we termed 'congruence' (Grebe and Woermann, 2011:24) emerges. The purpose of congruence in the model is to account for collective action and alignment of purpose in a way that is more flexible (but unfortunately also more vague) than the game theoretic notion of self-interested cooperation.

This does not imply full agreement on normative codes or purpose, but rather "the ability to accommodate difference and dissensus, without losing [the system's] functional unity or sense of purpose" (Painter-Morland, 2008:224). Hargadon and Fanelli (2002) define 'coherence' (which we use interchangeably with congruence) as follows:

Coherence in organisations exists as a social phenomenon in the recursive social interactions between individuals. Group and organisa- 
tional members come to hold (relatively) aligned interpretations of the world, (relatively) aligned goals, and (relatively) aligned identities because they tend to be surrounded by their own actions... Through the experiencing of actions by participation or by observations, individuals construct, reconstruct, and/or modify the scripts, goals, and identities that make up their relevant schema.

Effective leadership therefore involves facilitating the emergence of congruence - which is the basis of coalition-building and (over a longer time period) institutionalisation.

It should, however, be emphasised that a complex systemic model implies that the myriad complex interactions between individuals, sub-systems and systems cannot be exhaustively described in the way that rational choice models such as those described earlier try to do. It is impossible to fully predict the outcome of the competitive and cooperative activities of individuals that give rise to structures at the systemic level and a certain degree of uncertainty is therefore implied by this model. While the notion of congruence helps to describe how both pragmatic and normative structural patterns become reinforced and institutionalised, the irreducible complexities implied by this model mean that collective action problems can never be fully overcome.

It is also important to emphasise that this model does not imply that individual agents are 'imprisoned' or fully determined by institutions. Since the choices of individuals influence the particular form that institutions take, individuals can be important catalysts of transformation (at points in time that HI scholars might term 'critical junctures'). But any such account of 'transformative leadership' must avoid degenerating into the standard agential account of leadership (akin to the 'big man of history' approach), since critical junctures that allow for substantial transformation are few and far between, and in any event reflect opportunities rooted in the trajectory of historical change.

Although leadership implies the exercise of power, the traditional notion of leaders and followers (which assumes that power derives only from formal authority and flows uni-directionally) is untenable in a complex system. Instead, a complex system may have many centres of power (both formal and informal), power 
relations are not static (although they may be relatively stable over time) and power is often distributed or dispersed across levels. This means that leaders can only fulfil their central function of mobilising people and resources towards achieving goals if they are able to draw on this 'systemic' power - for example, by building coalitions in which disparate actors align their efforts.

Lastly, it is important to point out that despite the emphasis on processes in our systemic model of transformative leadership, actual end goals and the consequences of action remain important. Leaders must accept responsibility for the effects that their actions have on all stakeholders, including those they are not formally accountable to, and even when these effects are not fully predictable. In fact, one could argue that true responsibility results precisely from one's inability to fully know the consequences of one's actions (see Grebe, 2009a). Assuming responsibility requires that we develop successful strategies, which the complexity theorist Edgar Morin (2008:96) describes as 'the art of working with uncertainty'. Therefore, although calculation is both useful and necessary, "strategy is called for as soon as the unexpected or uncertainty arises, that is to say as soon as an important problem appears" (Morin, 2008:56). In complex systems where interests compete with one another, resources are limited and effects not fully predictable, this is a difficult, though crucial task.

Individual agency can therefore not be evacuated from an understanding of leadership (in AIDS or otherwise), but a relational perspective can link the individual and systemic levels through processes like 'feedback loops,' providing a credible response to the structure-agency problematic. 'Congruence' acts as a theoretical anchor point that allows us to conceive of meaningful action (both individual and collective), which in turn allows for a notion of transformative leadership while admitting structural limits. This is a model of leadership, therefore, that allows us to account for the impact of individuals, for meaningful transformative leadership by individuals like Zackie Achmat and Peter Piot, but that acknowledges the structural constraints on individual agency and emphasises the importance of institutional context in shaping the opportunities that individuals face. It is also a model in which building coalitions is of critical importance and constructing and participating in the networks that undergird coalitions is a key activity of leaders. 


\section{Appendix B}

\section{An epidemiological model for HIV incidence, prevalence and mortality trends in Uganda (1974-2004)}

The purpose of this model is to help contextualise the discussion of political and civil society leadership in Uganda by allowing the plotting of events such as the coming into power of the Museveni regime and Museveni's so-called 'zero grazing' campaigns against trends in HIV prevalence, incidence and mortality, especially during the late 1980s and early 1990s.

The model uses seroprevalence data from antenatal clinics and is calibrated using a population-based seroprevalence survey from 2003. It does not incorporate the impact of antiretroviral therapy. Widespread access to HAART would have resulted in lower mortality and higher HIV prevalence than this model predicts in the post-2000 period. However, it does allow for credible estimation of HIVrelated trends for the period during which large-scale behaviour change is widely supposed to have occurred in Uganda (the late 1980s and early 1990s) and it is well-suited to the purpose of policy analysis during this period. 


\section{B.1 Methods and data}

This model makes use UNAIDS's Epidemiological Projection Package released as part of the Spectrum/EPP 2011 suite of policy models (UNAIDS, 2011a), a tool for country-level estimation and short-term projection of HIV/AIDS epidemics by fitting a standard epidemiological model on observed HIV surveillance data.

The primary source of surveillance data used here is reported HIV seroprevalence among antenatal clinic (ANC) attendees at a range of urban and rural ANCs in Uganda for the period 1987-2002 as published by UNAIDS and WHO (2004). Urban sites with more than 2 data points are Mulago hospital, Nsambya Missionary Hospital and Rubaga Missionary Hospital (all in Kampala), while rural sites with more than two data points are Matany, Mbale, Moyo, Mutolere, Nyambani, Palisa, Ruimi, Rukunyo, Soroti, Tororo, Virikia, Aber, Arua, Bundibugyo, Fort Portal, Gulu district, Hoima, Jinja, Kagadi, Kasule, Kilembe and Lwala. Several further sites with one or two data points were included.

Total adult population and urban/rural population data were used as supplied with Spectrum/EPP 2011 (and sourced from the United Nations Office for Population Statistics). Urban and rural epidemics were modelled separately (but combined for overall estimates). Apart from division into urban and rural sites (weighted according to the population split), prevalence data from ANC sentinel sites are unweighted (i.e. all sites included in the model for urban and rural populations respectively are afforded equal weights), since population estimates for the relevant catchment areas were not available. In this respect I followed Musinguzi et al. (2009:79-80).

The model was calibrated using observed population-level seroprevalence data from the Uganda HIV/AIDS Sero-Behavioural Survey 2004-2005 (UHSBS). In other words, the model was adjusted so that predicted prevalence rates match the found population-level prevalence rates of the survey. The UHSBS found national seroprevalence rates of 10.1\% among urban adults (aged 15-49) and 5.7\% among rural adults, based on 2531 and 14375 blood tests respectively (Ministry of Health [Uganda] and ORC Macro, 2006:103).

The model prevalence curve was fit using EPP 2011 's 'Variable-R' algorithm, resulting in best-fit curves as shown in figure B.1. Estimates are produced for adults 
aged 15-49 years. The model estimates epidemiological parameters for the period 1970-2016, but estimates are only reported for 1974-2004 since no measurable HIV epidemic is predicted before 1974 and, as indicated before, the model is only likely to be accurate up to the mid-2000s. 
Figure B.1: EPP 2011 best fit prevalence curves (urban and rural)

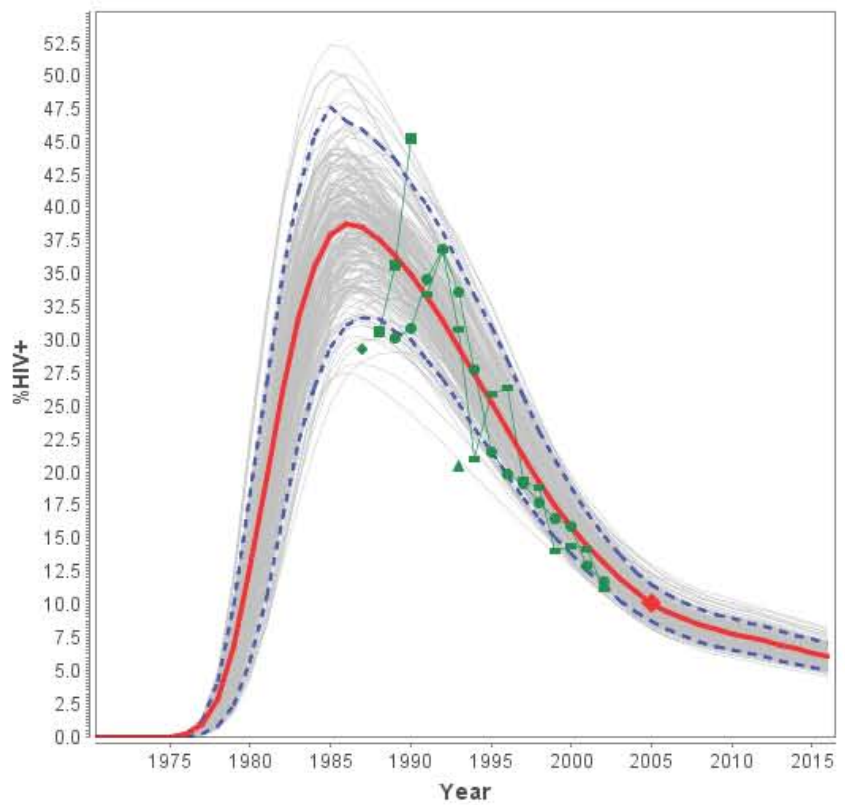

- Best fit - - Bounds Survey values $-\% H I V+$ (calibrated) Curves

(a) Urban

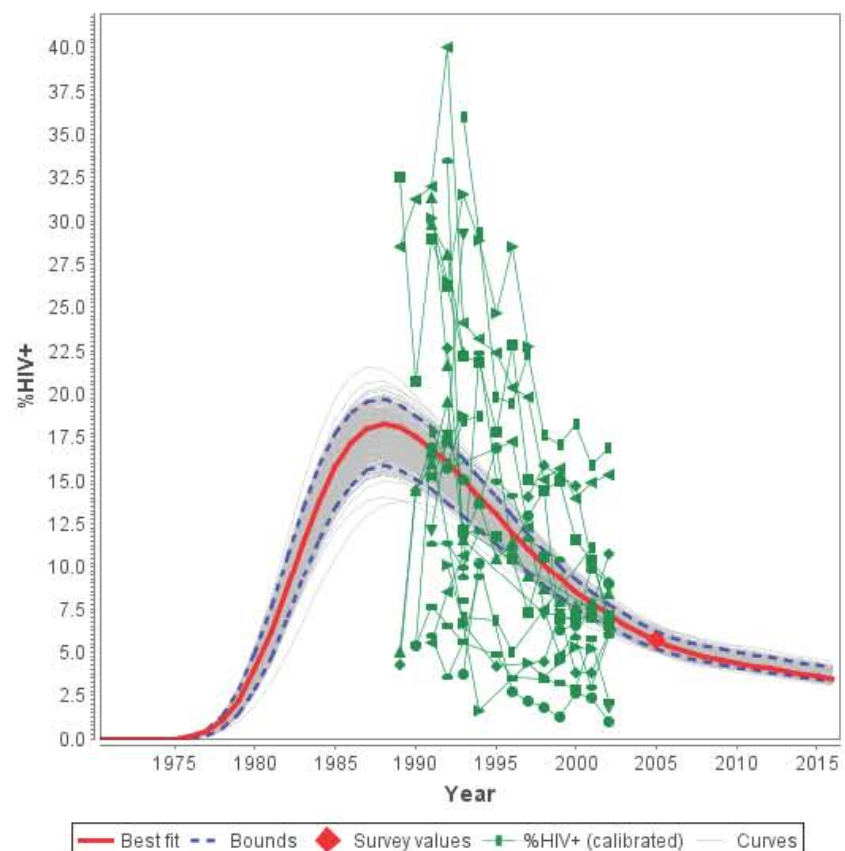

(b) Rural 


\section{B.2 Results}

The resulting model is summarised in figure B.2 and shown in greater detail in table B.1 and figures B.3 and B.4. This model is useful for our purposes because it estimates the likely trend in HIV incidence given the known trend in HIV prevalence at ANCs. What it does, essentially, is reverse-engineer from HIV prevalence and assumptions about the general path of HIV epidemics (including time from infection to death, etc.).

\section{Figure B.2: Epidemiological model for Uganda showing new HIV infections and HIV prevalence rate for adults (15-49), 1974-2004}

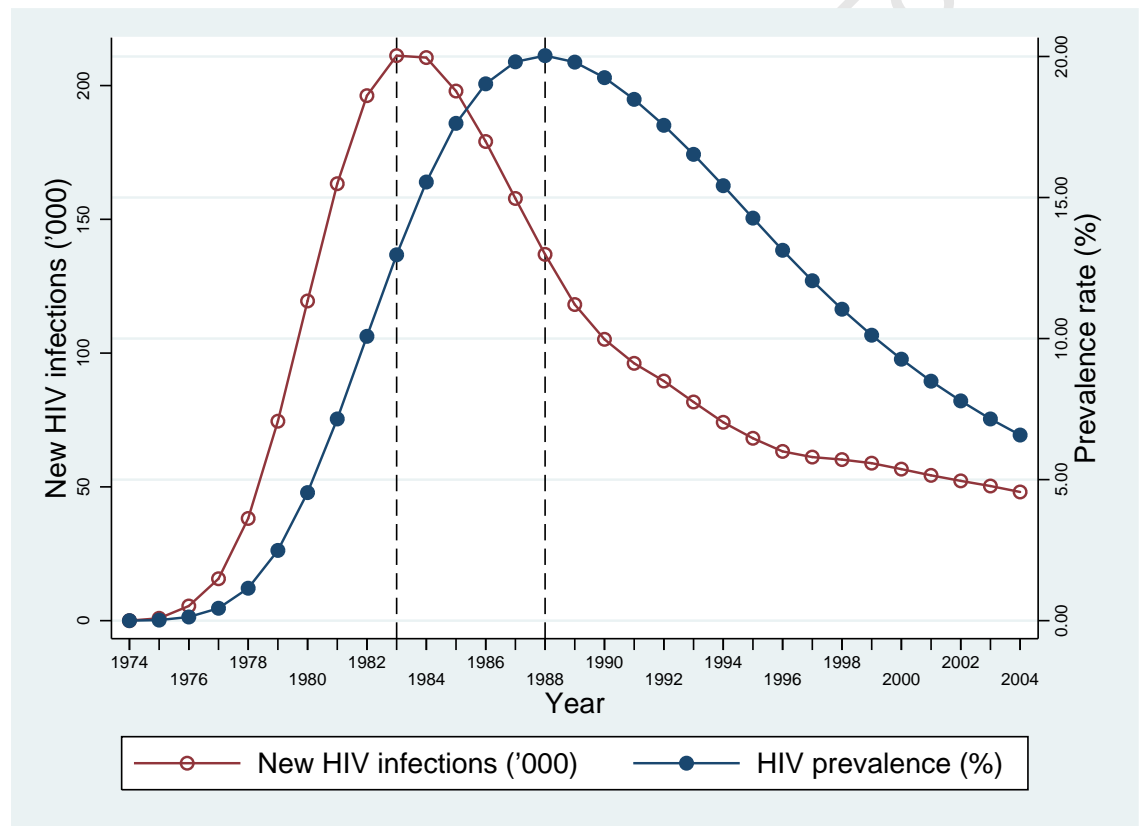

The model suggests that, given the rates of ANC HIV prevalence, new HIV infections probably started rising from 1975, peaking in 1983 at approximately 211000 new infections during that year. The adult HIV incidence rate (i.e. the proportion of uninfected adults aged 15-49 that contract the virus during a given year) peaked in 1984 at $4.0 \%{ }^{1}$ As a result of rapidly rising HIV incidence, the

\footnotetext{
${ }^{1}$ The number of new infections and and incidence rates can peak in different years because of changes in the uninfected population, e.g. shrinking because of infections in earlier years.
} 
infected adult population and adult prevalence rate (i.e. the proportion of the population that is HIV-positive) rose rapidly, lagging a few years behind incidence. Total infections and adult HIV prevalence eventually peaked in 1989 and 1988 respectively, at approximately 1418716 HIV-positive adults and 20.0\%. ${ }^{2}$ After 1984, incidence declined very rapidly, to $1.8 \%$ in 1990 and a mere $0.5 \%$ in 2004. HIV prevalence declined after 1988, reaching $10.1 \%$ in 1999 and $6.6 \%$ in 2004. Since the model was calibrated using a population seroprevalence survey, the predicted prevalence in 2004 is very close to the measured prevalence reported in the UHSBS. This decline in prevalence represented the visible 'success' in Uganda's struggle against HIV/AIDS. AIDS deaths started rising around 1980 and hovered around 100000 deaths per year from 1991 to 2000 (peaking in 1995 at about 112000 deaths). Yearly deaths had declined to just more than 75000 by 2004. Cumulative AIDS deaths reached a million in 1996 and 1.8 million deaths in 2004.

\footnotetext{
${ }^{2}$ Prevalence rates and total infected population can also peak in different years.
} 
Table B.1: Epidemiological model for Uganda (1974-2004)

\begin{tabular}{rrrrrrr}
\hline Year & New inf. & Inc. rate & Total HIV+ & Prev. rate & Deaths & Cum. deaths \\
\hline 1974 & 0 & $0.00 \%$ & 0 & $0.00 \%$ & 0 & 0 \\
1975 & 885 & $0.02 \%$ & 885 & $0.02 \%$ & 0 & 0 \\
1976 & 5485 & $0.12 \%$ & 6346 & $0.13 \%$ & 9 & 9 \\
1977 & 15661 & $0.32 \%$ & 21833 & $0.44 \%$ & 68 & 77 \\
1978 & 38208 & $0.77 \%$ & 59442 & $1.15 \%$ & 259 & 336 \\
1979 & 74543 & $1.46 \%$ & 132325 & $2.49 \%$ & 780 & 1116 \\
1980 & 119486 & $2.31 \%$ & 248004 & $4.54 \%$ & 1940 & 3056 \\
1981 & 163310 & $3.13 \%$ & 403841 & $7.15 \%$ & 4142 & 7198 \\
1982 & 196229 & $3.74 \%$ & 587064 & $10.08 \%$ & 7829 & 15027 \\
1983 & 211187 & $4.03 \%$ & 777975 & $12.97 \%$ & 13398 & 28425 \\
1984 & 210464 & $4.03 \%$ & 959233 & $15.55 \%$ & 21075 & 49500 \\
1985 & 197954 & $3.80 \%$ & 1117222 & $17.63 \%$ & 30823 & 80323 \\
1986 & 179090 & $3.43 \%$ & 1244076 & $19.03 \%$ & 42271 & 122594 \\
1987 & 157800 & $2.98 \%$ & 1336454 & $19.81 \%$ & 54762 & 177356 \\
1988 & 136911 & $2.53 \%$ & 1393933 & $20.03 \%$ & 67440 & 244796 \\
1989 & 118156 & $2.12 \%$ & 1418716 & $19.80 \%$ & 79419 & 324215 \\
1990 & 105158 & $1.83 \%$ & 1418303 & $19.25 \%$ & 89968 & 414183 \\
1991 & 96178 & $1.62 \%$ & 1399038 & $18.48 \%$ & 98595 & 512778 \\
1992 & 89556 & $1.45 \%$ & 1365924 & $17.56 \%$ & 105036 & 617814 \\
1993 & 81734 & $1.27 \%$ & 1320382 & $16.53 \%$ & 109251 & 727065 \\
1994 & 74136 & $1.11 \%$ & 1265128 & $15.42 \%$ & 111362 & 838427 \\
1995 & 68163 & $0.98 \%$ & 1204013 & $14.27 \%$ & 111621 & 950048 \\
1996 & 63258 & $0.87 \%$ & 1139962 & $13.13 \%$ & 110352 & 1060400 \\
1997 & 61135 & $0.81 \%$ & 1077177 & $12.05 \%$ & 107864 & 1168264 \\
1998 & 60202 & $0.77 \%$ & 1018091 & $11.04 \%$ & 104490 & 1272754 \\
1999 & 58858 & $0.72 \%$ & 963090 & $10.12 \%$ & 100521 & 1373275 \\
2000 & 56645 & $0.66 \%$ & 911528 & $9.27 \%$ & 96179 & 1469454 \\
2001 & 54308 & $0.61 \%$ & 863395 & $8.49 \%$ & 91593 & 1561047 \\
2002 & 52240 & $0.56 \%$ & 819539 & $7.79 \%$ & 86317 & 1647364 \\
2003 & 50320 & $0.52 \%$ & 780085 & $7.15 \%$ & 80797 & 1728161 \\
2004 & 48096 & $0.48 \%$ & 744501 & $6.58 \%$ & 75278 & 1803439 \\
\hline & & & & & &
\end{tabular}


Figure B.3: Detail of epidemiological model: prevalence rate, incidence rate and AIDS cases (peak years indicated with dotted lines)
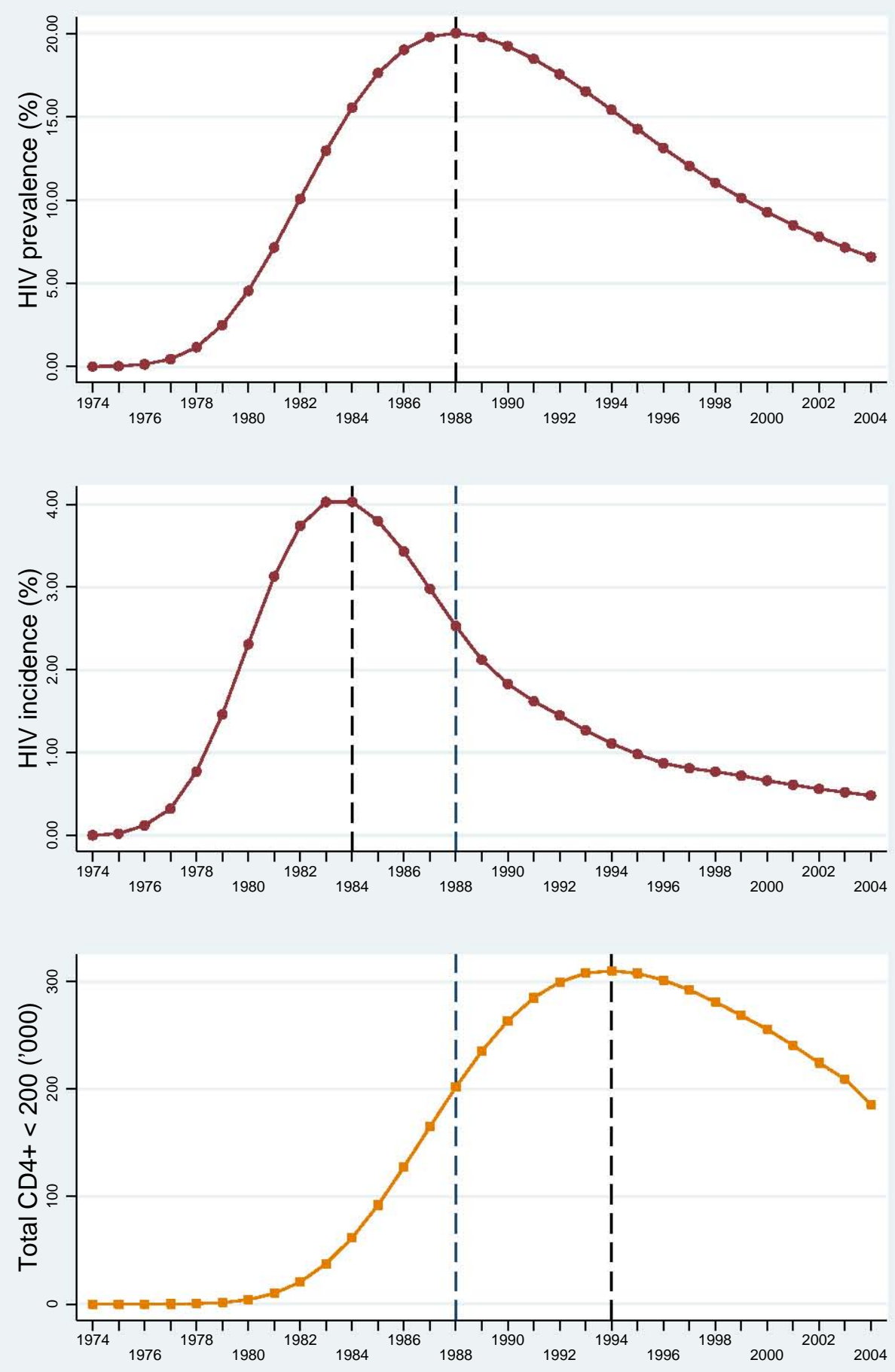
Figure B.4: Detail of epidemiological model: new infections, HIV+ population and AIDS deaths (peak years indicated with dotted lines)
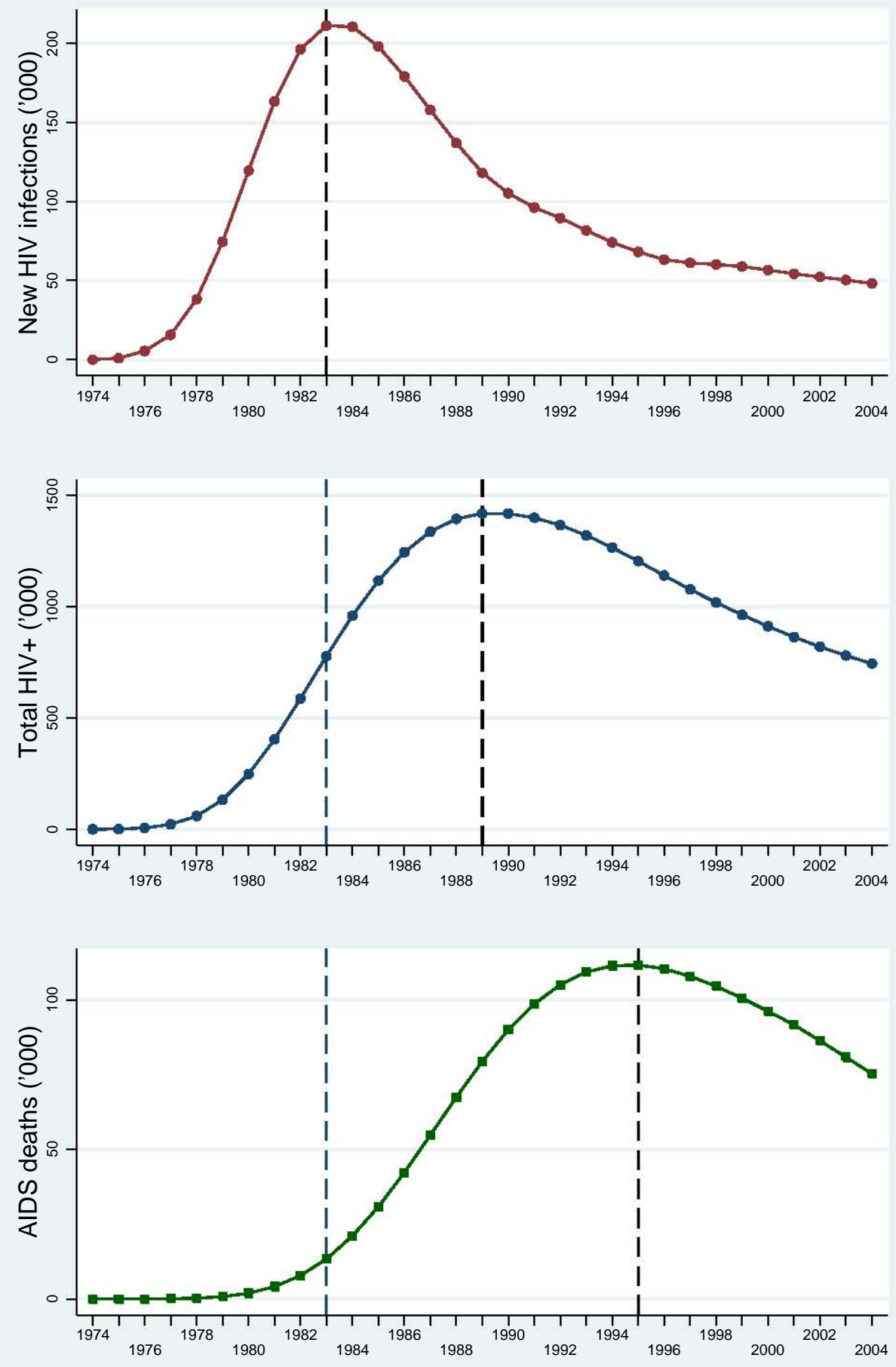


\section{Appendix G}

\section{List of interviews}

1. Abdool Karim, Quarraisha (Director: HIV/AIDS, South African Department of Health 1994-1995, Centre for the AIDS Programme of Research in South Africa [CAPRISA]): Durban, 9 June 2008.

2. Abdool Karim, Salim (Director: CAPRISA): Durban, 9 June 2008.

3. Achmat, Zackie (TAC Deputy General Secretary; TAC Chairperson 19992008): Cape Town, 16 June 2007 (conducted by Raja Farah); Cape Town, 30 April 2008; Cape Town, 16 May 2008.

4. Ajok, Susan (Straight Talk Foundation): Kampala, 20 October 2008.

5. Apuuli, David Kihumuro (Director General: Uganda AIDS Commission): Kampala, 21 October 2008.

6. Ayers, Elise (Chief: HIV/AIDS \& Health Office, USAID Uganda): Kampala, 29 October 2008.

7. Berger, Jonathan (Head of Research: AIDS Law Project): Johannesburg, 16 December 2007.

8. Bosch, Deena (TAG founding member): Cape Town, 26 November 2007.

9. Clayden, Polly (Editor: HIV i-base): Cape Town, 29 September 2008. 
10. Coovadia, Hoosen (Jerry) (Former head of Paediatrics, University of KwaZulu-Natal; CAPRISA): Durban, 10 June 2008.

11. Coutinho, Alex (Executive Director: Infectious Diseases Institute, Makarere University): Kampala, 14 October 2008.

12. Dubula, Vuyiseka (TAC General Secretary): Cape Town, 18 April 2008.

13. Ekambaram, Sharon (Director: MSF Johannesburg; First TAC Gauteng Provincial Coordinator): Johannesburg, 11 January 2008.

14. Geffen, Nathan (TAG National Treasurer 2008): Cape Town, 19 April 2008.

15. Gonsalves, Gregg (Former Director: AIDS \& Rights Alliance Southern Africa): Cape Town, 20 December 2007.

16. Gray, Andrew (Department of Pharmacology, University of KwaZuluNatal; CAPRISA): Durban, 10 June 2008.

17. Heywood, Mark (Director: AIDS Law Project, TAG National Treasurer 1998-2008): Johannesburg, 17 December 2007; Johannesburg, 10 January 2008.

18. Isiko, Samuel (Centre Manager: Tororo, TASO): Tororo, 23 October 2008.

19. Johnson, Leigh (Centre for Actuarial Research, University of Cape Town): Cape Town, 3 June 2008.

20. Kadowe, Joyce (Coordinator: Advocacy and Partner Relations, Uganda AIDS Commission): Kampala, 20 October 2008.

21. Kaleeba, Noerine (Founder and Patron: TASO): Masaka, 16 October 2008.

22. Kamara, Ronald (HIV/AIDS Advisor: Uganda Catholic Secretariat): Kampala, 28 October 2008.

23. Kana, Buweje (Senior Volunteer: Mbale Centre, TASO): Mbale, 22 October 2008. 
24. Katabira, Elly (Professor: Department of Medicine, Makarere University): Kampala, 14 October 2008.

25. Katana, Milly (Project Director: International AIDS Alliance Uganda): Kampala, 24 October 2008.

26. Lewis, Jack (Director: Community Health Media Trust; TAC founding member): Cape Town, 24 November 2007.

27. Majola, Mandla (TAG Khayelitsha District Coordinator): Cape Town, 21 April 2008.

28. Muhinda, Aaron (Assistant Advocacy Officer: Coalition for Health Promotion and Social Development; Local Contact: International Treatment Preparedness Coalition): Kampala, 27 October 2008.

29. Mworeko, Lilian (East Africa Regional Coordinator: International Community of Women Living with HIV/AIDS): Kampala, 14 October 2008.

30. Naloubowa, Prossy (Senior Volunteer: Mulago Centre, TASO): Kampala, 27 October 2008.

31. Ngobi, Charles (Medical Coordinator: Mbale Centre, TASO): Mbale, 22 October 2008.

32. Ochai, Robert (Executive Director: TASO): Kampala, 29 October 2008.

33. Okwello-Owor, Emmanuel (Secretary: Board of Trustees, TASO): Tororo, 23 October 2008.

34. Piot, Peter (Executive Director: UNAIDS 1996-2009): By telephone, 20 December 2010.

35. Ramothwala, Pholokgolo (Former TAC Gauteng Provincial Coordinator): Johannesburg, 11 January 2008.

36. Ruranga, Rubaramira (Director: National Guidance and Empowerment Network of People Living with HIV/AIDS): Kampala, 31 October 2008. 
37. Sawyer, Eric (NGO Liaison Officer, UNAIDS; Founder: Housingworks): New York City, 24 September 2008.

38. Ssebanja, Peter (Advocacy Director: TASO): Kampala, 15 October 2008.

39. Syahuka, Hannington (Executive Director: Uganda Network of AIDS Service Organisations): Kampala, 24 October 2008.

40. Tebigwa, Betty (Counsellor: Mbale Centre, TASO): Mbale, 22 October 2008.

41. Tembe, Juliet (Chairperson: Board of Trustees, TASO): Mbale, 22 October 2008.

42. Wamanya, Dan (Programme Management Specialist: USAID Uganda): Kampala, 29 October 2008.

43. Were, Beatrice (Founder: National Community of Women Living with HIV/AIDS in Uganda): Kampala, 30 October 2008. 
Appendix D

aids2031 Givil Society Online Survey Questionnaire 


\section{aids2031}

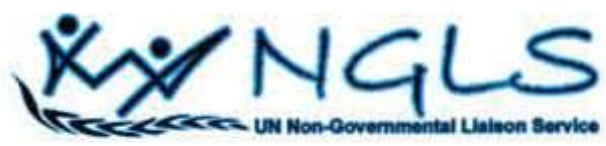

aids2031 Civil Society Online Survey

Conducted by the aids2031 Leadership Working Group and the United Nations Non-governmental Liaison Service (NGLS)

\section{About this survey}

\section{What is aids2031?}

"aids2031", is a "think tank"—a project hoping to shift the global response to HIV from a short-term, reactive, emergency response to a building long-term, proactive, strategic framework that would mitigate the consequences of the HIV epidemic.

aids2031 is about making recommendations which can be implemented now, to plot a course for the epidemic so that we might reach 2031 - 50 years from the first reported cases of AIDS - with everyone on treatment who needs to be on treatment; with no new infections in that year; and with the consequences of HIV for individuals, families and societies thoroughly minimized.

\section{How aids2031 works}

aids2031 has convened nine working groups of stakeholders in the HIV epidemic, including economists, epidemiologists, and biomedical, social, and political scientists, to make recommendations toward a longterm strategic framework to confront and stop the epidemic.

While science offers us understanding, tools, and technology to prevent and treat HIV, it is leaders who should demand the rights of people to access information, prevention, and treatment. Whether they are from grassroots organizations, the business sector, government, or the media, leaders have struck down laws that discriminate against people with HIV, secured the funds to treat thousands of people, and mobilized citizens to demand government action on AIDS.

Progress in the AIDS movement has always relied on leaders, and this is why we need your opinions, your insights and your recommendations now as we prepare a long-range plan to strategically guide the future response to the HIV epidemic.

For more information, visit the aids2031 website

\section{What is the purpose of the survey?}

While science offers us understanding, tools and technology to prevent and treat HIV, it is leaders who have rolled out services and secured the rights of people to access information, prevention, and treatment. Whether they are from grassroots organizations, multinational NGOs, the business sector, government, or the media, progress in the AIDS movement has always relied on leaders. This is why we need your opinions, your insights and your recommendations now, as we prepare a long-range framework to strategically guide the future response to the HIV epidemic.

The answers you provide will help the Leadership Working Group to formulate recommendations that will ultimately form part of the aids2031 final report, "An Agenda for the Future". The results of the survey will also be published separately as a free-standing report.

Please take the time to give us your insights on the future of the global response to HIV.

\section{Instructions}

While many of the questions ask for your opinion, our primary interest is in the perspective and views of your organization. Wherever possible, try to reflect organizational positions, or your best approximation of consensus in the organization, in your answers.

Many questions in this survey can be answered from either a local, regional, national, or global perspective. Please formulate your response to match the description of your organization as provided in question number A4. 
Please note that while most of the data collected as part of this survey will be used only in aggregate (and therefore in anonymous) form, it may be useful to present some data in a way which will allow the answers of individual organisations to be deduced. If you are concerned about this, mark the appropriate box below and your answers will be excluded from any such analyses. We encourage you to only impose this restriction if truly necessary.

Please tick where appropriate:

e My answers may be publicly attributed to my organization

e Please keep my answers confidential 


\section{aids2031 ※ NGLS}

\section{Module A. Basic details (1 of 7$)$}

A1. Please provide your personal details

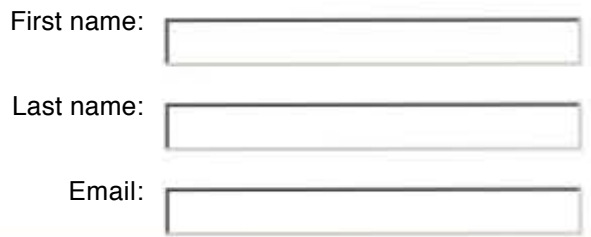

Please use an email address under your direct control, so that we can send you a link that allows you to retrieve your answers should you need to interrupt this session.

Phone:

Fax:

Postal address:

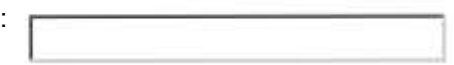

Province/State:

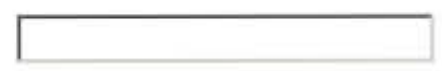

Country

\section{6}

\section{A2. Please provide your organization's details}

Organization's name:

Website:
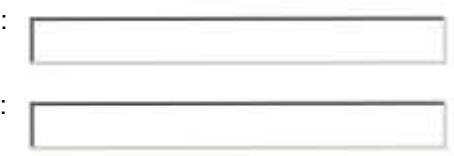

I work in the:

Headquarters: jn A country office: jn A subsidiary: jn A division: jne Other:

A3. My organization is (or is a subsidiary of) $a(n)$

Government agency

Business or business organization

International/multilateral agency $\mathrm{j}$

Bilateral donor organization jn

Charitable foundation

Trade union/labour organization

Faith-based organization

Network of people living with HIV

Multinational Non-Governmental Organization (NGO)

National or local NGO

Other (please specify): 
A4. My organization primarily works (select one)

In a village/town/city/region within one country

Throughout a single country

In Several countries within a region (e.g. Southern Africa)

Globally

A5.1 My organization has _ employees

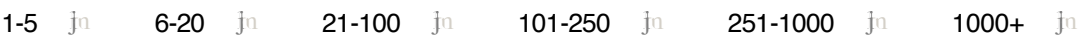

A5.2 My organization has _ volunteers (at least 10 work hours per week)
0-5 j
$6-20 \quad j$
$21-100$
$101-250$
$251-1000$
$1000+\quad j$

A6.1 My organization's primary activity is (select one)

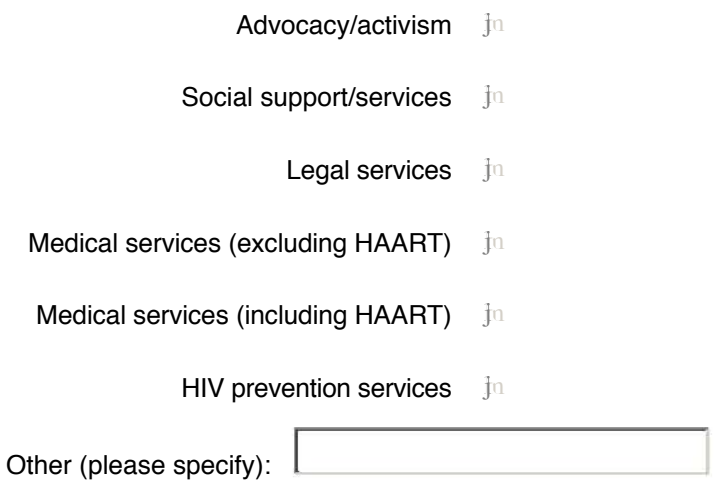

\section{A6.2 In addition, we conduct (select one or more)}

e Advocacy/activism

e Social support/services

e Legal services

e Medical services (excluding HAART)

e Medical services (including HAART)

e HIV prevention services

Other (please specify)

\section{A7 My organization receives funding from these sources (tick all that apply)}

e Membership dues

e Public contributions

e An endowment

e National AIDS Plan funding

e Other government funding (non-NAP)

e International Development Assistance Funding (IDAF)

e US President's Emergency Plan For AIDS Relief (PEPFAR) 
e Other foreign government source

e The Global Fund to fight AIDS, TB and Malaria

e Other multilateral institutions

e Gates Foundation

e Other foreign charitable foundations

e Other domestic charitable foundations 


\section{aids2031 $\forall$ NGLS}

\section{Module B. Priority areas $(2$ of 7$)$}

B1. Which of the following areas in the global HIV/AIDS response do you consider to be the highest priorities at present in order to ensure a successful long-term response? (By placing numbers next to each item, rank them in order of priority.)

Combating stigma and discrimination against people living with

HIV

Sustaining and increasing financing for HIVIAIDS programs

Strengthening health systems

6

Combating stigma and discrimination against most-at-risk
populations (MSM, CSWs, drug users, etc.)

Services tailored to most-at-risk populations (MSM, CSWs, drug users, etc.)

Expanding access to treatment, care and support for HIVIAIDS and related diseases

Promoting human rights

Promoting gender equality

Measures to expand access to generic production of essential medicines, technologies and diagnostics (preferential pricing,

related intellectual property issues, etc .)

Strengthening HIV prevention campaigns

6

6

6

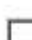

Improving programme monitoring and evaluation 6

Strengthening civil society organizations who work on HIV/AIDS

Providing comprehensive services to drug users

Other (please specify):

Other (please specify)

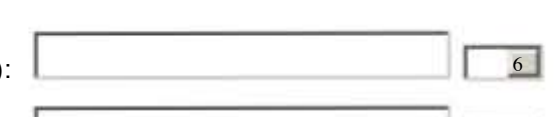

Other (please specify): 


\section{aids $2031^{\circ}$}

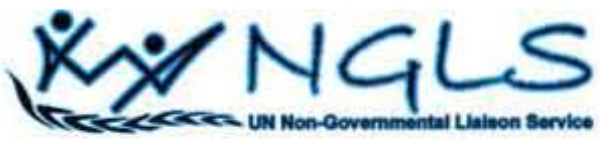

\section{Module C. Leadership and civil society strengthening ( 3 of 7$)$}

C1. (By placing numbers next to each item arrange the following in order of priority) Civil society's primary task in the field of HIV/AIDS is to:

Provide services (e.g. treatment, prevention, care, support) to people living with HIV / vulnerable groups

Raise awareness of HIVIAIDS and associated risks in the general population

Conduct advocacy on behalf of people living with HIV / vulnerable groups

Hold government and other agencies accountable

C2. Indicate to what extent you agree with each of the following statements by selecting the appropriate option. Note: answer with respect to the country or area where your organization is active

My organization is able to effectively discharge its functions

My organization receives adequate funding Government is susceptible to civil society pressure

Funders of Civil Society Organizations (CSO) are willing to support militant activism

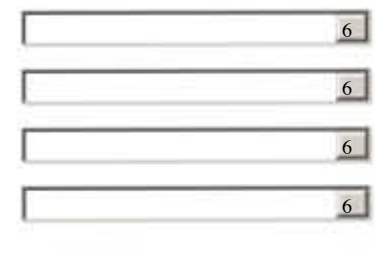

CSOs that are perceived as critical and independent are sidelined or otherwise punished

Political leaders are committed to the fight against HIVIAIDS CSOs have been successfully discharging a "watchdog" function

CSOs have maintained their independence from funders and
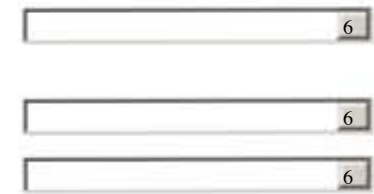
governments

C3.1 Does your organization work with and/or obtain support from an international network of activists/CSOs?

yes jo no jo

If you answered Yes above, in which respects is this network important? (Mark all that apply.)

e Exchanging information

e Joint mobilization (e.g. global days of action)

e Financial resources

e Exerting influence on multinational entities

e Exerting influence on foreign governments

Exerting influence on domestic government

Other (please specify) 
e International Treatment Preparedness Coalition

e AIDS \& Rights Alliance Southern Africa

e Global Network of People Living with HIV/AIDS (GNP+)

Other (please specify)

Other (please specify)

\section{Global agencies/organizations}

e Regional Network of People Living with HIVIAIDS

e International Council of AIDS Service Organizations (ICASO)

e Global AIDS Alliance

e International AIDS Alliance

e International Community of Women Living with HIVIAIDS (ICW)

e The Global Fund

UNAIDS

e The World Health Organization (WHO)

e The One Campaign

e HealthGAP

Knowledge Ecology International Other (please specify) Other (please specify)

C4 Please evaluate to what extent each of the following harm the ability of your organization to effectively perform its functions

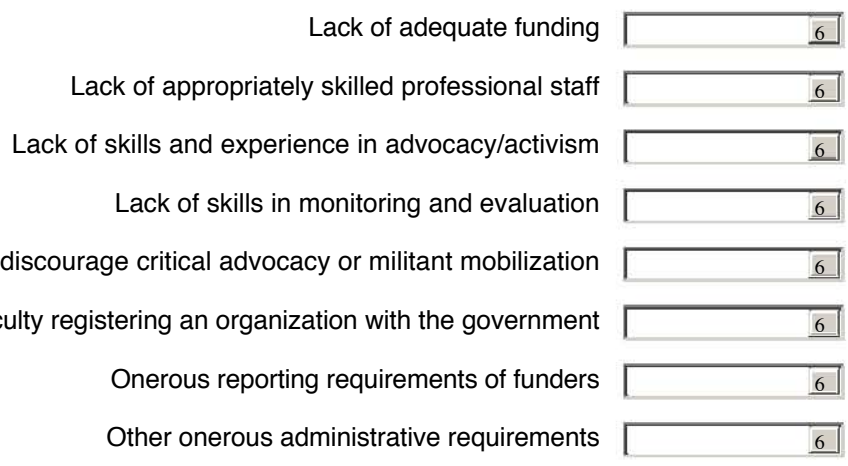

Repression or harassment by the state (e.g. arrests, tax investigations, etc.)

Other (please specify)

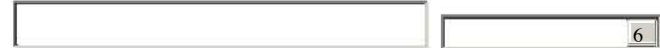

Other (please specify):

C5.1 What do you consider the main challenges, top priorities and key interventions with respect to developing political leadership on AIDS? 
C5.2 What do you consider the main challenges, top priorities and key interventions with respect to strengthening civil society? (e.g. capacity building, knowledge transfer, organizational development, etc.)

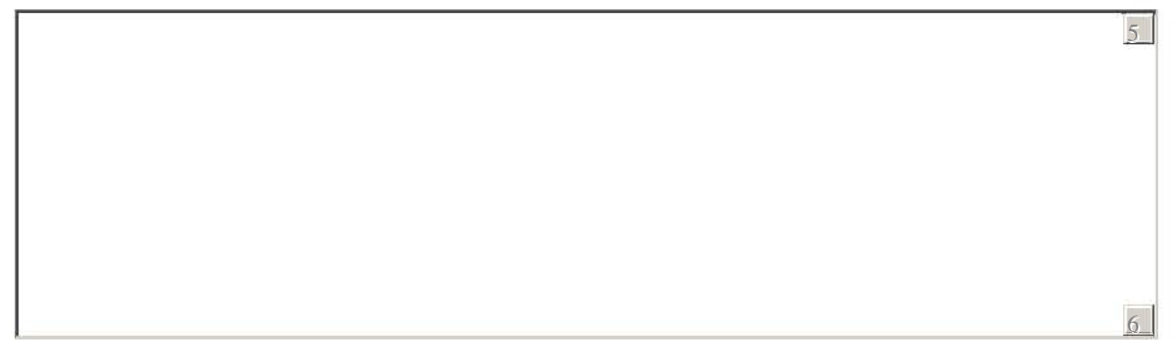

C5.3 What do you consider the main challenges, top priorities and key interventions with respect to sustaining and strengthening leadership and activism?

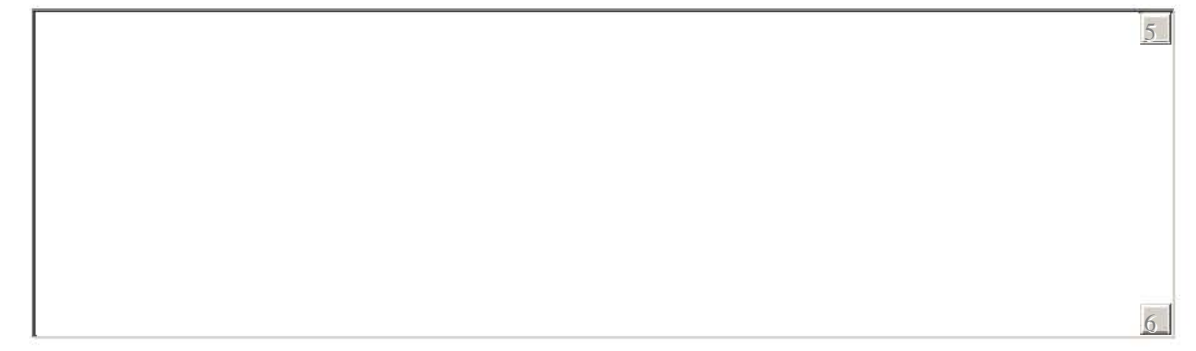




\section{aids2031 $\forall$ NGLS}

\section{Module D. Stigma, discrimination \& special populations (4 of 7)}

D1. My organization does significant work targeting the following population group(s) (Tick all that apply)

e Men who have sex with men

e Transgendered people

e Sex workers

e Injecting drug users

e Non-injecting drug users

e Refugees or asylum seekers

e Internally displaced persons

e Members of indigenous groups

e Migrant workers

e Transportation workers (e.g. truck drivers)

e Prisoners

e Women \& girls

e Adolescents

e Children

e Orphans

Other vulnerable group(s) (please specify):

D2. In the area where you work, which of these group(s) are neglected in the AIDS response, and to what extent?

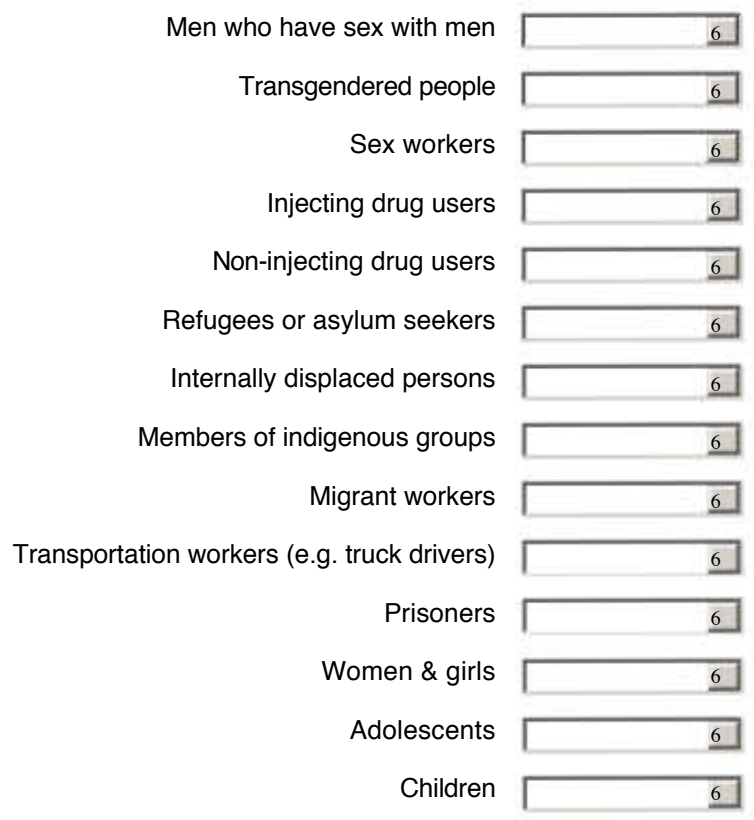


D3.1 Are there laws already in place or movements underway in your country / region to criminalize HIV transmission or to criminzalize "behaviours associated with at risk populations" (i.e. same sex behaviour, drug use, sex work, etc.)?

yes fin no $\mathrm{j}$

D3.2 If yes, is your organization involved in efforts to overturn or prevent these laws?

yes fin no fo

D3.3 What are the major obstacles you see to prevent or overturn these laws that criminalize HIV transmission or at risk population?

D4. Please evaluate to what extent each of the following harm HIV prevention, treatment and care in the area where your work:

Criminalization of HIV transmission Discrimination on the basis of HIV status

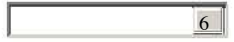
Inadequate legal protection of confidentiality

Criminalization of same-sex sexual behavio

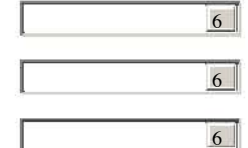

Discrimination on the basis of sexual orientation or sexual practices

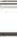

Discrimination on the basis of gender identity/designation

Discrimination against and/or low social status of women/girls

Criminalization of drug use

Criminalization of sex work
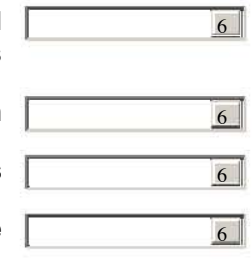

Inadequate social and medical services in prisons

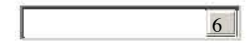

D5. Thinking of the vulnerable population groups listed in D1 and your answers in D4, which types of discrimination are most prevalent? (Tick no more than two)

e Social ostracization in society generally

e Social ostracization in the family

Discrimination in health facilities

e Discrimination in educational facilities

e Official (governmental) discrimination

e Police harassment

e Discrimination in employment practices

Discrimination by religions and or clergy 
D6 What do your consider the main challenges and priorities with respect to stigma and discrimination? 


\section{aids2031

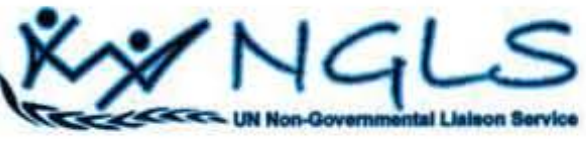

\section{Module E. HIV prevention (5 of 7 )}

Brief description explaining the content of this section goes here

E1. Indicate to what extent you agree with each of the following statements by selecting the appropriate option

Current prevention programmes are sufficient

Treatment programs are taking resources away from prevention programs

Prevention interventions should be targeted to specific most-atrisk populations

Prevention campaigns should focus on promoting abstinence

Prevention campaigns should focus on partner reduction

Prevention campaigns should focus on condom distribution

Harm reduction programs (incl. needle exchange) and substitution therapy for injecting drug users should be more widely rolled out
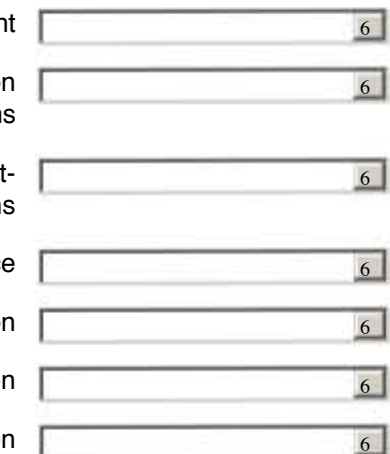

Male circumcision should be more widely rolled out

E2. Please evaluate to what extent each of the following contribute to HIV transmission in the area where your work

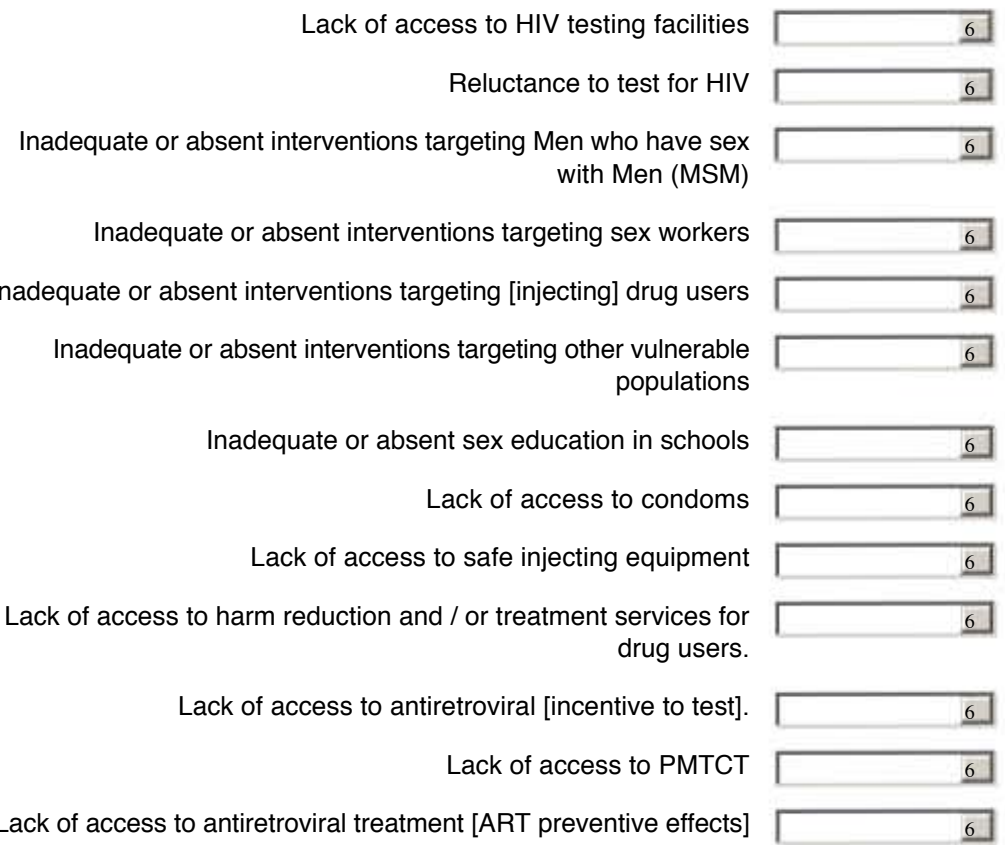

E3. Do you believe the following will be successfully developed/implemented and prove effective over the next $10-15$ years?

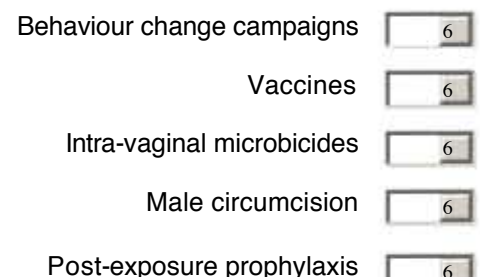

Post-exposure prophylaxis 
Combination prevention

Other (please specify):

Other (please specify):

E4. What do you consider the main challenges and priorities with respect to HIV prevention?

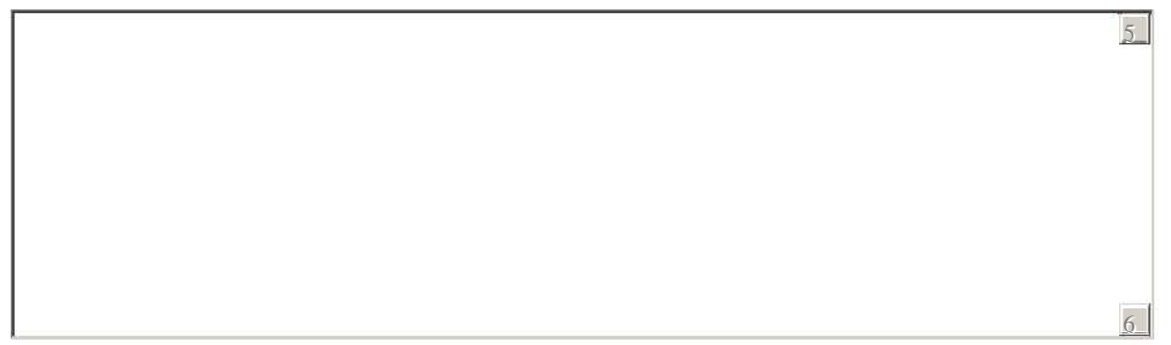




\section{aids $2031^{\circ}$}

\section{Module F. Access to treatment, care and support ( 6 of 7$)$}

F1. Indicate to what extent you agree with each of the following statements by selecting the appropriate option

The government is showing sufficient commitment to rolling out universal access to HAART and related services

There is sufficient civil society advocacy on universal access to HAART and related services

Pharmaceutical patents result in unaffordable prices for antiretrovirals

There is sufficient investment in developing new treatments for TB and other opportunistic infections

There is sufficient investment in developing affordable treatments for hepatitis $\mathrm{C}$

Countries are making sufficient use of flexibilities allowed under the TRIPS agreement (e.g. compulsory licences)

More local production of generic drugs is needed to ensure universal access to HAART and related services

There is sufficient civil society advocacy on trade policy and intellectual property rights issues

There is sufficient civil society advocacy on funding for treatment, care and support services

Weaknesses in technical skills/capacity impedes universal treatment access

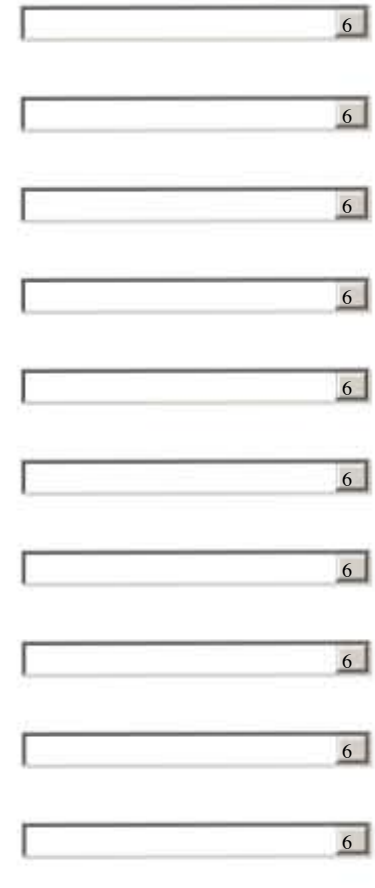

\section{F2. Do you believe the following will be achieved within the next 10-15 years?}

Universal access to HAART in the country/region where we work Universal access to HAART world-wide

Better treatments for Hepatitis $\mathrm{C}$ co-infection Better treatments for TB (incl MDR and XDR TB)

TB)

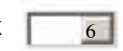

Sufficient international funding of treatment, care and support
services in poor countries

Sufficient international funding of treatment, care and support
services in poor countries

Sufficient local funding of treatment, care and support services in the country/area where we work

F3. Please evaluate to what extent each of the following impede access to comprehensive treatment, care and support in the are where you work.

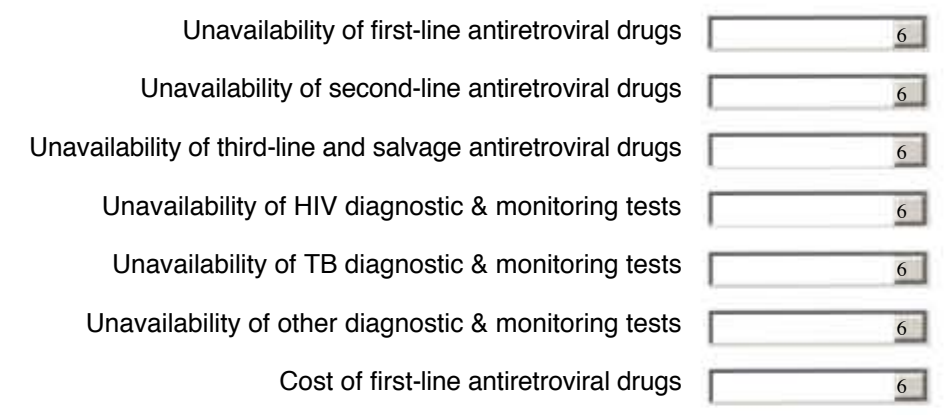

Cost of second-line, third-line and salvage antiretroviral drugs 
Cost of drugs for Ols/coinfections (e.g. TB or Hep C)

Cost of diagnostics and laboratory monitoring

Patents on antiretroviral drugs

Patents on other drugs

Patents on diagnostics and other technologies

Unavailability of generic antiretrovirals

Unavailability of generic drugs for Ols/coinfections (e.g. TB or Hep

C)

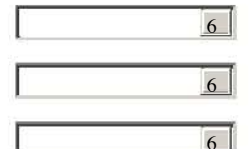

Lack of local drug mangufacturing capacity

Failure to integrate HIV and other healthcare services

Too few / lack of access to healthcare facilities

Patients not testing/knowing their HIV status

Reluctance to access healthcare services

Insufficient government funding for treatment \& care

Insufficient international funding for treatment \& care

Shortage of qualified medical staff
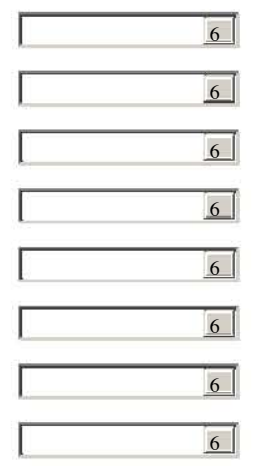

Shortage of appropriately qualified and skilled managers / other professional staff

Drug stock-outs / supply management problems

Lack of treatment/services in prisons, labour camps, etc.

Lack of skills/capacity in procurement and supply management

Unavailability of substitution therapy for drug users

Unavailability of TB treatment or failures in TB treatment programme
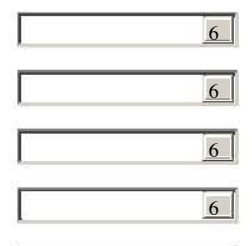

Unavailability of treatment for Opportunistic lnfections Unavailability of hepatitis $C$ treatment Side effects or toxicity from antiretroviral drugs Lack of governmental commitment to HIV programmes Lack of drugs regulatory capacity

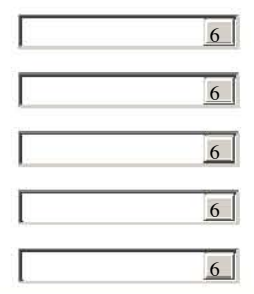

F4. What do you consider the main challenges and priorities with respect to access to comprehensive treatment, care and support?

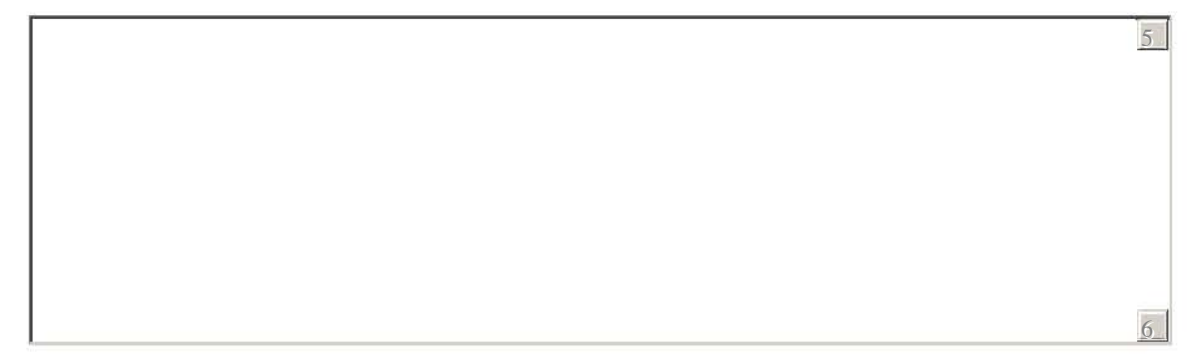




\section{aids2031}

\section{Module G. Health system strenthening (7 of 7)}

G1. "Indicate to what extent you agree with each of the following statements by selecting the appropriate option

AIDS-specific programs and health-system strengthening compete for international resources

The government spends sufficient resources on health Spending should be re-allocated from AIDS programs to general health spending and/or other diseases

Spending on AIDS programs strengthens the overall health system

There is sufficient civil society advocacy on health system strengthening and related issues

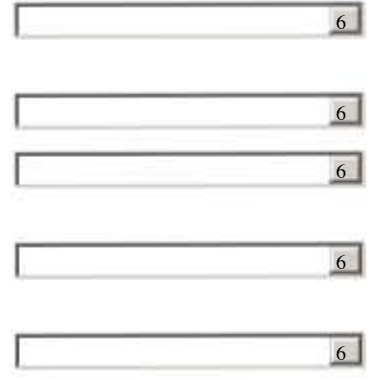

Shortages of skilled medical personnel is the main impediment to strengthening the health system

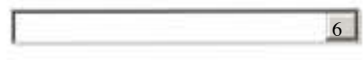

Shortages of skilled management and other technical personnel

is the main impediment to strengthening the health system

The health system can be strengthened through measures to facilitate knowledge transfer from Northern (developed) countries to Southern (developing) countries

Adding related services (e.g. for TB, malaria, maternal health, drug treatment or hepatitis $\mathrm{C}$ ) to HIV programs will strenghten general health care capacity in a cost-effective way

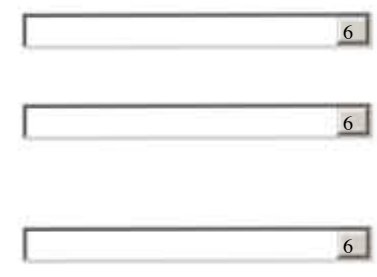

What do you consider the main challenges and priorities with respect to strengthening health systems?

Please tick where appropriate:

e I want to receive a copy of the report for the aids2031 Civil Society Online Survey

e I want to receive a copy of the final report of aids2031, "An Agenda for the Future"

e I want to be added to the aids2031 mailing list 


\section{Bibliography}

Achmat, Z. (2008). Chairperson's Report to the 4th National Congress of the Treatment Action Campaign.

Aminzade, R. (1992) 'Historical Sociology and Time'. Sociological Methods $\mathcal{E}$ Research, 20(4):456-480.

Amnesty International (2012). Amnesty International Report 2012: The state of the world's human rights. Technical report, Amnesty International, London. Available from: http://www. amnesty.org/en/library/asset/P0L10/002/2012/ en/56ec5df1-0e8d-4e99-a26d-a0e9514b451d/pol100022012en. pdf.

Atzori, C., Bonfanti, P., Carenzi, L., and Rizzardini, G. (2009) 'Efficacy evidences in prevention of HIV infection in developing countries. A critical appraisal from population-based studies'. Fournal of Medicine and the Person, 7(2):70-76. Available from: http: //www. springerlink. com/index/10.1007/s12682-009-0019-9.

Ballard, R., Habib, A., Valodia, I., and Zuern, E. (2006) 'Introduction: From Anti-Apartheid to Post-Apartheid Social Movements'. In Ballard, R., Habib, A., and Valodia, I., eds., Voices of Protest: Social Movements in Post-Apartheid South Africa, pages 1-22. University of KwaZulu-Natal Press, Durban.

Bates, R. H., Greif, A., Levi, M., Rosenthal, J.-1., and Weingast, B. (1998). Analytic Narratives. Princeton University Press, Princeton, NJ.

Bates, R. H., Greif, A., Levi, M., Rosenthal, J.-l., and Weingast, B. (2000) 'The Analytical Narratives Project'. The American Political Science Review, 94(3):696-702. Available from: http://www. jstor.org/stable/2585843. 
Baur, M., Benkert, M., Brandes, U., Cornelsen, S., Gaertler, M., Köpf, B., Lerner, J., and Wagner, D. (2002) 'Visone Software for Visual Social Network Analysis'. In Mutzel, P., Jünger, M., and Leipert, S., eds., Graph Drawing, volume 2265 of Lecture Notes in Computer Science, pages 554-557. Springer-Verlag, Berlin. Available from: http://dx.doi.org/10.1007/3-540-45848-4_47.

Berger, J. M. (2002) 'Tripping over patents: AIDS, access to treatment and the manufacturing of scarcity'. Connecticut fournal of International Law, 17(2):157-248.

Boas, T. C. (2007) 'Conceptualizing Continuity and Change: The CompositeStandard Model of Path Dependence'. Fournal of Theoretical Politics, 19(1):33-54. Available from: http://jtp. sagepub. com/cgi/content/abstract/19/1/33.

Bogart, L. M., Galvan, F. H., Wagner, G.J., and Klein, D. J. (2010a) 'Longitudinal Association of HIV Conspiracy Beliefs with Sexual Risk Among Black Males Living with HIV'. AIDS and Behavior. Available from: http://www. ncbi.nlm. nih.gov/pubmed/20734227.

Bogart, L. M., Kalichman, S. C., and Simbayi, L. C. (2008) 'Endorsement of a Genocidal HIV Conspiracy as a Barrier to HIV Testing in South Africa'. Fournal of Acquired Immune Deficiency Syndromes, 49(1):115-116. Available from: http://journals. lww.com/jaids/Abstract/2008/09010/ Endorsement_of_a_Genocidal_HIV_Conspiracy_as_a.20.aspx.

Bogart, L. M. and Thorburn, S. (2005) 'Are HIV/AIDS conspiracy beliefs a barrier to HIV prevention among African Americans?'. Journal of Acquired Immune Deficiency Syndromes, 38(2):213-8. Available from: http://www.ncbi.nlm.nih. gov/pubmed/15671808.

Bogart, L. M. and Thorburn Bird, S. (2003) 'Exploring the relationship of conspiracy beliefs about HIV/AIDS to sexual behaviors and attitudes among AfricanAmerican adults'. Fournal of the National Medical Association, 95(1 1):1057-65. Available from: http://www.ncbi.nlm.nih.gov/pubmed/14651372.

Bogart, L. M., Wagner, G., Galvan, F. H., and Banks, D. (2010b) 'Conspiracy beliefs about $\mathrm{HIV}$ are related to antiretroviral treatment 
nonadherence among african american men with HIV.' Fournal of Acquired Immune Deficiency Syndromes, 53(5):648-55. Available from: http://www. pubmedcentral.nih.gov/articlerender. fcgi?artid= 2845717\&tool=pmcent rez\&rendertype=abst ract.

Bohnert, A. S. B. and Latkin, C. A. (2009) 'HIV testing and conspiracy beliefs regarding the origins of HIV among African Americans'. AIDS patient care and STDs, 23(9):759-63. Available from: http: //www. pubmedcentral. nih.gov/articlerender. fcgi?artid= 2788153\&tool=pmcent rez\&rendertype=abst ract.

Bor, J. (2007) 'The political economy of AIDS leadership in developing countries: An exploratory analysis'. Social Science \& Medicine, 64:1585-1599.

Brandes, U. and Kenis, P. (2006) 'Explanation Through Network Visualization'. Methodology, 2(1):16-23.

Brandes, U. and Wagner, D. (2004) 'visone - Analysis and Visualization of Social Networks'. In Jünger, M. and Mutzel, P., eds., Graph Drawing Software, pages 321-340. Springer-Verlag, Berlin.

Brown, M. (1997). Replacing Gitizenship: AIDS Activism and Radical Democracy. Available from: http://books.google.com/books?id=Kf5n0qqJknkC\&vq= "Bearing+Witness"\&dq=chambre+volunteer+aids.

Buechler, S. M. (1995) 'New social movement theories'. The Sociological Quarterly, 36(3):441-464. Available from: http://www.blackwell-synergy.com/doi/ abs/10.1111/j . 1533-8525.1995. tb00447.x.

Cameron, E. (2000). The Deafening Silence of AIDS (First Jonathan Mann Memorial Lecture, delivered at the XIII International AIDS Conference, Durban, 10 July 2000). Available from: http: //www. actupny. org/reports/durban-cameron. html.

Cameron, E. and Geffen, N. (2005) "We are not the Red Cross"-Patents, profits and death from AIDS'. In Cameron, E., Witness to AIDS, pages 157-184. Tafelberg, Cape Town. 
Castells, M. (1983). The City and the Grassroots: A Cross-Cultural Theory of Urban Social Movements. Edward Arnold, London.

Castells, M. (1998). The Information Age: Economy, Society and Culture (Volumes I-III). Blackwell, Oxford.

Chigwedere, P., Seage, G. R., Gruskin, S., Lee, T.-H., and Essex, M. (2008) 'Estimating the Lost Benefits of Antiretroviral Drug Use in South Africa'. Fournal of Acquired Immune Deficiency Syndromes, 49(4):410-415. Available from: http://journals. lww.com/jaids/Abstract/2008/12010/ Estimating_the_Lost_Benefits_of_Antiretroviral.10.aspxhttp: //journals. Iww.com/jaids/Abstract/2008/09010/Endorsement_of_a_ Genocidal_HIV_Conspiracy_as_a.20.aspx.

Cilliers, P. (1998). Complexity and postmodernism. Routledge, London.

Cleary, S. M. and Ross, D. (2002) 'The 1998-2001 Legal Struggle between the South African Government and the International Pharmaceutical Industry: a Game-Theoretic Analysis'. The Journal of Social, Political and Economic Studies, 27(4):445-494.

Collier, D. (2007) 'Critical Junctures, Concepts, and Methods'. In Munck, G. L. and Snyder, R. O., eds., Passion, Craft, and Method in Comparative Politics, pages 556-600. Johns Hopkins University Press, Baltimore.

Collier, J. and Esteban, R. (2000) 'Systemic leadership: ethical and effective'. Leadership \& Organization Development Fournal, 21(4):207-215. Available from: http: //WwW. emeraldinsight. com/10.1108/01437730010335454.

Collier, R. B. and Collier, D. (1991). Shaping the Political Arena: Critical Functures, the Labor Movement, and Regime Dynamics in Latin America. Princeton University Press, Princeton, NJ.

Cran, W. (2006). FRONTLINE: The Age of AIDS. Available from: http://www. pbs.org/wgbh/pages/frontline/aids/.

de la Dehesa, R. (2010). Queering the Public Sphere in Mexico and Brazil: Sexual Rights Movements in Emerging Democracies. Duke University Press, Durham. 
De Waal, A. (2006). AIDS and Power: Why there is no political crisis - yet. Zed Books and David Philip, London and Cape Town.

della Porta, D. and Tarrow, S. (2005a) 'Conclusion: "Globalization," Complex Internationalism, and Transnational Contention'. In della Porta, D. and Tarrow, S., eds., Transnational Protest and Global Activism, pages 227-246. Rowman \& Littlefield, Maryland.

della Porta, D. and Tarrow, S. (2005b) 'Transnational Processes and Social Activism: An introduction'. In della Porta, D. and Tarrow, S., eds., Transnational Protest and Global Activism, pages 1-17. Rowman \& Littlefield, Maryland.

Desmond, C., Lieberman, E. S., Alban, A., and Ekström, A.-M. (2008) 'Relative Response: Ranking Country Responses to HIV and AIDS'. Health and Human Rights, 10(2):105-119. Available from: http://www.jstor.org/stable/ 20460106.

Dorrington, R., Bourne, D., Bradshaw, D., Laubscher, R., and Timaeus, I. (2001). The Impact of HIV/Aids on Adult Mortality in South Africa. Report, Burden of Disease Research Unit, Medical Research Council.

Dybul, M., Piot, P., and Frenk, J. (2012) 'Reshaping Global Health'. Policy Review, (173). Available from: http://www.hoover.org/publications/ policy-review/article/118116.

Edwards, M. and Hulme, D. (1996). Beyond the Magic Bullet: NGO Performance and Accountability in the Post-Cold War World. Kumarian, New Hartford, Connecticut.

Ekeh, P. P. (1975) 'Colonialism and the Two Publics in Africa: A Theoretical Statement'. Comparative Studies in Society and History, 17(1):91-112. Available from: http://www. jstor. org/stable/178372.

Elster, J. (1999). Alchemies of the Mind: Rationality and the Emotions. Cambridge University Press, Cambridge.

Elster, J. (2000) 'Rational Choice History: A Case of Excessive Ambition'. The American Political Science Review, 94(3):685-695. 
Epstein, H. and Halperin, D. T. (2007) 'Global sexual behaviour.'. Lancet, 369(9561):557. Available from: http://www.ncbi.nlm.nih.gov/ entrez/query. $\mathrm{fcgi}$ ? $\mathrm{cmd}=$ Ret $r i e v e \& d b=$ pubmed\&dopt=Abstract\&list_uids= 17307099.

Epstein, S. (1996) 'Impure Science: AIDS, Activism, and the Politics of Knowledge'.

Evans, P. (2000) 'Fighting Marginalization with Transnational Networks: Counter-Hegemonic Globalization'. Contemporary Sociology, 29(1):230-241. Available from: http://www.jstor.org/stable/2654947.

Fassin, D. (2007). When Bodies Remember: Experiences and Politics of AIDS in South Africa. University of California Press, Berkeley and Los Angeles.

Fassin, D. and Schneider, H. (2003) 'The politics of AIDS in South Africa: beyond the controversies'. British Medical fournal, 326(7387):495-497. Available from: http://dx.doi.org/10.1136/bmj . 326.7387.495.

Feinstein, A. (2007). After the Party: A personal and political journey inside the ANC. Jonathan Ball, Johannesburg.

Friedman, A. A. (2004) 'Beyond Mediocrity: transformational leadership within a transactional framework'. International Journal of Leadership Education, $7(3): 203-224$.

Friedman, S. and Mottiar, S. (2005) 'A Rewarding Engagement? The Treatment Action Campaign and the Politics of HIV/AIDS'. Politics E Society, 33(4):511-565. Available from: http://pas. sagepub.com/cgi/doi/10.1177/ 0032329205280928.

Friedman, S. and Mottiar, S. (2006) 'Seeking the High Ground: The Treatment Action Campaign and the Politics of Morality'. In Ballard, R., Habib, A., and Valodia, I., eds., Voices of Protest: Social Movements in Post-Apartheid South Africa, pages 23-44. University of KwaZulu-Natal Press, Durban.

Geertz, G. (1973). The interpretation of cultures. Basic Books, New York. 
Geffen, N. (2005) 'Echoes of Lysenko: State-Sponsored Pseudo-Science in South Africa'. Social Dynamics, 31(2):183-210. Available from: http://www. tand fonline. com/doi/abs/10.1080/02533950508628713.

Geffen, N. (2010). Debunking Delusions: The Inside Story of the Treatment Action Campaign. Jacana, Johannesburg.

George, A. L. and Bennett, A. (2004). Case studies and theory development in the social sciences. The MIT Press, Cambridge, MA, kindle edition.

Goldacre, B. (2010). Bad Science: Quacks, Hacks and Big Pharma Flacks. McClelland \& Stewart, Toronto.

Gould, D. B. (2002) 'Life During Wartime: Emotions and the Development of ACT UP'. Mobilization: An International fournal, 7(2):177-200. Available from: http://mobilization. metapress. com/openurl.asp?genre= article\&issn=1086-671X\&volume=7\&issue $=2 \&$ spage $=177$.

Gould, D. B. (2009). Moving Politics: Emotion and ACT UP's Fight against AIDS. University of Chicago Press, Chicago.

Granovetter, M. S. (1973) 'The Strength of Weak Ties'. The American Fournal of Sociology, 78(6):1360-1380.

Granovetter, M. S. (1983) 'The Strength of Weak Ties: A Network Theory Revisited'. Sociological Theory, 1:201-233.

Gray, R. H., Serwadda, D., Kigozi, G., Nalugoda, F., and Wawer, M. J. (2006) 'Uganda's HIV Prevention Success: The Role of Sexual Behavior Change and the National Response. Commentary on Green et al. (2006)'. AIDS and Behavior, 10(4):347-350. Available from: http://www.springerlink.com/index/ $10.1007 / \mathrm{s} 10461-006-9074-\mathrm{x}$.

Grebe, E. (2009a) 'Contingency, contestation and hegemony: The possibility of a non-essentialist politics for the left'. Philosophy \& Social Criticism, 35(5):589-611. Available from: http://psc. sagepub.com/cgi/doi/10.1177/ 0191453709103428. 
Grebe, E. (2009b) 'Leaders, Networks and Coalitions in the AIDS response: A comparison between Uganda and South Africa'. Research Paper. Developmental Leadership Program. Available from: http://www.dlprog.org/ftp/ index. php? showcat=researchpapers.

Grebe, E. (2011) 'The Treatment Action Campaign's Struggle for AIDS Treatment in South Africa: Coalition-building Through Networks'. Journal of Southern African Studies, 37(4):849-868. Available from: http: //www. tandfonline.com/ doi/abs/10.1080/03057070.2011.608271.

Grebe, E. and Nattrass, N. (2012) 'AIDS conspiracy beliefs and unsafe sex in Cape Town'. AIDS and Behavior, 16(3):761-773. Available from: http://www.ncbi. nlm.nih.gov/pubmed/21538083.

Grebe, E. and Woermann, M. (2011). Institutions of Integrity and the Integrity of Institutions: Integrity and ethics in the politics of developmental leadership. DLP Research Paper 15, Developmental Leadership Program. Available from: http: //www. dlprog.org/ftp/index. php?showcat=researchpapers.

Green, E. C., Halperin, D. T., Nantulya, V., and Hogle, J. a. (2006) 'Uganda's HIV prevention success: the role of sexual behavior change and the national response.'. AIDS and Behavior, 10(4):335-350. Available from: http://www. pubmedcentral.nih.gov/articlerender.fcgi?artid= 1544373\&tool=pmcent rez\&rendertype=abstract.

Greif, A. (2006). Institutions and the Path to the Modern Economy: Lessons from Medieval Trade. Cambridge University Press, Cambridge.

Gronn, P. (2003). The New Work of Educational Leaders: Changing Leadership Practices in an Era of School Reform. London.

Haacker, M. (2009). Determinants of Access to Antiretroviral Therapy Across Countries. Unpublished paper.

Hannigan, J. A. (1985) 'Alain Touraine, Manuel Castells and Social Movement Theory: A Critical Appraisal'. The Sociological Quarterly, 26(4):435-454. Available from: http://dx.doi.org/10.1111/j .1533-8525.1985. tb00237.x. 
Hardt, M. and Negri, A. (2000). Empire. Harvard University Press, Massachusetts.

Hardt, M. and Negri, A. (2004). Multitude: War and Democracy in the Age of Empire. Penguin, New York.

Hargadon, A. and Fanelli, A. (2002) 'Action and possibility: reconciling dual perspectives of knowledge in organizations'. Organization Science, 13(3):290-302.

Hay, C. and Wincott, D. (1998) 'Structure, Agency and Historical Institutionalism'. Political Studies, XLVI:951-957.

Health GAP Coalition (2000). Official Call: Global March for HIV/AIDS Treatment to the International Aids Conference 9 Fuly 2000 in Durban, South Arica (Endorsements). Available from: http://web.archive.org/web/20000816213056/ durban2000march.org/endorsements.html.

Heckscher, G. (2006) 'Organizations, movements and networks'. New York Law School Law Review, 50(2):313-336.

Hochschild, A. (2006). Bury the Chains: Prophets and Rebels in the Fight to Free an Empire's Slaves. Houghton Mifflin, New York.

Hosking, D. M. (2007) 'Not leaders, not followers: a post-modern discourse of leadership processes'. In Shamir, B., Pillai, R., Blighand, M. C., and Uhl-Bien, M., eds., Follower-Centred Perspectives on Leadership: A Tribute to the Memory of James R. Meindl, pages 243-264. Information Age Publishing, Greenwich.

Hosking, D. M., Dachler, H. P., and Gergen, Kenneth, J. (1995) 'Introduction'. In Hosking, D. M., Dachler, H. P., and Gergen, Kenneth, J., eds., Management and Organization: Relational Alternatives to Individualism. Avebury/Ashgate Publishing Co., Brookfield.

Izama, A. and Wilkerson, M. (2011) 'Uganda: Museveni's Triumph and Weakness'. Journal of Democracy, 22(3):64-78. Available from: http://muse.jhu.edu/content/crossref/journals/journal_of_ democracy/v022/22.3. izama. html. 
Johnson, K. (2006) 'Framing AIDS Mobilization and Human Rights in Postapartheid South Africa'. Perspectives on Politics, 4(4):663-670. Available from: http://dx.doi.org/10.1017/S1537592706060415.

Johnston, H., Laraña, E., and Gusfield, J. R. (1994) 'Identities, Grievances, and New Social Movements'. In Laraña, E., Johnston, H., and Gusfield, J. R., eds., New Social Movements: From Ideology to Identity. Temple University Press, Philadelphia.

Kates, J., Wexler, A., Lief, E., and Gobet, B. (2012). Financing the Response to AIDS in Low- and Middle-Income Countries: International Assistance from Donor Governments in 2011. Technical report, Kaiser Family Foundation. Available from: http: //www.kff.org/hivaids/upload/7347-08.pdf.

Keck, M. E. and Sikkink, K. (1998). Activists beyond borders: advocacy networks in international politics. Cornell University Press, New York.

Keohane, R. O. and Nye, J. S. (1972). Transnational Relations and World Politics. Harvard University Press, Massachussetts.

Knight, J. (1992). Institutions and Social Conflict. Cambridge University Press, Cambridge.

Knight, L. (2008). UNAIDS: the first 10 years, 1996-2006. Joint United Nations Programme on HIV/AIDS, Geneva. Available from: http://data. unaids. org/pub/Report/2008/JC1579_First_10_years_en.pdf.

Kriesi, H. (1996) 'The organisational structure of new social movements in a political context'. In McAdam, D., McCarthy, J. D., and Zald, M. N., eds., Comparative perspectives on social movements, pages 152-184. Cambridge University Press, Cambridge.

Kriesi, H., Koopmans, R., Duyvendak, J. W., and Giugni, M. G. (1995). New Social Movements in Western Europe: A Comparative Analysis. University of Minnesota Press, Minneapolis.

Krim, M. (1998) 'Jonathan Mann 1947-1998'. Nature Medicine, 4(10):1101-1101. Available from: http: //www. nature. com/doifinder/10.1038/2592. 
Laclau, E. (1990). New Reflections on the Revolution of Our Time. Verso, London.

Laclau, E. and Mouffe, C. (1985). Hegemony and Socialist Strategy: Towards a Radical Democratic Politics. Verso, London.

Leftwich, A. and Hogg, S. (2007). The case for leadership and the primacy of politics in building effective states, institutions and governance for sustainable growth and social development. Background Paper 1, Developmental Leadership Program.

Levi, M. (2002) 'Modeling Complex Historical Processes with Analytic Narratives'. In Mayntz, R., ed., Akteure - Mechanismen - Modelle: Zur Theoriefähigkeit makrosozialer Analysen, pages 108-127. Campus Verlag, Frankfurt am Main.

Lewis, J. (2003). TAC: The first five years... Video documentary, Community Health Media Trust.

Lieberman, E. S. (2007) 'Ethnic Politics, Risk and Policy-Making: A CrossNational Statistical Analysis of Government Responses to HIV/AIDS'. Comparative Political Studies, 40(12):1407-1432.

Ligon-Borden, B. (2003) 'Dr. Jonathan Mann: champion for human rights in the fight against AIDS'. Seminars in Pediatric Infectious Diseases, 14(4):314-322. Available from: http://linkinghub.elsevier.com/retrieve/pii/ S1045187003000815.

Lisk, F. (2010). Global Institutions and the HIV/AIDS Epidemic: Responding to an international crisis. Routledge, London.

Low-Beer, D. and Stoneburner, R. (2004) 'Uganda and the Challenge of HIV/AIDS'. In Poku, N. K. and Whiteside, A., eds., The Political Economy of AIDS in Africa, pages 165-190. Ashgate, Aldershot.

Makara, S. (2010) 'Deepening Democracy through Multipartyism: The Bumpy Road to Uganda's 2011 Elections'. Africa Spectrum, 45(2):81-94.

Makara, S., Rakner, L., and Svasand, L. (2009) 'Turnaround: The National Resistance Movement and the Reintroduction of a Multiparty System in Uganda'. 
International Political Science Review, 30(2):185-204. Available from: http://ips. sagepub.com/cgi/doi/10.1177/0192512109102436.

Mann, J. (1995) 'Human Rights and the New Public Health'. Health and Human Rights, 1(3):229-233. Available from: http://www.jstor.org/stable/ 4065135.

Mann, J. (1997) 'Medicine and Public Health, Ethics and Human Rights'. The Hastings Center Report, 27(3):6-13. Available from: http://www.jstor.org/ stable/3528660.

Mann, J. (1998) 'AIDS and Human Rights: Where Do We Go from Here?'. Health and Human Rights, 3(1):143-149. Available from: http: //www. j stor . org/ stable/4065288.

Marks, S. P. (2001) 'Jonathan Mann's Legacy to the 21st Century: The Human Rights Imperative for Public Health'. Journal of Law, Medicine \& Ethics, (29):131-138.

Mayhew, S. H. (2002) 'Donor Dealings: The Impact of International Donor Aid on Sexual and Reproductive Health Services'. International Family Planning Perspectives, 28(4):220. Available from: http://www. j stor.org/stable/3088225? origin=cross ref.

Mbali, M. (2006) 'TAC in the history of patient-driven AIDS activism: The Case for Historicizing South Africa's New Social Movements'. In Gibson, N. C., ed., Challenging Hegemony: Social Movements and the Quest for a New Humanism in PostApartheid South Africa, pages 129-155. Africa World Press, New Jersey.

Mbali, M. (2010) 'The "New Struggle": Resources, networks and the formation of the Treatment Action Campaign (TAC) 1994-1998'. In Beinart, W. and Dawson, M. C., eds., Popular Politics and Resistance Movements in South Africa, pages 227-242. Wits University Press, Johannesburg.

McAdam, D. (1996) 'Conceptual origins, current problems, future directions'. In McAdam, D., McCarthy, J. D., and Zald, M. N., eds., Comparative perspectives on social movements, pages 23-40. Cambridge University Press, Cambridge. 
McAdam, D., McCarthy, J. D., and Zald, M. N. (1996) 'Introduction: Opportunities, mobilizing structures, and framing processes - toward a synthetic, comparative perspective on social movements'. In McAdam, D., McCarthy, J. D., and Zald, M. N., eds., Comparative perspectives on social movements, pages 1-20. Cambridge University Press, Cambridge.

McAdam, D., Tarrow, S., and Tilly, C. (2001). Dynamics of Contention. Cambridge University Press, Cambridge.

Médecins Sans Frontières (2011). Untangling the Web of Antiretroviral Price Reductions (14th Edition). Technical report, Médecins Sans Frontières, Geneva. Available from: http://utw. msfaccess.org/.

Ménard, C. and Shirley, M. M., eds. (2005). Handbook of New Institutional Economics. Springer, Berlin \& Heidelberg. Available from: http://www.springerlink. com/content/xv3725/?sortorder=asc\&v=editorial\%\&p_o=10.

Merson, M. (2006) 'Uganda's HIV/AIDS Epidemic: Guest Editorial'. AIDS and Behavior, 10(4):333-334. Available from: http://www. springerlink.com/ index/10.1007/s10461-006-9120-8.

Ministry of Health [Uganda] and ORG Macro (2006). HIV/AIDS Sero-Behavioural Survey 2004-05. Technical report, Ministry of Health and ORC Macro, Calverton, Maryland, USA. Available from: http://pdf.usaid.gov/pdf_docs/ PNADG508. pdf.

Moe, T. M. (2006) 'Power and Political Institutions'. In Shapiro, I., Skowronek, S., and Galvin, D., eds., Rethinking Political Institutions: The Art of the State, pages 32-71. New York University Press, New York and London.

Morin, E. (2008). On Complexity. Hampton Press, Creskill.

Muriaas, R. L. (2009) 'Reintroducing a Local-Level Multiparty System in Uganda: Why Be in Opposition?'. Government and Opposition, 44(1):91-112. Available from: http://doi.wiley.com/10.1111/j .1477-7053.2008.01277.x. 
Museveni, J. K. (2004). "The AIDS Pandemic: Saving the Next Generation": Speech at "Common Ground: A Shared Vision for Health" (Washington, DC, 17 June 2004). Available from: http://catholiceducation.org/articles/sexuality/se0106. html.

Musinguzi, J., Kirungi, W., Opio, A., Montana, L., Mishra, V., Madraa, E., Biryahwaho, B., Mermin, J., Bunnell, R., Cross, A., Hladik, W., McFarland, W., and Stoneburner, R. (2009) 'Comparison of HIV prevalence estimates from sentinel surveillance and a national population-based survey in Uganda, 20042005.'. Journal of Acquired Immune Deficiency Syndromes, 51(1):78-84. Available from: http://www.ncbi.nlm.nih.gov/pubmed/19325495.

Myburgh, J. (2007a). The Virodene affair (I). Available from: http: //www.politicsweb.co.za/politicsweb/view/politicsweb/en/ page71619? oid=83156\&sn=Detail.

Myburgh, J. (2007b). The Virodene affair (II). Available from: http://www.politicsweb.co.za/politicsweb/view/politicsweb/en/ page71619? oid=83179\&sn=Detail\&pid=71619.

Myburgh, J. (2007c). The Virodene affair (III). Available from: http://www.politicsweb.co.za/politicsweb/view/politicsweb/en/ page71619? oid=83213\&sn=Detail\&pid=71619.

Myburgh, J. (2007d). The Virodene affair (IV). Available from: http://www.politicsweb.co.za/politicsweb/view/politicsweb/en/ page71619? oid=83231\&sn=Detail\&pid=71619.

Myburgh, J. (2007e). The Virodene affair (V). Available from: http: //www. politicsweb.co.za/politicsweb/view/politicsweb/en/ page71619? oid=83253\&sn=Detail\&pid=71619.

Nattrass, N. (2006) 'What Determines Cross-Country Access to Antiretroviral Treatment?'. Development Policy Review, 24(3):321-337. Available from: http: //doi.wiley.com/10.1111/j.1467-7679.2006.00327.x. 
Nattrass, N. (2007). Mortal Combat: AIDS denialism and the struggle for antiretrovirals in South Africa. UKZN Press, Pietermaritzburg.

Nattrass, N. (2008a) 'AIDS and the Scientific Governance of Medicine in PostApartheid South Africa'. African Affairs, 107(427):157-176.

Nattrass, N. (2008b) 'Are country reputations for good and bad leadership on AIDS deserved? An exploratory quantitative analysis'. Fournal of Public Health, 30(4):398-406. Available from: http://www.ncbi.nlm.nih.gov/ pubmed/18791202.

Nattrass, N. (2008c) 'The (political) economics of antiretroviral treatment in developing countries'. Trends in Microbiology, 16(12):574-9. Available from: http: //www.ncbi.nlm.nih.gov/pubmed/18964022.

Nattrass, N. (2012). The AIDS Conspiracy: Science Fights Back. Columbia University Press, New York.

Nattrass, N. and Gonsalves, G. (2010) 'AIDS funds: undervalued'. Science, 330(6001):174-5. Available from: http://www.ncbi.nlm.nih.gov/pubmed/ 20929755.

Niehaus, I. and Jonsson, G. (2005) 'Dr. Wouter Basson, Americans, and wild beasts: men's conspiracy theories of HIV/AIDS in the South African Lowveld'. Medical anthropology, 24(2):179-208. Available from: http://www.ncbi.nlm. nih.gov/pubmed/16019570.

Norris, P. (2009). Democracy Crossnational Data, Release 3.0. Available from: http: //www.hks.harvard.edu/fs/pnorris/Data/Data.htm.

North, D. C. (1990). Institutions, Institutional Change, and Economic Performance. Cambridge University Press, Cambridge.

North, D. C. (2005). Understanding the Processes of Economic Change. Princeton University Press, Princeton, NJ.

Offe, C. (1985) 'New Social Movements: Challenging the Boundaries of Institutional Politics'. Social Research, 52. 
Offe, C. (2006) 'Political Institutions and Social Power: Conceptual Explorations'. In Shapiro, I., Skowronek, S., and Galvin, D., eds., Rethinking Political Institutions: The Art of the State, pages 9-31. New York University Press, New York and London.

Olesen, T. (2006) "In the Court of Public Opinion": Transnational Problem Construction in the HIV/AIDS Medicine Access Campaign, 1998-2001'. International Sociology, 21(5):5-30. Available from: http://dx.doi.org/10.1017/ S1537592706060415.

Olson, M. (2000). Power and Prosperity: Outgrowing Communist and Capitalist Dictatorships. Basic Books, New York.

O’Manique, C. (2004). Neoliberalism and AIDS Crisis in Sub-Saharan Africa. Oxford University Press, Oxford.

Orkin, A. (1990) 'Boycott casts shadow over San Francisco AIDS conference'. Canadian Medical Association Fournal, 142(12):1411-1413.

Ostergard, R. L. and Barcello, C. (2005) 'Personalist Regimes and the Insecurity Dilemma: Prioritizing AIDS as a National Security Threat in Uganda'. In Patterson, A. S., ed., The African State and the AIDS Crisis, pages 155-170. Ashgate, Aldershot.

Painter-Morland, M. (2008) 'Systemic Leadership and the Emergence of Ethical Responsiveness'. Journal of Business Ethics, 82(2):509-524. Available from: http: //wWw. springerlink. com/index/10.1007/s10551-008-9900-3.

Paxton, N. A. (2012) 'Political science(s) and HIV: a critical analysis'. Contemporary Politics, 18(2):141-155. Available from: http://www.tandfonline.com/doi/ abs/10.1080/13569775.2012.674335.

Pierson, P. (2000) 'Increasing Returns, Path Dependence, and the Study of Politics'. The American Political Science Review, 94(2):251-267. Available from: http: //www.jstor.org/stable/2586011.

Pierson, P. and Skocpol, T. (2002) 'Historical Institutionalism in Contemporary Political Science'. New York. 
Piot, P. (2008). "Africa's Response: Face the facts": Speech at opening of 15th International Conference on AIDS and STIS in Africa (Dakar, 3 December 2008). Available from: http: //www. unaids.org/en/media/unaids/contentassets/ dataimport/pub/speechexd/2008/20081203_sp_pp_icasa_en.pdf.

Piot, P. (2012). No Time to Lose: A Life in Pursuit of Deadly Viruses. W.W. Norton, New York and London, kindle edition.

Piot, P. and Coll-Seck, A. M. (2001) 'International response to the HIV/AIDS epidemic: Planning for success'. Bulletin of the World Health Organization, 79(12):1106-1112.

Pisani, E. (2009). The Wisdom of Whores: Bureaucrats, Brothels and the Business of AIDS. W. W. Norton \& Company, New York.

Putzel, J. (2004) 'The Politics of Action on AIDS: A Case Study of Uganda'. Public Administration and Development, (24):19-30.

Robins, S. (2004) "Long live Zackie, long live": AIDS activism, science and citizenship after apartheid'. Journal of Southern African Studies, 30(3):651-672. Available from: http://www. informaworld.com/openurl? gen re=article\&do $i=10.1080 / 0305707042000254146 \&$ mag $i c=$ cross ref $\mid$ |D404A21C5BB053405B1A640AFFD44AE3.

Robins, S. (2006) 'From "Rights" to "Ritual": AIDS Activism in South Africa'. American Anthropologist, 108(2):312-323. Available from: http://dx.doi.org/ 10.1525/aa.2006.108.2.312.

Robins, S. (2008) 'AIDS, Science and the Making of a Social Movement: AIDS Activism and Biomedical Citizenship in South Africa'. In From Revolution to Rights in South Africa, chapter 5, pages 100-126. University of KwaZulu-Natal Press, Pietermaritzburg.

Ross, M. W., Essien, E. J., and Torres, I. (2006) 'Conspiracy beliefs about the origin of HIV/AIDS in four racial/ethnic groups.'. Fournal of Acquired Immune Deficiency Syndromes, 41(3):342-4. Available from: 
http: //Www. pubmedcentral. nih.gov/articlerender.fcgi?artid= 1405237\&tool=pmcent rez\&rendertype=abstract.

Sadgrove, J., Vanderbeck, R. M., Andersson, J., Valentine, G., and Ward, K. (2012) 'Morality plays and money matters: towards a situated understanding of the politics of homosexuality in Uganda'. The Fournal of Modern African Studies, 50(01):103-129. Available from: http://www. journals.cambridge.org/ abstract_S0022278X11000620.

Schneider, K. and Garrett, L. A. (2009). The Evolution and Future of Donor Assistance for HIV/AIDS. Technical report, Council on Foreign Relations. Available from: http://www.cfr.org/foreign-aid/ evolution-future-donor-assistance-hivaids/p19161.

Scholte, J. A. (2004) 'Civil Society and Democratically Accountable Global Governance'. Government and Opposition, 39(2):211-233.

Schwardmann, P. (2008). A Cross-country Analysis of the Determinants of Antiretroviral Drug Coverage. CSSR Working Paper 217, Centre for Social Science Research, Cape Town. Available from: http://www.cssr.uct.ac.za/publications/ working-paper/2008/217.

Seekings, J. (2000). The UDF: A History of the United Democratic Front in South Africa, 1983-1991. David Philip Publishers, Cape Town.

Skocpol, T. (1995) 'Why I Am an Historical Institutionalist'. Polity, 28(1):103-106. Available from: http: //www. jstor. org/stable/3235190.

Smith, A. M. (1998). Laclau and Mouffe: The radical democratic imaginary. Routledge, London.

Smith, J., Pagnucco, R., and Chatfield, C. (1997) 'Social Movements and World Politics: A Theoretical Framework'. In Smith, J., Pagnucco, R., and Chatfield, C., eds., Transnational Social Movements and Global Politics, pages 59-77. Syracuse University Press, Syracuse.

Smith, R. A. and Siplon, P. D. (2006). Drugs into Bodies: Global AIDS Treatment Activism. Praeger Publishers, Westport, CT. 
Soysal, Y. (1994). Limits of Citizenship: Migrants and Postnational Membership in Europe. Chicago University Press, Chicago, Illinois.

Ssebanja, P. (2007). The Story of TASO. Strategies for Hope Series. ActionAid, London.

Steinberg, J. (2008). Three-letter Plague / Sizwe's Test. Jonathan Ball, Cape Town.

Stoneburner, R. L. and Low-Beer, D. (2004) 'Population-level HIV declines and behavioral risk avoidance in Uganda.'. Science, 304(5671):714-8. Available from: http://www.ncbi.nlm.nih.gov/pubmed/15118157.

Strine, T. W., Kobau, R., Chapman, D. P., Thurman, D. J., Price, P., and Balluz, L. S. (2005) 'Psychological distress, comorbidities, and health behaviors among U.S. adults with seizures: results from the 2002 National Health Interview Survey'. Epilepsia, 46(7):1133-9. Available from: http://www.ncbi.nlm.nih.gov/ pubmed/16026567.

Sullivan Robinson, R. (2011). Social Resources and Health Disparities: The Impact of Local Nongovernmental Organizations on HIV Outcomes in Sub-Saharan Africa. Unpublished paper, School of International Service, American University.

't Hoen, E. (2002) 'TRIPS, pharmaceutical patents and access to essential medicines: a long way from Seattle to Doha'. Chicago Fournal of International Law, 3(1):27-46.

TAC (2001). Treatment Action Campaign: An Overview. Available from: http://www. tac. org.za/Documents/0ther/tachist.pdf.

TAC (2008). Constitution of the Treatment Action Campaign (As amended at TAC's Fourth National Congress, 2008).

Tarrow, S. (1996) 'States and opportunities: The political structuring of social movements'. In McAdam, D., McCarthy, J. D., and Zald, M. N., eds., Comparative perspectives on social movements, pages 41-61. Cambridge University Press, Cambridge. 
Tarrow, S. (1998). Power in Movement: Social Movements and Contentious Politics. Cambridge University Press, Cambridge.

Tarrow, S. (2001) 'Transnational Politics: Contention and Institutions in International Politics'. Annual Review of Political Science, 4:1-20. Available from: http://dx.doi.org/1094-2939/01/0623-0001.

Tarrow, S. and McAdam, D. (2005) 'Scale Shift in Transnational Contention'. In della Porta, D. and Tarrow, S., eds., Transnational Protest and Global Activism, pages 121-147. Rowman \& Littlefield, Maryland.

Taylor, R. (2004) 'Interpreting Global Civil Society'. In Taylor, R., ed., Creating a Better World: Interpreting Global Civil Society, pages 1-12. Kumarian Press, Connecticut.

Thelen, K. (1999) 'Historical Institutionalism in Comparative Politics'. Annual Review of Political Science, 2:369-404.

Thelen, K. (2002) 'The Explanatory Power of Historical Institutionalism'. In Mayntz, R., ed., Akteure - Mechanismen - Modelle: Zur Theoriefähigkeit makro-sozialer Analysen, pages 91-107. Campus Verlag, Frankfurt am Main.

Thornton, R. J. (2008). Unimagined Community: Sex, Networks, and AIDS in Uganda and South Africa. University of California Press, Berkeley, CA.

Touraine, A. (1981). The voice and the eye: An analysis of social movements. Cambridge University Press and Editions de la Maison des Sciences de l'Homme, Cambridge.

Tumushabe, J. (2006). The Politics of HIV/AIDS in Uganda. Social Policy and Development Programme Paper 28, United Nations Research Institute for Social Development. Available from: http://www.unrisd.org/ unrisd/website/document.nsf/240da49ca467a53f80256b4f005ef245/ 86cb69d103fcf94ec125723000380c60八protect\char"0024\relaxFILE/ tumushabe-pp.pdf. 
Tun, W., Kellerman, S., Maime, S., Fipaza, Z., Sheehy, M., Vu, L., and Nel, D. (2010). Conspiracy beliefs about HIV, attitudes towards condoms and treatment and HIVrelated preventive behaviors among men who have sex with men in Tshwane (Pretoria), South Africa (Abstract no TUPE0656). XVIII International AIDS Conference. International AIDS Society. Available from: http://pag. aids2010.org/Abstracts. aspx?AID=14825.

Tvedt, T. (2004) 'Development NGOs: Actors in a Global Civil Society or in a New International Social System?'. In Taylor, R., ed., Creating a Better World: Interpreting Global Civil Society, pages 133-146. Kumarian Press, Connecticut.

Uhl-Bien, M. (2006) 'Relational Leadership Theory: Exploring the social processes of leadership and organizing'. The Leadership Quarterly, 17(6):654-676. Available from: http://linkinghub.elsevier.com/retrieve/pii/ S1048984306001135.

UNAIDS (1998a). A measure of success in Uganda: The value of monitoring both HIV prevalence and sexual behaviour (UNAIDS Best Practice Collection). Technical report, Joint United Nations Programme on HIV/AIDS, Geneva. Available from: http://data.unaids.org/Publications/irc-pub04/value_ monitoring_uganda_en.pdf.

UNAIDS (1998b). Partners in prevention: International case studies of effective health promotion practice in HIV/AIDS (UNAIDS Best Practice Collection). Technical report, Joint United Nations Programme on HIV/AIDS, Geneva. Available from: http://www. unaids.org/en/media/unaids/contentassets/dataimport/ publications/irc-pub01/jc093-partnersinprevention_en.pdf.

UNAIDS (1999). Acting early to prevent AIDS: The case of Senegal (UNAIDS Best Practice Collection). Technical report, Joint United Nations Programme on HIV/AIDS, Geneva. Available from: http://www.unaids.org/en/media/unaids/ contentassets/dataimport/publications/irc-pub04/una99-34_en.pdf.

UNAIDS (2001). HIV Prevention Needs and Successes: a tale of three countries. An update on HIV prevention success in Senegal, Thailand and Uganda (UNAIDS Best Practice Collection). Technical report, Joint United Nations Pro- 
gramme on HIV/AIDS, Geneva. Available from: http://data.unaids.org/ publications/IRC-pub02/jc535-hi_en.pdf.

UNAIDS (2010). Global Report: UNAIDS report on the global AIDS epidemic 2010. Technical report, Joint United Nations Programme on HIV/AIDS, Geneva. Available from: http://www. unaids.org/globalreport/documents/ 20101123_GlobalReport_full_en.pdf.

UNAIDS (2011a). Spectrum/EPP 2011. UNAIDS, Geneva. Available from: http: //www. unaids.org/en/dataanalysis/tools/spectrumepp2011/.

UNAIDS (2011b). UNAIDS World AIDS Day Report 2011. Technical report, Joint United Nations Programme on HIV/AIDS, Geneva. Available from: http://www. unaids.org/en/media/unaids/contentassets/documents/ unaidspublication/2011/JC2216_WorldAIDSday_report_2011_en.pdf.

UNAIDS (2011c). Unite for universal access: Overview brochure on 2011 High Level Meeting on AIDS. Technical report, Joint United Nations Programme on HIV/AIDS, Geneva. Available from: http://www.unaids.org/en/media/unaids/ contentassets/documents/document/2011/20110204_HLM_Brochure_en. pdf.

UNAIDS and WHO (2004). Epidemiological Fact Sheet on HIV/AIDS and Sexually Transmitted Infection: Uganda. Technical report, UNAIDS and WHO, Geneva. Available from: http://data.unaids.org/publications/fact-sheets01/ Uganda_en.pdf.

United Nations (2003). Networking: Directory of African NGOs. Available from: http: //www. un.org/africa/osaa/ngodirectory.

Van Niekerk, A. A. (2005) 'Moral and social complexities of AIDS in Africa'. In Van Niekerk, A. A. and Kopelman, L. M., eds., Ethics and AIDS in Africa: The challenge to our thinking, pages 53-70. David Philip, Cape Town.

Vandenbruaene, M. and Piot, P. (2007) 'Interview with Peter Piot'. Sexually Transmitted Infections, 83(6):436-40. Available from: http://www. 
pubmedcentral.nih.gov/articlerender.fcgi?artid=2598722\&tool= pmcent rez\&rendertype=abst ract.

Wapner, P. (1995) 'Politics beyond the State: Environmental Activism and World Civic Politics'. World Politics, 47(3):311-340.

Wasserman, S. and Faust, K. (1994). Social Network Analysis: Methods and Applications. Cambridge University Press, Cambridge.

Weiss, M. (2006) 'Rejection as Freedom?: HIV/AIDS Organizations and Identity'. Perspectives on Politics, 4(4):671-678. Available from: http: //journals. cambridge. org/action/displayFulltext? fromPage= online\&type=6\& $\mathrm{id}=\$ 1537592706060415 \& \mathrm{a} i \mathrm{~d}=559488 \&$ next $=\mathrm{t}$ rue $\& \mathrm{j} \mathrm{id}=$ PPS\&volumeId $=4 \&$ issueId $=04 \&$ next $=Y$.

Wenger, E. (2000) 'Communities of practice and social learning'. Organizations, $7(2): 225-246$.

WHO (1992). Report of the External Review of the World Health Organisation's Global Programme on AIDS. Technical report, World Health Organisation, Geneva.

Woermann, M. (2010) 'Corporate identity, responsibility and the ethics of complexity'. In Cilliers, P. and Preiser, R., eds., Complexity, Difference and Identity, pages 167-191. Springer, Dordrecht.

Yashar, D. (1997). Demanding Democracy: Reform and Reaction in Costa Rica and Guatemala, 1870s-1950s. Stanford University Press, Stanford, California.

Youde, J. R. (2007a). AIDS, South Africa, and the Politics of Knowledge. Ashgate, Aldershot.

Youde, J. R. (2007b) 'Ideology's Role in AIDS Policies in South Africa and Uganda'. Global Health Governance, I(1). Available from: http://blogs.shu.edu/ghg/files/2011/10/Youde_Ideology $\% 2 \%$ $80 \% 99$ s-Role-in-AIDS-Policies-in-Uganda-and-South-Africa_ Spring-2007.pdf. 